\title{
Tax, transfers, and income inequality in New Zealand during 1988-2013
}

by

Matthew Nolan

\author{
A thesis \\ submitted to the Victoria University of Wellington \\ in fulfilment of the \\ requirements for the degree of \\ Doctor of Philosophy \\ in Economics. \\ Victoria University of Wellington \\ 2019
}





\begin{abstract}
This dissertation investigates the role tax and transfer policy changes played in the evolution of New Zealand disposable income inequality between 1988 and 2013. Across five papers, the key changes in tax and transfer policies are identified, the labour supply response of individuals to the changes are estimated, and the impact of these changes on the income distribution is quantified. Overall, nearly $40 \%$ of the increase in income inequality during this period is attributable to changes in the tax-transfer system.

The tax and transfer payment changes investigated in this dissertation cover the gradual flattening of the tax scale over the 1980/90s, the reduction in benefit payments following the 1991 Mother of All Budgets, the introduction of Working for Families in 2005, and the erosion of transfer payments relative to the average wage throughout the period.

Given these changes, the efficacy of the tax transfer system for meeting vertical and horizontal equity goals is evaluated using data from the Household Economic Survey (HES). The redistributive effect of tax-transfer policy fell from 22.6 Gini points to 18.2 Gini points between 1988/91 and $2011 / 13$, with a corresponding decline in the amount of vertical equity in the tax-transfer system. Between the same periods the degree of horizontal inequity rose, although this was predominantly the result of greater targeting in the tax-transfer system.

The adjustment in the structure of the tax-transfer system not only leads to a change in tax liabilities and transfer payments, but also generates a behavioural change by individuals with regards to the number of hours they
\end{abstract}


would be willing to work. Preference parameter estimates over hours of work and income are generated for individuals in the sample, with imputed wages estimated for those who are out of work.

A tax-transfer microsimulation model, that utilises wage and preference parameter estimates, is then used to construct counterfactual scenarios where the tax-transfer system of a given year is applied to the population of other years. For example, the tax-transfer system of 1988-1991 is applied to the population in 2010-2013 in order to create a scenario representing what the disposable income distribution in 2010-2013 would look like with the 1988-1991 tax-transfer system.

Estimates from this process suggest that nearly $40 \%$ of the increase in disposable income inequality between the 1988/91 and 2010/13 periods was due to the change in payments and labour supply behaviour associated with tax-transfer policy adjustments.

Other potential drivers of income inequality change were investigated by reweighting the HES data of one period to more closely represent the population of another period. Although shifts in the share of individuals in part time work also generated an increase in income inequality, the lift in higher educational attainment over this period is estimated to have reduced income inequality more sharply (by nearly $22 \%$ ). The shift in the age distribution towards prime-aged work was not associated with any change in the aggregate income inequality measure. 


\section{Acknowledgments}

I would like to express my gratitude to my primary supervisor, Professor John Creedy for his advice and support throughout my PhD studies. Without his mentoring and suggestions based on his wealth of experience regarding taxation and income inequality this thesis would not have been possible.

I am also thankful for the advice regarding early drafts of this thesis from other economists: my secondary supervisor Yigit Saglam, Productivity Commission economist (and my brother) Patrick Nolan, and Treasury economist Gulnara Huseynli. Special thanks to Infometrics Chief Economist Adolf Stroombergen for modelling advice and for funding my trip to Canberra for a microsimulation conference.

The papers that made up this dissertation were part of a larger project on 'Improving New Zealand's Tax Policy via International Tax Transfer Model Benchmarking', funded by an Endeavour Research Grant from the Ministry of Business, Innovation and Employment (MBIE) and awarded to the CPF (Professor Norman Gemmell). Access to the data used in this paper was provided by Statistics New Zealand in accordance with security and confidentiality provisions of the Statistics Act 1975. Facilities at the New Zealand Treasury were used when analysing this data.

Treasury also provided access to the microsimulation model used in this thesis (TAXWELL) and the behavioural add-on (TAXWELL-B). Important 
advice around using and extending this model was given by Treasury analysts Chris Ball, Gulnara Huseynli, Joseph Mercante, and Penny Mok. I would also like to thank Angela Mellish for providing access to the data and models available at Treasury and giving me facilities to extend them.

I would like to thank my whole family for their support both with the thesis and throughout life. Specifically, I want to thank my mother Veronica Nolan whose love and support of my critical thinking nature were essential for me undertaking these studies. And also my brother Patrick Nolan who inspired me to study economics and will constantly debate social and economic issues with me in a way that helps me grow. Special thanks to my partner in crime Gulnara Huseynli who put up with me while I was putting all of this together and who supported me when my studies became overwhelming.

Finally I'd like to acknowledge a couple of people who have passed on. My father, Tom Nolan, who instilled a passion for understanding and caring about social issues in me and taught me to enjoy talking. Also Rob Hosking, who was a journalist and friend who used to discuss the relationship between the tax-transfer policy changes he used would write about as a journalist and what was going on with income inequality. 


\section{Statistics New Zealand disclaimer}

Access to the data used in this study was provided by Statistics New Zealand under conditions designed to give effect to the security and confidentiality provisions of the Statistics Act 1975. The results presented in this study are the work of the author, not Statistics NZ. 


\section{Contents}

1 Introduction 1

1.1 Central question and motivation . . . . . . . . . . 1

1.1.1 New Zealand analysis of inequality . . . . . . . . . . 5

1.1.2 Main contribution of research . . . . . . . . . . . . . 9

1.2 Research outline . . . . . . . . . . . . . . . . . 12

2 Income tax and transfer policy changes in New Zealand: 1988$2013 \quad 15$

2.1 Introduction . . . . . . . . . . . . . . . . . . 15

2.2 Income tax rates. thresholds, and coverage . . . . . . . 18

2.3 First tier benefits . . . . . . . . . . . . . . . 23

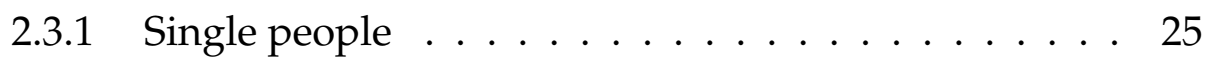

2.3 .2 Couples ...................... 38

2.4 Superannuation . . . . . . . . . . . . . . . . 42

2.5 Conclusion . . . . . . . . . . . . . . . . . 48

2.6 Appendix ...................... 49

3 Horizontal and vertical equity in the New Zealand tax-transfer system: 1988-2013 53

3.1 Introduction and motivation . . . . . . . . . . . . 53

3.2 Methodology and measurement framework . . . . . . . . . 56

3.2.1 Decomposition of the Gini coefficient . . . . . . . . 58

3.2.2 Exact equals and horizontal inequity . . . . . . . . 62 
3.2.3 Defining equals ................ 65

3.2.4 Absolute Horizontal Inequity . . . . . . . . . . . . 71

3.2.5 Varying bandwidth . . . . . . . . . . . . 72

3.3 Data sources and assumptions . . . . . . . . . . . . . 75

3.3.1 Smoothed Income . . . . . . . . . . . . . . 77

3.3 .2 Year selection . . . . . . . . . . . . . 83

3.4 Results of the decomposition . . . . . . . . . . . 86

3.4.1 Estimated horizontal and vertical equity changes . . 87

3.4.2 Why did Horizontal Inequity rise? . . . . . . . . . 89

3.5 Sensitivity of results to the equivalence scale . . . . . . . . 90

3.5.1 Varying scale economies . . . . . . . . . . . . 91

3.5.2 Varying the weight of the child . . . . . . . . . . . 95

3.6 Conclusion . . . . . . . . . . . . . . . . . . . 99

4 New Zealand Wage Equations: 1988-2013 101

4.1 Introduction . . . . . . . . . . . . . . . . . . . 101

4.2 Household Economic Survey Data . . . . . . . . . . . . 103

4.3 Method of analysis . . . . . . . . . . . . . . . 108

4.3.1 Industry and Occupation imputation for those out of work . . . . . . . . . . . . . . . . . 113

4.3.2 Correcting for heteroskedasticity in selection . . . . . 114

4.4 Summary of wage equation results . . . . . . . . . . . . . 116

4.4 .1 HES88-93 . . . . . . . . . . . . . . 116

4.4 .2 HES94-98 . . . . . . . . . . . . . . . . 119

4.4 .3 HES01-08 . . . . . . . . . . . . . . 122

$4.4 .4 \quad$ HES09-13 . . . . . . . . . . . . . . 125

4.5 Predicted wages . . . . . . . . . . . . . . . . . . 128

4.6 Comparison to previous estimates . . . . . . . . . . 130

4.7 Conclusion . . . . . . . . . . . . . . . . . . . . 134

4.8 Tables . . . . . . . . . . . . . . . . . . . 136

4.8.1 Reading the tables ............. 136 


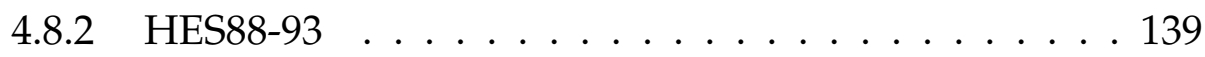

4.8 .3 HES94-98 . . . . . . . . . . . . . . . . 145

4.8 .4 HES01-08 . . . . . . . . . . . . . . . 151

4.8 .5 HES09-13 . . . . . . . . . . . . . 157

5 Income-leisure preferences in New Zealand: 1988-2013 163

5.1 Introduction . . . . . . . . . . . . . . 163

5.2 Data sources . . . . . . . . . . . . . . . 166

5.2.1 Wage imputation and assumptions . . . . . . . . 167

5.2 .2 Selection criteria . . . . . . . . . . . . . . . 171

5.2 .3 Summary of samples . . . . . . . . . . . . . . . . . . . . . . 172

5.2 .4 Distribution of hours . . . . . . . . . . . . 176

5.2 .5 Variables used . . . . . . . . . . . . . . . . 180

5.3 Parametric model, specification, and estimation . . . . . . 181

5.3.1 Discrete hours: van Soest's method . . . . . . . . . 183

5.3 .2 Estimation . . . . . . . . . . . . . . . . 188

5.4 Results of estimation . . . . . . . . . . . . . . . . . 189

5.4.1 Estimated hours distribution . . . . . . . . . . 201

5.4.2 Quasi-concavity............... . 207

5.5 Marginal Effects . . . . . . . . . . . . . . . . . . . 207

5.6 Conclusion . . . . . . . . . . . . . . . . . . 214

6 Decomposing New Zealand inequality changes from 1988-2013 into policy and non-policy related contributions 217

6.1 Introduction . . . . . . . . . . . . . . . . . . . 217

6.2 New Zealand Decomposition motivation . . . . . . . . . . . 220

6.3 Literature review . . . . . . . . . . . . . . . . 223

6.4 Data and data treatment . . . . . . . . . . . . . . 227

6.4 .1 Imputation . . . . . . . . . . . . . . . 228

6.5 Methodology and simulation . . . . . . . . . . . 231

6.5.1 Deflators, annual comparisons, and equivalent policies ....................... 234 
6.5.2 Weights and the treatment of tax and transfers in simulation . . . . . . . . . . . . . . 235

6.5.3 Behavioural policy responses . . . . . . . . . 237

6.6 Decomposition method: The role of tax-transfer policies . . . 239

6.6.1 The policy model . . . . . . . . . . . . . . 239

6.6.2 Income counterfactuals and take-up rates . . . . . . . 242

6.6.3 The behavioural response to policy . . . . . . . . . 242

6.6.4 Interpreting the results of this method . . . . . . . . 244

6.7 Decomposition method: The role of other factors . . . . . . 247

6.7.1 The method for investigating changing characteristics 250

6.7.2 Changes in age, employment status, and highest educational attainment . . . . . . . . . . . 256

6.7.3 Interpreting the results of the method . . . . . . . 258

6.7.4 Selection of counterfactual orderings . . . . . . . . . 260

6.8 Results of the decomposition . . . . . . . . . . . . . 261

6.8 .1 Equivalence Scale . . . . . . . . . . . . . . . . 262

6.8 .2 Results . . . . . . . . . . . . . 264

6.9 Conclusions . . . . . . . . . . . . . . . . . 273

7 Conclusions 


\section{Chapter 1}

\section{Introduction}

\subsection{Central question and motivation}

The core motivating question for this research is "why has the income distribution in New Zealand changed during the 1988 to 2013 period". However, this question is too broad and requires input from a range of different models and perspectives to create a compelling narrative.

As a result, this dissertation limits its attention to the role changes in income tax and transfer regimes played in transforming the distribution of income during this period. Specifically, the focus is on how income tax and transfer changes influenced inequality in family incomes over the 1988 and 2013 period.

Since 1984 the role of government in New Zealand society has changed significantly. In the following decade New Zealand experienced a period of liberalisation with trade protectionism reduced (Massey 1995), government institutions redesigned (Evans et al. 1996, Brash 1998), the benefit system changed (McClure 1996), the tax system adjusted (Treasury 2001a, Stephens 1987), and employment relations revised with the 1991 Employ- 
ment Contracts Act (Anderson 1991, Morrison 2004). A broad outline of the full series of policy changes can be found in Evans et al. (1996), Massey (1995), and Easton (1994).

This trend continued well into the 2000s with continued trade liberalisation, general reductions in tax rates, and a tightening in benefit eligibility criteria - although some of these changes were reversed through the 2000 Employment Relations Act and the introduction of Working for Families in 2005.

Such wide ranging policy changes will have had a myriad of socially and economically relevant consequences. One of the consequences of these changes has been the way incomes are distributed across New Zealand. This dissertation uses the Household Economic Survey (HES) to measure the distribution of income in New Zealand and to measure other characteristics of the population that may be associated with the distribution of income.

In order to describe the way income levels and the distribution of income have changed the income measure and unit of analysis need to be defined. Two key measures of income are used: market income which refers to all income from private sources and disposable income which refers to the income available after direct taxes are subtracted and income transfers are included. In this thesis equivalised family income per person is used, with the individual the unit of analysis. The equivalence scale applied is based on the Jensen (1988) scale that is often used in applied work in New Zealand.

Furthermore, in order to make inferences about the income distribution of the New Zealand population from the HES sample a series of survey weights are required. Calibrated weights which were initially generated for Ball and Creedy (2015) are used to reweight the HES sample and generate income inequality measures. 
Although the economic reforms began in 1984 the analysis in this dissertation will concentrate on the income distribution from 1988 to 2013. The relative unreliability of the sample data before 1988 (given increasing difficulty of matching characteristics such as industry, and the differing sample design) and the important role changes in income reporting had during this period (with the introduction of Fringe Benefit Taxation in 1985 among other accounting changes) justifies the exclusion of the 1984-1987 period from analysis. Furthermore, as established in Perry (2017) and Ball and Creedy (2015) the increase in income inequality observed in the 19841987 period was only small relative to the observed lift in the late 1980s and early 1990s implying that the later period is of greater interest for this study.

Given these assumptions about the income measure, unit of analysis, equivalence scale, and weights, the evolution of income inequality between 1988 and 2013 is outlined using various inequality measures in Figures 1, 2, and 3.

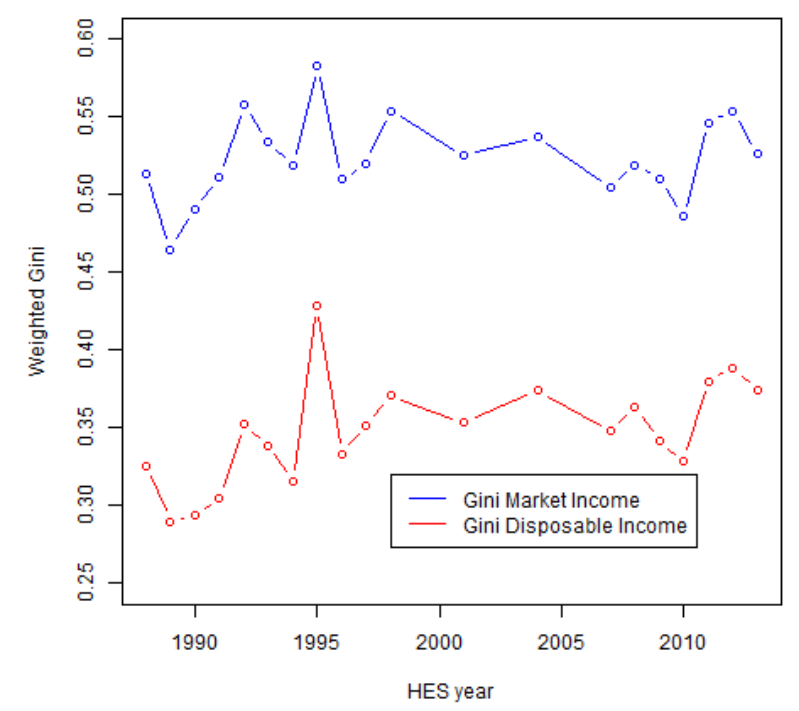

Figure 1: Market vs Disposable equivalised Income Gini coefficients 


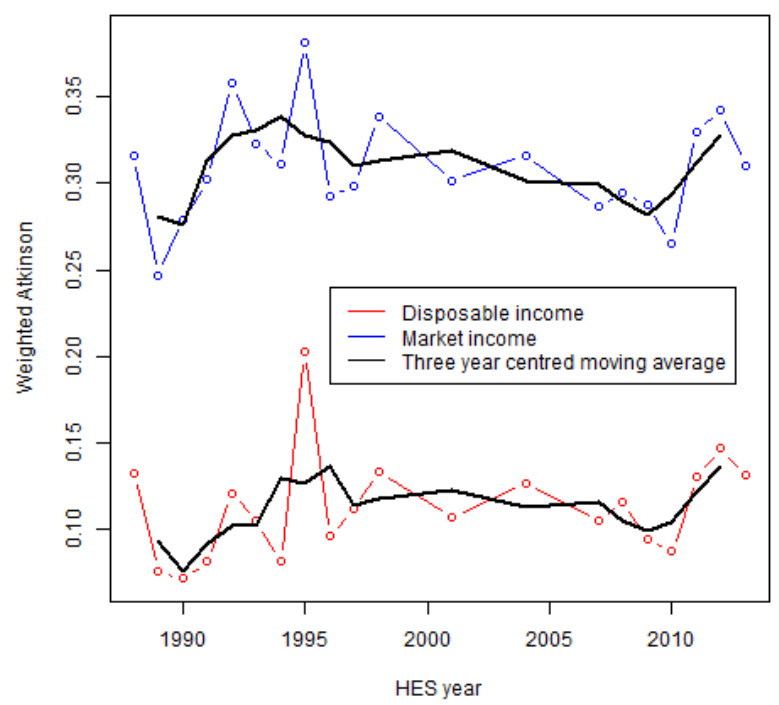

Figure 2: Market vs Disposable equivalised Income Atkinson inequality $\epsilon=0.5$

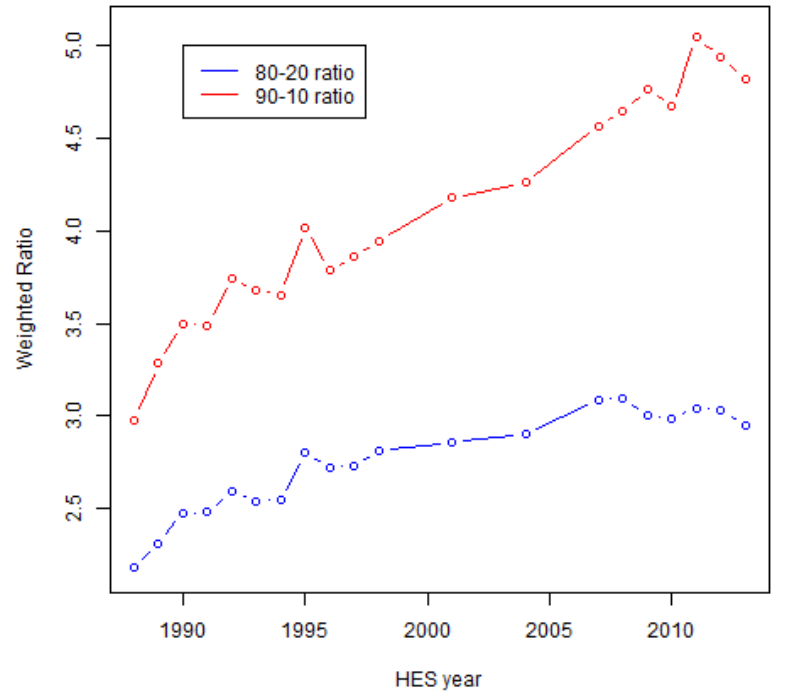

Figure 3: Disposable equivalised Income ratios 
Although the role of policy changes on the distribution of income is complex and multifaceted, the major period of policy change in the late-1980s and early 1990s was associated with rising disposable income inequality. This suggests that policy may have played some role in this increase. However, these figures also indicate that the market and disposable income distributions moved together over time. This suggests that other factors outside the tax-transfer system played a role in rising income inequality between 1988 and 2013 .

\subsubsection{New Zealand analysis of inequality}

An early modern discussion of New Zealand's income distribution can be found in Easton (1983), with a mix of IRD tax data, Statistics New Zealand Census data, and Department of Labour figures used to shed light on the evolution of the distribution of income through the 1950s to the 1970s. ${ }^{1}$

It was not until 1973/74 that a consistent household economic survey was undertaken - the Household Expenditure and Income Survey (HEIS), later renamed the Household Economic Survey (HES). The HES data has since been heavily used to discuss changes in the dispersion of income in New Zealand. The annual Incomes report produced by Perry (2017) through the Ministry of Social Development has been the key way that information from the HES regarding New Zealand income distribution has been disseminated publicly.

O'Dea (2000) summarised much of the literature discussing the pre-1998 distribution of income in New Zealand with a strong focus on studies that try to decompose the change into constituent causes. The primary studies

\footnotetext{
${ }^{1}$ Brian Easton has updated this work in recent years, with the additions found in Easton (2015a) and Easton (2015b).

${ }^{2}$ This represents the March 1974 year.
} 
that were summarised in this paper were Hyslop and Mare (1999), Podder and Chatterjee (1998), Martin (1998), and Statistics New Zealand (1999). Apart from Martin (1998), which was based on Census data, these studies make significant use of the HES microdata and focus on forms of decomposition of the microdata. ${ }^{3}$

In terms of dispersion of labour market earnings Dixon (1998) provided a detailed discussion of the HES data, and applied the decomposition techniques of Juhn et al. (1993) to discuss how much of the change in the dispersion of income can be explained by a change in the attributes/skills of employees and the return to these attributes/skills. Borland (2000) added further discussion of the causes of changes in earnings inequality with reference to international literature.

Hyslop and Mare (2005) indicated that changes in household structure was the main driver of changes in the inequality of gross household income between March 1984 and March 1998, with little evidence of rising returns to skills. Dixon (1998) indicated that much of the increase in inequality in labour market earnings occurred within demographic and skill groups - rather than being driven by changes in the groups or changes in the return to attributes/skills.

Together these studies indicated that there was a significant increase in the dispersion of income during the late-1980s and early-1990s, with a levelling off in inequality from the mid-1990s. This trend has been confirmed in more recent years by Perry (2017), with an increasing focus on what has occurred at the very top of the income distribution as in Easton (2015a) and Easton (2015b).

Using household labour force data both Crawford (2009) and Hyslop and Yahanpath (2005) have discussed the evolution of the labour market income distribution in more recent years. Hyslop and Yahanpath (2005) point out

\footnotetext{
${ }^{3}$ These papers were early versions of the following final publications: Hyslop and Mare (2005), Podder and Chatterjee (2002b), and Martin (2000).
} 
that growth in labour market income has been relatively evenly spread over the 1998-2004 period. However, the nature of the earnings growth has differed across the gross labour income distribution, with higher employment driving labour market income growth in the bottom half of the distribution while wage growth has been behind the lift in the upper half of the distribution.

Crawford (2009) used the HLFS Income Supplement to link individuals over two surveys and thereby calculate labour market earning transitions over that year. Unlike other surveys, the HLFS IS provides information on unemployment adding an extra, demand based, dimension to the analysis of labour market data. ${ }^{4}$

Although there has been a significant amount of analysis of HES data both in terms of labour market and household income outcomes, work on the role tax and transfers have played in influencing the income distribution has been more limited in scope. Podder and Chatterjee (2002b) did make inferences about the role of tax-transfer policies when analysing factor income shares. However the criticism of Jara and Tumino (2013) indicates that the given method does not imply that an increase in inequality of income for a factor will also increase overall inequality. With the overall discussion of factor income speculative, it is uncertain whether this analysis can be used to understand much about the role of policy changes. ${ }^{5}$

Related to this there is a rich strain of analysis focused on using national accounts data to describe changes in factor income shares in New Zealand

\footnotetext{
${ }^{4}$ The HLFS is a quarterly survey containing a rotating panel, with each panel staying in the survey for eight quarters. Once per year a more detailed Income Supplement survey is included which includes significant socio-demographic information. As a result, the linked income supplement (LIS) links the individuals between the two years they are included.

${ }^{5}$ In this discussion the case for changing income shares is largely explained by pointing to higher nominal interest rates - without reference to the real interest rate or the broader income generating process.
} 
with Statistics New Zealand (1999), Conway et al. (2015), Fraser (2018), and Rosenberg (2017) all documenting a decline in the labour income share in New Zealand. Although this shift mirrors the decline in the labour income share documented elsewhere the relative decline in New Zealand has been smaller. As a result, this literature provides little guidance about the role direct changes in tax and transfer payments have had in the income inequality outcomes in New Zealand.

In order to describe the role of policy it is useful to model the tax-transfer system. Maloney (1997) offered a discussion of changes in the income distribution focused on changes in benefit policies utilising TAXMOD - a precursor to TAWELL. Distributional analysis of the introduction of Working for Families using TAXMOD was also undertaken in Nolan (2005).

Several papers have made use of Treasury's newer arithmetic microsimulation model (TAXWELL) to investigate the way policy transformed the income distribution in New Zealand. Aziz et al. (2012) and Aziz, Gemmell and Laws (2013) focused on final income measures, with the later also investigating the age and sex breakdown in the 2009/10 HES data. Creedy et al. (2008) and Creedy and Eedrah (2014) together offer a detailed discussion of disposable income inequality trends between 2006/07 and 2010/11 along with a decomposition of the change in indices into policy and population effects.

However, there has been been no work extending this analysis back further or incorporating the role of behavioural changes (eg shifts in labour supply) into this analysis. This is a surprising omission given that, arguably, the redistributive properties of policy changes is the key justification for policy makers to change policy settings. Furthermore, the recent surge in public interest in income inequality, as seen through books such as Piketty (2014) and Rashbrooke (2013), indicates that a clear understanding of the way policy has influenced the income distribution is relevant to policy makers. 
This dissertation aims to help fill part of this gap by investigating how changes in household tax-transfer policies, a specific part of overall policy changes, influenced the distribution of income in New Zealand over the 1988-2013 period.

\subsubsection{Main contribution of research}

Using a behavioural microsimulation model the research in this thesis intends to add to the New Zealand literature in a number of ways:

1. Providing an analysis of potential drivers in the change in the income distribution in New Zealand during the 1988-2013 using the labour supply behaviour of an economic family unit, compared to the focus on household income in other similar New Zealand literature.

2. Separating out the contribution of tax and transfer policy on the basis of vertical and horizontal equity basis.

3. Providing a quantitative estimate of how the various tax and transfer policy changes of the past thirty years contributed to changes in the observed income distribution relative to other factors.

By providing this information the thesis will add to understanding of how the income distribution in New Zealand has changed and how tax and transfer setting changes helped to drive this transformation.

Such an understanding matters given the growing interest in income inequality as a target for government policy (eg Pickett and Wilkinson (2009), Piketty (2014), Rashbrooke (2013). If policy makers, or society at large, determine that measures of inequality matter, then knowledge about the efficacy and nature of the redistributive effects of tax-transfer policy is of central importance.

It is also important to explore the country-specific reasons why inequality 
may have occurred before making policy choices. The narrative of rising income inequality due to increasing capital accumulation, where capital is sufficiently substitutable with labour, described in Piketty (2014) does not match the experience of New Zealand as noted by Nolan (2014). As a result, research about the New Zealand experience is valuable for policy makers.

Furthermore, information about the way tax-transfer policies have changed in terms of equity principles is also of use for policy makers. Although the tax system's ability to raise revenue and the deadweight loss/efficiency of taxation are also important criterion, the redistributive properties of the tax and transfer system should not be ignored. In this way, filling this gap in the literature will provide a useful addition to our understanding of tax-transfer policies in New Zealand.

When trying to understand changes in income inequality in New Zealand, the change in labour market behaviour and associated wage incomes are important. As a result, a behavioural microsimulation model which takes into account how policy influenced labour supply behaviour is used for analysing income inequality in this research. Wage income accounted for between 59.1\% (March 1992 year) and 66.6\% (June 2004 year) of household income during this period according to the HES. ${ }^{6}$ As a result, adding estimates of labour market behaviour to any analysis of income generation and inequality has value.

The reconstruction of Treasury's behavioural tax-transfer microsimulation model (TAXWELL-B) in recent years offers a unique tool for considering the way policy changes have influenced the distribution of income through their impact on the labour market. The collation of historical policy data over the 1988-2013 period and estimation of labour supply responses for this broad period in this dissertation extends the capabilities of Treasury's microsimulation models for policy analysis.

\footnotetext{
${ }^{6}$ Excluding bonuses, self-employment income, and ACC payments.
} 
A reason why a detailed behavioural analysis of how tax and transfer policies have influenced the income distribution has not taken place may be that such descriptive work straddles itself between two-broader methodologies. At the most aggregate level, analysis of factor shares and broad elasticities of taxable income can be used to discuss aggregate policy questions as has been performed recently in Creedy et al. (2017) and Creedy and Gemmell (2018). Although such analysis lacks microfoundations, the focus on aggregates that are assumed to supervene on individual choices has practical relevance.

On the opposite side the structural wage models and quasi-experimental approaches that are common in applied economics aim to either recover structural parameters, or produce causal estimates of the impact of policy - using micro-data that includes the full heterogeneity of the individuals/families that are making choices. Such knowledge is useful for policy makers, but these methods can be undermined by the partial equilibrium nature of the results, the conditionality involved, and the paucity of appropriate data.

Decomposition analysis of income, using household microdata, provides an exploratory middle ground between these two methods of analysis. By using microdata to preform microeconometric estimation of the relationship between characteristics and incomes a richer understanding of the relationship between tax-transfer policies and the income distribution can be constructed. Although the results will tend to be non-causal, it provides a richer understanding of how the variation in the characteristics of individuals and families influences the dispersion of income in a country.

Another reason why this work has not been previously undertaken is the significant modelling requirements necessary to consider the tax-transfer system in such detail. Without the support of modellers at Treasury and the work they have undertaken in building TAXWELL and TAXWELL-B 
it would be infeasible to undertake this type of decompositional exercise of tax and transfer policies.

As a result, there is significant scope to investigate the role taxes and transfers have played in transforming the income distribution in New Zealand in more detail. Unlike the large number of studies mentioned above that are interested in describing specific market and institutional factors that are driving changes in the dispersion of income, the focus of this study will be on the role tax and transfer policies have played in transforming the income distribution over the 1988 to 2013 period.

\subsection{Research outline}

This thesis brings together five papers which cumulatively investigate the role tax and transfer changes in New Zealand had in the observed increase in income inequality between 1988 and 2013. Each of these papers refers to a chapter in this dissertation.

Chapter 2 outlines the changes in tax and transfer policies during this period. These changes were explicitly modelled using Treasury's microsimulation model TAXWELL, with a set of procedure files that represent the tax-transfer system having been created for every HES year between 1988 and 2013.

In Chapter 3 the consequences of the changes in tax and transfer policies are investigated in terms of vertical and horizontal equity.

The purpose of these first two chapters is to establish the role that tax transfer policy changes had in influencing the redistributive relationship between tax-transfer policies and the disposable income of families.

Once this relationship is established the goal is investigate the full influence of policy on income inequality, including changes in labour supply 
behaviour by individuals. That is the focus of the final three papers.

Chapter 4 establishes the wage relationship necessary to impute wages for individuals without an observed wage while Chapter 5 estimates the labour supply response of individuals to a change in the disposable income they could earn at varying hours points (their income-leisure budget constraint).

Given these responses and the full microsimulation model of the tax-transfer system it is possible to produce counterfactual scenarios where the taxtransfer system varies and the labour supply of individuals adjusts in response. Chapter 6 uses this model to construct counterfactual scenarios where the tax-transfer system of one year is applied to the tax-transfer system of another year.

Using these results the relative contribution of tax-transfer policy changes to the overall increase in income inequality can be estimated. Furthermore, a reweighting procedure is applied to account for the role played by changes in population characteristics, with the estimated policy effect allowed to vary based on changes in the distribution of population characteristics. 


\section{Chapter 2}

\section{Income tax and transfer policy changes in New Zealand: 1988-2013}

\subsection{Introduction}

This chapter provides an outline of changes to primary tax and transfer policies in New Zealand between 1988 and 2013. The purpose of such an outline is to provide descriptive context to the tax-transfer policy changes that occurred over this period, and to outline the policies that form the basis for extending the time horizon of Treasury's tax-transfer microsimulation model (TAXWELL).

Since 1984 there has been a raft of changes to social and economic policy settings in New Zealand. A broad outline of these changes is given in Evans et al. (1996), Massey (1995), and Easton (1994). Adjustments to the scope and structure of the welfare state made up an important element of these reforms. These changes have been written about widely, and are usually separated into discussions of welfare system reform (Mc- 
Clure 1996) and tax reform (Stephens 1993, Treasury 2001a).

Tax reforms were focused on providing a broad-base, low rate tax system (Treasury 2001a). A narrow base of (predominantly) income tax had to finance government spending prior to 1984 and as a result increasing the size of the tax base and reducing tax rates was seen as a way to increase the fairness of the tax system and reduce variability in government revenue. However, by 1988 the base broadening had already taken place. As noted by Stephens (1993) the debate switched in 1987 towards what rates, and thereby what size of government, was desired.

When it comes to the provision of social welfare, these policy changes shifted social support in New Zealand away from the traditional Australasian model of worker income support ${ }^{1}$ (Castles 1994) towards the Swedish model of government expenditure support ${ }^{2}$ (Davidson 1989). However, New Zealand's focus on targeted support - as compared to the more universal payments in Sweden - remained in place, and was in fact reinforced by the reforms from 1991 onwards. ${ }^{3}$

Increasing pressure on the cost of income support during the 1970s had led to a change in views about the purpose of income support among the public and in policy circles. This culminated in the 1991 Budget with increased enforcement of work testing for beneficiaries and a stratification of benefit types based on the perceived need or deserving characteristics of the individual requiring support. Although primary payment levels remained unchanged in real terms up until 2013, work testing criteria were continuously tightened.

\footnotetext{
${ }^{1}$ Examples of the Australasian model of income support are job guarantees, minimum wages, and targeted payments to those who were seen as in need.

${ }^{2}$ The Swedish model refers to providing income support through direct tax-transfer payments.

${ }^{3}$ New Zealand has traditionally focused more on expenditure support than Australia, so it is important to not overemphasis this change.
} 
The only area of income support that saw a reduction in targeting during 1988-2013 was National Superannuation. Although support was tightened through the increase in the age of eligibility (from 60 to 65), the superannuation surcharge was removed and the real value of superannuation payments increased.

In order to evaluate the change in policy focus in New Zealand, the literature has focused on the observed outcomes during the reform period (eg Podder and Chatterjee 2002b, Hyslop and Mare 2005, Ball and Creedy 2015). Although these exercises provide important insight into the changes New Zealand has experienced, given the number of confounding factors during this period an understanding of the change in the structure of the tax and transfer system is an essential starting point for additional analysis of tax-transfer policy since 1988. As a result, this chapter will provide a breakdown of the structure of income tax and transfer policy changes over the 1988 to 2013 period. ${ }^{4}$

Such an exercise is a first step towards an evaluation of the efficiency and equity principle of a tax-transfer system, and as a result it is important to take this descriptive exercise as an evaluation of tax-transfer changes. One of the purposes of the chapter is to document this information so further analysis of the redistributive and equity effects of policy can be undertaken.

Furthermore, an analysis that focuses only on changes in first tier tax and benefits can only capture some elements of the full change in tax-transfer policy. Changes in other taxes and benefits, the culture of welfare agencies, implicit targeting, screening, and considerations of what constitutes needs

\footnotetext{
${ }^{4}$ This implies that changes to indirect taxes (eg GST) will be excluded. Corporate taxes are also excluded from analysis. Furthermore, it should be noted that some forms of social assistance - such as supplementary benefits and the accommodation benefit/supplement will not be outlined here - even though they also contributed to the change in income support to households over this period.
} 
are all relevant to understanding a tax and benefit system but are not part of this chapter.

Prior discussions of New Zealand tax-transfer policy change over part of this period exist in the literature, although they tend to focus on a subset of these changes. An outline of policy change with respect to family assistance was provided in Nolan (2002) and extended to include Working for Families by Mercante and Mok (2014c), the outline of benefit changes in 1991 and pre-2001 tax reforms is given in Nolan (2005), and a description of superannuation policy change is outlined in St John (2013). These chapters outlined the changes in transfer setting for the policy of interest in detail with links to primary sources.

The outline of the chapter is as follows. In Section 2 changes to the income tax system are outlined and discussed. Section 3 covers first tier benefits (eg the unemployment benefit), first for single people and then for couples. Section 4 outlines the change in superannuation payments and policies between 1988 and 2013. Section 5 briefly concludes, while Section 6 provides links to the primary sources used for this analysis.

Links to primary legislation are denoted with a [X], where $\mathrm{X}$ stands for the number of the legislation in the Appendix. An electronic copy of this chapter includes hyperlinks to the noted legislation on Knowledge Basket.

\subsection{Income tax rates. thresholds, and coverage}

In the discussion that follows the notation TYXX refers to the tax year for the year denoted. For example TY93 is the 1993 tax year, which denotes the period between April 1992 and March 1993.

Between TY84 and TY88 the income tax system changed significantly. A 
clear example of this change was the adjustments to tax rates and thresholds. The reduction in tax rates and changes in tax thresholds can be seen in Table 3.1. ${ }^{5}$

Table 2.1: Tax thresholds and rates: TY84-88

\begin{tabular}{ccccc}
\hline Thresholds & \multicolumn{2}{c}{ TY84 } & \multicolumn{2}{c}{ TY85 } \\
& Threshold & Rate & Threshold & Rate \\
\hline Zero income & - & $20 \%$ & - & $20 \%$ \\
First threshold & $\$ 6,000$ & $31.25 \%$ & $\$ 6,000$ & $32 \%$ \\
Second threshold & $\$ 24,000$ & $45.1 \%$ & $\$ 24,000$ & $41.1 \%$ \\
Third threshold & $\$ 30,000$ & $56.1 \%$ & $\$ 25,000$ & $45.1 \%$ \\
Fourth threshold & $\$ 38,000$ & $66 \%$ & $\$ 30,000$ & $56.1 \%$ \\
Fifth threshold & - & - & $\$ 38,000$ & $66 \%$ \\
\hline & \multicolumn{5}{c}{ TY87 } & & \\
\hline Thresholds & & & TY88 \\
& Threshold & Rate & Threshold & Rate \\
\hline Zero income & - & $17.5 \%$ & - & $15 \%$ \\
First threshold & $\$ 6,000$ & $24 \%$ & $\$ 9,500$ & $30 \%$ \\
Second threshold & $\$ 9,500$ & $31.5 \%$ & $\$ 30,000$ & $48 \%$ \\
Third threshold & $\$ 25,000$ & $37.55 \%$ & - & - \\
Fourth threshold & $\$ 30,000$ & $52.05 \%$ & - & - \\
Fifth threshold & $\$ 38,000$ & $57 \%$ & - & - \\
\hline
\end{tabular}

However, looked at in isolation the rate and threshold changes give a misleading indication of what happened to the tax system.

There was tax base broadening with the introduction of a fringe benefit tax in March 1985 at 45\% [1] before rising to $48 \%$ in April 1986 [2]. Furthermore, the Transitional Tax Allowance was introduced in October

\footnotetext{
${ }^{5}$ The TY84 and TY85 scales include a surcharge introduced in TY82, which had to be approved each year - legislative rate was $41.1 \%$. The surcharge made permanent in TY86. The TY87 scale is a composite scale, given that the tax changes occurred in October 1986 to "compensate for the introduction of GST".
} 
1986 [3] as a replacement for the Principal Income Earner Rebate. These changes happened in the face of the introduction of GST as a partial replacement for an income tax [4] - initially at 10\% in October 1986, but rising to $12.5 \%$ in July 1989 [5]. Finally inflation, which ran at an average rate of over $11 \%$ pa during this period, significantly reduced the real value of tax thresholds. According to Stephens (1987) when these changes are combined the overall progression of the tax system was intended to remain unchanged between 1984 and 1987 while the tax base this scale was applied on was widened.

The focus of this chapter is on the period TY88-TY13. During this period the changes to the income tax schedule were more gradual. Changes in the gross income tax scale are outlined in Table 2.2.

Table 2.2: Tax thresholds and rates: TY88-13

\begin{tabular}{ccccccc}
\hline Thresholds & \multicolumn{2}{c}{ TY88 } & \multicolumn{2}{c}{ TY90 } & \multicolumn{2}{c}{ TY98 } \\
& Threshold & Rate & Threshold & Rate & Threshold & Rate \\
\hline Zero income & - & $15 \%$ & - & $15 \%$ & - & $15 \%$ \\
First threshold & $\$ 9,500$ & $30 \%$ & $\$ 9,500$ & $28 \%$ & $\$ 9,500$ & $21.75 \%$ \\
Second threshold & $\$ 30,000$ & $48 \%$ & $\$ 30,875$ & $33 \%$ & $\$ 34,200$ & $24 \%$ \\
Third threshold & - & - & - & - & $\$ 38,000$ & $33 \%$ \\
\hline \multicolumn{2}{c}{ Thresholds } & \multicolumn{2}{c}{ TY01 } & \multicolumn{2}{c}{ TY10 } & \multicolumn{2}{c}{ TY13 } \\
\hline Zero income & - & $15 \%$ & - & $12.5 \%$ & - & $10.5 \%$ \\
First threshold & $\$ 9,500$ & $21 \%$ & $\$ 14,000$ & $21 \%$ & $\$ 14,000$ & $17.5 \%$ \\
Second threshold & $\$ 38,000$ & $33 \%$ & $\$ 48,000$ & $33 \%$ & $\$ 48,000$ & $30 \%$ \\
Third threshold & $\$ 60,000$ & $39 \%$ & $\$ 70,000$ & $38 \%$ & $\$ 70,000$ & $33 \%$ \\
\hline
\end{tabular}

The first change from TY88 was the introduction of the Low Income Rebate LIR and tax cuts in the 1988 Budget [6]. Excluding this rebate the tax schedule had been changed to a two rate schedule - $24 \%$ on income below $\$ 30,875$ pa and 33\% above this threshold. However, the LIR reduced 
effective tax rates to $15 \%$ for labour income below $\$ 9,500$ and then was clawed back pushing the effective tax rate between $\$ 9,501$ and $\$ 30,875$ up to $28 \%$.

The purpose of the LIR was to ensure that the tax rate on low income wage earners did not rise even though the tax rate on the lowest income bracket had increased. With investment income sources not eligible for the LIR (unless the person was retired) these would be taxed at a different rate than labour income. The rates and thresholds discussed below are for personal wage income and so incorporate the LIR. The scale including the LIR is termed the gross tax scale.

In nominal terms, the income tax system remained broadly unchanged until July $1996 .{ }^{6}$ However, as a result of fiscal drag, the real value of the tax thresholds had fallen - the 1990 thresholds were equivalent to $\$ 11,043$ and $\$ 35,890$ in 1996 prices.

Rather than adjusting for this fiscal drag, prior to the election in 1996 the government introduced reductions to tax rates with corresponding adjustments to the LIR and increased the abatement rate on temporary benefits (eg the unemployment and sickness benefit) - changes that were expected to increase labour supply (Treasury 1996). The tax rate and threshold changes were not set to take place all at once, instead being phased in during July 1997 and July 1998. As a result, both TY97 and TY98 involved composite scales - with the tax scale only settling again in TY99 (IRD 1996).

In 1999 the new government introduced a new top tax bracket [7] with a $39 \%$ rate applied to each dollar earned above $\$ 60,000$ pa. The rate of FBT was also increased from $49 \%$ to $64 \%$ to be consistent with this new higher top tax rate.

${ }^{6}$ During this period the Income Tax Act 1994 was introduced - which modernised the 1976 Act and tided up the series of amendments that had been passed in the meantime. 
In TY01 an alternate multi-rate option for FBT was introduced [8], where if the employer could attribute fringe benefits to individual workers they would be taxed on the basis of the income of the specified worker. The purpose of this was to stop the fringe benefits of employees earning below the top tax rate getting overtaxed - given that the single rate was set to make the tax liability for the employer the same whether paying in cash or through the provision of fringe benefits (Carr and Chan 2004).

A tax review was then undertaken in 2001 (Treasury 2001a), but in terms of tax rates and thresholds the income tax system was left unchanged until 2008.

At the end of its third term in 2008 the government introduced cuts to the bottom tax rate [9] (from 15\% to 12.5\%) and changes to the first two gross thresholds. When the next government came into power in late 2008, threshold and rate changes were made for the top tax bracket [10] but the other changes (which came in the month before the election) were kept in place.

Although there were threshold adjustments, there had been a significant period of fiscal drag between the introduction of the previous tax scale in 1999 and these changes in $2008^{7}$. Comparing the real value of thresholds in TY01 to TY10 (the first full tax year for both tax systems) indicates that the TY01 thresholds were equivalent to $\$ 11,985, \$ 47,940$, and $\$ 75,694$ in 2010 dollars. As a result, in real terms the adjustments increased the lowest threshold relative 2001, but the top tax threshold was at a lower real level.

Comparing these thresholds to both wage growth and median incomes reinforces this story about the top tax rate, as they provide an indication of the change in where in the income distribution the thresholds fall. In 2001 this threshold was at $199 \%$ of median labour market income for individu-

\footnotetext{
${ }^{7}$ During this period of stability in tax thresholds and rates a new updated tax acts were introduced, the Income Tax Act 2004 and the Income Tax Act 2007.
} 
als in employment and 143\% of household median income. By 2010, after the threshold increase, the threshold was at $175 \%$ of median labour market income for individuals in employment and 108\% of household median income. $^{8}$

Following a report by the Tax Working Group (Victoria University of Wellington Tax Working Group 2010), the government undertook more significant changes in tax rates [11] which came in place from October 2010. The 2010 tax changes were also outlined and analysed in Creedy and Mok (2015). Although the tax thresholds remained unchanged, tax rates were reduced - more than compensating for the increase in the GST rate from $12.5 \%$ to $15 \%$ [12]. With personal income tax rates cut, the rates of fringe benefit tax were also cut.

\subsection{First tier benefits}

The legislative structure of the system of government benefit payments, including the naming convention of benefits, was largely unchanged between the introduction the the Social Security Act in 1938 and 2013. The key changes since 1938 were to do with the implementation of these payments and the nature of eligibility (McClure 1996). Even when the naming of benefits was changed the overarching structure of benefits based on payments stratified by unemployment, disability, and family structure, remained in place. ${ }^{9}$

Although the structure of government assistance remained unchanged the size of these payments - and the obligations associated with receiving them - did change sizeably between TY88 and TY13.

\footnotetext{
${ }^{8}$ These figures were estimated using weighted Household Economic Survey data.

${ }^{9}$ The naming conventions were changed temporarily between 1998-2001 and permanently from July 2013.
} 
The benefit system can be viewed as having three tiers of assistance. The first tier is made up of the main benefits. During the 1988-2013 period these were the Unemployment Benefit $(\mathrm{UB})^{10}$, the Sickness Benefit (SB), Domestic Purposes Benefit (DPB) ${ }^{11}$, and the the Invalid's Benefit (IB).

The second tier is made up of cost related payments - Working for Families (WfF) and the Accommodation Supplement fall into this category, along with childcare subsides. The third tier includes hardship payments (eg unrecoverable special needs grants, or recoverable interest free loans/benefit advances) and payments related to employment intervention. The second and third tiers can be grouped together and are often termed supplementary assistance.

In this chapter the focus is only on first tier payments, as the extension to TAXWELL only models first tier payments for families and WfF. As a result, the following description of changes to the benefit system misses some important changes in the focus of benefit provision which need to be taken into account when considering welfare reforms. The welfare reforms of the early to mid 1990s explicitly focused on increased targeting by increasing the provision of supplementary assistance - which was intended to reduce the cost of supporting those in need (McClure 1996). Furthermore, the Working for Families reforms included a significant increase in Accommodation Supplement payments which was justified on increasing assistance to those in need.

As a result, through the period of interest there has been a direct shift in payments away from first tier payments towards towards more targeted supplementary assistance. Evaluating the level of support associated with the benefit system using this information by looking at only first tier payments would bias downwards any estimate of social support.

\footnotetext{
${ }^{10}$ The UB discussed here includes the Independent Youth Benefit from 1996.

${ }^{11}$ Carers benefits, Orphan's/Unsupported Child Benefit, Emergency Benefits, and Widow's Benefit are being included in the IB and DPB here.
} 
For a comprehensive outline of the evolution of family assistance payments the work of Nolan (2002) and Mercante and Mok (2014c) already provide a summary of changes to assistance to families with dependants over this period.

An outline of many of the qualitative policy changes that are in the legislation (work testing, stand down periods) is given below. These are not elements of policy change that are modelled by TAXWELL, but they still played an important part of the policy changes that have been experienced.

\subsubsection{Single people}

\section{Unemployment Benefit}

Between 1982 and 1987 the unemployment benefit was cut, the standdown period for receiving a benefit was increased to two weeks, and the youth age for receiving a benefit for a single period was increased to 18 . With government job schemes being wound down over the $1980 \mathrm{~s}^{12}$ and unemployment climbing from the start of 1988, the unemployment benefit became a more important and more costly part of the social security safety net over this period. As a result, questions about the cost and eligibility for this benefit became pertinent (McClure 1996).

From March 1989 the training benefit was introduced [5]. Although it remained within the schedules of unemployment benefit payments, it required that the individual was independent and undertaking training (rather than solely looking for work) and was only available for up to 26 weeks. In essence the training benefit introduced an additional youth tier for unemployment benefit payments - on top of the distinction between young

\footnotetext{
${ }^{12}$ An example of this was the Project Employment Program which was cancelled in 1985.
} 
adults and adults that already existed. Furthermore, the distinction only held for those who were single. As of March 1989, this lower training benefit was for individuals who were newly on the unemployment benefit and were aged between 16 and 18 - once the individual turned 18 they were eligible for the young adult payment.

From December 1990, the minimum age for UB increased from 16 to 18 (or 16 if married) [13]. However, this was due to the introduction of the job search allowance and the independent youth benefit - which essentially function in the same way for the youth age group.

The 1991 Budget, dubbed the Mother of All Budgets at the time, saw significant reductions in weekly payments for most benefits [14]. All weekly payments on the unemployment benefit were cut, with the percentage size of the reductions for single adult families varying from $5.8 \%$ for a young adult to $13 \%$ for a sole parent with one child.

Also in TY92 the definition of young adult for the unemployment benefit changed, with the adult age rising from 20 to 25 [14]. As a result, unemployment payments for those aged between 20-24 fell more sharply than for other groups, with weekly benefit payments declining by nearly $25 \%$.

From TY92 onwards unemployment benefit payments rose roughly in line with the consumer price index, keeping real payments steady through until 2013 - but also ensuring that benefit payments compared to the average wage earner would consistently decline. ${ }^{13}$ This link was followed implicitly between 1992 and 2010, and was set into legislation in 2010 [15].

Payments and thresholds for the unemployment benefit for single adults are outlined in Table 2.3.

\footnotetext{
${ }^{13}$ Due to the fact that average wage growth consistently outpaces growth in consumer good prices.
} 
Table 2.3: Unemployment benefit (net of tax): Single Adult no dependants

\begin{tabular}{ccccc}
\hline Tax year & Weekly Payment & First Threshold & Second Threshold & Minimum Age \\
\hline TY88 & $\$ 126.23$ & $\$ 2,600$ & $\$ 4,160$ & 20 \\
TY92 & $\$ 129.81$ & $\$ 2,600$ & $\$ 4,160$ & 25 \\
TY98 & $\$ 146.13$ & - & $\$ 4,176$ & 25 \\
TY07 & $\$ 173.92$ & - & $\$ 4,176$ & 25 \\
TY13 & $\$ 204.96$ & - & $\$ 4,176$ & 25 \\
\hline
\end{tabular}

Table 2.4: Unemployment benefit 2013 prices (net of tax): Single Adult no dependants

\begin{tabular}{ccccc}
\hline Tax year & Weekly Payment & First Threshold & Second Threshold & Minimum Age \\
\hline TY88 & $\$ 240.56$ & $\$ 4,955$ & $\$ 7,928$ & 20 \\
TY92 & $\$ 206.04$ & $\$ 4,127$ & $\$ 6,603$ & 25 \\
TY98 & $\$ 207.22$ & - & $\$ 5,922$ & 25 \\
TY07 & $\$ 201.80$ & - & $\$ 4,845$ & 25 \\
TY13 & $\$ 204.96$ & - & $\$ 4,176$ & 25 \\
\hline
\end{tabular}

Until TY98 income above the first threshold faced an abatement rate of $30 \%$, while income above the second threshold faced an abatement rate of $70 \%$. From TY98 onwards there was only a single abatement rate of $70 \%$.

Although they are listed separately in the legislation, the unemployment benefit for sole parents and the domestic purposes benefit had the same weekly payment over the entire period of interest. Payments to carers through the DPB were at a higher rate than the standard DPB payment from TY92 onwards. ${ }^{14}$ Following the changes to abatement thresholds in July 1996 the DPB payment for sole parents was abated using the same income test as the unemployment benefit, while for carers the more gradual

\footnotetext{
14 The carer payment remained at the Invalid's Benefit rate.
} 
abatement schedule used for the Invalid's Benefit was applied.

In TY88, there was a single payment for the DPB along with a broad per child payment that was given to beneficiaries [16]. Per child payments were removed in TY90 and a new sole parent payment for beneficiaries with 2 or more dependants was listed in the legislation [5]. The payments depending on the number of children remained in place until Working for Families was introduced in 2005. An outline of DPB payments is give in Table 2.5..$^{15}$

Table 2.5: Domestic Purposes benefit: Sole parent

\begin{tabular}{ccccc}
\hline Tax year & Weekly Payment & First Threshold & Second Threshold & Second Child payment \\
\hline TY88 & $\$ 192.08$ & $\$ 2,600$ & $\$ 4,160$ & $\$ 16.00$ \\
TY92 & $\$ 185.93$ & $\$ 2,600$ & $\$ 4,160$ & $\$ 15.73$ \\
TY98 & $\$ 228.34$ & - & $\$ 4,176$ & $\$ 19.04$ \\
TY07 & $\$ 249.10$ & - & $\$ 4,176$ & $\$ 0.00$ \\
TY13 & $\$ 293.58$ & - & $\$ 4,176$ & $\$ 0.00$ \\
\hline
\end{tabular}

Table 2.6: Domestic Purposes benefit 2013 prices (net of tax): Sole parent

\begin{tabular}{ccccc}
\hline Tax year & Weekly Payment & First Threshold & Second Threshold & Second Child payment \\
\hline TY88 & $\$ 375.05$ & $\$ 4,955$ & $\$ 7,928$ & $\$ 30.49$ \\
TY92 & $\$ 295.11$ & $\$ 4,127$ & $\$ 6,603$ & $\$ 24.97$ \\
TY98 & $\$ 296.80$ & - & $\$ 5,922$ & $\$ 27.00$ \\
TY07 & $\$ 289.03$ & - & $\$ 4,845$ & $\$ 0.00$ \\
TY13 & $\$ 293.58$ & - & $\$ 4,176$ & $\$ 0.00$ \\
\hline
\end{tabular}

These figures exclude family related payments. As a result this excludes: the Family Benefit (in TY88), Family Support (in TY88, TY92, and TY98), and Family Tax Credits (in TY07 and TY13) which provide additional support to sole parent households. With the family tax credit households are eligible for the entire credit - not just the difference between their gross and net income. As a result, it is similar to the earlier family support program.

\footnotetext{
${ }^{15}$ The $\$ 16$ payment in TY 88 was for each additional child, not just the second child.
} 


\section{Work testing of the UB and DPB}

Prior to 1989 a married person or sole parent was eligible to receive an unemployment benefit 8 days after becoming unemployed ${ }^{16}$, and a single adult was eligible after 15 days. ${ }^{17}$ However, there was also discretion - if the person had been earning a sufficient salary (and had not been made redundant) payments could be delayed for 4 weeks. Furthermore, if the person appeared unwilling to find work payments could be delayed for 6 weeks.

The first benefit with a longer default stand-down period was the training benefit, which was introduced in 1989. The training benefit was kept separate from the standard unemployment benefit [17], with a 27 week stand-down period.

However, it was Budget 1991 that saw large scale changes in eligibility and work testing criteria. Section $60 \mathrm{H}$ was introduced in an amendment following the Budget [18]. This new section was partially a reorganisation of text that had been elsewhere in the Social Security Act. However, it also introduced the 26 week stand-down period for someone who voluntarily left their job or failed to meet the conditions of staying on a government benefit. The failure to accept employment - even of a temporary or seasonal nature - was also now grounds for being removed from the benefit, albeit on discretionary grounds.

Furthermore, stand-down periods in the face of redundancy now depended upon whether the net of tax income (including government support) received by the person exceeded average net weekly income. If the person was earning enough prior to being fired, the stand-down period could increase to 10 weeks.

\footnotetext{
${ }^{16}$ Assuming that they apply for the benefit immediately.

17 This marital status distinction was removed in Social Security Amendment Act (No. 2) 1990 .
} 
Finally, if a redundancy payment was given the person would be ineligible for a benefit for the period of time that would have given that same benefit payment (up to 26 weeks).

The community taskforce scheme was introduced in August 1991 [19]. Following the introduction of this scheme a beneficiary, who had been on the benefit for 26+ weeks, could be told to undertake community work for up to 26 weeks - and if the beneficiary refused they could have their benefit cancelled for 26 weeks. In this form, the offer of community work did need to be judged as suitable for the beneficiary, such that it was deemed unreasonable for them to refuse to do it.

Work testing then stayed largely unchanged until TY97. In TY97 the section "further conditions of entitlement for the unemployment benefit, etc" which was introduced in 1991 was extended [20], with the stated goal of clarifying the reciprocal obligations of work-tested beneficiaries to look for work. Mandatory interviews and further work testing were introduced in this amendment. The mandatory interviews could not take place for the first year on a benefit, or within a year of each other. Also compulsory interviews, which were already used for those on the unemployment benefit, were extended to people who were on the domestic purposes benefit and window's benefit. ${ }^{18}$

The reduction in benefits associated with a failure to turn up to mandatory interviews or to undertake work testing was also listed in the TY97 legislation. A single failure saw benefit payments cut by $20 \%$, with further $20 \%$ reductions for every 28 days where the failure was not remedied. A second failure saw an initial $40 \%$ reduction in the benefit payment, and the benefit cut by $100 \%$ after 28 days if the failure is not remedied. A third failure would see the benefit cancelled completely - and future applications would be treated as if they were a new benefit applicant with the asso-

\footnotetext{
${ }^{18}$ Those with a dependent aged over 14 would face work testing, and sole parents with a dependent aged over 7 had to attend mandatory interviews.
} 
ciated stand-down (non-entitlement) periods. However, involvement in a community task force project could be used to reduce this non-entitlement period.

A final related change was made in the TY97 amendment, with a reduction in the period someone was allowed to be on a work-tested benefit before they could be requested to take part in a community task force project. This minimum period was reduced from 26 weeks to 13 weeks. The twenty-eighth schedule was introduced in this amendment, to provide a clear run-down on benefit stand-down periods subject to prior income earned.

In 1998 further changes were made. There was a rewrite of the the unemployment legislation with the youth rate for those below 25 now called the young job seekers allowance [21]. After 13 weeks a recipient of this allowance would, if the individual was eligible, move onto the unemployment benefit. ${ }^{19}$ Furthermore, the age of eligibility for a single person without dependants for the training benefit rose from 16 to 18 .

From October 1998 the community wage was introduced as a replacement for the varying unemployment benefits and the sickness benefit [22]. Furthermore, the community taskforce scheme was removed and replaced with community work - which was pinned to the organised work initiatives tied to the community wage.

Sanctions were increased for work test failures [23]. A one week suspension of payment occurred following the first failure and then the benefit was cancelled with the second failure - with a 13 week stand down pe-

\footnotetext{
${ }^{19}$ At this point the legislation is unclear on what the youth age was. The related amendment Social Security Amendment Act (No. 3) 1997 and the Act as of 1994 Social Security Act 1964 both suggest it was 20 - when Social Security Amendment Act 1991 has reference to an age of 25. Given [158] use the age of 25 from 1992, and the fact that the UB payment would have been larger than the SB payment for those aged between 20 and 24 if the youth age was 20 , we have taken 25 as the age that was actually applied.
} 
riod introduced following the cancellation of a benefit. Furthermore, a distinction between part-time and full-time work-tested beneficiaries was introduced.

Starting in February 1999 the work testing on the DPB and widow's benefit for those with a dependant child was changed [22], now occurring when the child turned 6. Furthermore, once the child was aged 14 job search required looking for full time work.

Many of these changes during 1998/99 were due to be reversed once the new government came into power in 1999 [24]. The 13 week stand down after benefit cancellation was removed, parents of minors were no longer work tested, and the work tests were loosened somewhat - with the removal of the obligation to undertake voluntary work as a form of organised activity for benefit purposes [25], and the payment of the existing participation allowance for such work. However, the eventual amendment that did get passed continued to include a 13 week stand down period, although now it was after a third successive work test failure. As part of this amendment the community wage was removed, and was again replaced with the unemployment and sickness benefit.

Further assistance for finding work though personal development plans for those who were eligible for the widows benefit or DPB was introduced in 2003 [27] and was extended to include those on the invalid's benefit, sickness benefit, and the partners of those on a work-tested benefit in 2007 [28]. This amendment also saw the introduction of pre-benefit activity in order to access the unemployment benefit (eg attending an employment related seminar) and the reduction of stand-down periods for those who had been earning higher incomes, with a maximum stand-down based on previous labour market income of 2 weeks (compared to 10 weeks previously).

In 2010, the question of benefits and work obligations reappeared. In August 2010 work testing for those on the DPB was reintroduced [29] - as 
with the reforms in 1998 there was an increasing focus on the use of child care services to get parents back into work. However, the penalty for the first failure of a work test was eased slightly - from a full suspension of payments to a $50 \%$ reduction for the first 4 weeks.

2012 saw the government increase its focus on changing eligibility for youth and young parents [30]. The age of eligibility for the unemployment benefit and DPB rose to 19 for those with dependants (with a young parent payment for those aged 16-18 who are unsupported by their parents), while youth payments were more heavily tied to undertaking education.

The 2011 Welfare Working Group report had a significant influence on the direction the government took with welfare reform (Welfare Working Group 2011). This lead to the large scale changes in the benefit system in July 2013 through the Social Security (Benefit Categories and Work Focus) Amendment Act 2013. At this point the unemployment benefit was renamed Job Seeker Support and the DPB became Sole Parent Support.

\section{Sickness and Invalid's benefits}

In the late nineteenth century there was a growing agreement that a person should not be expected to work past a certain age for health reasons. There was an increasing number of people reaching this age, who were employed in physical labour and who had limited savings - a situation that people felt was unfair. As a result, an old age pension was introduced.

By the early 20th century a similar argument was used for those injured in the mining industry ${ }^{20}$, for widows, and for the blind. With the Social Security Act (1938) many of these payments were entrenched, and

${ }^{20}$ This was predominantly justified to help those with pneumoconiosis. 
broader invalid's benefit (IB) and sickness benefit (SB) payments were introduced.

The IB was an extension of the blindness benefit and was given for those who would not be able to work permanently for health reasons. The SB on the other hand referred to temporary departures from work for health reasons. Although the payment to someone on the $\mathrm{SB}$ was the same as the payment on the UB and below the payment given on the IB in 1938, the justification that both the SB and IB were given for what were seen as deserving reasons had seen the two benefits pay the same rates by the 1980s (Belgrave 2012).

One of the key areas of the benefit system that has seen significant change since the 1980s was the distinction between the SB and IB. In TY88, the sickness benefit, miners benefit, and invalids benefit all provided the same primary payment - the difference was instead based on eligibility criteria.

With conditionality of benefit provision and an increasing expectation of work, a principal that gained precedence in New Zealand, the payments for the sickness and invalid's benefits began to diverge.

Following the 1991 Budget, sickness benefit payments were cut significantly. In percentage terms the smallest decline among single individuals was for sole parents with two children (reduced by over 11\%), while the largest cut occurred for the youth payment (reduced by nearly $18 \%$ ).

Meanwhile, the invalid's benefits was the one first-tier benefit that was not cut in the 1991 Budget. In theory the invalid's benefit combined with more focus on supplementary assistance was intended to improve the targeting of those in dire need, however it took several years before these systems were properly in place to provide sufficient supplementary assistance (McClure 1996).

Over the 1990s views around the eligibility for the sickness benefit con- 
tinued to evolve. The full adult payment was now only available from the age of 25, compared to 18 previously. This compares to a similar lift for the unemployment benefit (20 to 25) and no change in the adult age for the invalids benefit (18), as the role of the sickness benefit was increasingly seen as similar to the unemployment benefit. The introduction of young adult payment for those between 18 and 24 occurred from April 1991 [18]. People between 18 and 24 who were subject to this new young adult rate saw, in conjunction with the general cut in weekly payments, their sickness benefit payments decline by 20\%. From August 1991 [19], the youth payment was no longer available for 15 year olds. ${ }^{21}$ The invalid's benefit was also made unavailable for 15 year olds.

In 1993 the miners benefit was repealed [31], due to claimants being sufficiently covered by the sickness and invalid's benefits.

Weekly payments for unemployment and sickness benefit were set equal [22] in the 1998 Budget. This change took place from July 1998 and saw single adult payments for people on sickness benefits fall $4.0 \%$ while payments to sole parents were unchanged. However, young adult and youth payments were cut sharply - falling by $17 \%$ and $20 \%$ respectively.

As the sickness benefit was seen as providing support for a temporary departure from work, the increasing policy focus on work testing post1991 did impact upon how this benefit was handed out. In this context, the sickness benefit was defined as a work-tested benefit. As a result, the tightening in work testing regimes for the unemployment benefit that were discussed above also held for the sickness benefit and stand down periods for both the sickness and invalid's benefit were increased in line with increases to the unemployment benefit stand down period.

Explicit reviews of people's eligibility for the invalid's benefit [22] also appeared in 1998. Although a medical test had always been required [32], the

\footnotetext{
${ }^{21}$ This reverted the age of a dependent back to where it was in the SSA (1938) through the Social Security Amendment Act 1991 (2).
} 
benefit now required a date for review of the permanency and / or severity or the disability. The distinction between a sickness and invalid's benefit often based on the estimated permanency - namely whether the individual is expected to be unavailable for work for 2 or more years - and so reviews were consistent with this definition. However, legislation does not make fully clear the nature of the certificates provided for varying levels of physical and mental disabilities which makes the implementation and quality of any reviews unclear. Finally, the work testing regime was also expanded [23], with invalid's and emergency benefits added to the list of work tested benefits. However, much of this work testing was removed with the new government in 1999.

In 2010, new policy regarding benefits and work obligations appeared with some of the previously removed work testing conditions for those on the sickness benefit reintroduced [29].

Overall, these changes cannot be seen in isolation from the Accident Compensation System in New Zealand (ACC). The introduction of workplace insurance started in 1900 but by 1974 this was extended out more widely on a no-faults basis through ACC [34], including coverage for non-earners. By the 2002 Injury Prevention, Rehabilitation, and Compensation Act [35] eligibility to ACC payments had been stretched out to cover a large number of non-work related non-gradual injuries - both physical and mental. As a result, targeted ACC payments can be seen as an at least partial replacement for such benefit payments.

By 2013 both the unemployment and sickness benefit were seen as temporary, offered the same payments, and involved work testing. As a result, they were combined in the July 2013 benefit reforms into job seekers support (JSS). The invalid's benefit was also renamed and combined with the carer rate from the DPB, the new benefit was termed the supported living payment (SLP). 
Table 2.7: Sickness benefit (net of tax): Single Adult no dependants

\begin{tabular}{ccccc}
\hline Tax year & Weekly Payment & First Threshold & Second Threshold & Minimum Age \\
\hline TY88 & $\$ 139.25$ & $\$ 2,600$ & $\$ 4,160$ & 18 \\
TY92 & $\$ 135.22$ & $\$ 2,600$ & $\$ 4,160$ & 25 \\
TY98 & $\$ 152.21$ & - & $\$ 4,176$ & 25 \\
TY07 & $\$ 173.92$ & - & $\$ 4,176$ & 25 \\
TY13 & $\$ 204.96$ & - & $\$ 4,176$ & 25 \\
\hline
\end{tabular}

Table 2.8: Sickness benefit 2013 prices (net of tax): Single Adult no dependants

\begin{tabular}{ccccc}
\hline Tax year & Weekly Payment & First Threshold & Second Threshold & Minimum Age \\
\hline TY88 & $\$ 271.90$ & $\$ 4,955$ & $\$ 7,928$ & 18 \\
TY92 & $\$ 214.63$ & $\$ 4,127$ & $\$ 6,603$ & 25 \\
TY98 & $\$ 215.84$ & - & $\$ 5,922$ & 25 \\
TY07 & $\$ 201.80$ & - & $\$ 4,845$ & 25 \\
TY13 & $\$ 204.96$ & - & $\$ 4,176$ & 25 \\
\hline
\end{tabular}

Table 2.9: Invalids benefit (net of tax): Single Adult no dependants

\begin{tabular}{ccccc}
\hline Tax year & Weekly Payment & First Threshold & Second Threshold & Minimum Age \\
\hline TY88 & $\$ 139.25$ & $\$ 2,600$ & $\$ 4,160$ & 18 \\
TY92 & $\$ 162.26$ & $\$ 2,600$ & $\$ 4,160$ & 18 \\
TY98 & $\$ 182.85$ & $\$ 4,176$ & $\$ 9,396$ & 18 \\
TY07 & $\$ 217.38$ & $\$ 4,176$ & $\$ 9,396$ & 18 \\
TY13 & $\$ 256.19$ & $\$ 5,220$ & $\$ 10,440$ & 18 \\
\hline
\end{tabular}

Table 2.10: Invalids benefit 2013 prices (net of tax): Single Adult no dependants

\begin{tabular}{ccccc}
\hline Tax year & Weekly Payment & First Threshold & Second Threshold & Minimum Age \\
\hline TY88 & $\$ 271.90$ & $\$ 4,955$ & $\$ 7,928$ & 18 \\
TY92 & $\$ 257.54$ & $\$ 4,127$ & $\$ 6,603$ & 18 \\
TY98 & $\$ 259.29$ & $\$ 5,922$ & $\$ 13,324$ & 18 \\
TY07 & $\$ 252.23$ & $\$ 4,845$ & $\$ 10,902$ & 18 \\
TY13 & $\$ 256.19$ & $\$ 5,220$ & $\$ 10,440$ & 18 \\
\hline
\end{tabular}




\subsubsection{Couples}

Unlike the tax system, the level of payment depends on the persons relationship status, while the abatement scale on benefits also depends on family - rather than individual - income. As a result, even though the payment of a benefit is to the individual, benefits are targeted to the family.

When someone is in a relationship, the benefit payment per person is less than when someone is single. This is motivated by the idea of economies of scale within the household, where the sharing of resources and specialisation of tasks implies that the family does not require double the income of a single person to cover the basic needs of the couple (Nelson 1988). Furthermore, this implies that the payment level of couples benefits are set in relation to the single person rates - as a result, the evolution of the transfer system described for single person payments also holds for couples and will not be repeated below. Instead the focus is on when this relationship with the single person rate was adjusted, and when working testing of spouses changed.

Until the introduction of Working For Families in 2005 benefit payments for couples directly varied based on whether there were dependants in the family. In TY88, this led to the interesting situation where someone who qualified for the sickness or invalid's benefit would receive less in their main benefit than they would if they did not have children - with family support and the family benefit filling the gap. What this did imply was that someone in a relationship with children would receive the same payment irrespective of the type of main benefit received - with eligibility and work testing conditions the only difference. This situation remained in place until the family benefit was removed and main benefits were cut in TY92. 


\section{Unemployment benefit}

During the entire period of interest a person's eligibility did not depend on their partners employment status. However, the income test used [16] (and subsequent abatement of unemployment benefit payments) does depend on the income earned by both people.

In TY88 the single person payment was $66 \%$ of what a couple on the unemployment benefit would receive. As a result, the per person couple payment was $75 \%$ of the single person payment. This relative per person rate crept up over the next few years, and following the benefit changes in the 1991 Budget the single person payment was $60 \%$ of what a couple would receive in TY92. With both payments increasing in line with growth in consumer prices from then onwards, this ratio of the single adult payment to the couple payment stayed in place all the way through until TY13.

In 1997 the special married rate of training benefit was removed [36]. Furthermore, the mandatory work testing for those on the unemployment benefit was also applied to the spouse of the person receiving the benefit [20].

Table 2.11: Unemployment benefit (net of tax): Coupled Adult no dependants

\begin{tabular}{cccc}
\hline Tax year & Weekly Payment & First Threshold & Second Threshold \\
\hline TY88 & $\$ 95.04$ & $\$ 2,600$ & $\$ 4,160$ \\
TY92 & $\$ 108.17$ & $\$ 2,600$ & $\$ 4,160$ \\
TY98 & $\$ 121.77$ & - & $\$ 4,176$ \\
TY07 & $\$ 144.92$ & - & $\$ 4,176$ \\
TY13 & $\$ 170.80$ & - & $\$ 4,176$ \\
\hline
\end{tabular}


Table 2.12: Unemployment benefit 2013 prices (net of tax): Coupled Adult no dependants

\begin{tabular}{cccc}
\hline Tax year & Weekly Payment & First Threshold & Second Threshold \\
\hline TY88 & $\$ 181.82$ & $\$ 4,955$ & $\$ 7,928$ \\
TY92 & $\$ 171.69$ & $\$ 4,127$ & $\$ 6,603$ \\
TY98 & $\$ 172.68$ & - & $\$ 5,922$ \\
TY07 & $\$ 168.15$ & - & $\$ 4,845$ \\
TY13 & $\$ 170.80$ & - & $\$ 4,176$ \\
\hline
\end{tabular}

\section{Sickness and Invalid's benefits}

During the entire period of interest a persons eligibility did not depend on their partners employment status. However, the income test used [16] (and subsequent abatement of sickness benefit payments) did depend on the income earned by both people.

In TY88 the single person payment was $60 \%$ of the payment to a couple on the sickness benefit would receive. This ratio remained in place until TY92, when it fell to 55\%. The sickness benefit was increased with inflation up until TY98 and as a result this ratio stayed in place until then.

However, the weekly payment between unemployment and sickness benefit was set equal in 1998 Budget through the Social Security Amendment Act 1998. The cut in couple payments was larger than for single adults (hence why the ratio rose), with weekly couple payments falling by $13 \%$. A couple with dependants on the sickness benefit saw their weekly payment fall by $6.5 \%$. This also pushed the ratio of single person to couple sickness benefit payments back up to $60 \%$.

The work testing of the spouse of those on the unemployment benefit and sickness benefit was extended to the partners of those on invalid's benefit from February 2000. 
For the most part the work testing changes introduced match those introduced for single people. However, the mandatory work testing for those on the sickness and invalid benefits was also applied to the spouse of the person receiving the benefit in 1997 [20].

Table 2.13: Sickness benefit (net of tax): Coupled Adult no dependants

\begin{tabular}{cccc}
\hline Tax year & Weekly Payment & First Threshold & Second Threshold \\
\hline TY88 & $\$ 118.90$ & $\$ 2,600$ & $\$ 4,160$ \\
TY92 & $\$ 122.93$ & $\$ 2,600$ & $\$ 4,160$ \\
TY98 & $\$ 138.39$ & - & $\$ 4,176$ \\
TY07 & $\$ 144.92$ & - & $\$ 4,176$ \\
TY13 & $\$ 170.80$ & - & $\$ 4,176$ \\
\hline
\end{tabular}

Table 2.14: Sickness benefit 2013 prices (net of tax): Coupled Adult no dependants

\begin{tabular}{cccc}
\hline Tax year & Weekly Payment & First Threshold & Second Threshold \\
\hline TY88 & $\$ 226.58$ & $\$ 4,955$ & $\$ 7,928$ \\
TY92 & $\$ 195.12$ & $\$ 4,127$ & $\$ 6,603$ \\
TY98 & $\$ 196.25$ & - & $\$ 5,922$ \\
TY07 & $\$ 168.15$ & - & $\$ 4,845$ \\
TY13 & $\$ 170.80$ & - & $\$ 4,176$ \\
\hline
\end{tabular}


Table 2.15: Invalid's benefit (net of tax): Coupled Adult no dependants

\begin{tabular}{cccc}
\hline Tax year & Weekly Payment & First Threshold & Second Threshold \\
\hline TY88 & $\$ 118.90$ & $\$ 2,600$ & $\$ 4,160$ \\
TY92 & $\$ 135.22$ & $\$ 2,600$ & $\$ 4,160$ \\
TY98 & $\$ 152.21$ & $\$ 4,176$ & $\$ 9,396$ \\
TY07 & $\$ 181.86$ & $\$ 4,176$ & $\$ 9,396$ \\
TY13 & $\$ 213.49$ & $\$ 5,220$ & $\$ 10,440$ \\
\hline
\end{tabular}

Table 2.16: Invalid's benefit 2013 prices (net of tax): Coupled Adult no dependants

\begin{tabular}{cccc}
\hline Tax year & Weekly Payment & First Threshold & Second Threshold \\
\hline TY88 & $\$ 226.58$ & $\$ 4,955$ & $\$ 7,928$ \\
TY92 & $\$ 214.63$ & $\$ 4,127$ & $\$ 6,603$ \\
TY98 & $\$ 215.84$ & $\$ 5,922$ & $\$ 13,324$ \\
TY07 & $\$ 210.20$ & $\$ 4,845$ & $\$ 10,902$ \\
TY13 & $\$ 213.49$ & $\$ 5,220$ & $\$ 10,440$ \\
\hline
\end{tabular}

\subsection{Superannuation}

A comprehensive description of changes in superannuation policy settings during this period can be found in St John (2013). Furthermore, a concise summary of recent reports on superannuation can be found in Littlewood (2015).

The TY88-TY13 period saw a variety of changes to superannuation policy within New Zealand, given persistent concerns about the affordability of National Superannuation.

As of April 1985 a 25\% surcharge was introduced on National Superannuation payments [37] based on other income earned above a given thresh- 
old. ${ }^{22}$ The surcharge was cut to $18 \%$ in August 1986 [38], and then increased to $20 \%$ at the end of July 1988 [39].

In October 1988 changes were made to the payments to married couples where only one partner qualified for superannuation (NQS) [40]. Prior to October 1988, a person with a non-qualifying spouse would be eligible for the single person superannuation payment (60\% of the married rate) unless their partner was receiving a benefit or other government pension in which case they would receive half of the married rate. From October 1988 , the payment was set to $50 \%$ irrespective of benefit status for anyone who becomes eligible from October 1988 onwards. If a couple had been receiving $60 \%$ of the married rate they would still be eligible for the same nominal payment (\$183.89) as long as this was greater than $50 \%$ of the married rate - a gap that held until TY97. Furthermore, couples who were eligible for NQS payments before October 1986 could continue to receive the single person rate ${ }^{23}$ with a $45 \%$ abatement rate on their personal income.

The next large change in National Superannuation took place in TY91 with the introduction of Guaranteed Retirement Income [41] as a replacement for National Superannuation.

From TY91 onwards, NQS superannuation payments were given to the couple, and abated with family income, rather than paid to the individual who was eligible as they were previously. In other words, a couple with a NQS would be paid the full married rate but it would abate in the same way as a standard benefit.

Prior to this policy change net superannuation payments for a couple were intended to stay close to $80 \%$ of net average wages ${ }^{24}$. But as part of the

\footnotetext{
${ }^{22}$ As given in the IRD description of policy.

${ }^{23}$ or half the married rate.

${ }^{24}$ The single person rate was set at $60 \%$ of the couple rate - as in Social Security Amendment Act 1988.
} 
change in name, this link was repealed as of April 1990. After the removal of this provision, superannuation payments remained unchanged in nominal terms until April 1993 - except for those who are single and live alone. In the middle of TY91 a living alone payment of \$20 per week was introduced [42].

In April 1992 the name of the transfer was reverted to National Superannuation [43]. In the same amendment the age of entitlement for National Superannuation stated to rise - increasing by six months every quarter following April 1992, where the age had been increased by a full year to 61 . This significantly moved forward the increases in the retirement age that had been legislated by the prior government [41], which would have begun in in 2007.

In the same amendment the government had also transformed National Superannuation to be more like a standard benefit - with abatement of all superannuation payments to take place from October 1991 [44] (replacing the surcharge) alongside a general cut in the base payment rate [45]. By April 1992 a distinction would have been made between those who were under 70 and those who are 70 and above, with a minimum annual payment remaining in place from this 70 and above.

However, this scheme was never implemented and was repealed in a following amendment [46] and the surcharge was then also reintroduced at a rate of $25 \%$ [47]. The cuts in NQS and married rate payments [45] from the cancelled scheme were kept in place for people retiring from October 1991, and the rate paid to those who retired earlier has continued to be adjusted upwards. This has ensured a difference in rates paid to these two groups of retirees.

As part of the repeal, from April 1993 a new provision was introduced that would see National Superannuation increase with prices (via CPI), and as a result nominal payments started to rise again. A new, lower, bipartisan floor for superannuation payments to net wages was agreed at 
$65 \%$ [48].

In TY95 the Transitional Retirement Payment (TRP) was introduced [49]. This payment was to support those who were near the retirement age when it increased and who are ineligible for NQS payments. Although the TRP was less that National Superannuation ${ }^{25}$, and was income tested, it can be seen as a cushion for those who had insufficient notice to save when the retirement age increase was announced.

The TRP provided a means tested benefit to single people, and married people with a non-qualifying spouse, for the three years prior to National Superannuation eligibility for those who turned 60 during TY95. The age of eligibility then rose at the same rate as the superannuation age (increasing by 3 months every half year), until it was irrelevant by TY02.

Prior to the TRP, policy had been focused on cutting the cost of National Superannuation, but with the introduction of the TRP policy changes became more mixed.

The surcharge remained extremely unpopular (St John 2015) and as a result the election of a new coalition government in 1996 led to changes in the surcharge in TY97. In both July 1996 and April 1997 the income threshold where the surcharge kicked in was increased with further plans to increase the other income threshold through the next two years. Then in 1998 the superannuation surcharge was removed completely for TY99 [50].

However, the government also tried to reduce costs by cutting the lower bound on the couples weekly National Superannuation payment to $60 \%$ of the average wage, from $65 \%$ previously ${ }^{26}$. After several years of adjusting

\footnotetext{
${ }^{25}$ Weekly payments for the TRP were set at the same level as the Invalid's Benefit, which at the time was comparable with NZS payments for someone with no other taxable income. However, for sole parents rates were more generous than standard superannuation payments.

${ }^{26}$ This is noted both as a bill and a following amendment.
} 
superannuation payments by growth in consumer goods prices the lower bound on these payments had become binding - implying that the government would either need to start increasing weekly payments by growth in average wages, or the bound would need to be cut. This cut in the peg was due to come into effect in TY00.

The election of a new government in 1999 saw a change in the payment peg to the average wage back to $65 \%$ from October 2001 [53]. As the payment floor was now binding this effectively ensured that superannuation payment would now rise with average wages instead of consumer prices.

This change in the peg was part of the passing of the New Zealand Superannuation Act 2001. This Act saw the introduction of direct hospital and disability payments through National Superannuation. The act was later renamed the New Zealand Superannuation and Retirement Income Act in 2005, with language in the act modernised for new forms of cohabitation and relationships (eg civil unions).

This act also left the floor for National Superannuation payments at $65 \%$ of the average wage - although governments have committed to a $66 \%$ floor over time (Littlewood 2015).

With National Superannuation payments effectively tied to the average wage their value has been rising at a time where other transfer payments have moved sideways in real terms. This can be seen in Table 2.17.

The payments reported below include the living alone payment, which was introduced in the middle of TY91 and increased the payment to single people who lived alone to $65 \%$ of the married rate. Payments to single people who lived in shared arrangements remained at $60 \%$ of the married rate. 
Table 2.17: National Superannuation (Gross of tax): Single Adult

\begin{tabular}{ccc}
\hline Tax year & Weekly Payment & Minimum Age \\
\hline TY88 & $\$ 172.12$ & 60 \\
TY92 & $\$ 227.07$ & 60 \\
TY98 & $\$ 252.82$ & 63 \\
TY07 & $\$ 320.13$ & 65 \\
TY13 & $\$ 400.07$ & 65 \\
\hline
\end{tabular}

Table 2.18: National Superannuation (Gross of tax) 2013 prices: Single Adult

\begin{tabular}{ccc}
\hline Tax year & Weekly Payment & Minimum Age \\
\hline TY88 & $\$ 328.01$ & 60 \\
TY92 & $\$ 360.41$ & 60 \\
TY98 & $\$ 358.52$ & 63 \\
TY07 & $\$ 371.45$ & 65 \\
TY13 & $\$ 400.07$ & 65 \\
\hline
\end{tabular}

Table 2.19: National Superannuation (Gross of tax): Partnered Adult

\begin{tabular}{ccc}
\hline Tax year & Weekly Payment & Minimum Age \\
\hline TY88 & $\$ 143.44$ & 60 \\
TY92 & $\$ 169.45$ & 60 \\
TY98 & $\$ 189.52$ & 63 \\
TY07 & $\$ 243.06$ & 65 \\
TY13 & $\$ 302.58$ & 65 \\
\hline
\end{tabular}

Table 2.20: National Superannuation (Gross of tax) 2013 prices: Partnered Adult

\begin{tabular}{ccc}
\hline Tax year & Weekly Payment & Minimum Age \\
\hline TY88 & $\$ 273.35$ & 60 \\
TY92 & $\$ 268.96$ & 60 \\
TY98 & $\$ 268.75$ & 63 \\
TY07 & $\$ 282.03$ & 65 \\
TY13 & $\$ 302.58$ & 65 \\
\hline
\end{tabular}




\subsection{Conclusion}

This chapter has provided an outline of changes to income taxes and the first tier benefit system between 1988 and 2013, with links to relevant primary sources.

Since 1988 the income tax system has seen an overall reduction in tax rates, while fiscal drag has pushed down the real value of thresholds. After the sharp cut in the top tax rate in TY90, the reduction in rates predominantly took place in the middle of the tax scale in the 1990s and at the lower end of the tax scale during the 2000s.

In terms of the benefit system the real value of payments were relatively stable during this period, apart from a significant cut in benefit payments in TY92 and a second cut in sickness beneficiary payments in TY98. However, the 1988-2013 period did see a progressive increase in work testing criteria for benefits with work testing introduced for the domestic purposes benefit and invalid's benefits. By 1998 the sickness benefit was largely equivalent to the unemployment benefit, with eligibility criterion the only difference.

Although the superannuation age increased from 60 to 65 during this period, payments did rise in real terms - especially over the 2000s when they were effectively indexed to average wage growth. The removal of the superannuation surcharge bucked the trend of increasing conditionality for other government transfers, by removing what was effectively means testing from National Superannuation.

As well as providing a description of what has happened with tax and benefit policy between 1988-2013, the information about income tests (including abatement scales, abatement rates, and assessable income) and payment rates can be used to model individuals net tax liability. Treasury's TAXWELL model does this by taking the characteristics reported 
in Household Economic Survey (HES) data and calculating the tax and benefit payments of these individuals.

This type of modelling allows analysts to do two things: Impute the tax paid and benefits received by individuals when the reported survey data is untrustworthy ${ }^{27}$ and model the net tax payments of individuals in a given HES year if they faced a different years tax-transfer system.

As a result, the characteristics of the tax-transfer system discussed in this chapter can and will be used to improve the reliability of net income measures for the 1988-2013 period and perform counterfactual analysis which allows an analyst to consider the role policy changes have had in influencing the income distribution.

\subsection{Appendix}

Below is the list of legislation used to source the above figures, with links to online versions of the legislation. The documents are listed in the order they were referenced in this chapter. Access to Knowledge Basket is required to access the documents.

[1] Income Tax Amendment Act (No. 2) 1985

[2] Income Tax Amendment Act (No. 4) 1985

[3] Income Tax Amendment Act (No 2) 1986

[4] Goods and Services Tax Act 1985

[5] Finance Act 1989

[6] Income Tax Amendment Act (No. 3) 1988

[7] Taxation (Tax Rate Increase) Act 1999

${ }^{27}$ As suggested for the HES by Hyslop and Mare (2005) and Ball and Ormsby (2017). 
[8] New Scale - Taxation (FBT, SSCWT and Remedial Matters) Act 2000

[9] Taxation (Personal Tax Cuts, Annual Rates, and Remedial Matters) Act 2008

[10] Taxation (Urgent Measures and Annual Rates) Act 2008

[11] Taxation (Budget Measures) Act 2010

[12] Taxation (Budget Measures) Act 2010: GST rate increase

[13] Social Security Amendment Act (No. 2) 1990

[14] Social Security Amendment Act 1991 - First Schedule

[15] Social Security (New Work Tests, Incentives, and Obligations) Amendment Act 2010

[16] Social Security Amendment Act (1986)

[17] Social Security Amendment Act 1989

[18] Social Security Amendment Act 1991

[19] Social Security Amendment Act (No. 2) 1991

[20] Social Security Amendment Act 1996

[21] Social Security Amendment Act (No. 3) 1997

[22] Social Security Amendment Act 1998

[23] Social Security (Work Test) Amendment Act 1998

[24] Social Security (Work Testing and Community Wage) Amendment

[25] Social Security (Participation Allowance) Regulations

[26] Social Security Amendment Act 2001

[27] Social Security (Personal Development and Employment) Amendment Act 2002 
[28] Social Security Amendment Act 2007

[29] Social Security (New Work Tests, Incentives, and Obligations) Amendment Act 2010

[30] Social Security (Youth Support and Work Focus) Amendment Act 2012

[31] Social Security Amendment Act (No. 3) 1993

[32] Social Security Act 1964-1994 (By Parliamentary Counsel)

[33] Workers' Compensation for Accidents Act (1900)

[34] Accident Compensation Act (1972)

[35] Injury Prevention, Rehabilitation, and Compensation Act (2001)

[36] Social Security Amendment Act (No. 3) 1996

[37] Income Tax Amendment Act 1984

[38] Income Tax Amendment Act (No. 3) 1986

[39] Income Tax Amendment Act (No. 3) 1988

[40] Social Security Amendment Act 1988

[41] Social Welfare (Transitional Provisions) Act 1990

[42] Social Welfare (Transitional Provisions) Amendment Act 1990

[43] Social Welfare (Transitional Provisions) Amendment (No. 2) Act 1991

[44] Income Tax Amendment Act (No. 5) 1991

[45] Social Welfare (Transitional Provisions) Amendment (No. 2) Act 1991

[46] Social Welfare (Transitional Provisions) Amendment (No. 3) Act 1991

[47] Income Tax Amendment Act (No. 6) 1991

[48] Social Welfare (Transitional Provisions) Amendment (No. 2) Act 1993 
[49] Social Welfare (Transitional Provisions) Amendment (No.2) Act 1993

[50] Taxation (Superannuitant Surcharge Abolition) Act 1997

[51] Social Welfare (Transitional Provisions) Amendment Bill (No. 2)

[52] Social Welfare (Transitional Provisions) Amendment Act 1998

[53] New Zealand Superannuation Act 2001 


\section{Chapter 3}

\section{Horizontal and vertical equity in the New Zealand tax-transfer system: 1988-2013}

\subsection{Introduction and motivation}

This chapter investigates how measures of redistribution, vertical equity, and horizontal inequity of the tax and transfer system changed between 1988 and 2013. The purpose of such an analysis is to evaluate the consequences of policy changes through the lens of equity, and to understand how adjustments in tax-transfer settings influence New Zealand equity measures.

With the election of the Fourth Labour government in 1984 New Zealand underwent significant economic reforms. In the decade that followed New Zealand went through a drastic period of liberalisation with trade protectionism reduced (Massey 1995), government institutions redesigned (Evans et al. 1996, Brash 1998), the benefit system changed (McClure 1996), and the tax system adjusted (Treasury 2001a, Stephens 1987). 
As part of these reforms income tax and transfer policies changed. The goal of this chapter is to ascertain how the observed change in the structure of the income tax-transfer system post-1988 met principles of vertical and horizontal equity using a decomposition of the Gini coefficient. As such this analysis is not a review of the equity principles satisfied by the reforms in their entirety, or a narrow analysis of the equity principles satisfied by a single policy. Instead, the focus of this chapter is on the equity effects of the package of tax and transfer policies introduced from 1988 onwards as outlined in Chapter 2.

A decomposition approach to this question allows for a quantitative evaluation of the equity characteristics of tax-transfer policies changes during this period. Furthermore, as it is conceivable policy makers may be more interested in adjusting tax settings rather than adjusting other policies that were introduced during the reforms, it gives guidance regarding the equity effect of changes in tax-transfer settings.

Stephens (1987) noted that, during Labour's first term the government explicitly aimed to maintain levels of vertical equity even with allocative efficiency and horizontal equity as primary concerns. However, Stephens (2003) indicates that, by the second term, there was an increasing willingness to ignore vertical equity concerns. Furthermore, the growing focus on efficiency was seen as consistent with horizontal equity - which had been a guiding principle for the initial broadening of the tax base with the introduction of Goods and Services and Fringe Benefit Taxation (Treasury 2001b).

The predominant attitude of policy makers during this time, with a focus on efficiency above vertical equity concerns, is articulated clearly by subsequent writing from the Committee of Experts on Tax Compliance (Report 1988) and the New Zealand Business Roundtable (Buchanan and Hartley 2000). McClure (1996) goes further in discussing the motivation for tax and transfer policy changes during this period, noting the shift away from 
universality in benefit payments towards greater targeting of need.

The previous literature on tax-transfer changes in New Zealand during this time has focused on analysis of factor incomes from raw survey data (Podder and Chatterjee 2002b), generalised Lorenz curve comparisons of disposable income (Chatterjee et al. 2008), comparisons of market and final income estimates (Aziz et al. 2012), and arithmetic microsimulation based decompositions (Creedy et al. 2010, Creedy and Eedrah 2016, and Ball and Creedy 2015). Although these exercises are all useful, they largely fail to give us a clear equity basis for considering the distributional consequences of the reforms. ${ }^{1}$

Although generalized Lorenz dominance and discussion of an equity to efficiency trade-off proxied by the relationship between inequality and income aggregates are useful, in order to more deeply understand the nature of changes in tax-transfer policy we would want to consider how tax-transfer policies transform the income distribution along the lines of vertical and horizontal equity.

As a result, the focus of this chapter is on the vertical and horizontal equity consequences that were embedded in tax and transfer changes between the 1988 tax year and the 2013 fiscal year. Contrary to received wisdom the tax-transfer system did not imply a decline in horizontal inequity among market income equals during this period. But rather than this being a policy failure, it suggests that the policy makers view of equals in the taxtransfer system differs from that defined solely by market income.

The outline of the chapter is as follows. In section 2 the method for measuring vertical equity and horizontal inequity is introduced. In section 3 ,

\footnotetext{
${ }^{1}$ Chatterjee et al. 2008 suggest that most of the generalized Lorenz Dominance of the pre-reform period can be put down to policy. However, this assumes that the pre-reform economic situation was sustainable - a large assumption given the external shocks New Zealand was experiencing and the fact that the unsustainability of government accounts was catalyst for reforms in both 1984-87 and 1991.
} 
an outline of the data used and a summary of the data is given. Section 4 provides the key results about changes in vertical equity and horizontal inequity between 1988 and 2013. Section 5 investigates the sensitivity of these results to the choice of equivalence scale. Finally, section 6 summarises and concludes the results of the chapter.

This research will add to the literature in several ways. It is the first application of this decomposition method to New Zealand data, extending the equity analysis of Creedy et al. 2010. This allows for a discussion of changes in horizontal inequity in the New Zealand tax-transfer system which is comparable to results from overseas (eg Herault and Azpitarte $2014 a)$.

It considers the combined effect of tax and transfer payments where the method has largely only been applied to taxation in isolation (Lambert and Urban 2008). The chapter then outlines the methodological shortcomings associated with extending this form of analysis, especially when it is extended to include transfer payments.

Finally it introduces bandwidth selection based on log income rather than the direct dollar bands which are used in previous studies. Log bands provide a more intuitively appealing way of forming groups of pre-tax income equals and shift the focus of horizontal inequity away from low income families toward middle income families.

\subsection{Methodology and measurement framework}

Discussions of vertical and horizontal equity are based on underlying concepts of ability to pay, natural rights and equal sacrifice (Young 1990, Musgrave 1990). These concepts are that those with the greatest ability to pay should pay more, that individuals have a natural right over the income they earn, and that the burden of taxation on individuals should be spread 
equally in terms of utility sacrificed. ${ }^{2}$

However, given that objective interpersonal comparisons of utility are not possible (Arrow 1950) and given the imprecision of the concept of ability to pay, these terms are inherently value laden. As a result, it is worthwhile to consider how the tax-transfer system satisfies certain principles of fairness in isolation. This focus gives rise to considering vertical and horizontal equity. Lambert (2001) gives the broadest definition of both:

The purpose of horizontal equity (HE) command generally is to pursue justice and equality and ensure that the law does not serve anybody's self-interest. The purpose of the vertical equity (VE) command is to take appropriately into account different people's relative merits. That word 'appropriately' makes VE a matter of judgement or societal taste, whereas HE can be seen as an absolute.

Vertical equity (VE) regards the redistribution of income, specifically from those with a greater ability to pay due to having access to more resources for meeting needs and satisfying wants. This is often termed the PigouDalton principle. Horizontal equity $(\mathrm{HE})$ regards non-discrimination - treating equals equally. In this context both vertical and horizontal equity are value-laden, as defining discrimination and ability to pay depends on a view of what constitutes equals.

To make horizontal equity consistent with vertical equity it is common to define equals in terms of initial access to resources. In the literature this is narrowed down to pre-tax and transfer (market) income. Then VE and HE concepts are measured through how this market income is transformed into post-tax and transfer (disposable) income.

\footnotetext{
${ }^{2}$ As noted in Musgrave (1993) there is an open debate regarding whether equal sacrifice refers to absolute, proportional, or marginal sacrifice - each of which imply very different levels of progressivity.
} 
In this way a tax-transfer system is exhibiting horizontal inequity (HI) if it is treating people with the same market income differently. While it is exhibiting vertical equity if it is, in net terms, taking proportionally more market income from those with greater market income.

The Gini coefficient can then be used to evaluate claims about the equity effects of tax and transfer policy. The Gini coefficient provides a summary measure of the relative absolute distance between income units (Yitzhaki and Schechtman 2013), and as a result a smaller Gini coefficient after the imposition of a tax-transfer system implies that the distance between individuals has declined. ${ }^{3}$

As a result, the difference between market and disposable income Gini coefficients that will be used as a measure of the redistributive effect of tax-transfer systems in this chapter. The goal is to decompose this measure into appropriate vertical and horizontal equity terms.

\subsubsection{Decomposition of the Gini coefficient}

As noted by Urban (2014) there is a large, and not necessarily consistent, literature regarding the decomposition of Gini coefficients into vertical, horizontal, and reranking components. The framework in this chapter is based upon the definitions of vertical equity, horizontal inequity, and reranking given in Lambert and Urban (2008). ${ }^{4}$

When the tax-transfer system transforms market income into disposable

\footnotetext{
${ }^{3}$ The Gini coefficient is equivalent to half of the relative mean absolute difference, which is the sum of all pairwise differences in income divided by mean income. As the transformation from market to disposable income lowers mean income a decrease in the absolute distance between income units does not ensure that the Gini coefficient will be lower, but a lower Gini coefficient implies that relative absolute distance between income units has declined.

${ }^{4}$ The definitions used in this chapter are outlined directly in Urban (2014).
} 
income it changes an income units income relative to other income units in two ways: It changes the relative distance between an income unit and other income units, and it changes the order of the income parade for income units. If there is progressivity in the tax-transfer system then income units higher up the income distribution are moved proportionally more relative to lower income units. In most circumstances this will (for the same ordering of income units) move income units closer together. However, this transformation may also lead some income units to change position on the income parade. This second effect is termed reranking.

The existence of reranking creates complications when considering the redistributionary impact of tax-transfer policy using the Gini coefficient. Kakwani's (1977ba) critique of Musgrave and Thin's (1948) discussion of progressivity in the tax system illustrated that the progressivity of a taxtransfer system and redistribution (in terms of a lower Gini coefficient after the application of taxes and transfers) are different things. It was then Kakwani (1984) who established a measure of redistribution that takes into account reranking among income units. ${ }^{5}$ An excellent, and critical, history of the measurement of progressivity and the redistributive effect can be found in Urban (2009).

The split into potential progressivity and reranking gives an initial decomposition of the observed redistribution caused by tax-transfer policies. The goal of such a decomposition is then to break down observed redistribution in the income distribution into a potential redistribution term that represents the progressivity inherent in the tax-transfer transformation (vertical equity) and a term that captures the effect of reranking due to the tax-transfer system and its impact on the distribution of income.

The observed redistributive effect of the tax-transfer system, $R E$, is defined as:

\footnotetext{
${ }^{5}$ Building off the work regarding reranking by Atkinson (1980), Plotnick (1981) and his own earlier work on progressivity in Kakwani (1977ab).
} 


$$
R E=G_{Y}-G_{D}
$$

Where $G_{Y}$ is the Gini coefficient of pre-tax income (market income, $Y$ ) and $G_{D}$ is the Gini coefficient of post-tax and transfer income (disposable income, $D){ }^{6}$

If the transformation from $Y$ to $D$ were to keep individuals in the same order and lead to a lower Gini coefficient then the narrowing of the distance between income units associated with this transformation is equivalent to the VE in the tax-transfer system. As a result, vertical equity involves considering the market and disposable income distributions keeping individuals in the same order. This is the idea behind the (modern) Kakwani progressivity / disproportionality measure (Reynolds and Smolensky 1977, Urban 2009, Aronson et al. 1994). Namely:

$$
V^{K}=G_{Y}-C_{D}
$$

\footnotetext{
${ }^{6}$ This is an imperfect measure of real redistribution, given that the pre-tax income distribution is not independent of the choice of policy instruments and the values associated with these instruments - as a result, this relies on the strong assumption that the pre-tax income is independent of policy settings.
} 
Where $C_{D}$ is the concentration coefficient for post-tax and transfer income. ${ }^{7,8}$ Kakwani (1984) extended the above method by noting that the key difference between $G_{D}$ and $C_{D}$ is the reranking of income units that occurs due to the transformation of pre-tax income $(y)$ caused by the tax function $(T(y))$. Reranking then explains why $G_{D}$ and $C_{D}$ differ.

It then follows that the redistributionary effect of a tax change can be decomposed into two terms - a term that represent the change in the Gini coefficient in the absence of reranking $\left(V_{t}^{K}\right)$, minus the redistribution that is lost due to the reranking of income units (The Atkinson-Plotnick measure defined by Aronson and Lambert (1994)). The redistributive effect of a policy change can then be defined in the following way motivated by Kakwani (1984) and the reranking definitions of Atkinson (1980) and Plotnick (1981).

$$
R E=\left(G_{Y}-C_{D}\right)-\left(G_{D}-C_{D}\right)=V^{K}-R^{A P}
$$

Where $V_{t}^{K}$ is the Kakwani vertical effect of taxation, and $R_{t}^{A P}$ is Atkinson-

\footnotetext{
${ }^{7}$ It is useful to think about the concentration index with reference to pre-tax Lorenz curve and concentration curves. The pre-tax Lorenz curve involves ordering pre-tax income units in ascending order and then plotting the cumulative income of all income units earning at or below given income levels. The concentration curve for post-tax and transfer income involves the same ordering of income units, but plots cumulative posttax and transfer income.

${ }^{8}$ Lambert (1985) initially questioned the appropriateness of the Kakwani (1977ba) measure of progressivity for considering the redistributive effect of taxation when we look at both tax and transfer changes that involve tax functions that cross. As in Herault and Azpitarte (2014a) we will use a value of $V^{K}$ based on Lambert (1985) to take account of both tax and transfer policies. However, unlike Herault and Azpitarte (2014a) and Herault and Azpitarte (2015) we do not estimate the tax and benefit systems effect separately.
} 
Plotnick reranking term. ${ }^{9}$

\subsubsection{Exact equals and horizontal inequity}

As Urban (2009) notes, this reranking term was traditionally called horizontal inequity in the literature (Atkinson 1980, Plotnick 1981, King 1983, and Kakwani 1984) with the authors explicitly defining horizontal inequity as reranking.

However, Aronson et al. (1994) and Aronson and Lambert (1994) pointed out that this still constituted unequal treatment of unequals, which differs from the classical definition of horizontal inequity as unequal treatment of equals. ${ }^{10}$

Aronson et al. (1994) determined classical HI by decomposing the Kakwani vertical effect into two terms, a vertical effect $V^{A J L}$ and a horizontal effect $H^{A J L}$, such that $V^{K}=V^{A J L}-H^{A J L}$ with a residual term that captures reranking $R^{A P}=R^{A J L}$. With defined groups of equals, horizontal inequity involves differential net tax treatment within these groups, while vertical equity pertains to the idea of differential tax treatment between these groups. In this context the residual term that exists for traditional population Gini coefficient decomposition represents reranking in the case of comparing market and disposable income distributions. Aronson and

\footnotetext{
${ }^{9}$ This is defined as the difference between $G_{D}$ and $C_{D}$ based on a lexicographic ordering of equals as in Aronson and Lambert (1994) - this stems from the population subgroup decomposition literature starting with Bhattacharya and Mahalanobis (1967). Note that this term will always be positive as an ordering from smallest to largest always gives the largest concentration coefficient, and that is what is occurring with $G_{D}$.

${ }^{10}$ The strong criticism of Kaplow (1989) clearly outlined this view.
} 
Lambert (1994) give a clear graphical representation of this result. ${ }^{11}$

Unlike Theil's entropy measure and the mean logarithmic deviation, the decomposition of the Gini coefficient into population subgroups cannot be subdivided solely into between and within group measures. Namely the Gini coefficient is not additively decomposable. As shown in Bhattacharya and Mahalanobis (1967) any decomposition of the Gini coefficient into subgroups requires an overlapping term, a requirement that sees the Gini fail in terms of the five axioms of a good relative inequality measure (the others being anonymity, the principle of transfers, scale invariance, and the principle of population (Cowell and Kuga 1981)). However, Aronson et al. (1994) discovered that this property is useful when discussing redistribution as it defined reranking.

Assuming that there are $j=\{1, \ldots, J\}$ groups, Creedy et al. (2001) state that the Gini coefficient for a given income distribution can be decomposed into the following:

$$
G=G_{B}-G_{W}-E
$$

Where $G_{B}$ is the Gini coefficient if each person in a group earned the mean income in that group (the between group term), $G_{W}$ is a weighted aggregate of the Gini coefficients for each group (the within group term), and $E$ is a residual/reranking term that captures how groups of equals overlap in terms of pre-tax income. Given this the redistributive effect can be rewritten as:

\footnotetext{
${ }^{11}$ There is a compelling argument that backs Plotnick's (1985) view that reranking may be all that matters - with Dardanoni and Lambert (2001) arguing that only ordinal comparisons make sense, and since in the limit classical HI only occurs when reranking occurs the distinction is inconsequential.
} 


$$
\begin{aligned}
R E & =\left(G_{Y, B}-G_{D, B}\right)-\left(G_{D, W}-G_{Y, W}\right)-\left(E_{D}-E_{Y}\right) \\
& =\left(G_{Y, B}-G_{D, B}\right)-\left(\sum_{j=1}^{J} a_{D, j} G_{D, j}-\sum_{j=1}^{J} a_{Y, j} G_{Y, j}\right)-\left(E_{D}-E_{Y}\right)
\end{aligned}
$$

Where $G_{j}$ is the Gini coefficient of population subgroup $j, a_{j}=\sum_{j=1}^{J} \frac{N_{j}^{2} \mu_{j}}{N^{2} \mu}$ is the product of the population and income shares of subgroup $j$, and $G_{B}, G_{W}$, and $E$ represent the between group, within group, and residual subgroup decomposition of the given Gini coefficient. ${ }^{12}$

When the income subgroups are for income units which are exact equals in terms of pre-tax income, as in Aronson et al. (1994), then $G_{Y, j}=0$, $G_{Y, B}=G_{Y}$, and the overlapping term $E_{Y}=0$.

Given exact equals the $R E$ from Equation 3.5 simplifies to the form:

$$
R E=V^{A J L}-H^{A J L}-R^{A J L}
$$

Where $V^{A J L}, H^{A J L}$, and $R^{A J L}$ can be defined as:

$$
\begin{gathered}
V^{A J L}=G_{Y}-G_{D, B} \\
H^{A J L}=\sum_{j=1}^{J} a_{j, D} G_{j, D} \\
R^{A J L}=E_{D}=G_{D}-C_{D}=R^{A P}
\end{gathered}
$$

This allows a clear definition of vertical, horizontal, and reranking effects.

\footnotetext{
${ }^{12}$ Where $N_{j}$ is the population of subgroup $j, N$ is the full population, $\mu_{j}$ is the average income of subgroup $j$, and $\mu$ the average income of the whole population.
} 
The vertical effect of the tax system is the change in inequality between groups of equals induced by the tax-transfer system.

The horizontal effect is the sum of the within group inequality among pretax equals created by the tax-transfer system.

The reranking effect is the overlapping of income groups induced by the tax-transfer system.

When considering horizontal inequity as a whole both classical horizontal inequity and reranking effects are forms of horizontal inequity (Dardanoni and Lambert (2001)), and so they must be considered together when discussing how horizontal inequality has changed.

\subsubsection{Defining equals}

With exact equals there is a clean distinction between horizontal and vertical equity, with both defined in terms of equals with respect to pre-tax income. However, in most datasets few people have exactly the same market income as others, which is problematic for talking about horizontal equity for exact equals.

As a result, an assumption about what constitutes close-equals must be made. Namely, the estimation of horizontal inequity and reranking due to tax-transfer policy requires the estimation of a tax schedule that is a function of pre-tax income for every group - an estimate that will be subject to large error bands when there are few people in each group. Furthermore, when there is only a single person in each income group, the horizontal effect will be zero. As a result, there is a question of the bandwidth for the range of income that defines close equal groups (CEGs) following Creedy et al. 2001.

The optimal bandwidth in this case involves a trade-off between the two effects of increasing the bandwidth: 
1. The averaging effect: The larger bandwidth increases the number of people in each CEG, improving the estimate of tax schedule. This tends to increase estimates of $V^{A J L}, H^{A J L}$, and $R^{A J L}$ as the bandwidth rises.

2. The appropriation effect: The larger the bandwidth gets (including a more diverse group of individuals as determined by pre-tax income), the greater amount of $V^{A J L}$ and $R^{A J L}$ are attributed to $H^{A J L}$. This will tend to decrease $V^{A J L}$ and $R^{A J L}$, but have an ambiguous effect on $H^{A J L}$.

As a result, the optimal bandwidth is given as the bandwidth value that maximises the value of $V^{A J L}$. Given $V$, and given $R^{A J L}$ and $R E$ as sample statistics, $H$ can be readily estimated.

Although the optimal bandwidth method was a significant improvement on defining arbitrary groups, the creation of close equal groups leads to the same issue of reranking within theses groups that occurs when considering the income distribution as a whole. As a result, the reranking term $R^{A J L}$ would differ from the true reranking in the income distribution $R^{A P}$.

According to Lambert and Urban (2008) there were two types of reranking that were not being taken account of in this framework: ${ }^{13}$

1. Reranking of individual income units within CEGs

2. Reranking of entire CEGs

Lambert and Urban (2008) propose that $R^{A P}=R^{A J L}+R^{W G}+R^{E G}$ where $R^{W G}$ and $R^{E G}$ are the within group and entire group reranking terms respectively. Given the nature of these reranking terms, VE and $\mathrm{HI}$ can be

\footnotetext{
${ }^{13}$ These are both mentioned in Creedy et al. (2001), hence why the authors suggests calculating $\mathrm{H}$ as a residual with $R=R^{A P}$ rather than through the within group definition.
} 
defined as $V=V^{A J L}+R^{E G}$ and $H=H^{A J L}-R^{W G}$. This gives RE as:

$$
R E=V-H-R^{A P}
$$

Here the reranking effect and the difference $V-H$ are both defined independently of CEGs, as $R^{A P}$ and $V^{K}$ respectively. As a result, a definition of close equal groups is only required for defining how $V^{K}$ is split into vertical and horizontal effects, as in Aronson et al. 1994.

Once the CEGs are defined $V^{K}$ can be defined as:

$$
V^{K}=\left(G_{p r e}-\hat{C}_{p s t}\right)-\left(C_{p s t}-\hat{C}_{p s t}\right)
$$

Where $\hat{C}_{p s t}$ is the post tax and transfer concentration coefficient assuming that all units in a CEG face common tax and transfer rates equal to the ratio of taxes and transfers to total pre-tax and transfer income for that CEG.

The way smoothed income is defined is centrally important for defining the decomposition of $V^{K}$ into their final vertical and horizontal terms. This is complicated in the case where a number of families have zero pre-tax income which is transformed into positive post-tax and transfer income. This issue is discussed further in section 4 .

Given smoothed income and Equation 3.11, $V=G_{p r e}-\hat{C}_{p s t}$ and $H=C_{p s t}-$ $\hat{C}_{p s t}$. Here $\mathrm{V}$ is the way the smoothed tax-transfer system redistributes from those with higher market income to those with lower market income, while $\mathrm{H}$ is the difference between the smoothed and actual tax-transfer system.

To calculate the CEGs involves selecting an income bandwidth for group size that maximises the vertical component as justified in Creedy et al. (2001) and applied in Herault and Azpitarte (2014a). This chapter does not 
select the maximum value for $V$, and instead follows Lambert and Urban (2008) in showing how $V$ and $H$ are sensitive to bandwidth selection.

\section{Distribution of equals}

When looking at equal groups the literature traditionally bases the CEGs on levels of market income, with an equally sized bandwidth value (band) across the income distribution. This leads to a large concentration of equals towards the bottom of the income distribution.

Figure 4 shows the number of people in each income band except the first income band, where the band is denoted by the minimum log income of that band. The first income band is excluded as it contains a high proportion of the sample, with nearly 3600 families, or $20 \%$ of the sample, in first band.

However, moving along the income distribution larger income bands are arguably representative of equal groups. For example, a $\$ 10,000$ income difference is large for people earning $\$ 20,000$ a year but small for a millionaire. This difference in the income associated with equals can be represented with an estimated bandwidth based on the logarithm of market income, which implies that the market income bands get wider as income rises. This bandwidth leads to a larger concentration of equals towards the middle of the income distribution.

Figure 5 illustrates the number of people in each income band (excluding the first band) where the band is denoted by the maximum log income of that band. As in the case with the level of income, the first income band is excluded as it contains a high proportion of the sample, with just over 2600 people in first band, or $14.6 \%$ of the sample.

Apart from the first band, families in the lower section of the income distribution are not grouped as equals by this method, while the size of the 
bands in the middle of the income distribution increases significantly. Using a log income bandwidth also reduces the size of the first band, as it now effectively only includes families with zero pre-tax income.

Overall, the use of a log bandwidth instead of a level bandwidth implies that the density of groups of equals moves from the bottom of the income distribution towards the middle of the distribution.

When comparing level and log bandwidth, it isn't until the 85th percentile when the level and log bandwidth refers to the same level of income - at a lower percentile the log bands refer to a lower income, while at a higher percentile they refer to a higher income. Furthermore, the bandwidth size is equal at approximately the 58th percentile - with the log band using a finer bandwidth at a lower percentile and a larger bandwidth at a higher percentile.

The differences in groupings of equals is illustrated by looking at the density plots for both bandwidth estimates in Figures 4 and 5 . 


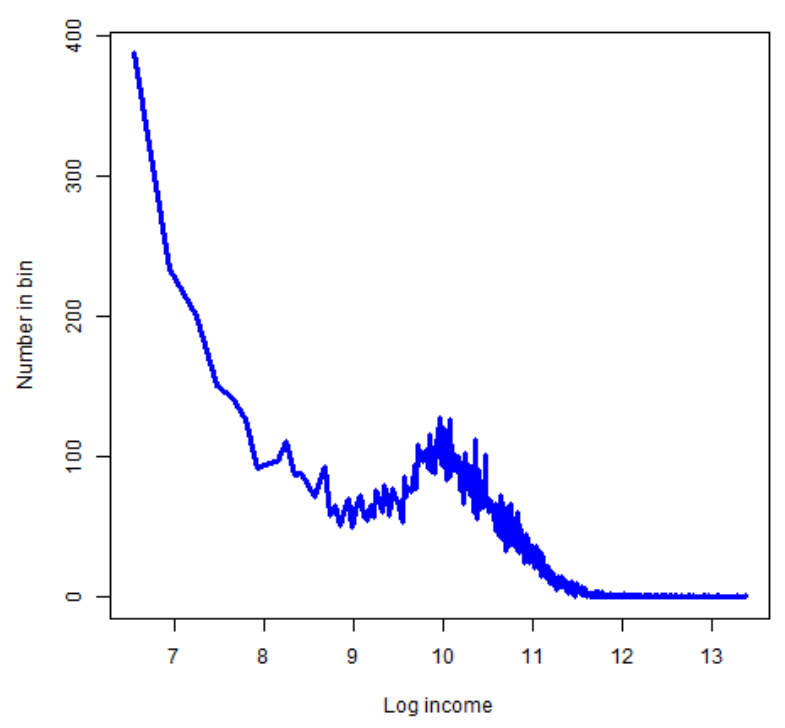

Figure 4: Families in each income band, selected by income level, HES8891.

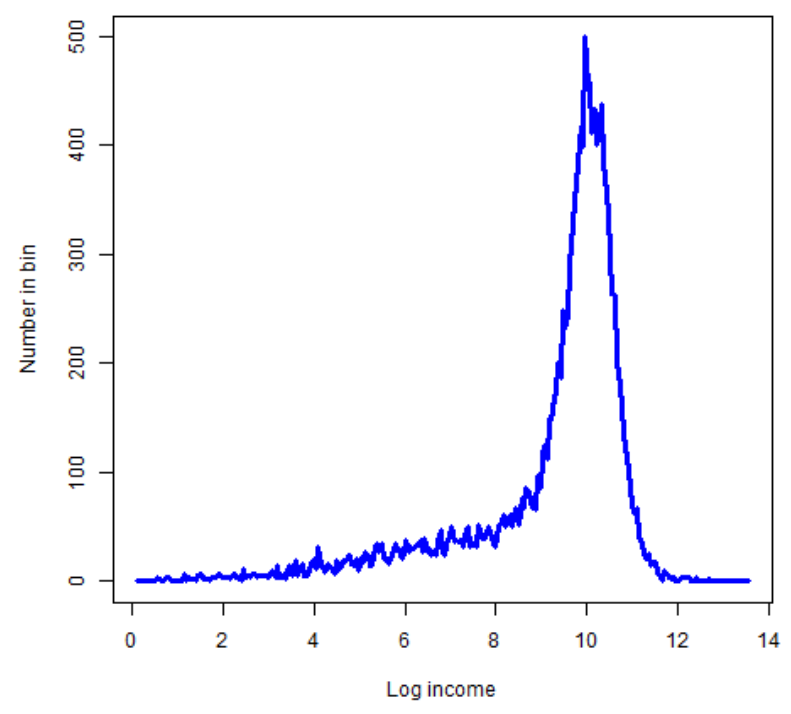

Figure 5: Families in each income band, by log income level, HES88-91. 
Intuitively, a larger income band for defining equals for larger incomes makes sense - eg a $\$ 10,000$ income gap is a lot less relevant to the difference between two millionaires than it is between two beneficiaries. As a result, equals defined by a log income bandwidth are used in this chapter to calculate $V$ and $H$. However, tables reporting results using both the level and log income bandwidths are provided in section 3.4.

\subsubsection{Absolute Horizontal Inequity}

As discussed in Lambert and Urban (2008) it is conceivable that the horizontal inequity term in this framework could be negative. With horizontal inequity defined as $\sum_{j=1}^{J} a_{D, j} G_{D, j}-\sum_{j=1}^{J} a_{Y, j} G_{Y, j}$ minus the reranking that occurs within groups, there may be groups where the tax system leads to a lower Gini coefficient within the group than existed prior. ${ }^{14}$ This redistribution within a group makes outcomes among a group of equals more equal, and hereby suggests a reduction in horizontal inequity as defined.

The propensity for horizontal inequity to become negative is reinforced by the inclusion of the benefit system. In Herault and Azpitarte (2014a) they estimate separate horizontal terms for the tax system and for the transfer system. The horizontal inequity transfer terms are significantly negative for eight of the ten years that are selected for analysis.

Lambert and Urban (2008) note that in such a situation the concentration curves for post-tax and smoothed post-tax income would cross. As the gap between these curves and the measure of complete income equality is captured by $C_{p s t}$ and $\hat{C}_{p s t}$ the given measure of horizontal inequity will be reduced whenever the cumulative sum of smoothed post-income is below the cumulative sum of actual post-tax income.

\footnotetext{
${ }^{14}$ Technically, where the tax system leads to a progressive transfer - equivalent to $V_{k}$ for that specific group.
} 
The horizontal measure, $H$, is then stating that if the actual tax system is redistributing within these groups then it is reducing horizontal inequity.

As stated this measure of HE appears to mix both vertical and horizontal equity concerns. However, if instead the relevant horizontal inequity is when equals faced proportionally different tax-transfer treatment the inequality in pre-tax income among the equals will be perceived as equitable while any change in it is seen as generating horizontal inequity.

To discuss horizontal inequity in this sense involves considering absolute difference between the treatment of the tax system (as given by the posttax income distribution) and the treatment of a system where all people in a group pay/receive the same tax-transfer rate (as given by the smoothed post-tax income distribution).

This is given by:

$$
H^{T}=H_{P}+\left|H_{N}\right|
$$

Where $H_{P}$ are the values of $H$ for the groups that show an increase in horizontal inequity while $H_{N}$ is the value of $H$ for the groups that show a decrease in horizontal inequity.

This value is also reported in the results in section 3.4 and will be termed absolute horizontal inequity.

\subsubsection{Varying bandwidth}

As noted in Lambert and Urban (2008), the criteria of maximising vertical equity was specific to the decomposition of Creedy et al. 2001.

After correcting for additional forms of reranking $V=V^{K}+H$ where $V^{K}$ takes a fixed values irrespective of the bandwidth. As a result, the 
maximisation of $V$ is equivalent to the maximisation of $H$ which occurs for a very large bandwidth. This is intuitively unappealing as in the limit it suggests the appropriate bandwidth will treat everyone as equals.

Herault and Azpitarte (2014a) estimate the bandwidth by maximising the $V$ value that is given by the Creedy et al. (2001) method. Given that estimate for the bandwidth, the authors then recalculate $V$ and $H$ using the Lambert and Urban (2008) method. This is not the method used in this chapter, however when using this method similar results for the size of the bandwidth were found.

In this chapter the log bandwidth is selected based on local maximisation of $V$ around 2000 bands for the HES89-91 period. Keeping the bandwidth range the same, adjusting for income growth, this bandwidth is then used to compute the values of $V$ and $H$ for the HES11-13 period.

Figure 6 illustrates how the value of $V$ varies as the number of bands increases, from 10 to 2000 .

Outside of the results for up to 25 bands, the measure of vertical equity falls in a very narrow range - as shown by Figure 7. As a result, the assumption about the appropriate number of bands (and thereby the size of the bandwidth) has very little effect on the estimates of $V$ or $H$ as long as there should be more than $25 \log$ income bands. 


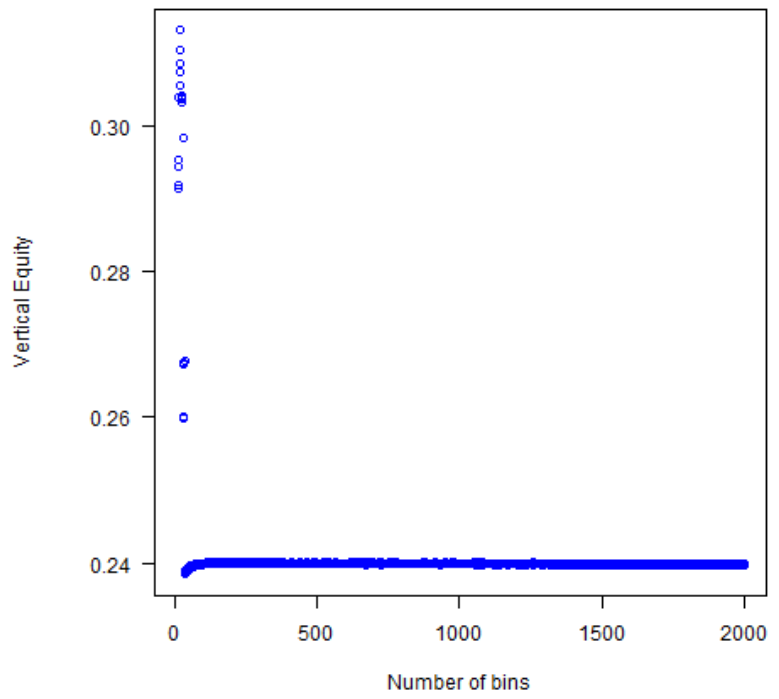

Figure 6: VE by number of bands - from 10 to 2000.

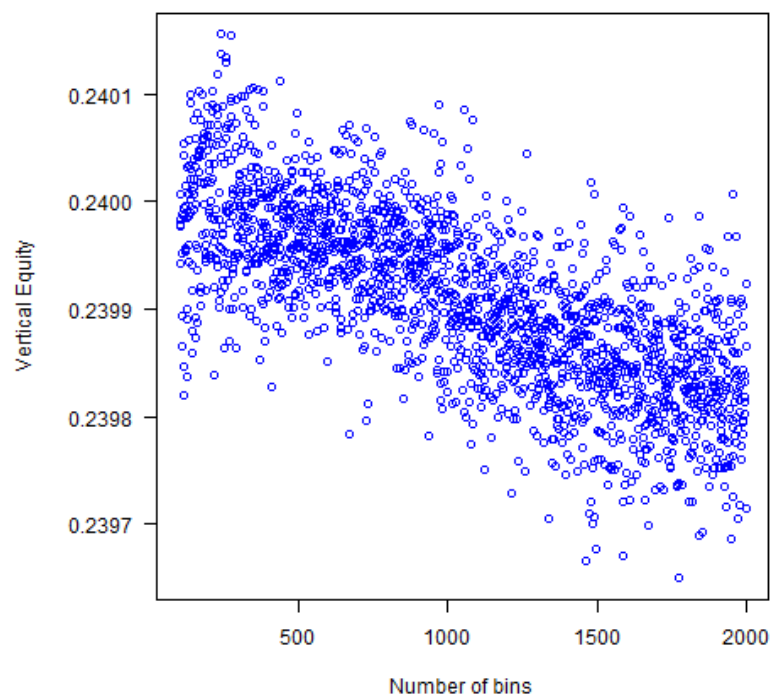

Figure 7: VE by number of bands - from 100 to 2000. 


\subsection{Data sources and assumptions}

This chapter uses survey data from Statistics New Zealand's Household Economic Survey (HES) from between the 1988 and 2013 surveys. HES years are referred to by the end date of the survey (eg HES88 refers to the survey that took place between April 1987 and March 1988).

In the HES, individuals within a household are asked to report on their characteristics, income, and expenditure for the prior year. ${ }^{15}$ The survey respondents may be interviewed at any point in a year long period, and as a result income data in HES can be reported from over a two year period - from a year before the start of the survey up until the end date of the survey.

The raw survey data collects information about all income categories (eg work income, tax paid) from both current sources and previous income sources for the past year. As this survey data is based on the recall of survey respondents, each income source reported is subject to recall bias. This bias is expected to be worse for more irregular payments and payments that are not current. Furthermore, given the characteristics of individuals, their reported incomes, and administrative data about tax-transfer expenditure by government the benefits and tax numbers in this survey data appear inaccurate Ball and Ormsby (2017).

Due to these limitations the raw data is transformed in two ways:

- Treasury's tax-transfer microsimulation model, TAXWELL, is used to calculate the tax paid and transfer payments received by individuals. Taking the details of the tax-transfer system for a given year TAXWELL calculates the tax that an individual was liable to pay and the transfer payments they were eligible to receive. This can then be

\footnotetext{
${ }^{15}$ Since 1998 the expenditure section of the survey has only been undertaken triannually.
} 
used to transform pre-tax income into post-tax income.

- For job and transfer income only current sources of income, rather than income from previous sources, are used. These figures are annualized, treating the individuals current situation as the situation they have been in for the entire year. The justification for this assumption is two fold: the poor quality of reporting about prior income sources, and in order to ensure that reported income only refers to the tax year of interest.

Only first tier benefits and the direct income tax system are modelled, with supplementary benefit and tax payments taken from the raw HES data. This combination of data is then used to transform market income into disposable income.

This transformation has the clear limitation that it captures only a subset of the policy changes that were implemented during the period of analysis.

Horizontal equity was an important driving force for the majority of policy changes from 1984 onwards, and so could only be comprehensively evaluated by taking into account changes in indirect taxes and tariffs, industrial and labour regulation, and the removal of quotas as well as changes in the direct tax and transfer system. Even though many of these types of policy changes occurred in 1984-87, which is outside the time period considered in this chapter, the influence of these policy changes remained relevant for judging the reforms well into the 1990s.

As a result, the analysis here is focused on the vertical and horizontal equity changes associated with family level tax and transfer changes, not an evaluation of the vertical and horizontal properties of the full set of reforms in New Zealand over the past 30 years. 


\subsubsection{Smoothed Income}

Prior application of these methods (eg Aronson et al. 1994, Creedy et al. 2001, and Lambert and Urban 2008) concentrated solely on the tax system. As a result, the transformation from pre-tax to post-tax income solely involved reducing incomes based upon the average tax rate for that group.

In such a case the construction of smoothed income (as discussed in the method section) is straightforward, as the counterfactual tax system that removes horizontal inequity is one that sees each individual/family pay the same proportion of their market income in tax. As a result, another conceptually useful way of viewing this distribution is that it is the assumed HE equivalent distribution of income.

This chapter evaluates the full tax-transfer system, and as a result this creates two clear issues when transforming income into horizontally equal smoothed income.

- Proportionally changing the income of those who earned $\$ 0$ leads to no change in their income.

- Very low income bands where transfer income dominates see wildly different proportional increases in the pre-tax income for these individuals. For example, comparing a person with $\$ 50$ of pre-tax earnings to someone with $\$ 100$ of pre-tax earnings - both of who are then paid $\$ 8,500$ in benefits. If these individuals are in the same band horizontal equity would denote giving these individuals very different benefit payments to keep the same tax and transfer transformation rate - when intuitively these people may be viewed as equals. This generates additional changes in $\mathrm{HI}$ and reranking.

Lambert and Urban (2008) state "In a tax system with refundable credits, $g$ [the proportional decrease in income due to taxation] could in principle be negative. 'Reducing' each pre-tax income $X$ by the same fraction $g$ would 
then amount to increasing those incomes, and by more, the higher $\mathrm{X}$ is". As a result, implementing benefit payments across most of the income distribution can be captured by the method. However, a benefit payment to someone with zero pre-tax income is different to a tax rebate for someone who already has positive pre-tax income.

Assumptions about how to treat those on zero and very low market incomes has a significant effect on estimates of horizontal inequity. As a result, the construction of smoothed income for this part of the income distribution needs to be stated clearly.

Figure 8 shows the HES88-91 income parade for market (in black) and disposable (in green) income in ascending order by the income units market income, using log income bands. Over $14 \%$ of families have pre-tax income equal to zero, while nearly a quarter of families have pre-tax income of less than $\$ 1,000$ in TY91 prices. ${ }^{16}$

As can be seen in Figure 8, there is significant reranking in the income distribution at the very low levels of income. By using log bands, there are fewer individuals/families in these low income bands.

Figure 9 shows the HES88-91 income parade for disposable (in green) and smoothed disposable (in red) income in ascending order by the income units market income, using log income bands. The smoothed income series transforms each individuals income by the average tax-transfer rate for that group - thereby removing horizontal inequity generated by the observed tax-transfer system. At zero income, the smoothed income function is undefined as the proportional transformation is infinite. The solution used in this chapter is to give everyone with zero market income the same absolute smoothed income, which is equal to the average disposable

\footnotetext{
${ }^{16}$ The sample used only excludes those who are outside the remit of the tax-transfer system (those who have negative market income, and those who have disposable income below $\$ 5,000$ in TY2013 prices, eg mostly students) or who are not surveyed (eg those living in shared accommodation).
} 
income for this group.

The concentration curve for disposable income and the concentration curve for smoothed disposable income are shown in Figures 10 and 11 for the HES88-91 and HES11-13 periods respectively. When forming close equal groups based on market income, horizontal inequity can be thought of as the difference between the concentration curve for disposable income and the concentration curve for smoothed disposable income. This difference is shown in Figure 12 for the first set of pooled years and Figure 13 for the second set of pooled years.

The actual tax-transfer system gives income units with zero market income varying levels of disposable income. As a result, attaching the same smoothed income to each income unit with zero market income implies that the actual tax-transfer system generates horizontal inequity according to this chapters measure of $\mathrm{HI} .{ }^{17}$

An alternative way of constructing smoothed income would be to set the smoothed income for every individual with zero pre-tax income equal to their observed disposable income. This would remove the HI generated by this group. However, this would not be consistent with the method applied to all other income units, as by definition units with the same pre-tax income (in this case zero) are equals. As a result, this is horizontal inequity via the definition of what an equal is and should be included.

\footnotetext{
${ }^{17}$ However, as we have used the average disposable income for this group it does not generate HI later in the income distribution - Which would occur if we used values that kept cumulative income for smoothed income at a different level than for disposable income. This indicates that any method used has to ensure that the cumulative smoothed income given to those with zero market income is equal to the cumulative disposable income of that group.
} 


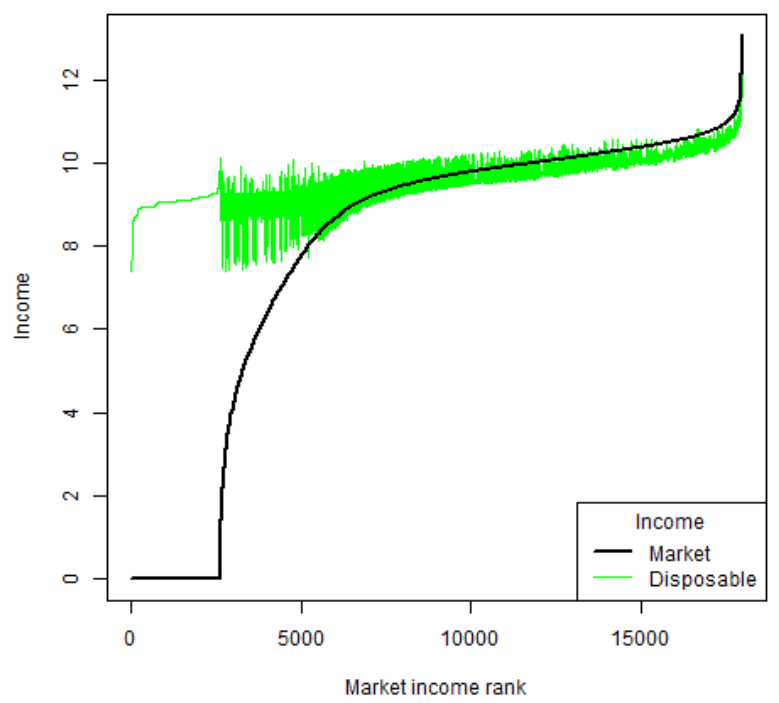

Figure 8: HES88-91 Income ordered by Market income rank.

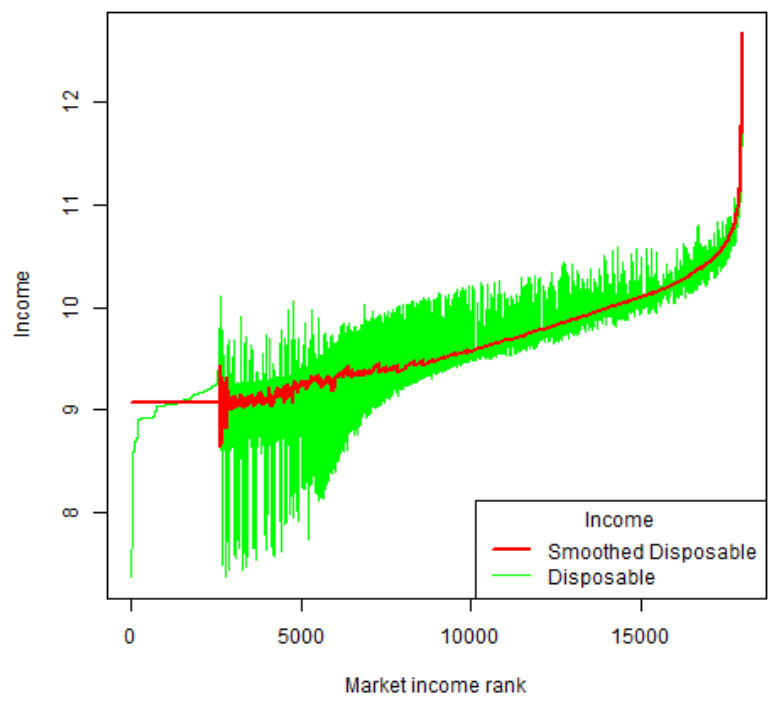

Figure 9: Disposable income ordered by Market income rank. 


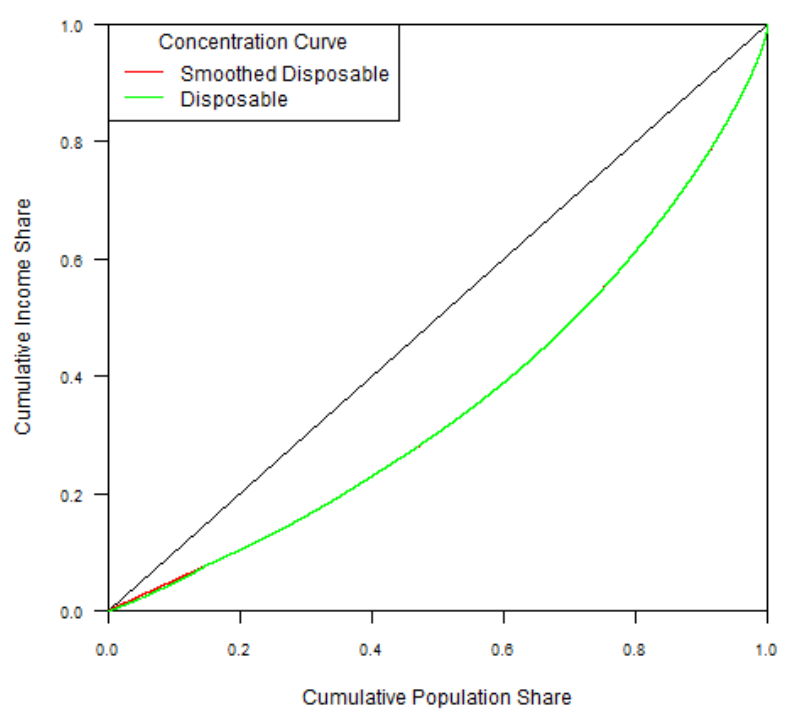

Figure 10: HES88-91 Concentration Curves for disposable income.

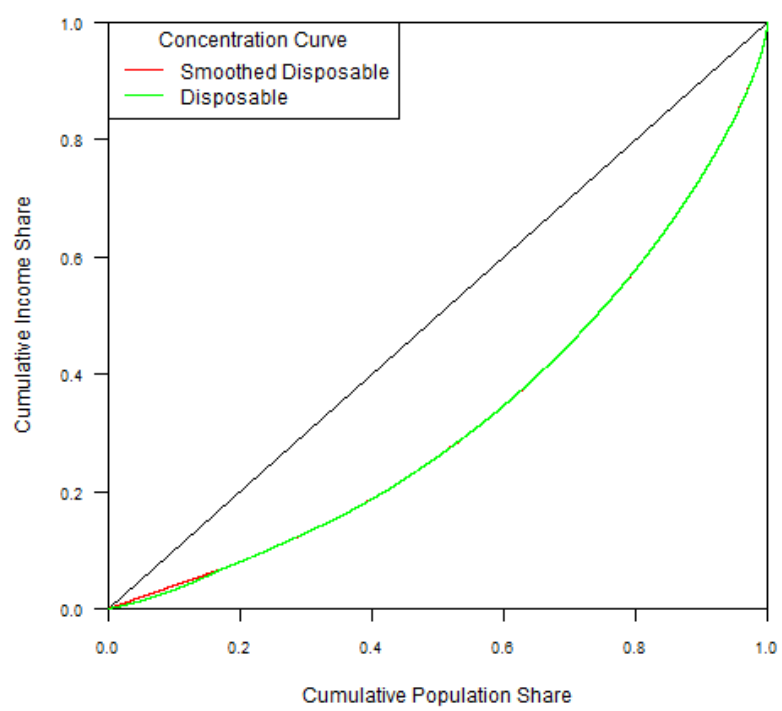

Figure 11: HES11-13 Concentration Curves for disposable income. 


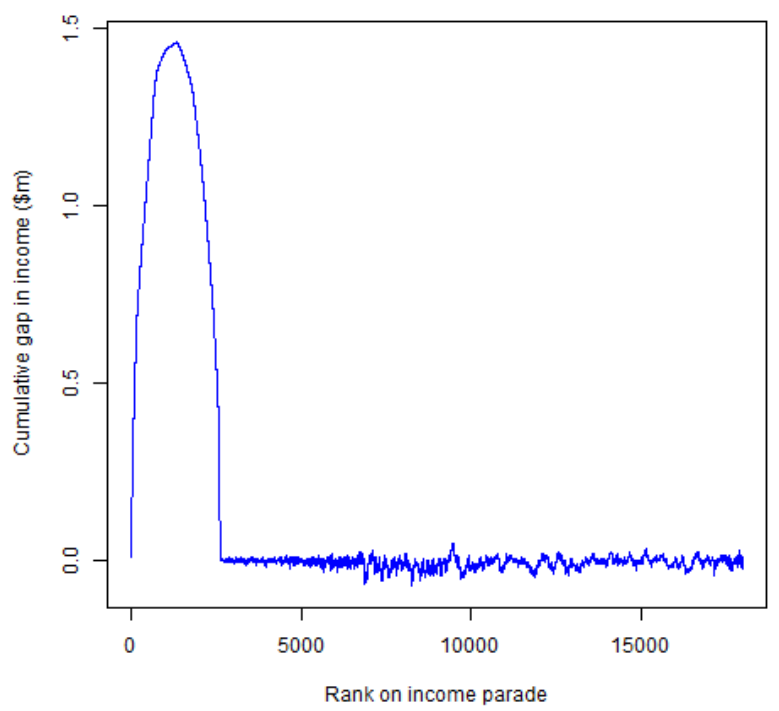

Figure 12: Disposable and smoothed income gaps HES88-91.

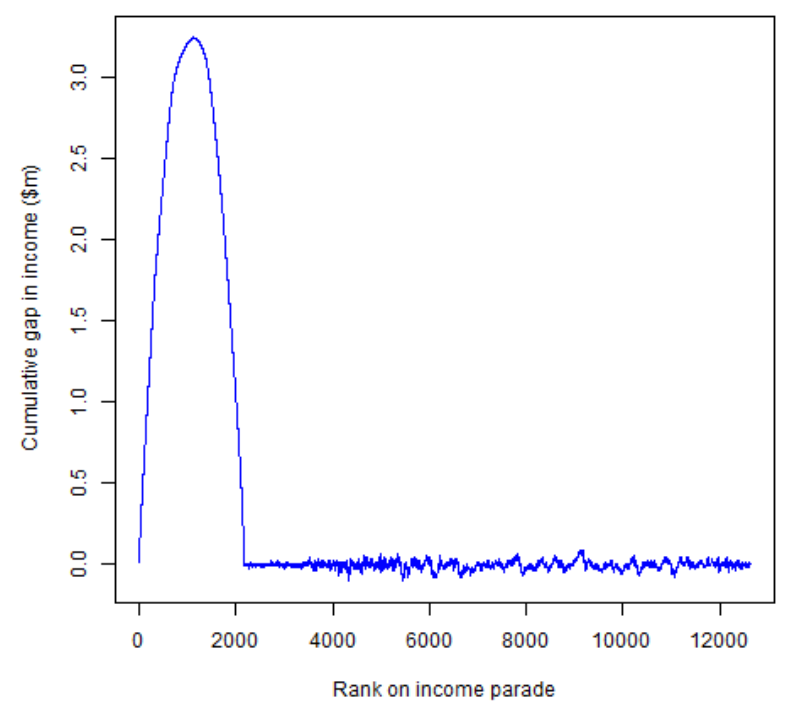

Figure 13: Disposable and smoothed gaps HES11-13. 
Herault and Azpitarte (2014a) use market income for this analysis and discuss the effect of benefit and tax policy separately, following the discussion of Urban (2009) and Lambert (1985) regarding how the effects of benefits and taxes can be separated. This allows Herault and Azpitarte (2014a) to concentrate on decomposing two vertical terms, one that references taxation and one that references benefits. In this chapter the focus is solely on the overall impact of net taxes.

\subsubsection{Year selection}

For the analysis in this chapter pooled data from two sets of HES years which represent the two ends of policy during this period are used.

The first set of years covers the HES88-HES91 surveys inclusively. ${ }^{18}$ Income data is deflated using the Consumer Price Index including interest to TY91 prices. From this dataset approximately 38,000 individuals, 26,500 non-dependants, and 17,900 families were selected for analysis.

The 1988 tax year is in the middle of the economic reforms of the Fourth Labour government. At this point, tax reforms had led to a broadening of the base - with the introduction of a 10\% rate of GST, a Fringe Benefit taxation, and a reduction in the number of tax thresholds from 5 to 2 . Although the top tax rate had been cut from $66 \%{ }^{19}$ in TY 84 to $48 \%$, this was partially compensation for the tax switch to GST and Fringe Benefit taxation, which mainly hit high income earners, rather than a genuine cut in tax burden Stephens (2003).

During this first period the top tax rate was cut (mid TY89), the GST rate was increased to $12.5 \%$, and the LIR (Low Income Rebate) was introduced.

\footnotetext{
18 This represents data collected from April 1987 to March 1991.

19 This includes a temporary tax surcharge on the top tax bracket that was reapproved each year.
} 
By the end of the period, the top tax rate was cut significantly - falling to $33 \%$ for TY 90.

In summary, the first period includes the significant tax reforms that happened during the 1980s but does not include the sizeable changes in the benefit system that were to occur over the following two decades following the 1991 Budget.

The second set of years covers the HES11-13 surveys inclusively. ${ }^{20}$ This period was prior to the July 2013 benefit reforms, but includes the 2010 tax cuts. Income data is deflated using the Consumer Price Index including interest to TY13 prices. From this dataset approximately 25,500 individuals, 19,000 non-dependants, and 12,500 families were selected for analysis.

As a result, changes in the tax and transfer systems from this period consider a system that largely had the same structure to the first period, but with very different rates and thresholds.

A history of the changes in tax rates and scales is shown below:

Table 3.1: Tax thresholds and rates: TY88-13

\begin{tabular}{ccccccc}
\hline Thresholds & \multicolumn{2}{c}{ TY88 } & \multicolumn{2}{c}{ TY90 } & \multicolumn{2}{c}{ TY98 } \\
& Threshold & Rate & Threshold & Rate & Threshold & Rate \\
\hline Zero income & - & $15 \%$ & - & $15 \%$ & - & $15 \%$ \\
First threshold & $\$ 9,500$ & $30 \%$ & $\$ 9,500$ & $28 \%$ & $\$ 9,500$ & $21.75 \%$ \\
Second threshold & $\$ 30,000$ & $48 \%$ & $\$ 30,875$ & $33 \%$ & $\$ 34,200$ & $24 \%$ \\
Third threshold & - & - & - & - & $\$ 38,000$ & $33 \%$ \\
\hline
\end{tabular}

${ }^{20}$ This represents data collected from July 2010 to June 2013. 


\begin{tabular}{ccccccc}
\hline Thresholds & \multicolumn{2}{c}{ TY01 } & \multicolumn{2}{c}{ TY10 } & \multicolumn{2}{c}{ TY13 } \\
& Threshold & Rate & Threshold & Rate & Threshold & Rate \\
\hline Zero income & - & $15 \%$ & - & $12.5 \%$ & - & $10.5 \%$ \\
First threshold & $\$ 9,500$ & $21 \%$ & $\$ 14,000$ & $21 \%$ & $\$ 14,000$ & $17.5 \%$ \\
Second threshold & $\$ 38,000$ & $33 \%$ & $\$ 48,000$ & $33 \%$ & $\$ 48,000$ & $30 \%$ \\
Third threshold & $\$ 60,000$ & $39 \%$ & $\$ 70,000$ & $38 \%$ & $\$ 70,000$ & $33 \%$ \\
\hline
\end{tabular}

When looking at the tax-transfer system the reforms during this period were focused on a move away from universality of payments towards targeting need with transfers. This shows up in three different ways:

- Changes in rates: First tier payments to beneficiaries have generally been increased with inflation. However, the 1991 Budget (colloquially termed the Mother of All Budgets) introduced sizeable cuts to the payments for most beneficiaries - with only nominal payments to those on Invalid's and Carer benefits unchanged. These real cuts persisted in real terms through until our second period of interest.

- Changes in eligibility: Tightening of eligibility criteria on benefits has ebbed and flowed over the history of the benefit system. However, the 1991 Budget signalled a watershed moment when the policy debate firmly shifted from providing a minimum standard to targeting need and incentivising work - with the introduction of binding work testing. Further welfare reform in 1996 and the community wage scheme in 1998 increased the intensity and severity of penalties for work testing, and even after the election of the Fifth Labour government in 1999 most of the work testing framework remained in place.

- Changes in second and third tier payments: The 1991 Budget was, in part, based on the view that technology had now allowed society to target benefit policy more closely to the needs of the individual McClure (1996). 


\subsection{Results of the decomposition}

The results reported below are based upon adult equivalent income per person, where log income bands were used unless otherwise stated.

The adult equivalence scale used was the parametric scale utilised in Creedy et al. (2010). This scale takes the form:

$$
m=\left(n_{a}+\theta n_{k}\right)^{\alpha}
$$

Where $n_{a}$ is the number of adults in the family, $n_{k}$ is the number of children, $0 \geq \theta \leq 1$ is the weight placed on the number of children, and $0 \geq \alpha \leq 1$ is a measure of scale economies among the family unit. Dividing family income by $m$ gives a measure of the equivalized income of each adult individual in the family unit. The results below use this adult equivalent scale to compare income across individuals.

The base comparison for this parametric scale has values of $\alpha=0.6$ and $\theta=0.7$ which is quantitatively similar to the Jensen scale applied in other Australasian studies (eg Herault and Azpitarte 2014b, Perry 2017). 


\subsubsection{Estimated horizontal and vertical equity changes}

Table 3.2: Adult Equivalent Income: Modelled data (\$ bands)

\begin{tabular}{ccccc}
\hline & \multicolumn{2}{c}{ HES88-91 } & \multicolumn{2}{c}{ HES11-13 } \\
& Raw & Base Scale & Raw & Base Scale \\
\hline Market Income Gini $\left(G_{Y}\right)$ & 55.05 & 52.60 & 57.22 & 54.38 \\
Disposable Income Gini $\left(G_{D}\right)$ & 34.84 & 30.03 & 41.09 & 35.90 \\
Redistributive Effect $(R E)$ & 20.20 & 22.57 & 16.14 & 18.18 \\
Kakwani progressivity $\left(V_{K}\right)$ & 22.41 & 23.97 & 17.49 & 19.69 \\
Atkinson-Plotnick Reranking $\left(R_{A P}\right)$ & 2.20 & 1.40 & 1.35 & 1.20 \\
Vertical Equity $(V)$ & 22.40 & 23.88 & 17.56 & 19.74 \\
Horizontal Inequity $(H)$ & -0.01 & -0.09 & 0.06 & 0.05 \\
Absolute HI $\left(H^{T}\right)$ & 0.27 & 0.17 & 0.24 & 0.19 \\
Bandwidth $(\$)$ & $\$ 347.72$ & $\$ 225.77$ & $\$ 744.22$ & $\$ 476.63$ \\
\hline
\end{tabular}

Table 3.3: Adult Equivalent Income: Modelled data (Log bands)

\begin{tabular}{ccccc}
\hline & \multicolumn{2}{c}{ HES88-91 } & \multicolumn{2}{c}{ HES11-13 } \\
& Raw & Base Scale & Raw & Base Scale \\
\hline Market Income Gini $\left(G_{Y}\right)$ & 55.05 & 52.60 & 57.22 & 54.38 \\
Disposable Income Gini $\left(G_{D}\right)$ & 34.84 & 30.03 & 41.09 & 35.90 \\
Redistributive Effect $(R E)$ & 20.20 & 22.57 & 16.14 & 18.18 \\
Kakwani progressivity $\left(V_{K}\right)$ & 22.41 & 23.97 & 17.49 & 19.69 \\
Atkinson-Plotnick Reranking $\left(R_{A P}\right)$ & 2.20 & 1.40 & 1.35 & 1.20 \\
Vertical Equity $(V)$ & 22.47 & 24.01 & 17.58 & 19.72 \\
Horizontal Inequity $(H)$ & 0.06 & 0.04 & 0.09 & 0.03 \\
Absolute HI $\left(H^{T}\right)$ & 0.21 & 0.11 & 0.22 & 0.18 \\
Bandwidth $\left(\log (\$)^{*} 100\right)$ & $\$ 2.77$ & $\$ 4.99$ & $\$ 2.98$ & $\$ 5.37$ \\
\hline
\end{tabular}

The estimates in Table 3.3 suggest that the redistributive nature of the taxtransfer system was larger in 1988-91 than it was in 2011-13. The Gini 
coefficient for disposable incomes was $42 \%$ lower than for market incomes in 1988-91, compared to a 32\% reduction in 2011-13.

Observed redistribution can then be broken in to two competing effects - the vertical equity associated with the tax system (how far cumulative post-tax incomes have moved towards the line of complete equality for the same ordering of individuals) and the reranking of individuals by income due to the tax-transfer system. Without groups of equals, this reranking is the only form of horizontal inequity.

The vertical equity inherent in the tax-transfer system fell from $44.7 \%$ of the market Gini in 1988-91 to 34\% in 2011-13. Although the vertical effect declined, it remained a similar proportion of the redistributive effect (RE) for the given year (105\%) implying that the decline in redistribution that was experienced was due to a less progressive tax-transfer schedule.

The observed reranking of income units associated with the tax-transfer system reinforces this result. Although the level of reranking declined (from 1.4 Gini points to 1.2 Gini points) as a percentage of the redistributive effect rose from $6.2 \%$ to $6.5 \%$ between the two periods. If we view $\mathrm{HI}$ solely as reranking, this would suggest that the changes in the tax-transfer system did manage to slightly reduce the horizontal inequity measure between these two periods - but did so in a way that induced relatively more HI for the amount of redistribution inherent in the tax-transfer system.

To discuss classical HI in terms of groups of equals requires close equal groups (CGEs). Defining these groups on the basis of a fixed log-income bandwidth allows the decomposition of the preceding vertical effect into a vertical term (the change in between group inequality due to the taxtransfer system) and a horizontal term (the additional inequality generated within groups due to the tax-transfer system).

According to this measure HI declined between these two periods, but 
rose as a percentage of the RE. HI decreased from 0.04 Gini points to 0.03 Gini points falling slightly as a percentage of the redistributive effect.

Progressivity in the tax schedule leads to redistribution within income groups, which reduces estimates of HI. If classical HI is instead seen as representing any departure from the previous distribution - be it an increase or decrease in the spread of incomes - then the measure of $\mathrm{HI}$ will differ. The term that represents this is $H^{T}$. Estimates of $H^{T}$ imply it increased from $0.5 \%$ of the RE to $1.0 \%$ between these periods.

Overall all these measures suggests that classical horizontal inequity - which involves the absolute unequal treatment of equals - rose as a percentage of the redistributive effect of the tax system following the myriad of tax and transfer changes between 1988 and 2013.

\subsubsection{Why did Horizontal Inequity rise?}

At first glance an increase in the absolute $\mathrm{HI}$ measure as a percentage of the redistributive effect between these two periods is inconsistent with the goals of policy makers in the late 1980s and early 1990s. However, rather than being due to policy failure the observed increase in HI measures is consistent with increased targeting in the tax-transfer system - illustrating that these measures of $\mathrm{HI}$ may by themselves be inappropriate for evaluating the role of the transfer system with respect to horizontal equity.

To understand this result it is useful to look at HI more closely. Figures 12 and 13 show the difference between the two concentration curves pictured in 10 and 11.

In these figures, those with zero pre-tax income are ordered by post-tax income, and the smoothed income given to each individual is equal to average post-tax income for all those with zero pre-tax income.

As a result, for all individuals with zero pre-tax income the concentration 
curve is at or below the concentration curve for smoothed income. This is automatically counted as $\mathrm{HI}$ by both the $H$ and $H^{T}$ methods.

Removing this source of $\mathrm{HI}$, then $H$ becomes virtually zero for both time periods. The unequal payments that exist in the benefit system are the primary driver of the classical horizontal inequity measure.

With the introduction of Working for Families, the independent earner tax credit, and rising labour force participation by retirees this period has also seen an increase in targeted payments for those who have positive pre-tax income. These payments generated further horizontal inequity in the taxtransfer system, since the definition of equals is characteristic free while these payments are based on individual characteristics.

\subsection{Sensitivity of results to the equivalence scale}

As Table 3.2 and Table 3.3 show, the estimates of the measures of redistribution and equity are dependent on the equivalence scale used. With reference to the distribution of income, unequivalized data has a smaller redistributive effect, smaller vertical effect, greater reranking, and larger horizontal inequity.

To investigate the general sensitivity of the results the parameters of the equivalence scale were varied. This scale takes the form:

$$
m=\left(n_{a}+\theta n_{k}\right)^{\alpha}
$$

Where $m$ is the number of equivalent adults in the family, $n_{a}$ is the number of adults in the family, $n_{k}$ is the number of children, $0 \geq \theta \leq 1$ is the weight placed on the number of children, and $0 \geq \alpha \leq 1$ is a measure of scale economies among the family unit. The unit of analysis (equivalised 
disposable income) is then equal to overall family income divided by the number of equivalent adults in that family. ${ }^{21}$

The base comparison has the values of $\alpha=0.6$ and $\theta=0.7$. As a result, when one of the parameters is varied the other parameter is fixed at its base level eg where $\alpha$ is varied $\theta$ is fixed at 0.7 .

\subsubsection{Varying scale economies}

The scale economies parameter represents how much the per capita cost of maintaining a given standard of living falls as the family size rises (Nelson 1988). At a value of $0 m$ always equals 1 and family income is unequivalised - this suggests that there are maximum scale economies, with family members consumption opportunities from a given family income not depending on the number of individuals in the family unit. At a value of 1 family income is divided by the number of adults in the family plus 0.7 times the number of children in the family implying that there are no scale economies.

The overall redistributive effect (RE) of policy rises with the level of scale economies in the family, but at a decreasing rate. For the HES88-91 period the RE peaked at $\alpha=0.8$ as shown in Figure 14 .

However, the estimate of the vertical effect of policy rises with the scale economies parameter for all $\alpha$. This suggests that at very high levels of the scale economies parameter the combination of horizontal inequity and reranking must be increasing.

Vertical equity (VE) as a percentage of the redistributive effect follows a U-shape in the scale economies parameter declining as relative to RE at

\footnotetext{
${ }^{21}$ Families, or Economic Family Units, differ from Households - as it is possible to have multiple families in a household. A family unit is assumed to include a principal, their spouse, and their dependant children.
} 
low values and rising at high values of $\alpha$ as shown in Figure 15. However, near the parameter value used in the base scale this ratio reaches its lowest level ${ }^{22}$ before increasing at a rising rate. This result suggests that, inadvertently, the use of the base scale provides a low estimate of the level of vertical equity in the tax-transfer system.

The most significant difference due to the change in scale economies occurs with reranking as shown in Figure 17. Reranking as a proportion of RE follows the same general pattern as VE. However, for both low and high values of the scale economies parameter reranking in HES88-91 was significantly higher (as a \% of RE) than in HES11-13. The result that reranking was greater in the later period only holds for scale economies near the base scale parameter of 0.6. This implies that the greater reranking (as a \% of RE) induced inequity in the estimates above only hold if the scale economies parameter is close to the base scale.

Horizontal inequity (HI) as a percentage of the redistributive effect generally declines as the scale economies parameter rises, however the relationship is imperfect as shown in Figure 16. In level terms, HI generally declined for both year periods as the scale economies parameter increased. However, HI was only substantially larger in HES11-13 than in HES88-91 when the scale economies parameter was near the base scale level, 0 , or 1.

However, the key result is robust to the scale parameter. Absolute $\mathrm{HI}\left(H^{t}\right)$ was greater in HES11-13 than in HES88-91 in both absolute terms and as a proportion of the redistributive effect (Figure 18).

${ }^{22}$ This occurred at approximately 0.6 for HES 88-91 and 0.4 for HES11-13. 


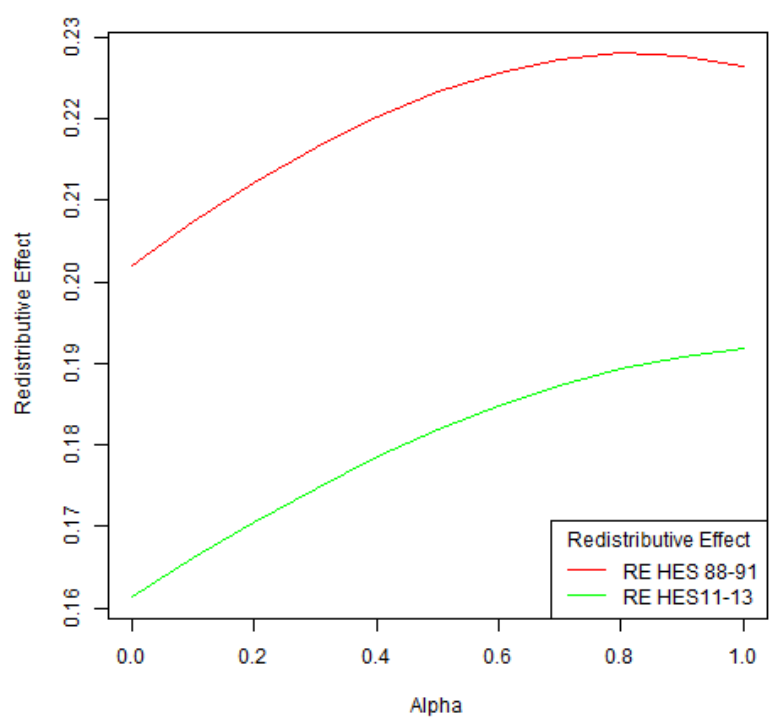

Figure 14: Redistributive effect for varying levels of scale economies.

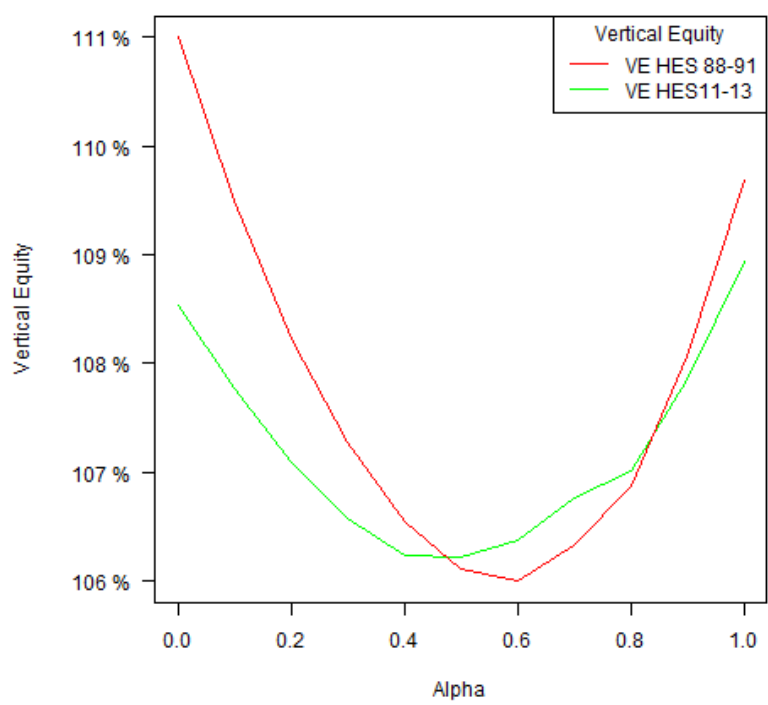

Figure 15: Vertical equity (\% RE) for varying levels of scale economies. 


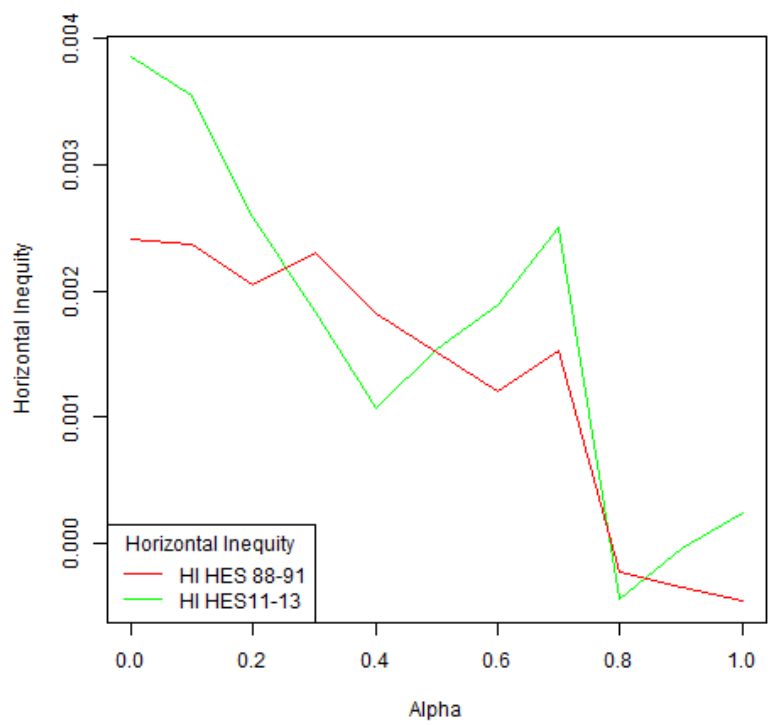

Figure 16: HI (\% RE) for varying levels of scale economies.

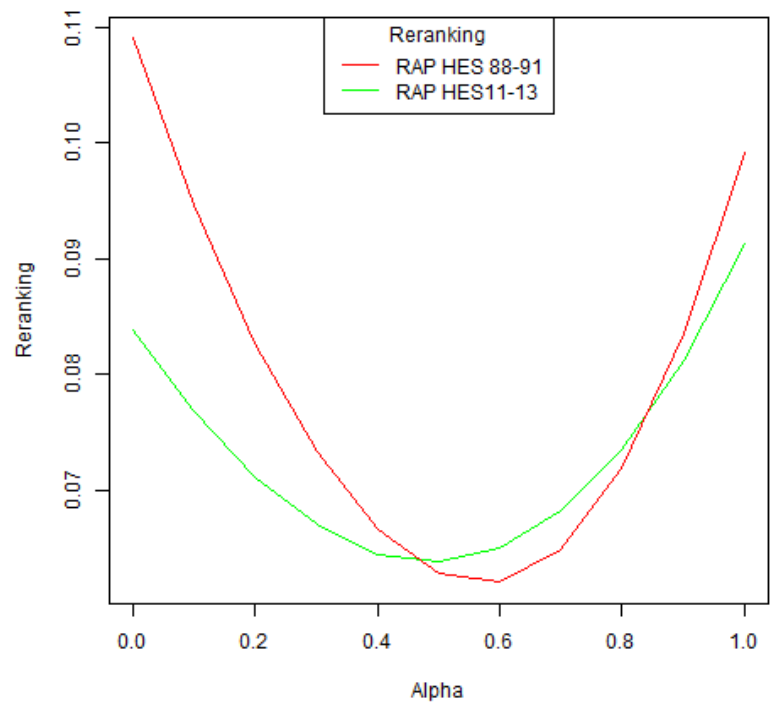

Figure 17: Reranking (\% RE) for varying levels of scale economies. 


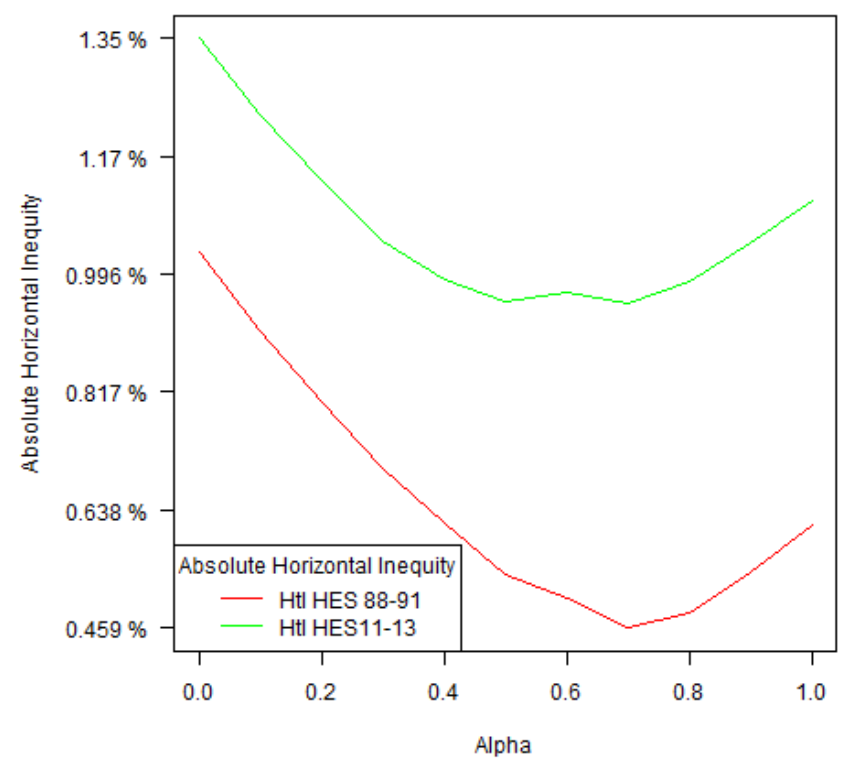

Figure 18: Absolute HI (\% RE) for varying levels of scale economies.

\subsubsection{Varying the weight of the child}

Changing the weight on the number of children has very little impact on the results as shown in Figure 19. While there was a 12.8\% (18.9\%) difference between the smallest and largest RE for HES88-91 (HES11-13) when changing the scale economy term, there was only a 1.0\% (0.7\%) maximum difference in the RE when considering varying child weights.

However, the composition of the decomposition of the redistributive effect does change as the weight placed on children changes - specifically for the HES88-91 year.

For the vertical effect, the base scale weight $(0.7)$ corresponds to the results in this chapter - with VE as a proportion of RE slightly higher in HES11-13 than in HES88-91. At a weight of zero, VE is significantly higher for the 
HES88-91 period than for HES11-13. For both year periods as the child weight is increased from zero to $0.4 \mathrm{VE}$ declines, but the decline is much sharper for the earlier period (Figure 20).

With VE declining and RE unchanged as the child weight rises for the HES88-91 period, this suggests that horizontal inequity must also decline as this weight rises. As shown in Figures 21 and 22 both $H$ and $R^{A P}$ decline as the child weight rises. However, it is the decline in reranking that explains most of the difference between the changes in VE and RE.

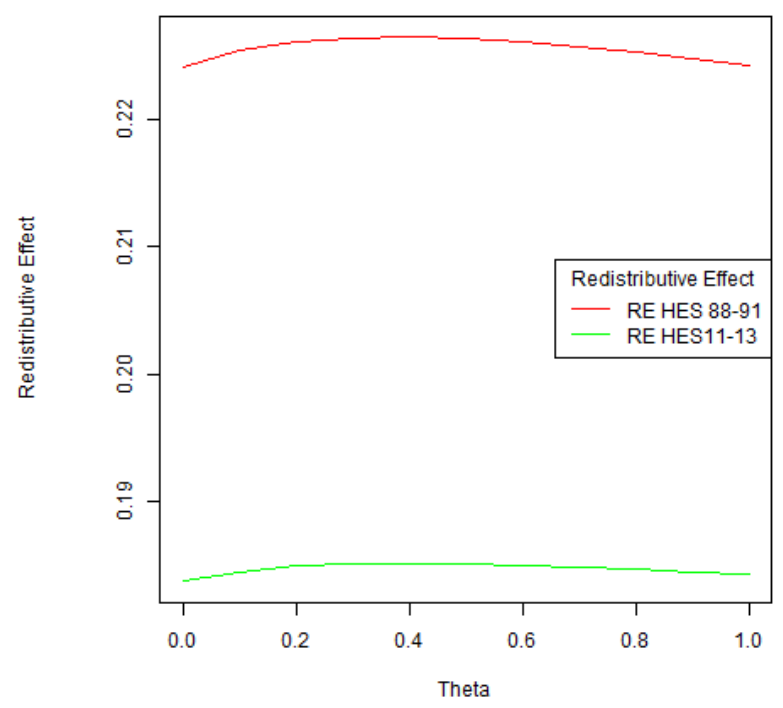

Figure 19: Redistributive effect for varying weights on children. 


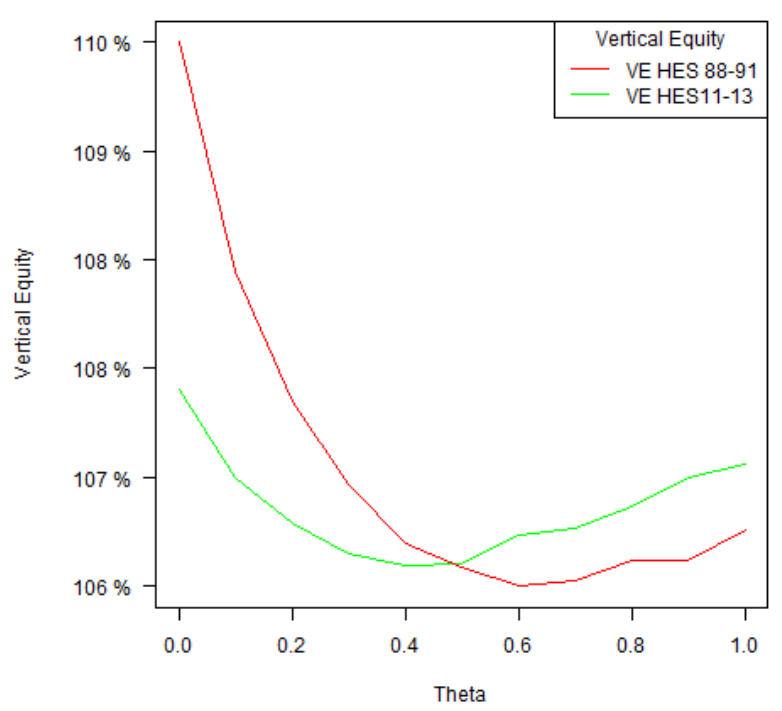

Figure 20: Vertical equity (\% RE) for varying weights on children.

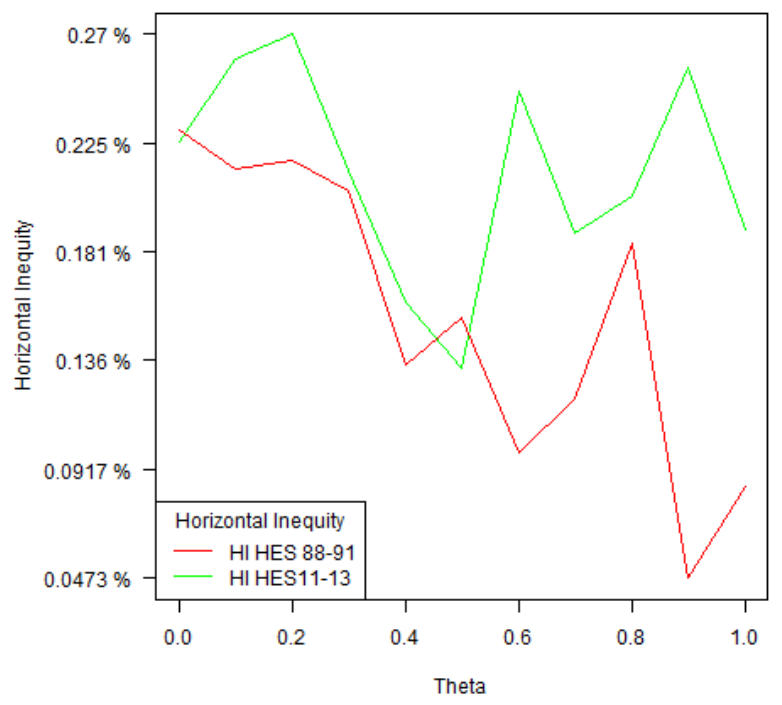

Figure 21: HI (\% RE) for varying weights on children. 


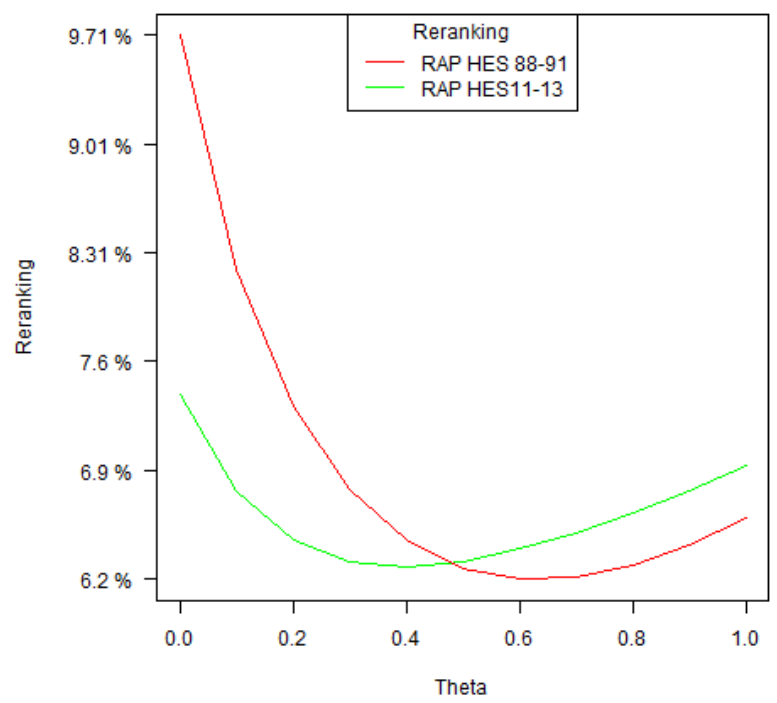

Figure 22: Reranking (\% RE) for varying weights on children.

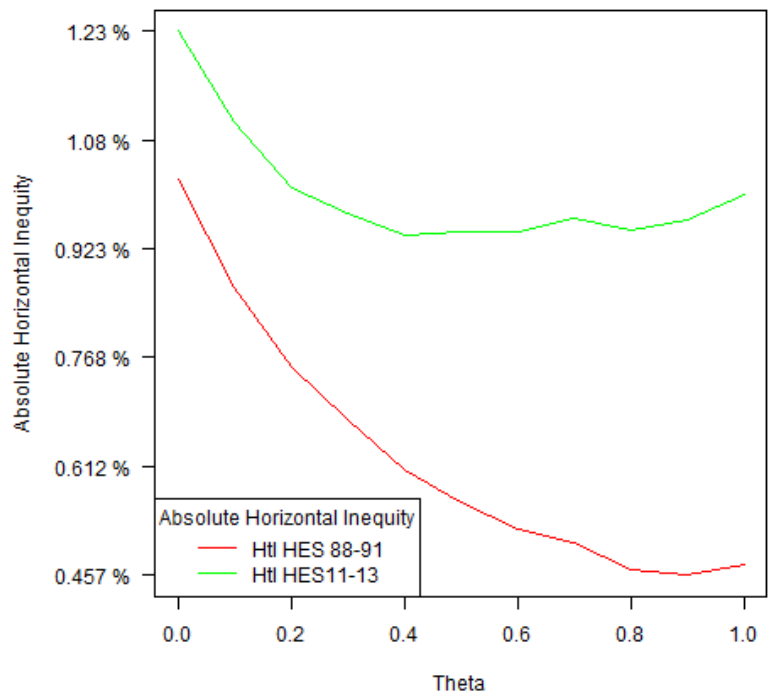

Figure 23: Absolute HI (\% RE) for varying levels weights on children. 


\subsection{Conclusion}

This chapter focused on evaluating the equity characteristics of tax-transfer policies changes between 1988-91 and 2011-13. Specifically the goal was to evaluate two claims: whether vertical equity declined in line with the reduction in the redistributive effect of the tax-transfer system, and whether measures of horizontal inequity (in both classical and reranking forms) declined.

There was strong evidence that vertical equity did decline in line with the reduction in the redistributive effect between these two periods, with the estimate of VE falling by the same proportion as the overall redistributive effect of policy during this time.

However, measures of horizontal inequity did not decline. Specifically, all measures of horizontal inequity between families as a proportion of the redistributive effect rose during this period - with the measure of absolute horizontal inequity also rising in level terms. Although the increase in the classical horizontal inequity term is predominantly the result of increasing targeting of transfer payments, the lift in reranking suggests that the overall system is slightly more wasteful at achieving vertical equity goals due to the reranking of families.

The reranking result is highly sensitive to the equivalence scale used. If the scale economies parameter is sufficiently different from the base scale value - either higher or lower - then the reranking implied by the taxtransfer system as a proportion of the redistributive effect is greater in HES88-91 than it is in HES11-13. Other horizontal inequity change results are largely unaffected by the equivalence scale used.

One lesson to come out of this chapter is that the traditional method for estimating the horizontal inequity in the tax system is ill-suited to offering an objective evaluation of the transfer system given that explicit targeting 
of need in the transfer system is represented as horizontal inequity.

Using an income measure to analyse horizontal equity and then stating the view that reducing horizontal inequities is always just implies that all people with the same (or very similar) income are equivalent in terms of the standard of living they can derive from that income. Equivalence scales are used due to the view that larger households require less income per person to meet the same material standard of living (Nelson 1993). However, this is insufficient to account for the myriad of other differences between these households (eg disabilities, the cost of living in a given location) and the difference that may exist between material standards of living from income and a more general standard of living concept.

A transfer system that targets these non-income characteristics that influence individuals material standard of living will generate horizontal inequity according to these measures, but such horizontal inequity is by design and exists to satisfy policy goals (eg equalizing opportunity or capabilities (Sen 2000)) which are predicated on the idea that these individuals are not equals.

Following Musgrave (1976) the definition of individuals being in an equal position needs to be given operational meaning, and assuming people are equals due to the equivalised market income is insufficient for this. These result suggests that applying this general method to a more careful definition of equals that more accurately represents the disparate needs/characteristics of individuals would be a useful direction for future research. 


\section{Chapter 4}

\section{New Zealand Wage Equations: 1988-2013}

\subsection{Introduction}

This chapter reports estimates of the wage equation for a number of demographic groups in New Zealand between 1987/88 and 2012/13. Using Household Economic Survey (HES) data four different periods of pooled data are created, and the wage equation for each demographic year is estimated for each pooled data period. The purpose of estimating these wage equations is to allow for the imputation of wage rates for individuals who are not employed, given that their wage rate is not observed in the data. Once wages for those who are not employed are imputed it is possible to ask what if questions about the income the individual would earn if they moved into work.

Thoughout the period between 1988 and 2013 the response of labour supply to changes in tax and transfer policies was seen as centrally important (eg Treasury 1996, Creedy and Mok 2015). As a result, any analysis of changes in incomes or the tax-transfer system during this period requires 
imputed wage rates for those who were not employed in order to evaluate their labour market opportunities.

The method applied takes into account that there is sample selection bias in the data due to the fact that only the wages of those who are employed are observed (Cameron and Trivedi 2005). A standard way to correct for this is to make use of the Heckman correction, which involves incorporating the probability that an individual is employed based on their characteristics into the wage regression (Creedy et al. 2000).

Imputing wages in a way that accounts for this bias in the New Zealand context has been investigated for the HES92-HES01 period in Kalb and Scutella (2003) and for the HES07-HES11 period in Mercante and Mok $(2014 b)$. This chapter considers wage imputation over four subperiods: HES88-93, HES94-HES98, HES01-HES08, and finally HES09-HES13. The results for these subperiods are then compared, to give an indication of how the relationship may have changed over time.

By comparing the wage equations for these four year groupings, it is possible to discuss how returns to characteristics (education level, age, occupation etc) changed for each demographic subgroup between 1988 and 2013. The wage equations are not strictly comparable due to differences in the independent variables used for each model, and changes in the definitions used for some dummy variables (eg industry, ethnicity). Even so, given that the selected models are relatively similar across years changes in parameter estimates are a useful indication of change in the underlying wage equation.

However, this chapter does more than apply this existing method to a larger set of data. Heteroskedasticity is identified in the selection equation for most of the demographic groups over time, implying that the Inverse Mills Ratio used in the wage equation is not consistently estimated. This chapter estimates and corrects for the variance in the selection equations in order to improve estimates of the wage equation, and the corresponding 
imputed wages, for this period.

The results of this wage imputation can be used to analyse changes in labour supply behaviour ${ }^{1}$, and ultimately used to decompose changes in the observed income distribution in New Zealand into policy related and non-policy related effects (Bargain 2010). As a result, this process forms an important step in the analysis of the income distribution in New Zealand.

The chapter is organised as follows: Section 2 outlines the data used in the chapter. Section 3 introduces the method used to impute wages. Section 4 discusses the wage equations for each pooled year grouping. Section 5 reports the predicted wages from the method and Section 6 comes these wages to previous results from the literature. Section 7 concludes, and the full set of regression results are reported in tables in Section 8.

\subsection{Household Economic Survey Data}

The data used for this analysis comes from Statistics New Zealand's Household Economic Survey (HES). The HES is a household survey that has been run annually since the April 1974 year, except for a brief period where it was taken triennially between 1998 and 2006. The HES surveys 5,000 private households ${ }^{2}$, with 3,000-4,000 responses of sufficient quality each year. HES years will be denoted using the year when the survey ended. For example HES95 refers to the household survey that took place between April 1994 until March 1995.

The survey collects data on income by source, hours of work, and a variety of household, family, and personal characteristics (eg ethnicity). A key advantage of the survey is that it links familial relationships. As a

\footnotetext{
${ }^{1}$ In a way consistent with the prior New Zealand research by both Guyonne Kalb and Rosanna Scutella (2003) and Mercante and Mok (2014a).

2 Private households exclude institutional households, such as resthomes and prisons.
} 
result this survey allows the construction of economic family units. This allows the estimation of separate wage equations for individuals based on their familial role and to also include variables related to family status (eg partners income, child's age) into the estimation. An economic family unit refers to an adult, their partner ${ }^{3}$, and their dependants ${ }^{4}$. Using these familial linkages five key groups are constructed: Coupled men, coupled women, single men (without children), single women (without children), and sole parents. Wage equations are then estimated for each of these groups.

Data regarding the characteristics of individuals was recoded into dummy variables for: Ethnicity, highest education level, region, industry and occupation of primary job, and age of youngest child.

Given these characteristics there are four separate pooled data sets for which the wage equation for each demographic group is estimated: HES8893, HES94-98, HES01-08, and HES09-13. The demographic groups of interest are coupled men, coupled women, single men without dependants, single women without dependants, and sole parents.

Two sets of weights are available for the HES data. Household survey weights are provided that relate to the inverse probability of the household being selected for the survey. There are also calibrated survey weights which reweight the sample data to match a set of externally sourced population statistics Statistics New Zealand (2001). These weights are available from Statistics New Zealand from HES01 onwards. Treasury has calculated a set of calibrated weights for the entire time horizon of the survey in this chapter which will be utilized here. These weights were originally used and recalibrated to consider counterfactual population distributions in Ball and Creedy (2015).

The estimation, and results provided, below focus on sample means so

\footnotetext{
${ }^{3}$ Where a defacto or married partner exists.

${ }^{4}$ Dependants are children aged below 15, or below 18 and in full-time education.
} 
these weights are not used. This matches the analysis of Kalb and Scutella (2003) and Mercante and Mok (2014b), but differs from the estimates of Ball and Huseynli (2018) which make use of calibrated weights. As a result, this requires justification. Incorporating calibrated weights allows for inference with regards to the population of interest, and gives a better estimate of the population parameters in the wage equation. However, given the primary purpose of this chapter is to impute data for the sample, nonweighted estimation is preferable.

The non-use of weights can be justified in the following way. For a question such as "what is the wage premium for living in Auckland" applying sample weights gives estimates for the population from the sample.

However, when imputing wage rates the question being asked is "what is available wage rate for individuals in the sample who are not employed" - a question about the sample not the population. By estimating wage equations with weights the imputed wage rates for these individuals uses the assumption that there is no sampling bias for those who are not employed. As a result, if the wage rate relationship for non employed respondents differed to non-respondents this would be a false assumption which would lead to biased results.

In the HES, individuals are asked about income and expenditure for the prior year. As a result the data contained in the entire HES95 survey refers to the period April 1993 until March 1995. The income data used refers to total income from all sources. However, the wage figure used in this chapter is derived from current wage and salary earnings. Here current refers to a job that the individual is employed in at the end date of the survey. As a result, the wage figures used from the HES95 survey refer to wage and salary earnings that occurred between April 1994 and March 1995.

The wage measure used in this chapter is the implied wage from wage and salary income in the HES data. This is equal to total current weekly 
wage and salary earnings from the individuals primary job divided by the number of hours worked per week in their primary job. ${ }^{5}$

On a few occasions inconsistent/unreliable wage data was removed. The key times this occurred were when the calculated wage rate was less than half the minimum wage, when the wage above $\$ 150$ was reported, and when a very large income was earned on only one hour of work.This excluded less than $1 \%$ of the sample.

Excluded from the analysis were several groups who are not included in the corresponding labour supply analysis, and so who do not require estimated imputed wage rates. These are:

1. The self employed.

2. Those too young to be in the labour force (aged below 15).

3. Individuals who have reached retirement age. ${ }^{6}$

4. Individuals who are unable to work (those reporting being on the invalids benefit).

5. Those in full time study.

Data are pooled into four separate year groups, and the wage equation for each family type is estimated separately for each set of pooled years. The pooled years are HES88-93, HES94-98, HES01-08, HES09-13. The reason why these year groups were selected is discussed in the Section 4 . The approximate sample size for each demographic group, in each pooled year

\footnotetext{
${ }^{5}$ The earnings from prior jobs, self-employed work, and secondary jobs are ignored when calculating the wage. The primary job is defined as the wage and salary job the individual is currently employed in that offers the largest average weekly income at current hours of work.

${ }^{6}$ Aged over 65 - therefore wages are still imputed for those who were at retirement age earlier in the time period of interest. A dummy variable is included in the analysis for people who are below 65 but are receiving National Superannuation.
} 
period, is shown in Table $4.1 .^{7}$

Table 4.1: HES sample sizes

\begin{tabular}{|c|c|c|c|c|c|}
\hline & Coupled men & Coupled women & Single men & Single women & Sole Parent \\
\hline \multicolumn{6}{|c|}{ Sample size } \\
\hline HES88-93 & 7,050 & 8,470 & 3,370 & 2,850 & 1,790 \\
\hline HES94-98 & 5,810 & 6,160 & 2,260 & 1,880 & 1,100 \\
\hline HES01-08 & 4,890 & 5,250 & 1,930 & 1,680 & 870 \\
\hline HES09-13 & 6,860 & 7,430 & 2,690 & 2,630 & 1,310 \\
\hline
\end{tabular}

There are specific cases where the variables used for analysis differ between these pooled year groups. For the HES94-98 years reported ethnicity was restricted to only take two values - Maori and/or Pacific Islander and Other. As a result, the wage imputation for the HES94-98 period uses only a Maori-Pacific dummy, as compared to the Maori-Pacific only, Maori-Pacific full, and Other non-European dummies used for later periods.

For the estimates provided below there were a variety of different industry, occupation, and education categories used through time. To make the data comparable a correspondence was applied to all the years of analysis, to attempt to replicate the categories that held in the final year of analysis (2013). However, any such correspondence is imperfect and as Statistics New Zealand points out this provides significant comparability issues Statistics New Zealand (2006).

The industry classification used refers to the ANZSIC06 classification codes [Level 1] from Statistics New Zealand (2017a). The occupation classification refers to the ANZSCO06 classification codes [Level 1] from Statistics New Zealand (2017b). The education levels follow from the NZQF qualification levels from NZQA (2017).

\footnotetext{
${ }^{7}$ The sample sizes in this table have been randomly adjusted to a neighbouring 10 in line with Statistics New Zealand confidentially requirements.
} 
The wage equations use wage data that is deflated by a wage index to make it comparable between years. As a result, the wage relationship that is discussed and shown in the coefficients indicate the relative importance of characteristics for setting wages - not their absolute impact on the wage level. Furthermore, due to this deflating the wage equations will be comparable between periods.

Outside of the HES data several other data sources from Statistics New Zealand are used. Quarterly Employment Survey (QES) and Earnings and Employment Survey (QEX) data provide an external estimate of average weekly earnings. The Consumer Price Index (CPI) is the measure of consumer prices, in this case we use CPI All Groups plus interest payments. Furthermore, the Household Labour Force Survey (HLFS) gives a measure of unemployment by sex.

\subsection{Method of analysis}

The method used to impute wages for those who are out of work is based on that applied by Kalb and Scutella (2003) and Mercante and Mok (2014b).

When imputing wages for someone who is out of work, it is not sufficient to take average wage of individuals with the same observed characteristics who are employed as an estimate of the available wage rate. The fact that they are not in employment may suggest that they are different for unobserved reasons. If this is the case, and these unobserved factors are related to the wage a person receives, then the expected wage that person would earn if there were employed will vary from the average of those with the same observed characteristics.

The traditional way of dealing with this issue is to act as if there is an unobserved omitted variable which explains the difference in employment status between people with given observed characteristics. 
Viewing the problem in this way, the process that determines whether someone is employed (the selection/employment equation) will be related to the process that determines the wage available to the individual (the wage equation). As a result, estimating the imputed wage via an OLS regression on only those who are employed will give a biased estimate of the wage available to those who are not employed.

The solution to this is to apply the Heckman correction of Heckman (1979).

Both the employment status and the wage rate of an individual are a product of the individuals characteristics. In the case of employment, assume that there is some underlying propensity for the individual to be in paid employment which is a linear function of the observed characteristics of the individual $(z)$. For the $i^{\text {th }}$ individual this can be denoted as:

$$
E_{i}^{*}=z_{i}^{\prime} \gamma+u_{i}
$$

Where $u_{i}$ is assumed to be independently distributed with $\mathrm{N}(0,1){ }^{8}$

The employment index is neither the availability of jobs or individuals willingness to participate in work. Instead it is the probability that an individual receives a wage offer that is greater than their reservation wage - making it a hybrid of both factors. As a result, anything changing the employment index should not be interpreted as solely due to difference in the opportunity or willingness to work of individuals.

This underlying employment index then gives the probability that an individual will be observed in employment. Denoting observed employment status as $E$, where $E=1$ is an index variable that represents that the individual is employed. Given this the possible outcomes are:

\footnotetext{
${ }^{8}$ There is no way of identifying the variance of this equation when all we observe is whether $E^{*}>0$ or not and not the scale. However, as $u_{i}$ is positive and $\gamma$ scales with the variance this is independent of scale. As a result, $u_{i}$ can be normalised (Cameron and Trivedi 2005)
} 


$$
E_{i}= \begin{cases}1 & \text { if } E_{i}^{*}>0 \\ 0 & \text { if } E_{i}^{*} \leq 0\end{cases}
$$

Given the assumed distribution of $u$, the probability of being employed is $P\left(E_{i}=1\right)=\Phi\left(z_{i}^{\prime} \gamma\right)$ where $\Phi$ is the standard normal distribution function. With employment status observed for everyone in the sample, the probability of being employed can be estimated via standard probit regression.

For the observed data the wage rate (and therefore the wage conditional on being employed) for an individual takes the form:

$$
\left.W_{i}\right|_{E_{i}=1}=x_{i}^{\prime} \beta+\epsilon_{i}
$$

Where $x_{i}$ is a vector of characteristics ${ }^{9}$, and $\epsilon_{i} \sim \mathrm{N}\left(0, \sigma_{\epsilon}\right)$.

Given the observable characteristics $\left(x_{i}\right)$ of individuals out of employment, the OLS or censored Tobit estimate appear to be a natural way to impute the wage that is available to those who are not employed $(E=0)$. However, selection into employment and the wage available to the individual are not likely to be independent - namely if the covariance between $\epsilon$ and $u$ is non-zero then the OLS estimate of the wage will be biased. This is shown by the conditional expectation of the wage rate given that the person works.

$$
\begin{aligned}
\mathrm{E}\left(w_{i} \mid E_{i}^{*}>0\right) & =\mathrm{E}\left(x_{i}^{\prime} \beta+\epsilon_{i} \mid E_{i}>0\right) \\
& =x_{i}^{\prime} \beta+\mathrm{E}\left(\epsilon_{i} \mid z_{i}^{\prime} \gamma+u_{i}>0\right)
\end{aligned}
$$

As a result, estimates of the wage rate need to account for this bias by estimating $\mathrm{E}\left(\epsilon_{i} \mid z_{i}^{\prime} \gamma+u_{i}>0\right)$. This is achieved by using the Heckman

\footnotetext{
${ }^{9}$ Where this vector of characteristics may in part overlap with the vector of characteristics from the employment equation, $z_{i}$.
} 
correction.

The Heckman correction involves fitting a probit model to the selection equation (equation (4.2)) to estimate the employment probability for each individual on the basis of their characteristics.

The procedure then incorporates the probability of the given individual being in employment in the wage equation. Given the assumption that the error term from the employment equation $\left(u_{i}\right)$ and the wage equation $\left(\epsilon_{i}\right)$ are jointly normally distributed as $\mathrm{N}\left(0,0,1, \sigma_{\epsilon}, \rho\right)$ then $\mathrm{E}\left(\epsilon_{i} \mid z_{i}^{\prime} \gamma+u_{i}>\right.$ $0)=\rho \sigma_{\epsilon} \lambda_{i} \cdot{ }^{10}$ Here $\rho$ is the correlation between unobserved factors that influence the propensity to work and the unobserved factors that influence the wage rate. Furthermore, $\lambda_{i}\left(z_{i}^{\prime} \gamma\right)=\frac{\phi\left(z_{i}^{\prime} \gamma\right)}{\Phi\left(z_{i}^{\prime} \gamma\right)}$ where $\phi\left(z_{i}^{\prime} \gamma\right)$ is the standard normal density function evaluated at $z_{i}^{\prime} \gamma$ from the estimated probit model. $\lambda$ is also called the Inverse Mills Ratio (Maddala 1983).

In order to calculate wages $\beta, \rho$ and $\sigma_{\epsilon}$ need to be estimated. By performing an OLS regression on the wage rate for those who are employed that includes the vector of $\lambda_{i}{ }^{\prime} \mathrm{s}, \lambda, \hat{\beta}$ and $\rho \hat{\sigma}_{\epsilon}$ can be estimated. ${ }^{11}$ As a result, $\rho$ can be recovered by dividing the estimated coefficient of $\lambda$ by the estimate of $\hat{\sigma}_{\epsilon}$

The error term from this OLS regression $(\hat{v})$ does not give an unbiased estimate of $\sigma_{\epsilon}$, as observed wages only provide a truncated distribution of wage rates. However, using the truncated variance formula of a left truncated normal distribution and where $N$ is the size of the sample gives:

$$
\hat{\sigma}_{\epsilon}=N^{-1} \sum_{i}^{N}\left[\hat{v}_{i}^{2}+\widehat{\rho \sigma}_{\epsilon} \hat{\lambda}_{i}\left(x_{i}^{\prime} \hat{\beta}+\hat{\lambda}_{i}\right)\right]
$$

\footnotetext{
10 This comes from the definition of the truncated normal distribution, the proof is shown in Mercante and Mok (2014b).

11 This is the value of $\sigma_{\epsilon u}$, or the covariance between the wage and employment equations, by definition.
} 
Give this error term, and with $\mathrm{E}\left(\epsilon_{i} \mid z_{i}^{\prime} \gamma+u_{i}<0\right)=-\rho \sigma_{\epsilon} \frac{\phi\left(z_{i}^{\prime} \gamma\right)}{1-\Phi\left(z_{i}^{\prime} \gamma\right)}$ the conditional wage estimates can be written as:

$$
\begin{gathered}
\mathrm{E}\left(w_{i} \mid E_{i}=1\right)=x_{i}^{\prime} \beta+\rho \sigma_{\epsilon} \lambda_{i} \\
\mathrm{E}\left(w_{i} \mid E_{i}=0\right)=x_{i}^{\prime} \beta-\rho \sigma_{\epsilon} \frac{\phi\left(z_{i}^{\prime} \gamma\right)}{1-\Phi\left(z_{i}^{\prime} \gamma\right)}
\end{gathered}
$$

As a result, equation (4.7) can be used to impute the wage of individuals who are out of work.

This is a clear way of viewing the problem, and is also the general method used in this chapter for imputing wages. However, it is not the method used in Guyonne Kalb and Rosanna Scutella (2003) and Mercante and Mok (2014a), as it is more efficient to solve equations (4.1) and (4.3) simultaneously via maximum likelihood (Cameron and Trivedi 2005).

Wooldridge (2010) points out that the key difference in assumptions between the two forms of estimation is that non-linear restrictions are imposed automatically on the structural parameters when the simultaneous estimation is used. Generally this is seen as a reasonable cost for the increase in estimation efficiency.

However, in this chapter the two-stage Heckman method is used due to concerns about heteroskedasticity in the data and the clarity the two-stage method gives for dealing with this issue.

Given the similarity of this method to instrumental variable estimation, an exclusion restriction is usually recommended. The household non-labour income variable provides this restriction, as it is included in the selection equation but not the wage equation. For couples dummy variables related to children and partners are also only in the selection equation. 
The estimates undertaken below are performed separately for different subsets of the data depending on sex and family type: Coupled Men (with or without children), Coupled Women (with or without children), Single Men (without children), Single Women (without children), and Sole Parents (Male or Female).

\subsubsection{Industry and Occupation imputation for those out of work}

Using the Heckman correction, the wage estimates that are derived are a function of a number of observed characteristics. All of these characteristics are observed for people in employment, but some of the characteristics are not observed for those who are not working.

Specifically, the HES data collects information on the industry and occupation of an individual's job. However, if someone is not working no industry or occupation is collected. As a result, in order to impute a wage for someone who is out of work the industry and occupation of that individual also needs to be imputed.

The solution used in Kalb and Scutella (2003) and Mercante and Mok $(2014 b)$ is to construct composite industry and occupation variables for the unemployed. These papers take HLFS survey data that captures the proportion of unemployed people who desire working in a given industry/occupation. This method of creating the composite industry via external data is recommended by Creedy et al. (2000).

In this chapter the proportion of employed people of that demographic group who are employed in that industry/occupation is used as the industry/occupation variable for imputing wages. The HLFS data was not used as it was not available for the entire time period of interest, and also because its quality as an indicator of job take up is dubious. The vast ma- 
jority of respondents to the HLFS survey did not give a preferred industry or occupation, suggesting that the real distribution also differs from this external data.

With unemployment/non-participation tending to be higher among those who would receive or accept wage offers from lower waged industries/occupations this form of imputation biases the wage estimate for those out of work upwards slightly.

\subsubsection{Correcting for heteroskedasticity in selection}

Whether estimating the two-step method or the bivariate sample selection model, a probit model is used to estimate the probability of being employed given the individuals characteristics. These estimates could be inconsistent if there is heteroskedasticity in the error term of the employment equation (Wooldridge 2010). ${ }^{12}$

In Creedy et al. (2000) the authors tested for heteroskedasticity in the selection equations for each group, and found that homoscedasticity was valid in each case. As a result, no adjustment was necessary. However, when performing specification tests on the New Zealand data heteroskedasticity was found in the majority of the selection equations.

To test for this potential source of bias a likelihood ratio test was performed for the difference between the parameters in the estimated employment model with heteroskedasticity adjusted standard errors and the model without this adjustment. If the parameter values differ in a statistically significant way, then the model likely suffers from heteroskedasticity. $^{13}$

\footnotetext{
${ }^{12}$ This differs from the fact the wage equation is heteroskedastic, as the wage equation is linear and is heteroskedastic by design.

${ }^{13}$ The test performed is a chi ${ }^{2}$ test comparing the hetprob estimate and the het estimate in Stata.
} 
In order to make estimation of the selection equation consistent it is necessary to incorporate the form of the heteroskedasticity into the likelihood function. ${ }^{14}$ No matter how large the dataset is, this is an issue for this modelling framework (Greene 2011).

To deal with the issue of heteroskedasticity the Heckman correction is used as defined above, but the initial probit equation estimated with using a heteroskedastic probit model as suggested by Gould (1998).

The hetprob command in Stata allows the estimation of a multiplicative form for the variance (Harvey 1976). Take a variance function $\sigma_{v}^{2}=\left\{\exp \left(g_{i} \theta\right)\right\}^{2}$, where $g_{i}$ is a vector of dependent variables and $\theta$ are the parameters. A multiplicative form of the variance assumes that the probability of employment can now be estimated as:

$$
P\left(E_{i}=1\right)=\Phi\left(\frac{z_{i}^{\prime} \gamma}{\sigma_{v}}\right)
$$

These corrected estimates of the selection equation lead to new estimates of the Inverse Mills Ratio, which is then fed into the linear estimator of the wage equation. On average this process led to a smaller Inverse Mills Ratio than the estimated model without taking into account heteroskedasticity. However, this was not always the case, with single men in the HES94-98 data reporting a larger Inverse Mills Ratio after adjustment. ${ }^{15}$

Estimated variance functions are given with the results.

\footnotetext{
14 This can be done automatically with the hetprob function in Stata in a conceptually similar way to weighted least squares using the set of variables that are believed to be causing the heteroskedasticity (Wooldridge 2014).

${ }^{15}$ A priori the test suggests there is a bias due to heteroskedasticity in the error term of the selection equation, but it is not clear what sign this bias would take.
} 


\subsection{Summary of wage equation results}

The estimation of the above wage equations gives an estimate of how certain observed individual characteristics are associated with the wage rate an individual earns.

Care needs to be taken when interpreting the table of coefficients, as is discussed in the Section 8. Below is a brief non-technical description of how different variables are related to the wage rate in the data and how this evolved through time.

The reason why certain periods were selected for a given wage and employment equation will also be discussed. The general goal when selecting the year groupings was to create periods with a similar amount of data, similar data reporting/definitions, and corresponding to a similar point in the economic cycle.

\subsubsection{HES88-93}

\section{Reason for year selection}

The period from April 1987 to March 1993 was a period of economic turmoil in New Zealand - with falling household incomes, climbing unemployment, and rapid structural change.

Annual GDP was only 0.3\% higher in the March 1993 year than it was in March 1988 while employment levels had fallen 6.1\%. The unemployment rate climbed from $4.2 \%$ to nearly $11 \%$ during this period - and was starting a gradual decline in the year to March 1993. As a result, the economic and labour market conditions during this five year period were significantly different from those that were experienced at other points in time in New Zealand. 


\section{Wage equation}

The wage and selection equation results can be seen in detail for single people without dependents in Table 4.4, sole parents in Table 4.5, and couples in Table 4.6.

For single people and couples the wage tended to rise with age (excluding any interaction with education level), albeit at a decreasing rate. The age premium peaks for those in their early 40's for the majority of the sample, consistent with Kalb and Scutella (2003). The peak was relatively consistent across most demographic groups, occurring at between 42 and 43 for everyone except sole parents - whose age wage premium peaked in their mid-60s. However, the age relationship for sole parents in this sample is statistically insignificant so the general age relationship for this demographic group in this time period is uncertain.

In terms of ethnicity, there is a significant wage penalty to non-Europeans during this time period for all demographic groups except sole parents. Higher levels of education also led to a higher wage for all demographic groups.

For both industry and occupation, the correspondences used for this period matched poorly, so any results must be treated with caution. Given this warning, the results are reported below.

Conditional on occupation and other characteristics, industry wages vary in a relatively consistent way by demographic group. The three industries offering statistically significantly higher wages than the reference industry across all demographic group (agriculture) were the transport, communications, and financial services industry. Excluding sole parents, manufacturing, construction, wholesale trade, professional services, and public administration also offered a premium. However, the retail and accommodation industries offered negative to no wage premium across demographic types. The largest wage premiums in the HES88-93 period were 
found for the communications and financial service industries.

Relative to the reference occupation (labourers) managers and professionals offer the largest wage premium. However, every occupation except sales offered higher wages across demographic groups during this period.

The Inverse Mills Ratio was negative for sole parents during this period. A negative ratio implies that, for given observed characteristics, someone who is out of work has a higher available wage than someone who is working. Although this is possible, it is generally not seen as credible. In this instance the Inverse Mills Ratio was not statistically different from zero and as a result this suggests that the existence of selection bias is rejected for sole parents during this period.

\section{Marginal effects}

Following Kalb and Scutella (2003) and Mercante and Mok (2014b), the wage premium for a number of characteristics for each subgroup is reported for a representative member of that group. Specifically, the premium for vocational education relative no formal education ${ }^{16}$ and residing in the North of the North Island ${ }^{17}$ relative to Auckland are reported for a 30 year old European. Finally the premium for various age groups are reported.

\footnotetext{
${ }^{16}$ In previous papers the comparison was with postgraduate education. Relative to these papers the results of this chapter showed a slightly higher wage premium for all groups, but the result that sole parents had a smaller premium remained. However, in HES94-98 the Single men estimates grouped together all graduate and post-graduate education. As a result, vocational education has been selected as a consistent benchmark between the years.

${ }^{17}$ This includes Northland, Waikato, Bay of Plenty, and Gisborne.
} 
Having a vocational qualification ${ }^{18}$ offered a significant wage premium for all demographic subgroups. Coupled women, single men, and single women all had an estimated wage premium over $20 \%(25 \%, 23 \%$, and $20 \%$ respectively). However, coupled men and sole parent also reported double digit premiums (17\% and 14\% respectively).

All demographic subgroups except sole parent reported a wage penalty for living outside of Auckland. Three of the groups had an estimated penalty that was statistically significant, coupled women $(8.7 \%)$, single women $(8.5 \%)$, and coupled men $(6.8 \%)$.

Apart from sole parents (whose age terms were statistically insignificant), the wage increase for a European with no formal education between the ages of 25 and 35 was substantial. Wage rates for single women and men increase by over two-thirds (rising by $74 \%$ and $68 \%$ respectively) while coupled men wages increase by a quarter. The estimated increase in coupled women wages was more modest $(8.3 \%)$.

However, the wage effect of age is non-linear. By the age of 45 wages were higher for each demographic subgroup, but the rate of increase between 35 and 45 was significantly lower than between 25 and 35 . The three largest increases were for single women, single men, and coupled men (up by $13 \%, 10 \%$, and $6.5 \%$ respectively).

\subsubsection{HES94-98}

\section{Reason for year selection}

The second period selected refers to the data between HES94 and HES98. As a result, this includes survey data from April 1993 to March 1998.

\footnotetext{
${ }^{18} \mathrm{~A}$ vocational qualification is when an individual has a highest qualification that is between Level 4 and Level 6 in the NZQA Qualifications Framework
} 
This period was selected to coincide with the strong lift in economic activity in New Zealand from the March 1994 year. Over the March 1994 year, annual GDP rose by $6.4 \%$. Activity increased by a further $16 \%$ (an average of $3.9 \%$ pa) between 1994 and 1998 .

Employment rose alongside economic activity - increasing 12\% between the March 1994 and March 1998 years. This saw the unemployment rate fall from $10 \%$ to $6.4 \%$ in 1997 - although this figure began to creep back up as the Asian Financial Crisis took hold in 1997/98.

\section{Wage equation}

The wage and selection equation results can be seen in detail for single people without dependents in Table 4.7, sole parents in Table 4.8, and couples in Table 4.9.

The age relationship to wages remained similar to HES88-93 during this period, with the average premium rising slightly for couples and single men. For sole parents the age structure switched to being more closely in line with other groups, with the average peak earning age in the early 40s. The peak age among single women declined in this period. The peak wage age for all coupled men and single women shifted out towards their mid-late 40s, while the peak stayed in the early 40s for coupled women and single men.

The ethnicity definition used in HES94-98 differed from that in HES8893. Previously ethnicity was split into three categories: Maori/Pacific, European, and Other. In this data the split is only into Maori/Pacific and Other. As a result, the ethnicity figures are not strictly comparable. For this new split there was a clear wage penalty for the Maori/Pacific subgroup amongst all demographic groupings.

The returns to additional education remained positive in the HES94-98 pe- 
riod. Furthermore, estimated returns rose for single people while staying broadly unchanged for couples.

By industry, communication and financial services remained the two industries with the largest wage premiums, followed by professional services and public administration.

Relative to agricultural work there remained a wage penalty for working in the retail and accommodation industries for coupled men and women. The education industry (introduced from the HES94-98 data set) also saw a wage penalty for all demographic types.

The large wage premium for managerial, professional, and personal service work remained in place in HES94-98. However, all occupations except machinery operating reported a wage premium above labouring during this period.

The Inverse Mills Ratio for single men was substantially larger than estimates for other periods, or for other demographic groups, in this wage equation. This was due to a high estimate for the correlation between unobserved covariates in the wage and selection equations, suggesting that an underlying determinant of selection was also influencing the wage available to single men. As this was a period with historically very high employment growth for this group this temporary change in the wage relationship is plausible.

\section{Marginal effects}

The wage premium associated with having a vocational qualification remained sizeable in HES94-98. Although only single men had an estimated premium over $20 \%(29 \%)$, sole parents, coupled women, and single women were all close to this threshold (with premiums of $19 \%, 19 \%$, and $17 \%$ respectively). The coupled men premium declined from HES88-93 
but was still $14 \%$.

The wage penalty for living outside Auckland remained for all demographic groups in HES94-98. For coupled women, coupled men, and single women the penalty declined from HES88-93 (to 6.1\%, 4.2\%, and 3.9\% respectively) while the sole parent penalty (6.9\%) was statistically insignificant. However, the single men penalty rose sharply to $12 \%$.

A ten year increase in age from 25-35 lead to a double-digit percentage lift in wages for all demographic subgroups in HES94-98. Single men reported by far the largest increase $(84 \%)$, while the estimated increase single women, coupled men, and sole parent was still over a quarter (38\%, $35 \%$, and $29 \%$ respectively). The wage increase was smallest for coupled women (14\%) but was still higher than the estimated increase in HES8893.

As in HES88-93, the wage increase between 35 and 45 was much lower than during the prior ten year age increase. However, the estimated wage premium for HES94-98 was slightly higher for all demographic subgroups than it had been in HES88-93.

\subsubsection{HES01-08}

\section{Reason for year selection}

The third period selected refers to the data between HES01 and HES08. As a result, this includes survey data from July 2000 to June 2008. Although the HES data was taken for a specific June year, there were not annual surveys during this period. As a result, the sample includes data from the HES01, HES04, HES07, and HES08 years.

This period was selected to coincide with the strong lift in economic activity in New Zealand following the Asian Financial Crisis. This is a longer 
time period than our other datasets, largely as a result of the sparse data available for this period. However, this also corresponds to an unusually long period of sustained economic growth - with GDP rising by at least 2.8\% each year between March 2001 and March 2008.

Strong growth in economic activity was matched by an average $2.6 \%$ pa increase in employment during this period. This saw the unemployment rate decline from $5.9 \%$ in 2001 to $3.6 \%$ in 2008 - while the labour force participation rate rose to historically high levels.

\section{Wage equation}

The wage and selection equation results can be seen in detail for single people without dependents in Table 4.10, sole parents in Table 4.11, and couples in Table 4.12.

The age premiums generally rose during the HES01-08 period. The age effect on wage peaked all demographic groups in their mid-40s.

Once again the ethnicity definition changed from the previous estimates. For the HES01-08 period people could report multiple ethnicities. As a result, the categories are set in line with the analysis used by Mercante and Mok (2014b) to allow for comparability. The four groups that are defined are: Maori/Pacific (some) $)^{19}$, Maori/Pacific (only) ${ }^{20}$, European, Other. The reference group in this case is European.

For all demographic groups, those that responded with Maori/Pacific (only) or Other had lower wages than the reference group. However, the results for Maori/Pacific (some) were more mixed.

\footnotetext{
${ }^{19}$ When an individual responds with a Maori/Pacific ethnicity and another ethnicity in their HES response.

${ }^{20}$ When an individual responds with only Maori/Pacific ethnicities in their HES response.
} 
Returns to education remained positive in the HES01-08 year, but the level of the wage premium for couples declined slightly from its HES94-98 level. Industry specific wage premiums remained large for financial services, professional services, and public administration during the HES01-08 period. However, among all groups the wage premium for working in the communications industry declined sharply. Wage premiums in the construction industry rose markedly during this period. The wage penalty for working in the retail and accommodation sectors held for both singles and couples during the HES01-08 period. However, the penalty for working in the education industry became statistically insignificant during this time.

Managerial and professional position continued to demand a significant wage premium in the HES01-08 period. The previous large premium for working in professional services largely disappeared for all demographic groups during this time. The wage premium (relative to working in a labouring job) for women in managerial and professional roles was significantly larger than for men during this period.

\section{Marginal effects}

The wage premium for vocational qualification dropped significantly for all groups except coupled men between the HES94-98 and HES01-08 estimates, with all other demographic subgroups reporting a premium between $11 \%$ and $13 \%$.

Even the increase in the wage premium for coupled men (to $18 \%$ ) was conditional on age, due to the premium declining with the age of the individual. By around 50 years of age the wage premium for vocational work was equivalent to that reported in the HES94-98 results.

The wage penalty for living outside Auckland increased in HES01-08, with 
a double-digit estimated percentage penalty for all demographic subgroups. The largest estimated penalty was for single women at $14 \%$. Single men were the only group who reported a lower penalty for living outside Auckland than in HES94-98 at 10\%.

In HES01-08, all demographic subgroups reported a sizeable wage premium for a ten year increase in age from 25 to 35 . Although the single men premium declined from the 1990s it remained the largest premium at $45 \%$. All subgroups had an estimated premium above $20 \%$, with coupled men also above $40 \%$ (43\%).

A smaller wage premium for a ten year increase in age from 35 to 45 persisted in HES01-08. Single men, sole parent, coupled men, and coupled women all had a higher estimated premium for this age increase than during the $1990 \mathrm{~s}(17 \%, 17 \%, 16 \%$, and $8.8 \%$ respectively). However, the single women premium declined to $7.5 \%$.

\subsubsection{HES09-13}

\section{Reason for year selection}

The final period chosen consists of survey data between HES09 and HES13. As a result, this refers to survey results from between July 2008 and June 2013. The final period captures the Global Financial Crisis, Canterbury Earthquakes, and the start of the recovery - although the labour market stayed persistently weak according to HES and HLFS non-employment measures during this period.

GDP declined 1.1\% in the March 2009 year as the combination of drought, tight monetary conditions, and the effects of the Global Financial Crisis took their tool. With global uncertainty persisting, and the 2010 and 2011 Canterbury Earthquakes taking place, the economy only grew at an average annual rate of 1.4\% pa between March 2009 and March 2013. 
The employment situation was relatively worse. In March 2013 employment was only $0.3 \%$ above its March 2009 level - a similarly anaemic performance when compared to employment growth in the first period of interest in HES88-93. However, this did not come with quite the same sharp lift in the unemployment rate - with the annual unemployment rate peaking at $6.3 \%$ in the March 2013 year. ${ }^{21}$ A mixture of net migration outflows, a reduction in labour force participation (from record high levels), and a relatively smaller decline in employment when the recession kicked off during the March 2009 year, had prevented a sharper lift in unemployment.

\section{Wage equation}

The wage and selection equation results can be seen in detail for single people without dependents in Table 4.13, sole parents in Table 4.14, and couples in Table 4.15.

The age premium declined for all age groups in the HES09-13 period. The age where wages peaked continued to move out for most groups, varying between 45 and 50 . The slight increase in the age where average wages peaked between 1988 and 2013 is consistent with the findings of Mercante and Mok (2014b). The wage penalty for Maori/Pacific (only) and Other ethnicity individuals persisted into the HES09-13 period.

The average wage premium for educational attainment remained at a similar level to prior years, but had become more strongly dependent on the age of the individual than it had previously. In prior years an increasing educational wage premium with age had been insignificant, but in HES0913 this relationship was strong and positive for all groups.

\footnotetext{
${ }^{21}$ Quarterly seasonally adjusted unemployment peaked at 6.7\% in September 2012 however, this figure appeared to be somewhat of an outlier and so annual averages are used to smooth out the result.
} 
By industry, the wage premiums remained strongest in financial services and public administration. The wage premium for professional services remained similar to HES01-08, with a larger premium for coupled people than singles. Communication industry wage premiums fell for most groups, but remained high for coupled men. The retail and accommodation industries continued to report a wage penalty for all demographic groups in HES09-13.

In terms of occupations, managerial and professional roles continued to pay a significant premium. The reduction in the personal services wage premium continued into HES09-13, falling to near zero for all groups except single men. The wage premium (relative to working in a labouring job) for women in managerial and professional roles remained significantly larger than for men during this period.

The Inverse Mills Ratio was negative for sole parents during this period. A negative ratio implies that, for given observed characteristics, someone who is out of work has a higher available wage than someone who is working. Although this is possible, it is generally not seen as credible. In this instance the Inverse Mills Ratio was not statistically different from zero and as a result this suggests that the existence of selection bias is rejected for sole parent is rejected during this period.

\section{Marginal effects}

Apart from sole parent (whose estimated premium fell below 10\%), the wage premium for a vocational qualification rose for each demographic subgroup in the HES09-13 estimates. Although the premium rose to its highest level of any time period for coupled men (reaching 19\%), the premium remained below its 1990s level for coupled women, single men, and single women (at $17 \%, 15 \%$, and $12 \%$ respectively).

In HES09-13, the wage penalty for living outside Auckland declined from 
HES01-08 for all demographic subgroups. The penalty was relatively consistent across subgroups, with the largest penalty reported for coupled men $(9.2 \%)$ and single men and sole parents with the lowest estimated penalty $(6.3 \%)$.

The age premium for then ten year increases from 25 and from 35 declined for all demographic subgroups in HES09-13.

The wage premium for coupled men and women declined back to the level recorded in HES94-98. However, for single people the premium fell to its lowest recorded level. Single women and men had an estimated premium of $23 \%$ and $21 \%$ respectively for the ten year increase between 25 and 35 , with a further $8.2 \%$ and $11 \%$ increase for the lift in age from 35 to 45. The wage premium for sole parents was statistically insignificant (5.3\% between 25 and 35).

\subsection{Predicted wages}

As well as providing an estimate of how certain observed individual characteristics are associated with the wage rate an individual earns the method described in Section 3 allows the imputation of wage rates for individuals who are not employed based upon their characteristics via equation (4.7). However, the conditional wage equations of (4.6) and (4.7) tend to give a distribution that is significantly narrower than the observed distribution of wages. As a result, a random disturbance term is added to reincorporate unobserved heterogeniety into individuals wage levels.

The addition of this random disturbance comes from the assumed relationship between the error terms from the employment equation $\left(u_{i}\right)$ and from the wage equation $\left(\epsilon_{i}\right)$. Given estimated values for $\rho$ and $\sigma_{\epsilon}$ take a random draw from this distribution and add it to the deterministic component of the wage equation calculated above. For someone in employment, 
with a random draw $v_{i}$ this gives the new wage equation as:

$$
\mathrm{E}\left(w_{i} \mid E_{i}=1\right)=x_{i}^{\prime} \beta+\rho \sigma_{\epsilon} \lambda_{i}+v_{i}
$$

However, these error terms are also conditional. If someone is observed in employment, then a random draw of $\epsilon_{i}$ cannot be selected as $v_{i}$ if it implies that $u_{i}<z_{i}^{\prime} \gamma$ (or that $E_{i}<0$ ). As a result, only error draws that continue to predict the observed employment status of the individual are accepted.

Even after adding this random disturbance back into the the wage prediction, the estimated wage distribution does remain narrower than the observed distribution for those in work.

Given this method, estimates for the average predicted wage condition on employment status can be made for each of the pooled years. The predicted wages are then deflated by the CPI to allow for comparison over time. These results are shown in Table 4.2. 
Table 4.2: Average predicted wage (2006 prices)

\begin{tabular}{|c|c|c|c|c|c|}
\hline & Coupled men & Coupled women & Single men & Single women & Sole Parent \\
\hline \multicolumn{6}{|c|}{ Employed observed } \\
\hline HES88-93 & $\$ 21.81$ & $\$ 17.34$ & $\$ 16.43$ & $\$ 15.78$ & $\$ 17.52$ \\
\hline HES94-98 & $\$ 21.56$ & $\$ 17.66$ & $\$ 16.29$ & $\$ 15.76$ & $\$ 16.84$ \\
\hline HES01-08 & $\$ 24.25$ & $\$ 20.57$ & $\$ 18.67$ & $\$ 18.09$ & $\$ 18.37$ \\
\hline HES09-13 & $\$ 28.68$ & $\$ 24.28$ & $\$ 20.82$ & $\$ 20.76$ & $\$ 22.20$ \\
\hline \multicolumn{6}{|c|}{ Employed predicted } \\
\hline HES88-93 & $\$ 21.62$ & $\$ 17.24$ & $\$ 16.21$ & $\$ 15.65$ & $\$ 17.34$ \\
\hline HES94-98 & $\$ 21.32$ & $\$ 17.45$ & $\$ 16.17$ & $\$ 15.63$ & $\$ 16.64$ \\
\hline HES01-08 & $\$ 23.83$ & $\$ 20.23$ & $\$ 18.22$ & $\$ 17.98$ & $\$ 18.24$ \\
\hline HES09-13 & $\$ 28.06$ & $\$ 23.83$ & $\$ 20.42$ & $\$ 20.40$ & $\$ 21.92$ \\
\hline \multicolumn{6}{|c|}{ Not employed } \\
\hline HES88-93 & $\$ 15.58$ & $\$ 13.47$ & $\$ 13.71$ & $\$ 12.83$ & $\$ 15.01$ \\
\hline HES94-98 & $\$ 15.98$ & $\$ 13.34$ & $\$ 7.03$ & $\$ 13.77$ & $\$ 12.69$ \\
\hline HES01-08 & $\$ 15.38$ & $\$ 15.14$ & $\$ 14.36$ & $\$ 14.09$ & $\$ 10.69$ \\
\hline HES09-13 & $\$ 22.44$ & $\$ 17.08$ & $\$ 17.02$ & $\$ 17.98$ & $\$ 19.65$ \\
\hline
\end{tabular}

\subsection{Comparison to previous estimates}

Relative to Kalb and Scutella (2003) and Mercante and Mok (2014b) all three sets of results reported above use the same underlying raw data and the same estimation techniques. As a result, estimates would only be expected to differ in these models due to:

- The difference in the time periods used for estimating each individual model - this is especially important if the relationship genuinely varies over time.

- Differences in the model selected.

- Differences in how the data was deflated.

- Differences in the treatment of the raw data.

- Differences in the occupation and industry placement of those who 
are not employed.

The estimates reported in Kalb and Scutella (2003) are deflated by an average wage index to the December 2001 quarter, while the estimates in Mercante and Mok (2014b) are deflated by an average wage index to the December 2011 quarter. $^{22}$ Similarly the estimates for each of the wage equations in this chapter is deflated by a wage index to make the data within that set of pooled years comparable for estimation.

When comparing estimates from different time periods, the real wage figures in Table 4.2 are calculated by transforming the estimated wages back to nominal wages, then deflating the estimated nominal wage series by CPI to the June 2006 quarter. $^{23}$ Deflating the results in Kalb and Scutella (2003) and Mercante and Mok (2014b) by CPI to June 2006 prices gives the following comparison table of average predicted wages:

\footnotetext{
${ }^{22}$ When estimating the models parameters, all three papers deflate wages by a wage index that is set to 1 at the quarters mentioned.

${ }^{23}$ In terms of the parameter values presented later, wages were deflated by average weekly earnings to the June 2006 quarter for all estimates - making the parameters comparable.
} 
Table 4.3: Average predicted wage (2006 prices)

\begin{tabular}{|c|c|c|c|c|c|}
\hline & Coupled men & Coupled women & Single men & Single women & Sole Parent \\
\hline \multicolumn{6}{|c|}{ Employed observed } \\
\hline K\&S (HES92-01) & $\$ 20.78$ & $\$ 17.43$ & $\$ 15.52$ & $\$ 13.77$ & $\$ 15.93$ \\
\hline Paper 92-01 avg & $\$ 21.96$ & $\$ 17.94$ & $\$ 16.62$ & $\$ 16.06$ & $\$ 17.20$ \\
\hline M\&M (HES07-11) & $\$ 28.29$ & $\$ 23.55$ & $\$ 20.63$ & $\$ 20.85$ & $\$ 21.82$ \\
\hline Paper $07-11$ avg & $\$ 26.91$ & $\$ 22.80$ & $\$ 19.96$ & $\$ 19.69$ & $\$ 20.67$ \\
\hline \multicolumn{6}{|c|}{ Employed } \\
\hline K\&S (HES92-01) & $\$ 20.81$ & $\$ 17.09$ & $\$ 15.63$ & $\$ 15.50$ & $\$ 15.98$ \\
\hline Paper 92-01 avg & $\$ 21.71$ & $\$ 17.75$ & $\$ 16.44$ & $\$ 15.93$ & $\$ 17.02$ \\
\hline M\&M (HES07-11) & $\$ 27.90$ & $\$ 23.35$ & $\$ 20.54$ & $\$ 20.59$ & $\$ 21.52$ \\
\hline Paper 07-11 avg & $\$ 26.37$ & $\$ 22.39$ & $\$ 19.54$ & $\$ 19.43$ & $\$ 20.45$ \\
\hline \multicolumn{6}{|c|}{ Not employed } \\
\hline K\&S (HES92-01) & $\$ 13.99$ & $\$ 12.62$ & $\$ 11.23$ & $\$ 11.01$ & $\$ 15.09$ \\
\hline Paper 92-01 avg & $\$ 15.81$ & $\$ 13.60$ & $\$ 9.62$ & $\$ 13.58$ & $\$ 13.02$ \\
\hline M\&M (HES07-11) & $\$ 17.39$ & $\$ 19.00$ & $\$ 22.42$ & $\$ 13.16$ & $\$ 11.57$ \\
\hline Paper 07-11 avg & $\$ 19.62$ & $\$ 16.30$ & $\$ 15.96$ & $\$ 16.42$ & $\$ 16.07$ \\
\hline
\end{tabular}

When it comes to the observed data there were slight differences. Both prior studies used the same definition for calculating the wage rate using current labour income. However, the way the data has been deflated creates a difference between the historic series. In this chapter the reported figures are taken from raw data at the date is is reported. It is this data that has been deflated by CPI to work out real wage figures in June 2006 prices.

The figures this chapter reports for the Mercante and Mok (2014b) result rely on averages from their paper, which were uprated by average weekly earnings to the December 2011 level. As earnings growth exceeded growth in consumer prices, this will push up the average value wages. ${ }^{24}$ Similarly, the [106] data was uprated by average earnings growth to the December

\footnotetext{
${ }^{24}$ During this period the CPI rose $11.9 \%$ while average weekly earnings from the QEX rose $20.6 \%$.
} 
2001 level, which will push down the average value of wages. ${ }^{25}$

However, even given this there is a significant gap between the observed single woman average wage used in this chapter and the value from Kalb and Scutella (2003). This gap is all the more surprising given that the imputed wages in both papers are fairly similar, and both papers work off the same underlying dataset.

There are also a smaller difference in the observed sole parent wage in the two papers. Here the definition of sole parent differed slightly in this chapter to Kalb and Scutella (2003). A sole parent in this analysis included anyone who did not report a partner in the same household - as a result, people saying they were in a defacto relationship with someone who was not in the household were coded as sole parents for this analysis. The reasoning for this is two-fold: Firstly, if the partner is not in the household it is less likely the individual will be supported in the standard way we would expect with an economic family unit. Secondly, if the partner is not in the household it is likely that the individual will be able to claim sole parent support benefits in the case where their work history allows it.

Relative to the Kalb and Scutella (2003) results, the wage available to couples and single women who are out of work is slightly higher than can be explained by differences in the data. However, single men and sole parent imputed wages are significantly lower.

The lower imputed wage for single men is predominantly due to a much higher Inverse Mills Ratio in the HES94-98 period in this chapter, due to a strong correlation between the unobserved elements of the selection and wage equations after the model is corrected for heteroskedasticity.

For most of the 1992-2001 period the estimates in this chapter impute

\footnotetext{
${ }^{25}$ During this period the CPI rose $12.4 \%$ while average weekly earnings from the QEX rose $17.7 \%$.
} 
wages for sole parents using a positive Inverse Mills Ratio. However, in Kalb and Scutella (2003) a negative Inverse Mills Ratio was reported. This difference explains the fact that the imputed wage for sole parents in this chapter are lower during this period.

Compared to the Mercante and Mok (2014b) estimates, coupled men, single women, and sole parents have a higher imputed wage while coupled women and single men have a lower imputed wage. The results in this chapter have a relatively more stable Inverse Mills Ratio between groups than the Mercante and Mok (2014b), as a result the ratio of the wage available to employed vs not employed individuals is more stable.

Furthermore, even though a negative Inverse Mills Ratio is recorded for sole parents during this period the available wage for this group is still lower given the characteristics of the individuals who are out of employment - as compared to the single men result in Mercante and Mok (2014b) where the average wage rate is higher for those that are out of work.

If heteroskedasticity was not corrected for in these estimates then similar extreme swings in the Inverse Mills Ratio were found for the data used in this chapter. This implies that the relative stability of the estimates found in this chapter come from correcting for heteroskedasticity in the selection equation which existed in the dataset.

\subsection{Conclusion}

In this chapter wage equations for five demographic groups were estimated for four separate sets of years with the goal of inputing the wage rate available to people who were out of work between 1988 and 2013. These estimates corrected for selection bias and allow for heteroskedasticity in the selection equation thereby providing improved estimates of the imputed wage for this period. 
Relative to prior estimates for New Zealand imputed wages were higher for coupled men and single women and lower for single men. The implied growth in wages available for not employed coupled women was softer than previously found, while the estimated decline in available wages for not employed sole parents was reversed.

Additionally, this exercise outlines how the wage generating process changed between 1988 and 2013.

The age premium for all demographic groups rose and then fell for all demographic over the 1988-2013 period. The peak premium was roughly unchanged for coupled individuals, but declined for single men and women. The age associated with the largest wage premium rose over time for all demographic groups, increasing from the early 40 s to the late 40 s.

Financial services, professional services and public administration paid a wage premium above agricultural work throughout the period of interest. However, the premium in the communication industry declined sharply. A wage penalty was found in the retail and accommodation industries across time.

Managerial and professional roles had a consistent wage premium across demographic groups over time. However, couple and single women saw their wage premium for these roles rise during the 2000s. The large wage premium that existed for personal services at the start of this time period had all but disappeared by HES09-13. 


\subsection{Tables}

\subsubsection{Reading the tables}

In the estimation process two variables are solved for - the natural logarithm of hourly wages and employment status. However, when evaluating the parameters it is important to keep in mind that there are interaction terms for age, qualification, and ethnicity. As a result, the parameters do not generally refer to the estimated marginal effect on the dependent variable on the independent variable.

When comparing the results, and any interpretation regarding the impact of a given variable (eg qualification) on wages it is important to keep in mind the importance of interaction terms.

For example, in both the following results and prior estimates performed by Kalb and Scutella (2003) and Mercante and Mok (2014b) the coefficient on high levels of education (NCEA Level 7 and above) is often negative. However, this does not in of itself suggest that high levels of education lead to lower wages - as there are interaction terms which also capture the return to education in association with other variables (eg age) .

What does this mean? Take into account a qualification levels interaction with age. Generally, the return to education will rise as a person ages given that:

1. Age is a proxy for experience and their additional returns associated with the combination of education and experience.

2. People who have invested in education have sacrificed several years of work. Assuming that wages rise at a diminishing rate with years of experience this experience gap implies a similar pattern would be observed. 
In this way, the combination of education + education*age represents the non-linearity inherent in the returns to education - and the parameters alone be interpreted sensibly individually.

Furthermore age is always positive, and so if a qualification level was positively associated with wages and everyone was the same age then we would have perfect multicollinearity. Although age varies, it is possible that the coefficient on a given qualification level will be poorly identified due to this relationship and so the individual parameters should not be used in isolation.

More generally, when considering what a variable represents it is important to remember the change in wages associated with it is conditional on all the other variables in the model. For example, the change in wages associated with a degree are conditional on the industry and occupation worked. However, in order to work in a given industry and occupation the individual may require that level of education - as a result we cannot always look at these parameter estimates in isolation.

Relative to previous literature this chapter makes less use of interaction terms, as they tended to significantly increase standard errors of the parameters precision without significantly improving the fit of the model indicating a risk of overfitting.

Finally note that the $\mathrm{R}^{2}$ of the wage equations and the pseudo- $\mathrm{R}^{226}$ of the selection equations are relatively low, while the assumptions about the error terms required to causally interpret the model are likely to be unre-

\footnotetext{
${ }^{26}$ The McFadden pseudo- $\mathrm{R}^{2}$ is used as a measure of goodness of fit for the probit selection model McFadden (1974). A common rule of thumb for such models is that a value between 0.2 and 0.4 suggests good model fit.
} 
alistic. $^{27}$

Due to the limitations to interpretation, the main purpose of the estimation exercise undertaken in this chapter is to impute wages for those who are out of work, not to provide estimates of how certain factors determine the wage rate.

\footnotetext{
${ }^{27}$ In prior papers only a pseudo- $\mathrm{R}^{2}$, as the wage and selection equations are estimated simultaneously. The process used in this chapter is sequential, and so the $\mathrm{R}^{2}$ refers to the wage equation while the pseudo- $\mathrm{R}^{2}$ refers to only the selection equation - and so is not comparable to those from earlier New Zealand wage equation estimates.
} 


\subsubsection{HES88-93}

Table 4.4: Single people without children: HES88-93

\begin{tabular}{|c|c|c|c|c|c|c|c|c|}
\hline \multicolumn{5}{|c|}{ Wage Equation } & \multicolumn{4}{|c|}{ Selection Equation } \\
\hline & \multicolumn{2}{|c|}{ Single men } & \multicolumn{2}{|c|}{ Single women } & \multicolumn{2}{|c|}{ Single men } & \multicolumn{2}{|c|}{ Single women } \\
\hline & Coefficient & P-value & Coefficient & P-value & Coefficient & P-value & Coefficient & $\mathrm{P}$-value \\
\hline Age $\div 10$ & 0.681 & 0.000 & 0.696 & 0.000 & 0.390 & 0.006 & 1.175 & 0.000 \\
\hline Age $^{2} \div 100$ & -0.082 & 0.000 & -0.083 & 0.000 & -0.058 & 0.004 & -0.175 & 0.000 \\
\hline \multicolumn{9}{|c|}{ Highest Qualification attained (reference group less than NZCA level 1 completion) } \\
\hline Level 1-3 & 0.079 & 0.000 & 0.128 & 0.000 & 0.431 & 0.000 & 0.596 & 0.000 \\
\hline Level 4-6 & 0.203 & 0.000 & 0.185 & 0.000 & 0.542 & 0.000 & 0.696 & 0.000 \\
\hline Level 7 & 0.316 & 0.000 & 0.286 & 0.000 & 0.622 & 0.000 & 0.518 & 0.000 \\
\hline Postgraduate & 0.385 & 0.000 & 0.337 & 0.000 & 0.558 & 0.004 & 0.756 & 0.001 \\
\hline Other & 0.249 & 0.000 & 0.185 & 0.000 & 0.384 & 0.071 & 0.352 & 0.078 \\
\hline \multicolumn{9}{|c|}{ Ethnicity (reference group European) } \\
\hline Maori/Pacific & -0.034 & 0.174 & -0.104 & 0.000 & -0.500 & 0.000 & -0.544 & 0.000 \\
\hline Other Ethnicity & -0.066 & 0.059 & -0.086 & 0.036 & -0.090 & 0.489 & -0.355 & 0.026 \\
\hline \multicolumn{9}{|c|}{ Region (reference group is Auckland) } \\
\hline North North Island & -0.031 & 0.159 & -0.089 & 0.000 & -0.269 & 0.000 & -0.162 & 0.051 \\
\hline Central North Island & -0.092 & 0.000 & -0.100 & 0.000 & -0.202 & 0.012 & -0.093 & 0.307 \\
\hline Wellington & 0.061 & 0.004 & 0.026 & 0.135 & 0.194 & 0.041 & 0.235 & 0.011 \\
\hline Canterbury & -0.031 & 0.178 & -0.069 & 0.003 & 0.148 & 0.104 & 0.000 & 1.000 \\
\hline Rest of South Island & -0.067 & 0.001 & -0.090 & 0.000 & -0.099 & 0.199 & -0.190 & 0.033 \\
\hline
\end{tabular}

${ }^{28} \mathrm{chi}^{2}$ statistic reported. Calculated through hetprobit in Stata for unadjusted model. 


\section{Single people without children: HES88-93 (continued}

\begin{tabular}{|c|c|c|c|c|c|c|c|c|}
\hline \multicolumn{5}{|c|}{ Wage Equation } & \multicolumn{4}{|c|}{ Selection Equation } \\
\hline & \multicolumn{2}{|c|}{ Single men } & \multicolumn{2}{|c|}{ Single women } & \multicolumn{2}{|c|}{ Single men } & \multicolumn{2}{|c|}{ Single women } \\
\hline & Coefficient & P-value & Coefficient & $\mathrm{P}$-value & Coefficient & $\mathrm{P}$-value & Coefficient & $\mathrm{P}$-value \\
\hline \multicolumn{9}{|c|}{ Industry (reference group is Agriculture or ANZSIC 2006 A) } \\
\hline Mining & -0.126 & 0.001 & -0.111 & 0.044 & - & - & - & - \\
\hline Manufacturing & 0.089 & 0.002 & 0.135 & 0.000 & - & - & - & - \\
\hline Construction & 0.077 & 0.020 & 0.145 & 0.001 & - & - & - & - \\
\hline Wholesale Trade & 0.108 & 0.010 & 0.178 & 0.000 & - & - & - & - \\
\hline Retail Trade & -0.015 & 0.660 & 0.008 & 0.820 & - & - & - & - \\
\hline Accommodation & -0.041 & 0.362 & 0.091 & 0.023 & - & - & - & - \\
\hline Transport & 0.112 & 0.003 & 0.266 & 0.000 & - & - & - & - \\
\hline Communication & 0.204 & 0.000 & 0.214 & 0.000 & - & - & - & - \\
\hline Financial Services & 0.163 & 0.000 & 0.238 & 0.000 & - & - & - & - \\
\hline Professional Services & 0.090 & 0.024 & 0.189 & 0.000 & - & - & - & - \\
\hline Public Administration & 0.111 & 0.002 & 0.216 & 0.000 & - & - & - & - \\
\hline Education & - & - & - & - & - & - & - & - \\
\hline Health & 0.032 & 0.424 & 0.150 & 0.000 & - & - & - & - \\
\hline \multicolumn{9}{|c|}{ Occupation (reference group is Labourers } \\
\hline Manager & 0.197 & 0.000 & 0.183 & 0.000 & - & - & - & - \\
\hline Professional & 0.206 & 0.000 & 0.242 & 0.000 & - & - & - & - \\
\hline Technical Worker & 0.073 & 0.000 & 0.048 & 0.122 & - & - & - & - \\
\hline Personal Services & 0.138 & 0.000 & 0.099 & 0.006 & - & - & - & - \\
\hline Administration & 0.101 & 0.000 & 0.048 & 0.134 & - & - & - & - \\
\hline Sales & -0.011 & 0.723 & 0.036 & 0.403 & - & - & - & - \\
\hline Machine Operator & 0.054 & 0.031 & 0.101 & 0.005 & - & - & - & - \\
\hline \multicolumn{9}{|c|}{ Other variables } \\
\hline Year (trend) & -0.013 & 0.279 & 0.011 & 0.317 & 0.007 & 0.874 & -0.056 & 0.213 \\
\hline Unemployment Rate & -0.013 & 0.149 & -0.019 & 0.084 & 0.001 & 0.974 & 0.074 & 0.078 \\
\hline Constant & 1.551 & 0.000 & 1.380 & 0.000 & -0.156 & 0.550 & -1.655 & 0.000 \\
\hline $\begin{array}{l}\text { Hhld Non-labour in- } \\
\text { come }(\$ 000)\end{array}$ & - & - & - & - & -1.722 & 0.000 & -1.365 & 0.017 \\
\hline \multicolumn{9}{|c|}{ Variance function } \\
\hline $\begin{array}{l}\text { Hhld Non-labour in- } \\
\text { come }(\$ 000)\end{array}$ & - & - & - & - & 0.906 & 0.000 & 1.694 & 0.030 \\
\hline \multicolumn{9}{|c|}{ Model evaluation } \\
\hline Mills Ratio & 0.051 & 0.079 & 0.023 & 0.376 & - & - & - & - \\
\hline R-squared & 0.419 & - & 0.450 & - & - & - & - & - \\
\hline Pseudo R-squared & - & - & - & - & 0.076 & - & 0.122 & - \\
\hline $\begin{array}{l}\text { LR test for Het- } \\
\text { eroskedasticity }{ }^{28}\end{array}$ & - & - & - & - & 85.00 & 0.00 & 99.32 & 0.00 \\
\hline
\end{tabular}


Table 4.5: Sole parent: HES88-93

\begin{tabular}{|c|c|c|c|c|}
\hline & \multicolumn{2}{|c|}{$\begin{array}{c}\text { Wage Equation } \\
\text { Sole parent }\end{array}$} & \multicolumn{2}{|c|}{$\begin{array}{c}\text { Selection Equation } \\
\text { Sole parent }\end{array}$} \\
\hline & Coefficient & P-value & Coefficient & P-value \\
\hline Age $\div 10$ & 0.013 & 0.945 & 1.199 & 0.000 \\
\hline Age $^{2} \div 100$ & -0.001 & 0.965 & -0.151 & 0.000 \\
\hline Woman & -0.200 & 0.000 & -0.167 & 0.119 \\
\hline \multicolumn{5}{|c|}{ Highest Qualification attained (reference - less than NCEA level 1) } \\
\hline Level 1-3 & 0.088 & 0.056 & 0.433 & 0.000 \\
\hline Level 4-6 & 0.131 & 0.052 & 0.693 & 0.000 \\
\hline Level 7 & 0.149 & 0.076 & 0.709 & 0.000 \\
\hline Postgraduate & 0.152 & 0.190 & 1.408 & 0.000 \\
\hline Other & 0.101 & 0.317 & 0.756 & 0.005 \\
\hline \multicolumn{5}{|c|}{ Ethnicity (reference group European) } \\
\hline Maori/Pacific & -0.010 & 0.842 & -0.286 & 0.001 \\
\hline Other Ethnicity & -0.013 & 0.889 & -0.101 & 0.632 \\
\hline \multicolumn{5}{|c|}{ Children } \\
\hline Number of children & - & - & -0.009 & 0.826 \\
\hline Youngest Age $=0$ & - & - & -1.107 & 0.000 \\
\hline Youngest Age 1-3 & - & - & -0.814 & 0.000 \\
\hline Youngest Age 4-5 & - & - & -0.666 & 0.000 \\
\hline Youngest Age 6-9 & - & - & -0.532 & 0.000 \\
\hline Youngest Age 10-12 & - & - & -0.086 & 0.456 \\
\hline \multicolumn{5}{|c|}{ Industry (reference group is Agriculture or ANZSIC 2006 A) } \\
\hline Mining & -0.021 & 0.838 & - & - \\
\hline Manufacturing & 0.077 & 0.243 & - & - \\
\hline Construction & -0.017 & 0.858 & - & - \\
\hline Wholesale Trade & 0.020 & 0.861 & - & - \\
\hline Retail Trade & -0.134 & 0.066 & - & - \\
\hline Accommodation & 0.065 & 0.444 & - & - \\
\hline Transport & 0.253 & 0.015 & - & - \\
\hline Communication & 0.517 & 0.001 & - & - \\
\hline Financial Services & 0.227 & 0.032 & - & - \\
\hline Professional Services & 0.127 & 0.104 & - & - \\
\hline Public Administration & 0.166 & 0.025 & - & - \\
\hline Education & - & - & - & - \\
\hline Health & 0.130 & 0.028 & - & - \\
\hline
\end{tabular}


Sole parent: HES88-93 (continued)

\begin{tabular}{|c|c|c|c|c|}
\hline & \multicolumn{2}{|c|}{$\begin{array}{c}\text { Wage Equation } \\
\text { Sole parent }\end{array}$} & \multicolumn{2}{|c|}{$\begin{array}{c}\text { Selection Equation } \\
\text { Sole parent }\end{array}$} \\
\hline & Coefficient & P-value & Coefficient & P-value \\
\hline \multicolumn{5}{|c|}{ Occupation (reference group is Labourer) } \\
\hline Manager & 0.428 & 0.000 & - & - \\
\hline Professional & 0.430 & 0.000 & - & - \\
\hline Technical Worker & 0.118 & 0.070 & - & - \\
\hline Personal Services & 0.196 & 0.009 & - & - \\
\hline Administration & 0.085 & 0.191 & - & - \\
\hline Sales & 0.248 & 0.002 & - & - \\
\hline Machine Operator & 0.123 & 0.110 & - & - \\
\hline \multicolumn{5}{|c|}{ Region (reference group is Auckland) } \\
\hline North North Island & 0.036 & 0.453 & -0.128 & 0.205 \\
\hline Central North Island & -0.081 & 0.126 & -0.224 & 0.042 \\
\hline Wellington & 0.004 & 0.938 & 0.325 & 0.007 \\
\hline Canterbury & -0.065 & 0.203 & 0.003 & 0.980 \\
\hline Rest of South Island & -0.092 & 0.094 & 0.001 & 0.994 \\
\hline \multicolumn{5}{|c|}{ Other variables } \\
\hline Year (trend) & -0.057 & 0.018 & 0.044 & 0.424 \\
\hline Unemployment Rate & 0.027 & 0.220 & 0.009 & 0.854 \\
\hline Constant & 3.435 & 0.000 & -2.918 & 0.000 \\
\hline $\begin{array}{l}\text { Hhld Non-labour in- } \\
\text { come }(\$ 000)\end{array}$ & - & - & 0.268 & 0.098 \\
\hline Living with parents & - & - & -0.126 & 0.761 \\
\hline \multicolumn{5}{|c|}{ Model evaluation } \\
\hline Mills Ratio & -0.086 & 0.276 & - & - \\
\hline R-squared & 0.386 & - & - & - \\
\hline Pseudo R-squared & - & - & 0.194 & - \\
\hline $\begin{array}{l}\text { LR test for Het- } \\
\text { eroskedasticity }\end{array}$ & - & - & NA & NA \\
\hline
\end{tabular}


Table 4.6: Coupled people: HES88-93

\begin{tabular}{|c|c|c|c|c|c|c|c|c|}
\hline & \multicolumn{4}{|c|}{ Wage Equation } & \multicolumn{4}{|c|}{ Selection Equation } \\
\hline & \multicolumn{2}{|c|}{ Coupled men } & \multicolumn{2}{|c|}{ Coupled women } & \multicolumn{2}{|c|}{ Coupled men } & \multicolumn{2}{|c|}{ Coupled women } \\
\hline & Coefficient & $\mathrm{P}$-value & Coefficient & P-value & Coefficient & $\mathrm{P}$-value & Coefficient & P-value \\
\hline Age $\div 10$ & 0.381 & 0.000 & 0.206 & 0.000 & 1.230 & 0.000 & 1.494 & 0.000 \\
\hline Age $^{2} \div 10$ & -0.044 & 0.000 & -0.025 & 0.000 & -0.168 & 0.000 & -0.220 & 0.000 \\
\hline \multicolumn{9}{|c|}{ Highest Qualification attained (reference group less than NCEA level 1 completion) } \\
\hline Level 1-3 & 0.112 & 0.000 & 0.108 & 0.000 & 0.496 & 0.000 & 0.328 & 0.000 \\
\hline Level 4-6 & 0.192 & 0.000 & 0.225 & 0.000 & 0.616 & 0.000 & 0.641 & 0.000 \\
\hline Level 7 & 0.179 & 0.017 & 0.360 & 0.000 & 0.993 & 0.000 & 0.579 & 0.014 \\
\hline Postgraduate & 0.034 & 0.779 & 0.461 & 0.000 & 1.589 & 0.000 & 1.085 & 0.000 \\
\hline Other & 0.254 & 0.000 & 0.301 & 0.000 & 0.648 & 0.021 & 0.782 & 0.000 \\
\hline Postgrad $\times$ age $\div 10$ & 0.116 & 0.000 & - & - & - & - & - & - \\
\hline Level $7 \times$ age $\div 10$ & 0.036 & 0.058 & - & - & - & - & - & - \\
\hline Level $4-6 \times$ age $\div 10$ & -0.012 & 0.275 & - & - & - & - & - & - \\
\hline Postgrad Maori/Pacific & -0.000 & 1.000 & - & - & - & - & - & - \\
\hline Level 7 Maori/Pacific & - & - & - & - & - & - & - & - \\
\hline Level 4-6 Maori/Pacific & 0.002 & 0.958 & - & - & - & - & - & - \\
\hline $\begin{array}{l}\text { Postgrad Other Ethnic- } \\
\text { ity }\end{array}$ & -0.061 & 0.272 & - & - & - & - & - & - \\
\hline Level 7 Other Ethnicity & - & - & - & - & - & - & - & - \\
\hline $\begin{array}{l}\text { Level 4-6 Other Ethnic- } \\
\text { ity }\end{array}$ & 0.025 & 0.725 & - & - & - & - & - & - \\
\hline \multicolumn{9}{|c|}{ Ethnicity (reference group European) } \\
\hline Maori/Pacific & -0.096 & 0.019 & -0.072 & 0.000 & -0.341 & 0.000 & -0.016 & 0.806 \\
\hline Other Ethnicity & -0.130 & 0.003 & -0.095 & 0.004 & -0.342 & 0.044 & -0.408 & 0.001 \\
\hline \multicolumn{9}{|c|}{ Children } \\
\hline Number of children & - & - & - & - & -0.082 & 0.023 & -0.040 & 0.139 \\
\hline Youngest age $=0$ & - & - & - & - & -0.043 & 0.760 & -2.041 & 0.000 \\
\hline Youngest age 1-3 & - & - & - & - & -0.072 & 0.574 & -1.453 & 0.000 \\
\hline Youngest age 4-5 & - & - & - & - & 0.026 & 0.867 & -1.196 & 0.000 \\
\hline Youngest age 6-9 & - & - & - & - & -0.141 & 0.321 & -0.530 & 0.000 \\
\hline Youngest age 10-12 & - & - & - & - & 0.045 & 0.770 & -0.132 & 0.169 \\
\hline Youngest age $13+$ & - & - & - & - & -0.108 & 0.406 & 0.173 & 0.055 \\
\hline \multicolumn{9}{|c|}{ Industry (reference group is Agriculture or ANZSIC 2006 A) } \\
\hline Mining & -0.033 & 0.271 & -0.073 & 0.055 & - & - & - & - \\
\hline Manufacturing & 0.115 & 0.000 & 0.044 & 0.091 & - & - & - & - \\
\hline Construction & 0.100 & 0.000 & 0.158 & 0.000 & - & - & - & - \\
\hline Wholesale Trade & 0.086 & 0.007 & 0.187 & 0.000 & - & - & - & - \\
\hline Retail Trade & -0.103 & 0.000 & -0.008 & 0.775 & - & - & - & - \\
\hline Accommodation & -0.275 & 0.000 & -0.097 & 0.002 & - & - & - & - \\
\hline Transport & 0.160 & 0.000 & 0.186 & 0.000 & - & - & - & - \\
\hline Communication & 0.255 & 0.000 & 0.229 & 0.000 & - & - & - & - \\
\hline Financial Services & 0.275 & 0.000 & 0.209 & 0.000 & - & - & - & - \\
\hline Professional Services & 0.218 & 0.000 & 0.181 & 0.000 & - & - & - & - \\
\hline Public Administration & 0.186 & 0.000 & 0.199 & 0.000 & - & - & - & - \\
\hline Education & - & - & - & - & - & - & - & - \\
\hline Health & 0.005 & 0.858 & 0.111 & 0.000 & - & - & - & - \\
\hline
\end{tabular}


Coupled people: HES88-93 (continued)

\begin{tabular}{|c|c|c|c|c|c|c|c|c|}
\hline & \multicolumn{4}{|c|}{ Wage Equation } & \multicolumn{4}{|c|}{ Selection Equation } \\
\hline & \multicolumn{2}{|c|}{ Coupled men } & \multicolumn{2}{|c|}{ Coupled women } & \multicolumn{2}{|c|}{ Coupled men } & \multicolumn{2}{|c|}{ Coupled women } \\
\hline & Coefficient & P-value & Coefficient & P-value & Coefficient & P-value & Coefficient & P-value \\
\hline \multicolumn{9}{|c|}{ Occupation (reference group is Labourer) } \\
\hline Manager & 0.235 & 0.000 & 0.234 & 0.000 & - & - & - & - \\
\hline Professional & 0.300 & 0.000 & 0.244 & 0.000 & - & - & - & - \\
\hline Technical Worker & 0.153 & 0.000 & 0.097 & 0.000 & - & - & - & - \\
\hline Personal Services & 0.196 & 0.000 & 0.132 & 0.000 & - & - & - & - \\
\hline Administration & 0.078 & 0.000 & 0.084 & 0.000 & - & - & - & - \\
\hline Sales & 0.038 & 0.159 & 0.053 & 0.087 & - & - & - & - \\
\hline Machine Operator & 0.095 & 0.000 & 0.110 & 0.000 & - & - & - & - \\
\hline \multicolumn{9}{|c|}{ Region (reference group is Auckland) } \\
\hline North North Island & -0.070 & 0.000 & -0.091 & 0.000 & -0.324 & 0.001 & -0.119 & 0.051 \\
\hline Central North Island & -0.090 & 0.000 & -0.080 & 0.000 & -0.304 & 0.003 & -0.029 & 0.651 \\
\hline Wellington & 0.044 & 0.006 & 0.012 & 0.480 & 0.080 & 0.455 & 0.120 & 0.073 \\
\hline Canterbury & -0.109 & 0.000 & -0.066 & 0.000 & 0.058 & 0.595 & -0.019 & 0.780 \\
\hline Rest of South Island & -0.079 & 0.000 & -0.092 & 0.000 & -0.048 & 0.648 & -0.022 & 0.739 \\
\hline \multicolumn{9}{|c|}{ Other variables } \\
\hline Year (trend) & -0.023 & 0.011 & -0.000 & 1.000 & -0.045 & 0.405 & -0.075 & 0.027 \\
\hline Unemployment Rate & -0.005 & 0.405 & -0.005 & 0.532 & 0.043 & 0.270 & 0.226 & 0.000 \\
\hline Constant & 2.141 & 0.000 & 2.203 & 0.000 & -1.495 & 0.012 & -3.668 & 0.000 \\
\hline $\begin{array}{l}\text { Hhld Non-labour in- } \\
\text { come (thousands) }\end{array}$ & - & - & - & - & -0.139 & 0.006 & -0.317 & 0.004 \\
\hline Partner participation & _ & - & - & - & 0.308 & 0.029 & 0.719 & 0.000 \\
\hline $\begin{array}{l}\text { Partner income (thou- } \\
\text { sands) }\end{array}$ & - & - & - & - & 2.799 & 0.001 & -0.166 & 0.000 \\
\hline \multicolumn{9}{|c|}{ Variance Function } \\
\hline Age $\div 10$ & - & - & - & - & 0.087 & 0.007 & 0.121 & 0.000 \\
\hline $\begin{array}{l}\text { Hhld Non-labour in- } \\
\text { come (thousands) }\end{array}$ & - & - & - & - & 1.084 & 0.000 & 0.162 & 0.043 \\
\hline Partner participation & - & - & - & - & - & - & -0.229 & 0.002 \\
\hline \multicolumn{9}{|c|}{ Model evaluation } \\
\hline Mills Ratio & 0.085 & 0.002 & 0.066 & 0.000 & - & - & - & - \\
\hline R-squared & 0.324 & - & 0.261 & - & - & - & - & - \\
\hline Pseudo R-squared & - & - & - & - & 0.075 & - & 0.183 & - \\
\hline $\begin{array}{l}\text { LR test for Het- } \\
\text { eroskedasticity }\end{array}$ & - & - & - & - & 237.49 & 0.000 & 152.21 & 0.000 \\
\hline
\end{tabular}




\subsubsection{HES94-98}

Table 4.7: Single people without children: HES94-98

\begin{tabular}{|c|c|c|c|c|c|c|c|c|}
\hline & \multicolumn{4}{|c|}{ Wage Equation } & \multicolumn{4}{|c|}{ Selection Equation } \\
\hline & \multicolumn{2}{|c|}{ Single men } & \multicolumn{2}{|c|}{ Single women } & \multicolumn{2}{|c|}{ Single men } & \multicolumn{2}{|c|}{ Single women } \\
\hline & Coefficient & P-value & Coefficient & P-value & Coefficient & P-value & Coefficient & P-value \\
\hline Age $\div 10$ & 0.741 & 0.000 & 0.460 & 0.000 & 0.698 & 0.000 & 1.696 & 0.001 \\
\hline Age $^{2} \div 100$ & -0.089 & 0.000 & -0.051 & 0.000 & -0.109 & 0.000 & -0.223 & 0.000 \\
\hline \multicolumn{9}{|c|}{ Highest Qualification attained (reference group less than NCEA level 1 completion) } \\
\hline Level 1-3 & 0.187 & 0.000 & 0.094 & 0.000 & 0.634 & 0.000 & 0.993 & 0.000 \\
\hline Level 4-6 & 0.256 & 0.000 & 0.159 & 0.005 & 0.734 & 0.000 & 1.225 & 0.000 \\
\hline Level 7 & 0.395 & 0.000 & -0.014 & 0.846 & 0.737 & 0.000 & 1.111 & 0.000 \\
\hline Postgraduate & - & - & -0.083 & 0.545 & - & - & 1.692 & 0.003 \\
\hline Other & 0.157 & 0.000 & 0.162 & 0.016 & 0.416 & 0.083 & 0.745 & 0.022 \\
\hline Postgrad $\times$ age $\div 10$ & - & - & 0.118 & 0.000 & - & - & - & - \\
\hline Level $7 \times$ age $\div 10$ & - & - & 0.082 & 0.000 & - & - & - & - \\
\hline Level $4-6 \times$ age $\div 10$ & - & - & 0.000 & 1.000 & - & _- & - & - \\
\hline Postgrad Maori/Pacific & - & - & -0.040 & 0.674 & _- & - & - & - \\
\hline Level 4-6 Maori/Pacific & - & - & 0.035 & 0.572 & _- & - & - & - \\
\hline Postgraduate Other & - & - & 0.131 & 0.373 & _- & - & - & - \\
\hline Level 4-6 Other & - & - & -0.963 & 0.001 & - & - & - & - \\
\hline \multicolumn{9}{|c|}{ Ethnicity (reference group Non-Maori/Pacific) } \\
\hline Maori/Pacific & -0.084 & 0.011 & -0.037 & 0.233 & -0.519 & 0.000 & -0.609 & 0.001 \\
\hline \multicolumn{9}{|c|}{ Industry (reference group is Agriculture or ANZSIC 2006 A) } \\
\hline Mining & 0.062 & 0.159 & 0.018 & 0.768 & - & - & - & - \\
\hline Manufacturing & 0.141 & 0.000 & 0.090 & 0.021 & - & - & - & - \\
\hline Construction & 0.024 & 0.558 & 0.056 & 0.505 & - & - & - & - \\
\hline Wholesale Trade & 0.125 & 0.018 & 0.101 & 0.076 & - & - & - & - \\
\hline Retail Trade & 0.000 & 0.981 & -0.039 & 0.330 & - & - & - & - \\
\hline Accommodation & -0.010 & 0.853 & -0.020 & 0.634 & - & - & - & - \\
\hline Transport & 0.175 & 0.000 & 0.042 & 0.419 & - & - & - & - \\
\hline Communication & 0.245 & 0.000 & 0.229 & 0.000 & - & - & - & - \\
\hline Financial Services & 0.319 & 0.000 & 0.184 & 0.000 & - & - & - & - \\
\hline Professional Services & 0.124 & 0.006 & 0.118 & 0.003 & - & - & - & - \\
\hline Public Administration & 0.219 & 0.000 & 0.134 & 0.002 & - & - & - & - \\
\hline Education & -0.032 & 0.682 & -0.078 & 0.104 & - & - & - & - \\
\hline Health & 0.031 & 0.543 & 0.051 & 0.145 & - & - & - & - \\
\hline \multicolumn{9}{|c|}{ Occupation (reference group is Labourer) } \\
\hline Manager & 0.284 & 0.000 & 0.307 & 0.000 & - & - & - & - \\
\hline Professional & 0.239 & 0.000 & 0.281 & 0.000 & - & - & - & - \\
\hline Technical Worker & 0.151 & 0.000 & 0.147 & 0.000 & - & - & - & - \\
\hline Personal Services & 0.197 & 0.073 & 0.179 & 0.007 & - & - & - & - \\
\hline Administration & 0.104 & 0.006 & 0.174 & 0.000 & - & - & - & - \\
\hline Sales & 0.100 & 0.023 & 0.119 & 0.013 & - & - & - & - \\
\hline Machine Operator & 0.037 & 0.218 & 0.007 & 0.891 & - & - & - & - \\
\hline
\end{tabular}


Single people without children: HES94-98 (continued)

\begin{tabular}{|c|c|c|c|c|c|c|c|c|}
\hline & \multicolumn{4}{|c|}{ Wage Equation } & \multicolumn{4}{|c|}{ Selection Equation } \\
\hline & \multicolumn{2}{|c|}{ Single men } & \multicolumn{2}{|c|}{ Single women } & \multicolumn{2}{|c|}{ Single men } & \multicolumn{2}{|c|}{ Single women } \\
\hline & Coefficient & $P$-value & Coefficient & P-value & Coefficient & P-value & Coefficient & P-value \\
\hline \multicolumn{9}{|c|}{ Region (reference group is Auckland) } \\
\hline North North Island & -0.127 & 0.000 & -0.040 & 0.110 & -0.343 & 0.001 & -0.210 & 0.214 \\
\hline Central North Island & -0.102 & 0.000 & -0.134 & 0.000 & -0.301 & 0.008 & 0.218 & 0.276 \\
\hline Wellington & -0.043 & 0.098 & 0.047 & 0.033 & -0.084 & 0.477 & 0.275 & 0.122 \\
\hline Canterbury & -0.095 & 0.000 & -0.082 & 0.001 & 0.018 & 0.884 & 0.212 & 0.272 \\
\hline Rest of South Island & -0.088 & 0.001 & -0.103 & 0.000 & -0.252 & 0.022 & 0.225 & 0.241 \\
\hline \multicolumn{9}{|c|}{ Other variables } \\
\hline Year (trend) & 0.008 & 0.317 & 0.002 & 0.739 & 0.104 & 0.006 & -0.014 & 0.745 \\
\hline Unemployment Rate & -0.016 & 0.046 & 0.010 & 0.211 & -0.006 & 0.864 & -0.081 & 0.199 \\
\hline Constant & 1.125 & 0.000 & 1.557 & 0.000 & -0.448 & 0.347 & -1.391 & 0.119 \\
\hline $\begin{array}{l}\text { Hhld Non-labour in- } \\
\text { come (thousands) }\end{array}$ & - & - & - & - & -0.888 & 0.032 & -1.571 & 0.028 \\
\hline Living with parents & - & - & - & - & - & - & - & - \\
\hline \multicolumn{9}{|c|}{ Variance Function } \\
\hline Age $\div 10$ & - & - & - & - & - & - & 0.109 & 0.065 \\
\hline $\begin{array}{l}\text { Hhld Non-labour in- } \\
\text { come (thousands) }\end{array}$ & - & - & - & - & 0.911 & 0.056 & 0.840 & 0.246 \\
\hline \multicolumn{9}{|c|}{ Model evaluation } \\
\hline Mills Ratio & 0.430 & 0.000 & 0.017 & 0.395 & - & - & - & - \\
\hline R-squared & 0.414 & - & 0.443 & - & - & - & - & - \\
\hline Pseudo R-squared & - & - & - & - & 0.128 & - & 0.136 & - \\
\hline $\begin{array}{l}\text { LR test for Het- } \\
\text { eroskedasticity }\end{array}$ & - & - & - & - & 38.22 & 0.001 & 54.27 & 0.000 \\
\hline
\end{tabular}


Table 4.8: Sole parent: HES94-98

\begin{tabular}{|c|c|c|c|c|}
\hline & \multicolumn{2}{|c|}{$\begin{array}{c}\text { Wage Equation } \\
\text { Sole parent }\end{array}$} & \multicolumn{2}{|c|}{$\begin{array}{c}\text { Selection Equation } \\
\text { Sole parent }\end{array}$} \\
\hline & Coefficient & P-value & Coefficient & P-value \\
\hline Age $\div 10$ & 0.426 & 0.030 & 0.823 & 0.021 \\
\hline $\operatorname{Age}^{2} \div 10$ & -0.050 & 0.046 & -0.123 & 0.008 \\
\hline Woman & -0.096 & 0.112 & -0.298 & 0.024 \\
\hline \multicolumn{5}{|c|}{ Highest Qualification attained (reference - less than NCEA level 1) } \\
\hline Level 1-3 & 0.033 & 0.569 & 0.524 & 0.000 \\
\hline Level 4-6 & 0.178 & 0.010 & 0.641 & 0.000 \\
\hline Level 7 & 0.216 & 0.022 & 0.940 & 0.000 \\
\hline Postgraduate & 0.435 & 0.003 & 0.545 & 0.090 \\
\hline Other & 0.259 & 0.059 & 0.688 & 0.027 \\
\hline \multicolumn{5}{|c|}{ Ethnicity (reference group Non-Maori/Pacific) } \\
\hline Maori/Pacific & -0.028 & 0.611 & -0.157 & 0.116 \\
\hline \multicolumn{5}{|c|}{ Children } \\
\hline Number of children & - & - & -0.190 & 0.000 \\
\hline Youngest Age $=0$ & - & - & -1.608 & 0.000 \\
\hline Youngest Age 1-3 & - & - & -1.216 & 0.000 \\
\hline Youngest Age 4-5 & - & - & -0.848 & 0.000 \\
\hline Youngest Age 6-9 & - & - & -0.620 & 0.000 \\
\hline Youngest Age 10-12 & - & - & -0.406 & 0.006 \\
\hline \multicolumn{5}{|c|}{ Industry (reference group is Agriculture or ANZSIC 2006 A) } \\
\hline Mining & 0.116 & 0.361 & - & - \\
\hline Manufacturing & 0.053 & 0.569 & - & - \\
\hline Construction & 0.067 & 0.644 & - & - \\
\hline Wholesale Trade & -0.034 & 0.829 & - & - \\
\hline Retail Trade & -0.051 & 0.624 & - & - \\
\hline Accommodation & -0.060 & 0.528 & - & - \\
\hline Transport & 0.073 & 0.559 & - & - \\
\hline Communication & 0.032 & 0.884 & - & - \\
\hline Financial Services & 0.202 & 0.138 & - & - \\
\hline Professional Services & 0.281 & 0.009 & - & - \\
\hline Public Administration & 0.220 & 0.040 & - & - \\
\hline Education & -0.056 & 0.568 & - & - \\
\hline Health & -0.101 & 0.207 & - & - \\
\hline
\end{tabular}


Sole parent: HES94-98 (continued)

\begin{tabular}{|c|c|c|c|c|}
\hline & \multicolumn{2}{|c|}{$\begin{array}{l}\text { Wage Equation } \\
\text { Sole parent }\end{array}$} & \multicolumn{2}{|c|}{$\begin{array}{c}\text { Selection Equation } \\
\text { Sole parent }\end{array}$} \\
\hline & Coefficient & P-value & Coefficient & P-value \\
\hline \multicolumn{5}{|c|}{ Occupation (reference group is Labourer) } \\
\hline Manager & 0.183 & 0.087 & - & - \\
\hline Professional & 0.397 & 0.000 & - & - \\
\hline Technical Worker & 0.178 & 0.015 & - & - \\
\hline Personal Services & 0.390 & 0.012 & - & - \\
\hline Administration & 0.105 & 0.211 & - & - \\
\hline Sales & 0.042 & 0.729 & - & - \\
\hline Machine Operator & 0.147 & 0.154 & - & - \\
\hline \multicolumn{5}{|c|}{ Region (reference group is Auckland) } \\
\hline North North Island & -0.072 & 0.222 & -0.018 & 0.883 \\
\hline Central North Island & -0.064 & 0.302 & 0.166 & 0.202 \\
\hline Wellington & -0.023 & 0.724 & 0.139 & 0.341 \\
\hline Canterbury & 0.016 & 0.817 & 0.298 & 0.050 \\
\hline Rest of South Island & -0.001 & 0.988 & 0.034 & 0.820 \\
\hline \multicolumn{5}{|c|}{ Other variables } \\
\hline Year (trend) & 0.022 & 0.196 & 0.048 & 0.170 \\
\hline Unemployment Rate & -0.004 & 0.849 & -0.032 & 0.487 \\
\hline Constant & 1.744 & 0.000 & -0.420 & 0.615 \\
\hline $\begin{array}{l}\text { Hhld Non-labour in- } \\
\text { come (thousands) }\end{array}$ & - & - & -0.083 & 0.377 \\
\hline Living with parents & - & - & -1.184 & 0.140 \\
\hline \multicolumn{5}{|c|}{ Model evaluation } \\
\hline Mills Ratio & 0.036 & 0.665 & - & - \\
\hline R-squared & 0.257 & - & - & - \\
\hline Pseudo R-squared & - & - & 0.197 & - \\
\hline $\begin{array}{l}\text { LR test for Het- } \\
\text { eroskedasticity }\end{array}$ & - & - & NA & NA \\
\hline
\end{tabular}


Table 4.9: Coupled people: HES94-98

\begin{tabular}{|c|c|c|c|c|c|c|c|c|}
\hline & \multicolumn{4}{|c|}{ Wage Equation } & \multicolumn{4}{|c|}{ Selection Equation } \\
\hline & \multicolumn{2}{|c|}{ Coupled men } & \multicolumn{2}{|c|}{ Coupled women } & \multicolumn{2}{|c|}{ Coupled men } & \multicolumn{2}{|c|}{ Coupled women } \\
\hline & Coefficient & P-value & Coefficient & P-value & Coefficient & P-value & Coefficient & P-value \\
\hline Age $\div 10$ & 0.425 & 0.000 & 0.279 & 0.000 & 0.786 & 0.000 & 1.399 & 0.000 \\
\hline $\mathrm{Age}^{2} \div 100$ & -0.046 & 0.000 & -0.033 & 0.000 & -0.110 & 0.000 & -0.191 & 0.000 \\
\hline \multicolumn{9}{|c|}{ Highest Qualification attained (reference group less than NCEA level 1 completion) } \\
\hline Level 1-3 & 0.131 & 0.000 & 0.102 & 0.000 & 0.338 & 0.000 & 0.451 & 0.000 \\
\hline Level 4-6 & 0.134 & 0.000 & 0.170 & 0.000 & 0.493 & 0.000 & 0.634 & 0.000 \\
\hline Level 7 & 0.287 & 0.000 & 0.260 & 0.000 & 0.489 & 0.000 & 0.745 & 0.000 \\
\hline Postgraduate & 0.416 & 0.000 & 0.377 & 0.000 & 0.663 & 0.000 & 1.370 & 0.000 \\
\hline Other & 0.140 & 0.001 & 0.161 & 0.000 & 0.493 & 0.026 & 1.055 & 0.000 \\
\hline \multicolumn{9}{|c|}{ Ethnicity (reference group non-Maori/Pacific) } \\
\hline Maori/Pacific & -0.069 & 0.008 & -0.069 & 0.011 & -0.177 & 0.127 & -0.096 & 0.870 \\
\hline \multicolumn{9}{|c|}{ Children } \\
\hline Number of children & - & - & - & - & -0.016 & 0.628 & -0.130 & 0.001 \\
\hline Youngest age $=0$ & _- & _- & _- & _- & 0.248 & 0.081 & -1.850 & 0.000 \\
\hline Youngest age 1-3 & - & - & - & - & -0.058 & 0.629 & -1.216 & 0.000 \\
\hline Youngest age 4-5 & - & - & - & - & -0.159 & 0.260 & -0.825 & 0.000 \\
\hline Youngest age 6-9 & - & - & - & - & -0.123 & 0.337 & -0.352 & 0.00 \\
\hline Youngest age 10-12 & - & - & - & - & -0.268 & 0.044 & -0.103 & 0.406 \\
\hline Youngest age 13+ & - & - & - & - & -0.132 & 0.259 & 0.054 & 0.607 \\
\hline \multicolumn{9}{|c|}{ Partner Characteristics } \\
\hline Maori/Pacific & -0.040 & 0.139 & -0.030 & 0.249 & -0.232 & 0.044 & 0.229 & 0.045 \\
\hline Level 1-3 & - & - & - & - & 0.127 & 0.078 & 0.005 & 0.945 \\
\hline Level 4-6 & - & - & - & - & 0.228 & 0.010 & 0.018 & 0.791 \\
\hline Level 7 & - & - & - & - & -0.009 & 0.949 & -0.230 & 0.024 \\
\hline Postgraduate & - & - & - & - & -0.159 & 0.491 & -0.570 & 0.001 \\
\hline Other & - & - & - & - & 0.151 & 0.522 & -0.017 & 0.924 \\
\hline \multicolumn{9}{|c|}{ Industry (reference group is Agriculture or ANZSIC 2006 A) } \\
\hline Mining & 0.031 & 0.376 & 0.125 & 0.001 & - & - & - & - \\
\hline Manufacturing & 0.121 & 0.000 & 0.111 & 0.000 & - & - & - & - \\
\hline Construction & 0.015 & 0.639 & 0.106 & 0.054 & - & - & - & - \\
\hline Wholesale Trade & 0.111 & 0.004 & 0.087 & 0.034 & - & - & - & - \\
\hline Retail Trade & -0.072 & 0.024 & -0.100 & 0.001 & - & - & - & - \\
\hline Accommodation & -0.287 & 0.000 & -0.170 & 0.000 & - & - & - & - \\
\hline Transport & 0.081 & 0.014 & 0.061 & 0.127 & - & - & - & - \\
\hline Communication & 0.245 & 0.000 & 0.117 & 0.005 & - & - & - & - \\
\hline Financial Services & 0.337 & 0.000 & 0.113 & 0.001 & - & - & - & - \\
\hline Professional Services & 0.203 & 0.000 & 0.135 & 0.000 & - & - & - & - \\
\hline Public Administration & 0.175 & 0.000 & 0.121 & 0.000 & - & - & - & - \\
\hline Education & -0.118 & 0.014 & -0.113 & 0.001 & - & - & - & - \\
\hline Health & -0.031 & 0.376 & -0.030 & 0.255 & - & - & - & - \\
\hline
\end{tabular}


Coupled people: HES94-98 (continued)

\begin{tabular}{|c|c|c|c|c|c|c|c|c|}
\hline & \multicolumn{4}{|c|}{ Wage Equation } & \multicolumn{4}{|c|}{ Selection Equation } \\
\hline & \multicolumn{2}{|c|}{ Coupled men } & \multicolumn{2}{|c|}{ Coupled women } & \multicolumn{2}{|c|}{ Coupled men } & \multicolumn{2}{|c|}{ Coupled women } \\
\hline & Coefficient & P-value & Coefficient & $\mathrm{P}$-value & Coefficient & P-value & Coefficient & $\mathrm{P}$-value \\
\hline \multicolumn{9}{|c|}{ Occupation (reference group is Labourer) } \\
\hline Manager & 0.324 & 0.000 & 0.313 & 0.000 & - & - & - & - \\
\hline Professional & 0.287 & 0.000 & 0.374 & 0.000 & - & - & - & - \\
\hline Technical Worker & 0.212 & 0.000 & 0.131 & 0.000 & - & - & - & - \\
\hline Personal Services & 0.220 & 0.016 & 0.354 & 0.000 & - & - & - & - \\
\hline Administration & 0.104 & 0.002 & 0.225 & 0.000 & - & - & - & - \\
\hline Sales & 0.033 & 0.421 & 0.112 & 0.001 & - & - & - & - \\
\hline Machine Operator & 0.099 & 0.000 & -0.008 & 0.819 & - & - & - & - \\
\hline \multicolumn{9}{|c|}{ Region (reference group is Auckland) } \\
\hline North North Island & -0.043 & 0.017 & -0.063 & 0.000 & -0.026 & 0.751 & 0.026 & 0.714 \\
\hline Central North Island & -0.106 & 0.000 & -0.069 & 0.000 & 0.003 & 0.973 & 0.121 & 0.123 \\
\hline Wellington & 0.061 & 0.001 & 0.024 & 0.182 & 0.229 & 0.026 & 0.302 & 0.001 \\
\hline Canterbury & -0.056 & 0.003 & -0.084 & 0.000 & 0.013 & 0.888 & 0.044 & 0.582 \\
\hline Rest of South Island & -0.056 & 0.003 & -0.082 & 0.000 & -0.000 & 1.000 & 0.066 & 0.404 \\
\hline \multicolumn{9}{|c|}{ Other variables } \\
\hline Year (trend) & 0.005 & 0.405 & 0.006 & 0.230 & 0.074 & 0.008 & -0.006 & 0.752 \\
\hline Unemployment Rate & -0.004 & 0.424 & -0.006 & 0.317 & -0.013 & 0.630 & -0.059 & 0.042 \\
\hline Constant & 1.758 & 0.000 & 2.037 & 0.000 & -0.898 & 0.088 & -1.736 & 0.004 \\
\hline $\begin{array}{l}\text { Hhld Non-labour in- } \\
\text { come (thousands) }\end{array}$ & - & - & - & - & -0.199 & 0.114 & -0.254 & 0.013 \\
\hline Partner participation & - & - & - & - & 0.358 & 0.002 & 0.932 & 0.000 \\
\hline $\begin{array}{l}\text { Partner income (thou- } \\
\text { sands) }\end{array}$ & - & - & - & - & 2.284 & 0.000 & -0.094 & 0.004 \\
\hline \multicolumn{9}{|c|}{ Variance Function } \\
\hline Age $\div 10$ & - & - & - & - & - & - & 0.122 & 0.002 \\
\hline $\begin{array}{l}\text { Hhld Non-labour in- } \\
\text { come (thousands) }\end{array}$ & - & - & - & - & 0.365 & 0.003 & 0.202 & 0.050 \\
\hline $\begin{array}{l}\text { Partner income (thou- } \\
\text { sands) }\end{array}$ & - & - & - & - & 0.892 & 0.000 & - & - \\
\hline Partner participation & - & - & - & - & - & - & -0.290 & 0.003 \\
\hline \multicolumn{9}{|c|}{ Model evaluation } \\
\hline Mills Ratio & 0.090 & 0.006 & 0.101 & 0.000 & - & - & - & - \\
\hline R-squared & 0.287 & - & 0.256 & - & - & - & - & - \\
\hline Pseudo R-squared & - & - & - & - & 0.107 & - & 0.177 & - \\
\hline $\begin{array}{l}\text { LR test for Het- } \\
\text { eroskedasticity }\end{array}$ & - & - & - & - & 87.59 & 0.000 & 93.59 & 0.000 \\
\hline
\end{tabular}




\subsubsection{HES01-08}

Table 4.10: Single people without children: HES01-08

\begin{tabular}{|c|c|c|c|c|c|c|c|c|}
\hline & \multicolumn{4}{|c|}{ Wage Equation } & \multicolumn{4}{|c|}{ Selection Equation } \\
\hline & \multicolumn{2}{|c|}{ Single men } & \multicolumn{2}{|c|}{ Single women } & \multicolumn{2}{|c|}{ Single men } & \multicolumn{2}{|c|}{ Single women } \\
\hline & Coefficient & P-value & Coefficient & P-value & Coefficient & P-value & Coefficient & P-value \\
\hline Age $\div 10$ & 0.497 & 0.000 & 0.400 & 0.000 & 1.131 & 0.000 & 1.297 & 0.000 \\
\hline Age $^{2} \div 100$ & -0.055 & 0.000 & -0.046 & 0.000 & -0.158 & 0.000 & -0.165 & 0.000 \\
\hline \multicolumn{9}{|c|}{ Highest Qualification attained (reference group less than NCEA level 1 completion) } \\
\hline Level $1 / 2$ & 0.075 & 0.006 & 0.090 & 0.006 & 0.092 & 0.376 & 0.589 & 0.000 \\
\hline Level 3 & 0.130 & 0.001 & 0.077 & 0.336 & 0.392 & 0.026 & 1.024 & 0.000 \\
\hline Level 4-6 & 0.103 & 0.001 & 0.094 & 0.167 & 0.365 & 0.007 & 0.703 & 0.000 \\
\hline Level 7 & 0.285 & 0.000 & -0.007 & 0.927 & 0.650 & 0.000 & 0.952 & 0.000 \\
\hline Postgraduate & 0.382 & 0.000 & -0.037 & 0.725 & 0.203 & 0.290 & 0.777 & 0.000 \\
\hline Other & 0.180 & 0.000 & 0.082 & 0.261 & 0.149 & 0.484 & 0.516 & 0.011 \\
\hline Postgrad $\times$ age $\div 10$ & - & - & 0.078 & 0.001 & - & - & - & - \\
\hline Level $7 \times$ age $\div 10$ & - & - & 0.049 & 0.004 & - & - & - & - \\
\hline Level $4-6 \times$ age $\div 10$ & - & - & 0.006 & 0.644 & - & - & - & - \\
\hline Postgrad Maori/Pacific & - & - & 0.077 & 0.222 & - & - & - & - \\
\hline Level 4-6 Maori/Pacific & - & - & -0.121 & 0.018 & - & - & - & - \\
\hline Postgraduate Other & - & - & 0.120 & 0.029 & - & - & - & - \\
\hline Non-European & & & & & & & & \\
\hline Level 4-6 $\times$ Other Non- & - & - & -0.020 & 0.758 & - & - & - & - \\
\hline European & & & & & & & & \\
\hline \multicolumn{9}{|c|}{ Ethnicity (reference group European) } \\
\hline Maori/Pacific & -0.036 & 0.380 & 0.001 & 0.980 & -0.142 & 0.425 & 0.093 & 0.650 \\
\hline Maori/Pacific Only & -0.046 & 0.125 & -0.091 & 0.009 & -0.384 & 0.001 & -0.580 & 0.000 \\
\hline Other Non-European & -0.094 & 0.001 & -0.142 & 0.001 & -0.549 & 0.000 & -0.514 & 0.000 \\
\hline \multicolumn{9}{|c|}{ Industry (reference group is Agriculture or ANZSIC 2006 A) } \\
\hline Mining & 0.047 & 0.338 & 0.077 & 0.229 & - & - & - & - \\
\hline Manufacturing & 0.096 & 0.008 & 0.037 & 0.330 & - & - & - & - \\
\hline Construction & 0.050 & 0.200 & 0.052 & 0.488 & - & - & - & - \\
\hline Wholesale Trade & 0.029 & 0.554 & 0.108 & 0.019 & - & - & - & - \\
\hline Retail Trade & -0.036 & 0.380 & -0.120 & 0.001 & - & - & - & - \\
\hline Accommodation & -0.060 & 0.230 & -0.109 & 0.005 & - & - & - & - \\
\hline Transport & 0.041 & 0.373 & 0.057 & 0.264 & - & - & - & - \\
\hline Communication & 0.161 & 0.007 & -0.037 & 0.477 & - & - & - & - \\
\hline Financial Services & 0.230 & 0.000 & 0.114 & 0.004 & - & - & - & - \\
\hline Professional Services & 0.099 & 0.024 & 0.112 & 0.001 & - & - & - & - \\
\hline Public Administration & 0.139 & 0.005 & 0.167 & 0.000 & - & - & - & - \\
\hline Education & 0.084 & 0.148 & -0.051 & 0.168 & - & - & - & - \\
\hline Health & 0.143 & 0.011 & -0.004 & 0.904 & - & - & - & - \\
\hline
\end{tabular}




\section{Single person without children: HES01-08 (continued)}

\begin{tabular}{|c|c|c|c|c|c|c|c|c|}
\hline & \multicolumn{4}{|c|}{ Wage Equation } & \multicolumn{4}{|c|}{ Selection Equation } \\
\hline & \multicolumn{2}{|c|}{ Single men } & \multicolumn{2}{|c|}{ Single women } & \multicolumn{2}{|c|}{ Single men } & \multicolumn{2}{|c|}{ Single women } \\
\hline & Coefficient & P-value & Coefficient & P-value & Coefficient & $\mathrm{P}$-value & Coefficient & P-value \\
\hline \multicolumn{9}{|c|}{ Occupation (reference group is Labourer) } \\
\hline Manager & 0.211 & 0.000 & 0.375 & 0.000 & - & - & - & - \\
\hline Professional & 0.267 & 0.000 & 0.353 & 0.000 & - & - & - & - \\
\hline Technical Worker & 0.099 & 0.000 & 0.094 & 0.016 & - & - & - & - \\
\hline Personal Services & 0.031 & 0.535 & 0.080 & 0.057 & - & - & - & - \\
\hline Administration & 0.067 & 0.111 & 0.147 & 0.000 & - & - & - & - \\
\hline Sales & 0.017 & 0.678 & 0.116 & 0.006 & - & - & - & - \\
\hline Machine Operator & 0.054 & 0.123 & -0.021 & 0.943 & - & - & - & - \\
\hline \multicolumn{9}{|c|}{ Region (reference group is Auckland) } \\
\hline North North Island & -0.109 & 0.000 & -0.155 & 0.000 & -0.151 & 0.216 & -0.044 & 0.727 \\
\hline Central North Island & -0.123 & 0.000 & -0.130 & 0.000 & -0.217 & 0.098 & 0.246 & 0.113 \\
\hline Wellington & -0.048 & 0.065 & -0.041 & 0.088 & 0.005 & 0.967 & 0.276 & 0.032 \\
\hline Canterbury & -0.127 & 0.000 & -0.110 & 0.000 & -0.033 & 0.790 & 0.214 & 0.118 \\
\hline Rest of South Island & -0.130 & 0.000 & -0.107 & 0.000 & -0.045 & 0.737 & 0.143 & 0.311 \\
\hline \multicolumn{9}{|c|}{ Other Variables } \\
\hline Year (trend) & -0.001 & 0.868 & -0.013 & 0.001 & -0.001 & 0.972 & -0.020 & 0.385 \\
\hline Unemployment Rate & 0.002 & 0.912 & -0.023 & 0.176 & -0.027 & 0.736 & -0.052 & 0.559 \\
\hline Constant & 1.680 & 0.000 & 2.030 & 0.000 & -0.516 & 0.379 & -1.241 & 0.049 \\
\hline $\begin{array}{l}\text { Hhld Non-labour in- } \\
\text { come (thousands) }\end{array}$ & - & - & - & - & -1.128 & 0.012 & -0.561 & 0.249 \\
\hline \multicolumn{9}{|c|}{ Variance Function } \\
\hline $\begin{array}{l}\text { Hhld Non-labour in- } \\
\text { come (thousands) }\end{array}$ & - & - & - & - & 1.249 & 0.000 & 1.153 & 0.066 \\
\hline \multicolumn{9}{|c|}{ Model evaluation } \\
\hline Mills Ratio & 0.099 & 0.001 & 0.060 & 0.453 & - & - & - & - \\
\hline R-squared & 0.417 & - & 0.474 & - & - & - & - & - \\
\hline Pseudo R-squared & - & - & - & - & 0.091 & - & 0.129 & - \\
\hline $\begin{array}{l}\text { LR test for Het- } \\
\text { eroskedasticity }\end{array}$ & - & - & - & - & 56.71 & 0.000 & 43.91 & 0.021 \\
\hline
\end{tabular}


Table 4.11: Sole parent: HES01-08

\begin{tabular}{|c|c|c|c|c|}
\hline & \multicolumn{2}{|c|}{$\begin{array}{c}\text { Wage Equation } \\
\text { Sole parent }\end{array}$} & \multicolumn{2}{|c|}{$\begin{array}{c}\text { Selection Equation } \\
\text { Sole parent }\end{array}$} \\
\hline & Coefficient & P-value & Coefficient & P-value \\
\hline Age $\div 10$ & 0.389 & 0.039 & 1.282 & 0.000 \\
\hline $\mathrm{Age}^{2} \div 100$ & -0.040 & 0.082 & -0.163 & 0.000 \\
\hline Woman & -0.034 & 0.513 & -0.108 & 0.368 \\
\hline \multicolumn{5}{|c|}{ Highest Qualification attained (reference - less than NCEA level 1) } \\
\hline Level 1/2 & 0.065 & 0.237 & 0.524 & 0.000 \\
\hline Level 3 & 0.124 & 0.126 & 0.434 & 0.031 \\
\hline Level 4-6 & 0.121 & 0.055 & 0.563 & 0.000 \\
\hline Level 7 & 0.310 & 0.000 & 0.547 & 0.000 \\
\hline Postgraduate & 0.460 & 0.000 & 0.731 & 0.000 \\
\hline Other & 0.085 & 0.300 & 0.199 & 0.179 \\
\hline \multicolumn{5}{|c|}{ Ethnicity (reference group European) } \\
\hline Maori/Pacific & -0.065 & 0.332 & 0.030 & 0.851 \\
\hline Maori/Pacific Only & -0.083 & 0.071 & -0.152 & 0.144 \\
\hline Other Non-European & -0.086 & 0.159 & -0.489 & 0.000 \\
\hline \multicolumn{5}{|c|}{ Children } \\
\hline Number of children & - & - & 0.022 & 0.617 \\
\hline Youngest Age $=0$ & - & - & -1.404 & 0.000 \\
\hline Youngest Age 1-3 & - & - & -0.875 & 0.000 \\
\hline Youngest Age 4-5 & - & - & -0.788 & 0.000 \\
\hline Youngest Age 6-9 & - & - & -0.433 & 0.001 \\
\hline Youngest Age 10-12 & - & - & -0.327 & 0.004 \\
\hline \multicolumn{5}{|c|}{ Industry (reference group is Agriculture or ANZSIC 2006 A) } \\
\hline Mining & 0.319 & 0.025 & - & - \\
\hline Manufacturing & 0.250 & 0.001 & - & - \\
\hline Construction & 0.284 & 0.003 & - & - \\
\hline Wholesale Trade & 0.187 & 0.042 & - & - \\
\hline Retail Trade & 0.031 & 0.675 & - & - \\
\hline Accommodation & 0.001 & 0.990 & - & - \\
\hline Transport & 0.207 & 0.029 & - & - \\
\hline Communication & 0.002 & 0.987 & - & - \\
\hline Financial Services & 0.216 & 0.022 & - & - \\
\hline Professional Services & 0.207 & 0.007 & - & - \\
\hline Public Administration & 0.180 & 0.034 & - & - \\
\hline Education & -0.014 & 0.842 & - & - \\
\hline Health & 0.046 & 0.472 & - & - \\
\hline
\end{tabular}


Sole parent: HES01-08 (continued)

\begin{tabular}{|c|c|c|c|c|c|}
\hline & \multicolumn{2}{|c|}{$\begin{array}{l}\text { Wage Equation } \\
\text { Sole parent }\end{array}$} & & \multicolumn{2}{|c|}{$\begin{array}{l}\text { Selection Equation } \\
\text { Sole parent }\end{array}$} \\
\hline & Coefficient & P-value & & Coefficient & P-value \\
\hline \multicolumn{6}{|c|}{ Occupation (reference group is Labourer) } \\
\hline Manager & 0.408 & 0.000 & & - & - \\
\hline Professional & 0.396 & 0.000 & & - & - \\
\hline Technical Worker & 0.079 & 0.210 & & - & - \\
\hline Personal Services & 0.135 & 0.072 & & - & - \\
\hline Administration & 0.228 & 0.000 & & - & - \\
\hline Sales & 0.127 & 0.126 & & - & - \\
\hline Machine Operator & -0.056 & 0.551 & & - & - \\
\hline \multicolumn{6}{|c|}{ Region (reference group is Auckland) } \\
\hline North North Island & -0.138 & 0.008 & & -0.061 & 0.623 \\
\hline Central North Island & -0.055 & 0.290 & & 0.193 & 0.165 \\
\hline Wellington & 0.045 & 0.413 & -0.057 & & 0.654 \\
\hline Canterbury & 0.006 & 0.913 & 0.419 & & 0.002 \\
\hline Rest of South Island & -0.107 & 0.075 & & 0.377 & 0.003 \\
\hline \multicolumn{6}{|c|}{ Other variables } \\
\hline Year (trend) & -0.011 & 0.271 & & 0.003 & 0.896 \\
\hline Unemployment Rate & -0.037 & 0.290 & & 0.127 & 0.131 \\
\hline Constant & 1.743 & 0.001 & & -2.618 & 0.001 \\
\hline $\begin{array}{l}\text { Hhld Non-labour in- } \\
\text { come (thousands) }\end{array}$ & - & - & & -0.344 & 0.000 \\
\hline \multicolumn{6}{|c|}{ Variance Function } \\
\hline $\begin{array}{l}\text { Hhld Non-labour in- } \\
\text { come (thousands) }\end{array}$ & - & - & & -2.984 & 0.001 \\
\hline \multicolumn{6}{|c|}{ Model evaluation } \\
\hline Mills Ratio & 0.188 & 0.065 & & - & - \\
\hline R-squared & 0.400 & - & & - & - \\
\hline Pseudo R-squared & - & - & & 0.200 & - \\
\hline $\begin{array}{l}\text { LR test for Het- } \\
\text { eroskedasticity }\end{array}$ & - & - & & 8.41 & 0.004 \\
\hline
\end{tabular}


Table 4.12: Coupled person: HES01-08

\begin{tabular}{|c|c|c|c|c|c|c|c|c|}
\hline & \multicolumn{4}{|c|}{ Wage Equation } & \multicolumn{4}{|c|}{ Selection Equation } \\
\hline & \multicolumn{2}{|c|}{ Coupled men } & \multicolumn{2}{|c|}{ Coupled women } & \multicolumn{2}{|c|}{ Coupled men } & \multicolumn{2}{|c|}{ Coupled women } \\
\hline & Coefficient & $\mathrm{P}$-value & Coefficient & P-value & Coefficient & P-value & Coefficient & $\mathrm{P}$-value \\
\hline Age $\div 10$ & 0.487 & 0.000 & 0.330 & 0.000 & 0.499 & 0.000 & 0.741 & 0.000 \\
\hline Age $^{2} \div 100$ & -0.054 & 0.000 & -0.036 & 0.000 & -0.078 & 0.000 & -0.110 & 0.000 \\
\hline \multicolumn{9}{|c|}{ Highest Qualification attained (reference group less than NCEA level 1 completion) } \\
\hline Level 1/2 & 0.086 & 0.000 & 0.031 & 0.103 & 0.106 & 0.141 & 0.222 & 0.000 \\
\hline Level 3 & 0.174 & 0.004 & 0.091 & 0.012 & 0.196 & 0.055 & 0.286 & 0.015 \\
\hline Level 4-6 & 0.201 & 0.001 & 0.111 & 0.000 & 0.337 & 0.000 & 0.326 & 0.000 \\
\hline Level 7 & 0.205 & 0.005 & 0.227 & 0.000 & 0.400 & 0.000 & 0.504 & 0.000 \\
\hline Postgraduate & -0.020 & 0.830 & 0.333 & 0.000 & 0.338 & 0.002 & 0.466 & 0.000 \\
\hline Other & 0.277 & 0.000 & 0.127 & 0.000 & 0.146 & 0.301 & 0.222 & 0.018 \\
\hline Postgrad $\times$ age $\div 10$ & 0.104 & 0.000 & - & - & - & - & - & - \\
\hline Level $7 \times$ age $\div 10$ & 0.030 & 0.078 & - & - & - & - & - & - \\
\hline Level $4-6 \times$ age $\div 10$ & -0.013 & 0.415 & - & - & - & - & - & - \\
\hline Postgrad Maori/Pacific & 0.010 & 0.858 & - & - & - & - & - & - \\
\hline Level 4-6 Maori/Pacific & -0.031 & 0.304 & - & - & - & - & - & - \\
\hline $\begin{array}{l}\text { Postgrad Other Non- } \\
\text { European }\end{array}$ & -0.218 & 0.000 & - & - & - & - & - & - \\
\hline $\begin{array}{l}\text { Level 4-6 Other Non- } \\
\text { European }\end{array}$ & 0.029 & 0.554 & - & - & - & - & - & - \\
\hline \multicolumn{9}{|c|}{ Ethnicity (reference group European) } \\
\hline Maori/Pacific & 0.024 & 0.480 & -0.059 & 0.057 & 0.326 & 0.641 & -0.115 & 0.201 \\
\hline Maori/Pacific Only & -0.175 & 0.000 & -0.110 & 0.000 & -0.691 & 0.000 & 0.050 & 0.397 \\
\hline Other Non-European & -0.153 & 0.033 & -0.165 & 0.000 & -0.800 & 0.000 & -0.422 & 0.000 \\
\hline \multicolumn{9}{|c|}{ Children } \\
\hline Number of children & - & - & - & - & 0.034 & 0.331 & -0.104 & 0.001 \\
\hline Youngest age $=0$ & - & - & - & - & -0.164 & 0.179 & -1.233 & 0.000 \\
\hline Youngest age 1-3 & - & - & - & - & -0.132 & 0.239 & -0.723 & 0.000 \\
\hline Youngest age 4-5 & - & - & - & - & -0.233 & 0.080 & -0.505 & 0.000 \\
\hline Youngest age 6-9 & - & - & - & - & -0.016 & 0.890 & -0.251 & 0.008 \\
\hline Youngest age $10-12$ & - & - & - & - & -0.291 & 0.012 & -0.081 & 0.363 \\
\hline Youngest age $13+$ & - & - & - & - & 0.072 & 0.489 & 0.142 & 0.091 \\
\hline \multicolumn{9}{|c|}{ Industry (reference group is Agriculture or ANZSIC 2006 A) } \\
\hline Mining & -0.022 & 0.518 & 0.019 & 0.659 & - & - & - & - \\
\hline Manufacturing & 0.166 & 0.000 & 0.074 & 0.011 & - & - & - & - \\
\hline Construction & 0.110 & 0.000 & 0.169 & 0.002 & - & - & - & - \\
\hline Wholesale Trade & 0.153 & 0.000 & 0.075 & 0.043 & - & - & - & - \\
\hline Retail Trade & -0.024 & 0.439 & -0.108 & 0.000 & - & - & - & - \\
\hline Accommodation & -0.246 & 0.000 & -0.164 & 0.000 & - & - & - & - \\
\hline Transport & 0.124 & 0.000 & 0.063 & 0.089 & - & - & - & - \\
\hline Communication & 0.141 & 0.002 & 0.139 & 0.002 & - & - & - & - \\
\hline Financial Services & 0.348 & 0.000 & 0.203 & 0.000 & - & - & - & - \\
\hline Professional Services & 0.227 & 0.000 & 0.138 & 0.000 & - & - & - & - \\
\hline Public Administration & 0.218 & 0.000 & 0.159 & 0.000 & - & - & - & - \\
\hline Education & -0.032 & 0.347 & -0.057 & 0.035 & - & - & - & - \\
\hline Health & 0.128 & 0.001 & -0.012 & 0.631 & - & - & - & - \\
\hline
\end{tabular}




\section{Couple people: HES01-08 (continued)}

\begin{tabular}{|c|c|c|c|c|c|c|c|c|}
\hline & \multicolumn{4}{|c|}{ Wage Equation } & \multicolumn{4}{|c|}{ Selection Equation } \\
\hline & \multicolumn{2}{|c|}{ Coupled men } & \multicolumn{2}{|c|}{ Coupled women } & \multicolumn{2}{|c|}{ Coupled men } & \multicolumn{2}{|c|}{ Coupled women } \\
\hline & Coefficient & P-value & Coefficient & P-value & Coefficient & P-value & Coefficient & P-value \\
\hline \multicolumn{9}{|c|}{ Occupation (reference group is Labourer) } \\
\hline Manager & 0.320 & 0.000 & 0.387 & 0.000 & - & - & - & - \\
\hline Professional & 0.270 & 0.000 & 0.405 & 0.000 & - & - & - & - \\
\hline Technical Worker & 0.129 & 0.000 & 0.127 & 0.000 & - & - & - & - \\
\hline Personal Services & 0.091 & 0.023 & 0.134 & 0.000 & - & - & - & - \\
\hline Administration & 0.078 & 0.015 & 0.189 & 0.000 & - & - & - & _- \\
\hline Sales & 0.106 & 0.003 & 0.113 & 0.000 & - & - & - & - \\
\hline Machine Operator & 0.004 & 0.873 & 0.028 & 0.495 & - & - & - & - \\
\hline \multicolumn{9}{|c|}{ Region (reference group is Auckland) } \\
\hline North North Island & -0.120 & 0.000 & -0.116 & 0.000 & -0.071 & 0.337 & 0.030 & 0.579 \\
\hline Central North Island & -0.145 & 0.000 & -0.144 & 0.000 & 0.023 & 0.798 & 0.050 & 0.420 \\
\hline Wellington & -0.039 & 0.030 & -0.011 & 0.541 & -0.023 & 0.774 & 0.142 & 0.014 \\
\hline Canterbury & -0.104 & 0.000 & -0.090 & 0.000 & 0.099 & 0.255 & 0.159 & 0.009 \\
\hline Rest of South Island & -0.139 & 0.000 & -0.097 & 0.000 & -0.069 & 0.411 & 0.116 & 0.046 \\
\hline \multicolumn{9}{|c|}{ Other variables } \\
\hline Year (trend) & 0.001 & 0.803 & -0.013 & 0.000 & -0.008 & 0.657 & -0.016 & 0.110 \\
\hline Unemployment Rate & 0.004 & 0.739 & -0.029 & 0.026 & -0.034 & 0.521 & -0.111 & 0.007 \\
\hline Constant & 1.693 & 0.000 & 2.119 & 0.000 & 0.635 & 0.193 & -0.108 & 0.773 \\
\hline $\begin{array}{l}\text { Hhld Non-labour in- } \\
\text { come (thousands) }\end{array}$ & - & - & - & - & -0.226 & 0.031 & -0.110 & 0.012 \\
\hline Partner participation & - & - & - & - & 0.471 & 0.000 & 0.469 & 0.000 \\
\hline $\begin{array}{l}\text { Partner income (thou- } \\
\text { sands) }\end{array}$ & - & - & - & - & -0.102 & 0.037 & -0.028 & 0.020 \\
\hline \multicolumn{9}{|c|}{ Variance Function } \\
\hline Maori/Pacific & - & - & - & - & 0.356 & 0.374 & - & - \\
\hline Maori/Pacific Only & - & - & - & - & -0.452 & 0.034 & - & - \\
\hline Other Non-European & - & - & - & - & -0.320 & 0.108 & - & - \\
\hline Age $\div 10$ & - & - & - & - & - & - & 0.045 & 0.199 \\
\hline $\begin{array}{l}\text { Hhld Non-labour in- } \\
\text { come (thousands) }\end{array}$ & - & - & - & - & 0.386 & 0.001 & 0.102 & 0.089 \\
\hline \multicolumn{9}{|c|}{ Model evaluation } \\
\hline Mills Ratio & 0.193 & 0.000 & 0.103 & 0.000 & - & - & - & - \\
\hline R-squared & 0.364 & - & 0.347 & - & - & - & - & - \\
\hline Pseudo R-squared & _- & _- & _- & _- & 0.107 & _- & 0.154 & _- \\
\hline $\begin{array}{l}\text { LR test for Het- } \\
\text { eroskedasticity }\end{array}$ & - & - & - & - & 87.49 & 0.000 & 82.25 & 0.000 \\
\hline
\end{tabular}




\subsubsection{HES09-13}

Table 4.13: Single people without children: HES09-13

\begin{tabular}{|c|c|c|c|c|c|c|c|c|}
\hline & \multicolumn{4}{|c|}{ Wage Equation } & \multicolumn{4}{|c|}{ Selection Equation } \\
\hline & \multicolumn{2}{|c|}{ Single men } & \multicolumn{2}{|c|}{ Single women } & \multicolumn{2}{|c|}{ Single men } & \multicolumn{2}{|c|}{ Single women } \\
\hline & Coefficient & $\mathrm{P}$-value & Coefficient & P-value & Coefficient & $\mathrm{P}$-value & Coefficient & P-value \\
\hline Age $\div 10$ & 0.289 & 0.000 & 0.350 & 0.000 & 0.984 & 0.000 & 1.021 & 0.000 \\
\hline Age $^{2} \div 100$ & -0.029 & 0.000 & -0.039 & 0.000 & -0.108 & 0.000 & -0.118 & 0.000 \\
\hline \multicolumn{9}{|c|}{ Highest Qualification attained (reference group less than NCEA level 1 completion) } \\
\hline Level $1 / 2$ & 0.029 & 0.227 & 0.067 & 0.005 & 0.286 & 0.007 & 0.219 & 0.029 \\
\hline Level 3 & 0.189 & 0.001 & 0.049 & 0.382 & 0.947 & 0.000 & 0.480 & 0.002 \\
\hline Level 4-6 & 0.160 & 0.008 & 0.112 & 0.042 & 0.788 & 0.002 & 0.286 & 0.021 \\
\hline Level 7 & -0.082 & 0.300 & -0.061 & 0.293 & 0.866 & 0.002 & 0.657 & 0.000 \\
\hline Postgraduate & 0.013 & 0.162 & -0.027 & 0.708 & 1.025 & 0.008 & 0.580 & 0.000 \\
\hline Other & 0.191 & 0.004 & 0.161 & 0.007 & 1.000 & 0.001 & 0.482 & 0.006 \\
\hline Postgrad $\times$ age $\div 10$ & 0.082 & 0.000 & 0.055 & 0.001 & -0.119 & 0.171 & - & - \\
\hline Level $7 \times$ age $\div 10$ & 0.074 & 0.000 & 0.055 & 0.000 & -0.68 & 0.331 & - & - \\
\hline Level $4-6 \times$ age $\div 10$ & -0.006 & 0.644 & 0.001 & 0.928 & -0.127 & 0.013 & - & - \\
\hline Postgrad Maori/Pacific & -0.077 & 0.285 & 0.044 & 0.317 & 0.243 & 0.315 & - & - \\
\hline Level 7 Maori/Pacific & - & - & - & - & - & - & - & - \\
\hline Level 4-6 Maori/Pacific & -0.103 & 0.028 & 0.029 & 0.479 & 0.030 & 0.871 & - & - \\
\hline $\begin{array}{l}\text { Postgrad Other Non- } \\
\text { European }\end{array}$ & -0.034 & 0.488 & 0.017 & 0.678 & 0.174 & 0.357 & - & - \\
\hline $\begin{array}{l}\text { Level } 7 \text { Other Non- } \\
\text { European }\end{array}$ & - & - & - & - & - & - & - & - \\
\hline $\begin{array}{l}\text { Level 4-6 Other Non- } \\
\text { European }\end{array}$ & -0.086 & 0.105 & 0.008 & 0.875 & 0.203 & 0.371 & - & - \\
\hline \multicolumn{9}{|c|}{ Ethnicity (reference group European) } \\
\hline Maori/Pacific & 0.015 & 0.617 & -0.045 & 0.121 & -0.026 & 0.846 & 0.013 & 0.914 \\
\hline Maori/Pacific Only & -0.047 & 0.105 & -0.111 & 0.000 & -0.535 & 0.000 & -0.504 & 0.000 \\
\hline Other Non-European & -0.066 & 0.052 & -0.058 & 0.046 & -0.523 & 0.000 & -0.441 & 0.000 \\
\hline \multicolumn{9}{|c|}{ Industry (reference group is Agriculture or ANZSIC 2006 A) } \\
\hline Mining & 0.002 & 0.962 & -0.007 & 0.922 & - & - & - & - \\
\hline Manufacturing & 0.085 & 0.003 & 0.038 & 0.250 & - & - & - & - \\
\hline Construction & 0.053 & 0.077 & 0.019 & 0.725 & - & - & - & - \\
\hline Wholesale Trade & 0.017 & 0.646 & 0.071 & 0.083 & - & - & - & - \\
\hline Retail Trade & -0.078 & 0.022 & -0.122 & 0.000 & - & - & - & - \\
\hline Accommodation & -0.103 & 0.004 & -0.091 & 0.002 & - & - & - & - \\
\hline Transport & 0.034 & 0.383 & 0.062 & 0.121 & - & - & - & - \\
\hline Communication & 0.081 & 0.078 & -0.012 & 0.785 & - & - & - & - \\
\hline Financial Services & 0.195 & 0.000 & 0.153 & 0.000 & - & - & - & - \\
\hline Professional Services & 0.103 & 0.005 & 0.035 & 0.274 & - & - & - & - \\
\hline Public Administration & 0.141 & 0.000 & 0.139 & 0.000 & - & - & - & - \\
\hline Education & -0.002 & 0.961 & -0.014 & 0.617 & - & - & - & - \\
\hline Health & 0.038 & 0.409 & 0.031 & 0.233 & - & - & - & - \\
\hline
\end{tabular}


Single people without children: HES09-13 (continued)

\begin{tabular}{|c|c|c|c|c|c|c|c|c|}
\hline & \multicolumn{4}{|c|}{ Wage Equation } & \multicolumn{4}{|c|}{ Selection Equation } \\
\hline & \multicolumn{2}{|c|}{ Single men } & \multicolumn{2}{|c|}{ Single women } & \multicolumn{2}{|c|}{ Single men } & \multicolumn{2}{|c|}{ Single women } \\
\hline & Coefficient & P-value & Coefficient & P-value & Coefficient & $\mathrm{P}$-value & Coefficient & P-value \\
\hline \multicolumn{9}{|c|}{ Occupation (reference group is Labourer) } \\
\hline Manager & 0.233 & 0.000 & 0.323 & 0.000 & - & - & - & - \\
\hline Professional & 0.271 & 0.000 & 0.362 & 0.000 & - & - & - & - \\
\hline Technical Worker & 0.120 & 0.000 & 0.077 & 0.032 & - & - & - & - \\
\hline Personal Services & 0.097 & 0.004 & 0.044 & 0.116 & - & - & - & - \\
\hline Administration & 0.090 & 0.008 & 0.170 & 0.000 & - & - & - & - \\
\hline Sales & 0.058 & 0.070 & 0.092 & 0.003 & - & - & - & - \\
\hline Machine Operator & 0.052 & 0.073 & 0.002 & 0.969 & - & - & - & - \\
\hline \multicolumn{9}{|c|}{ Region (reference group is Auckland) } \\
\hline North North Island & -0.065 & 0.001 & -0.074 & 0.000 & 0.020 & 0.835 & 0.021 & 0.827 \\
\hline Central North Island & -0.088 & 0.002 & -0.108 & 0.000 & 0.214 & 0.061 & 0.216 & 0.058 \\
\hline Wellington & 0.005 & 0.275 & -0.018 & 0.344 & 0.250 & 0.006 & 0.242 & 0.008 \\
\hline Canterbury & -0.050 & 0.023 & -0.081 & 0.000 & 0.334 & 0.001 & 0.332 & 0.001 \\
\hline Rest of South Island & -0.076 & 0.002 & -0.063 & 0.003 & 0.083 & 0.407 & 0.081 & 0.418 \\
\hline \multicolumn{9}{|c|}{ Other variables } \\
\hline Year (trend) & -0.011 & 0.023 & -0.009 & 0.199 & 0.031 & 0.348 & 0.031 & 0.348 \\
\hline Unemployment Rate & -0.003 & 0.785 & 0.010 & 0.363 & -0.045 & 0.378 & -0.047 & 0.357 \\
\hline Constant & 2.106 & 0.000 & 1.967 & 0.000 & -1.145 & 0.003 & -1.089 & 0.004 \\
\hline $\begin{array}{l}\text { Hhld Non-labour in- } \\
\text { come (thousands) }\end{array}$ & - & - & - & - & -1.153 & 0.000 & -1.145 & 0.000 \\
\hline \multicolumn{9}{|c|}{ Variance Function } \\
\hline $\begin{array}{l}\text { Hhld Non-labour in- } \\
\text { come (thousands) }\end{array}$ & - & - & - & - & 0.703 & 0.000 & 0.696 & 0.000 \\
\hline \multicolumn{9}{|c|}{ Model evaluation } \\
\hline Mills Ratio & 0.046 & 0.238 & 0.012 & 0.689 & - & - & - & - \\
\hline R-squared & 0.369 & - & 0.486 & - & - & - & - & - \\
\hline Pseudo R-squared & - & - & - & - & 0.087 & - & 0.103 & - \\
\hline $\begin{array}{l}\text { LR test for Het- } \\
\text { eroskedasticity }\end{array}$ & - & - & - & - & 83.85 & 0.000 & 63.59 & 0.000 \\
\hline
\end{tabular}


Table 4.14: Sole parent: HES09-13

\begin{tabular}{|c|c|c|c|c|}
\hline & \multicolumn{2}{|c|}{$\begin{array}{l}\text { Wage Equation } \\
\text { Sole parent }\end{array}$} & \multicolumn{2}{|c|}{$\begin{array}{l}\text { Selection Equation } \\
\text { Sole parent }\end{array}$} \\
\hline & Coefficient & P-value & Coefficient & P-value \\
\hline Age $\div 10$ & 0.108 & 0.624 & 1.035 & 0.001 \\
\hline $\mathrm{Age}^{2} \div 100$ & -0.011 & 0.432 & -0.102 & 0.002 \\
\hline Woman & -0.086 & 0.027 & -0.074 & 0.572 \\
\hline \multicolumn{5}{|c|}{ Highest Qualification attained (reference group less than NCEA level 1 completion } \\
\hline Level 1/2 & 0.057 & 0.18 & 0.481 & 0.000 \\
\hline Level 3 & 0.062 & 0.268 & 0.567 & 0.000 \\
\hline Level 4-6 & 0.089 & 0.112 & 0.768 & 0.190 \\
\hline Level 7 & 0.238 & 0.000 & 0.785 & 0.000 \\
\hline Postgraduate & 0.356 & 0.000 & 1.183 & 0.000 \\
\hline Other & 0.150 & 0.025 & 0.205 & 0.340 \\
\hline \multicolumn{5}{|c|}{ Ethnicity (reference group European) } \\
\hline Maori/Pacific & -0.068 & 0.089 & -0.026 & 0.837 \\
\hline Maori/Pacific Only & -0.008 & 0.829 & -0.210 & 0.046 \\
\hline Other Non-European & -0.108 & 0.016 & -0.153 & 0.314 \\
\hline \multicolumn{5}{|c|}{ Children } \\
\hline Number of children & - & - & -0.122 & 0.011 \\
\hline Youngest Age $=0$ & - & - & -0.797 & 0.001 \\
\hline Youngest Age 1-3 & - & - & -0.633 & 0.000 \\
\hline Youngest Age 4-5 & - & - & -0.589 & 0.001 \\
\hline Youngest Age 6-9 & - & - & -0.355 & 0.012 \\
\hline Youngest Age 10-12 & - & - & -0.356 & 0.012 \\
\hline \multicolumn{5}{|c|}{ Industry (reference group is Agriculture or ANZSIC 2006 A) } \\
\hline Mining & 0.096 & 0.337 & - & - \\
\hline Manufacturing & 0.118 & 0.014 & - & - \\
\hline Construction & 0.183 & 0.029 & - & - \\
\hline Wholesale Trade & 0.118 & 0.121 & - & - \\
\hline Retail Trade & -0.105 & 0.117 & - & - \\
\hline Accommodation & -0.040 & 0.551 & - & - \\
\hline Transport & 0.122 & 0.142 & - & - \\
\hline Communication & 0.292 & 0.004 & - & - \\
\hline Financial Services & 0.135 & 0.057 & - & - \\
\hline Professional Services & 0.224 & 0.001 & - & - \\
\hline Public Administration & 0.213 & 0.001 & - & - \\
\hline Education & 0.038 & 0.497 & - & - \\
\hline Health & 0.064 & 0.218 & - & - \\
\hline
\end{tabular}


Sole parent: HES09-13 (continued)

\begin{tabular}{|c|c|c|c|c|}
\hline & \multicolumn{2}{|c|}{$\begin{array}{c}\text { Wage Equation } \\
\text { Sole parent }\end{array}$} & \multicolumn{2}{|c|}{$\begin{array}{c}\text { Selection Equation } \\
\text { Sole parent }\end{array}$} \\
\hline & Coefficient & P-value & Coefficient & $\mathrm{P}$-value \\
\hline \multicolumn{5}{|c|}{ Occupation (reference group is Labourer) } \\
\hline Manager & 0.441 & 0.000 & - & - \\
\hline Professional & 0.253 & 0.000 & - & - \\
\hline Technical Worker & 0.121 & 0.055 & - & - \\
\hline Personal Services & -0.060 & 0.267 & - & - \\
\hline Administration & 0.151 & 0.003 & - & - \\
\hline Sales & 0.081 & 0.227 & - & - \\
\hline Machine Operator & -0.059 & 0.482 & - & - \\
\hline \multicolumn{5}{|c|}{ Region (reference group is Auckland) } \\
\hline North North Island & -0.065 & 0.104 & 0.215 & 0.078 \\
\hline Central North Island & -0.074 & 0.093 & 0.307 & 0.028 \\
\hline Wellington & 0.070 & 0.080 & 0.267 & 0.043 \\
\hline Canterbury & -0.065 & 0.122 & 0.405 & 0.004 \\
\hline Rest of South Island & -0.014 & 0.756 & 0.432 & 0.003 \\
\hline \multicolumn{5}{|c|}{ Other variables } \\
\hline Year (trend) & -0.028 & 0.020 & 0.005 & 0.910 \\
\hline Unemployment Rate & 0.014 & 0.484 & -0.049 & 0.471 \\
\hline Constant & 2.534 & 0.000 & -1.899 & 0.007 \\
\hline $\begin{array}{l}\text { Hhld Non-labour in- } \\
\text { come (thousands) }\end{array}$ & - & - & 6.360 & 0.000 \\
\hline \multicolumn{5}{|c|}{ Variance equation } \\
\hline $\begin{array}{l}\text { Hhld Non-labour in- } \\
\text { come (thousands) }\end{array}$ & - & - & 3.130 & 0.000 \\
\hline \multicolumn{5}{|c|}{ Model evaluation } \\
\hline Mills Ratio & -0.084 & 0.148 & - & - \\
\hline R-squared & 0.423 & - & - & - \\
\hline Pseudo R-squared & - & - & 0.189 & - \\
\hline $\begin{array}{l}\text { LR test for Het- } \\
\text { eroskedasticity }\end{array}$ & - & - & 83.00 & 0.000 \\
\hline
\end{tabular}


Table 4.15: Coupled people: HES09-13

\begin{tabular}{|c|c|c|c|c|c|c|c|c|}
\hline & \multicolumn{4}{|c|}{ Wage Equation } & \multicolumn{4}{|c|}{ Selection Equation } \\
\hline & \multicolumn{2}{|c|}{ Coupled men } & \multicolumn{2}{|c|}{ Coupled women } & \multicolumn{2}{|c|}{ Coupled men } & \multicolumn{2}{|c|}{ Coupled women } \\
\hline & Coefficient & P-value & Coefficient & P-value & Coefficient & $\mathrm{P}$-value & Coefficient & $\mathrm{P}$-value \\
\hline Age $\div 10$ & 0.427 & 0.000 & 0.250 & 0.000 & 2.409 & 0.000 & 0.982 & 0.000 \\
\hline Age $^{2} \div 100$ & -0.047 & 0.000 & -0.027 & 0.000 & -0.293 & 0.000 & -0.127 & 0.000 \\
\hline \multicolumn{9}{|c|}{ Highest Qualification attained (reference group less than NCEA level 1 completion } \\
\hline Level 1/2 & 0.055 & 0.002 & 0.081 & 0.000 & 0.443 & 0.006 & 0.344 & 0.000 \\
\hline Level 3 & 0.093 & 0.068 & 0.054 & 0.299 & 0.728 & 0.000 & 0.429 & 0.000 \\
\hline Level 4-6 & 0.165 & 0.002 & 0.099 & 0.057 & 0.736 & 0.001 & 0.530 & 0.000 \\
\hline Level 7 & -0.037 & 0.602 & 0.200 & 0.001 & 0.701 & 0.001 & 0.775 & 0.000 \\
\hline Postgraduate & 0.186 & 0.017 & 0.106 & 0.114 & 0.651 & 0.003 & 0.681 & 0.000 \\
\hline Other & 0.199 & 0.000 & 0.051 & 0.354 & 0.894 & 0.002 & 0.477 & 0.000 \\
\hline Postgrad $\times$ age $\div 10$ & 0.044 & 0.006 & 0.051 & 0.000 & - & - & - & - \\
\hline Level $7 \times$ age $\div 10$ & 0.084 & 0.000 & 0.013 & 0.279 & - & - & - & - \\
\hline Level $4-6 \times$ age $\div 10$ & 0.003 & 0.764 & 0.018 & 0.72 & - & - & - & - \\
\hline Postgrad Maori/Pacific & -0.062 & 0.206 & 0.018 & 0.617 & - & - & - & - \\
\hline Level 7 Maori/Pacific & - & - & - & - & - & - & - & - \\
\hline Level 4-6 Maori/Pacific & -0.055 & 0.076 & 0.027 & 0.413 & - & - & - & - \\
\hline $\begin{array}{l}\text { Postgrad Other Non- } \\
\text { European }\end{array}$ & -0.142 & 0.000 & -0.032 & 0.317 & - & - & - & - \\
\hline $\begin{array}{l}\text { Level } 7 \text { Other Non- } \\
\text { European }\end{array}$ & - & - & - & - & - & - & - & - \\
\hline $\begin{array}{l}\text { Level 4-6 Other Non- } \\
\text { European }\end{array}$ & 0.008 & 0.833 & 0.017 & 0.637 & - & - & - & - \\
\hline \multicolumn{9}{|c|}{ Ethnicity (reference group European) } \\
\hline Maori/Pacific & 0.007 & 0.795 & -0.065 & 0.009 & -0.279 & 0.184 & 0.116 & 0.172 \\
\hline Maori/Pacific Only & -0.123 & 0.000 & -0.132 & 0.000 & -0.645 & 0.000 & -0.091 & 0.155 \\
\hline Other Non-European & -0.166 & 0.000 & -0.137 & 0.000 & -0.833 & 0.000 & -0.543 & 0.000 \\
\hline \multicolumn{9}{|c|}{ Children } \\
\hline Number of children & - & - & - & - & 0.220 & 0.140 & -0.150 & 0.000 \\
\hline Youngest age $=0$ & - & - & - & - & 0.171 & 0.465 & -1.189 & 0.000 \\
\hline Youngest age 1-3 & - & - & - & - & -0.173 & 0.421 & -0.839 & 0.000 \\
\hline Youngest age 4-5 & - & - & - & - & -0.013 & 0.963 & -0.468 & 0.000 \\
\hline Youngest age 6-9 & - & - & - & - & 0.071 & 0.782 & -0.243 & 0.008 \\
\hline Youngest age 10-12 & - & - & - & - & 0.378 & 0.206 & 0.149 & 0.128 \\
\hline Youngest age 13+ & - & - & - & - & 0.181 & 0.435 & 0.192 & 0.016 \\
\hline \multicolumn{9}{|c|}{ Industry (reference group is Agriculture or ANZSIC 2006 A) } \\
\hline Mining & 0.027 & 0.352 & -0.038 & 0.291 & - & - & - & - \\
\hline Manufacturing & 0.172 & 0.000 & 0.056 & 0.015 & - & - & - & - \\
\hline Construction & 0.096 & 0.000 & 0.116 & 0.001 & - & - & - & - \\
\hline Wholesale Trade & 0.128 & 0.000 & 0.124 & 0.000 & - & - & - & - \\
\hline Retail Trade & -0.061 & 0.024 & -0.135 & 0.000 & - & - & - & - \\
\hline Accommodation & -0.141 & 0.000 & -0.103 & 0.000 & - & - & - & - \\
\hline Transport & 0.114 & 0.000 & 0.089 & 0.007 & - & - & - & - \\
\hline Communication & 0.225 & 0.000 & 0.084 & 0.020 & - & - & - & - \\
\hline Financial Services & 0.414 & 0.000 & 0.172 & 0.000 & - & - & - & - \\
\hline Professional Services & 0.281 & 0.000 & 0.193 & 0.000 & - & - & - & - \\
\hline Public Administration & 0.258 & 0.000 & 0.211 & 0.000 & - & - & - & - \\
\hline Education & 0.011 & 0.705 & -0.043 & 0.041 & - & - & - & - \\
\hline Health & 0.153 & 0.000 & 0.042 & 0.036 & - & - & - & - \\
\hline
\end{tabular}




\section{Coupled people: HES09-13 (continued)}

\begin{tabular}{|c|c|c|c|c|c|c|c|c|}
\hline & \multicolumn{4}{|c|}{ Wage Equation } & \multicolumn{4}{|c|}{ Selection Equation } \\
\hline & \multicolumn{2}{|c|}{ Coupled men } & \multicolumn{2}{|c|}{ Coupled women } & \multicolumn{2}{|c|}{ Coupled men } & \multicolumn{2}{|c|}{ Coupled women } \\
\hline & Coefficient & P-value & Coefficient & $P$-value & Coefficient & P-value & Coefficient & P-value \\
\hline \multicolumn{9}{|c|}{ Occupation (reference group is Labourer) } \\
\hline Manager & 0.277 & 0.000 & 0.392 & 0.000 & - & - & - & - \\
\hline Professional & 0.279 & 0.000 & 0.371 & 0.000 & - & - & - & - \\
\hline Technical Worker & 0.099 & 0.000 & 0.109 & 0.000 & - & - & - & - \\
\hline Personal Services & 0.007 & 0.809 & 0.001 & 0.967 & - & - & - & - \\
\hline Administration & 0.091 & 0.001 & 0.157 & 0.000 & - & - & - & - \\
\hline Sales & 0.064 & 0.027 & 0.082 & 0.002 & - & - & - & - \\
\hline Machine Operator & -0.003 & 0.892 & 0.001 & 0.979 & - & - & - & - \\
\hline \multicolumn{9}{|c|}{ Region (reference group is Auckland) } \\
\hline North North Island & -0.097 & 0.000 & -0.090 & 0.000 & 0.219 & 0.158 & 0.075 & 0.211 \\
\hline Central North Island & -0.089 & 0.000 & -0.074 & 0.000 & 0.381 & 0.040 & 0.076 & 0.250 \\
\hline Wellington & 0.018 & 0.230 & 0.000 & 1.000 & 0.214 & 0.170 & 0.264 & 0.000 \\
\hline Canterbury & -0.092 & 0.000 & -0.050 & 0.001 & 0.751 & 0.000 & 0.130 & 0.028 \\
\hline Rest of South Island & -0.082 & 0.000 & -0.073 & 0.000 & 0.255 & 0.122 & 0.160 & 0.008 \\
\hline \multicolumn{9}{|c|}{ Other variables } \\
\hline Year (trend) & -0.010 & 0.012 & -0.006 & 0.453 & 0.040 & 0.293 & -0.022 & 0.271 \\
\hline Unemployment Rate & 0.00 & 0.901 & -0.000 & 1.000 & -0.139 & 0.086 & 0.021 & 0.498 \\
\hline Constant & 1.934 & 0.000 & 2.136 & 0.000 & -2.803 & 0.003 & -1.278 & 0.000 \\
\hline $\begin{array}{l}\text { Hhld Non-labour in- } \\
\text { come (thousands) }\end{array}$ & - & - & - & - & -0.547 & 0.001 & -0.400 & 0.000 \\
\hline Partner participation & - & - & - & - & 1.886 & 0.008 & 0.392 & 0.000 \\
\hline $\begin{array}{l}\text { Partner income (thou- } \\
\text { sands) }\end{array}$ & - & - & - & & 1.064 & 0.111 & -0.126 & 0.000 \\
\hline \multicolumn{9}{|c|}{ Variance Function } \\
\hline Age $\div 10$ & - & - & - & - & 0.063 & 0.020 & - & - \\
\hline Number of kids & - & - & - & - & 0.092 & 0.013 & - & - \\
\hline Partner participation & - & - & - & - & 0.562 & 0.001 & - & - \\
\hline $\begin{array}{l}\text { Partner income (thou- } \\
\text { sands) }\end{array}$ & - & - & - & - & 0.301 & 0.013 & 0.052 & 0.038 \\
\hline $\begin{array}{l}\text { Hhld Non-labour in- } \\
\text { come (thousands) }\end{array}$ & - & - & - & - & 0.295 & 0.000 & 0.241 & 0.001 \\
\hline \multicolumn{9}{|c|}{ Model evaluation } \\
\hline Mills Ratio & 0.041 & 0.023 & 0.142 & 0.000 & - & - & - & - \\
\hline R-squared & 0.387 & - & 0.403 & - & - & - & - & - \\
\hline Pseudo R-squared & - & - & - & - & 0.087 & - & 0.135 & - \\
\hline $\begin{array}{l}\text { LR test for Het- } \\
\text { eroskedasticity }\end{array}$ & - & - & - & - & 156.62 & 0.000 & 94.89 & 0.000 \\
\hline
\end{tabular}




\section{Chapter 5}

\section{Income-leisure preferences in New Zealand: 1988-2013}

\subsection{Introduction}

In this chapter, preference functions for individuals' preferences over income and hours of work are estimated. Preference functions are estimated for four subgroups of the New Zealand population: single women, single men, sole parents, and couples. The estimates are at the economic family unit (EFU) level and as a result the labour supply choices of couples are estimated jointly.

Estimates are provided for four separate time periods: 1988-1993, 19941998, 2001-2008, and 2009-2013. The data are sourced from the Household Economic Survey (HES) for each of these periods. The data are surveyed on an annual basis, as a result HES years are pooled and deflated to the end of the period for analysis.

By estimating preference parameters for these four separate time periods it is also possible to gain an insight into how these changes in the char- 
acteristics of the labour market influenced the labour market choices and outcomes of families in New Zealand.

The periods chosen correspond to four very different labour market situations, the recession of the late-1980s and early 1990s, the sharp recovery from this recession, the long period of growth in the 2000s, and the Global Financial Crisis.

Furthermore the characteristics of the labour market changed considerably during this time. The 1991 Employment Contracts Act (Anderson 1991) and 2000 Employment Relations Act both considerably changed the institutional structure of the New Zealand labour market where labour supply choices were determined - with the net effect a movement away from collective bargaining towards individual employee negotiations. An outline of the 1990s policy changes and estimates of the consequences can be found in Gorter and Poot (1999). These changes in policy settings were part of an explicit policy choice by government, with the influence of policy changes on the work incentives given as a key reason for tax cuts, changing benefit settings, and the introduction of Working for Families as noted in Treasury1996 1996 and Nolan 2005.

In addition to these policy changes the long-term shift away from manufacturing work towards service jobs and the increasingly technical nature of service work are both shifts that have driven a change in necessary qualifications and the job offers available for individuals.

By estimating preference parameters for differing time periods for the demographic subgroups the relationships are allowed to vary between points in time. As a result, it is possible to gain a richer understanding of how the changes in the labour market structure and economic situation influenced labour market outcomes.

A primary purpose of such an estimation is to simulate the change in labour supply choices of individuals when the net income available to in- 
dividuals for different hours of work change. Estimating the preferences individuals have over leisure and consumption in a structural model allows a researcher to ask what hours level would be chosen if the set of available net income were to change, either due to a change in the gross wage rate this individual is paid or an adjustment in the policy parameters (tax and transfers) which transform gross income into net income.

In the New Zealand context, preference parameter estimation for Treasury's microsimulation model has been performed twice, in 2003 in Guyonne Kalb and Rosanna Scutella (2003) covering the 1991-2001 period and in 2014 in Mercante and Mok (2014a) covering the 2007 to 2011 period. The parameters estimated in these two different exercises varied in a number of ways, suggesting that the estimated preference parameters do change through time, helping to justify the use of separate time periods in this chapter.

The method used is based on the discrete choice framework applied in previous New Zealand estimates. Such a framework deals with the complex budget constraints observed in real world data without applying restrictive assumptions about the properties of the underlying utility function ex-ante. In this framework it is also possible to incorporate the fixed costs of work and observed heterogeneity in the estimated preference parameters.

These preference parameters will be incorporated in Treasury's microsimulation model, TAXWELL-B. The incorporation of these preference parameters in turn allows the analysis of how changes in government tax and transfer policies change the labour supply of individuals and the associated income distribution.

The chapter is organised as follows: Section 2 discusses the data used in the chapter, selection criteria, and details of the wage imputation process for those out of work. Section 3 describes the method used for estimating preference parameters. Section 4 provides results of the estimation 
exercise. Section 5 outlines indicative marginal effects from the estimated preference parameters to explain the results. Section 6 concludes.

\subsection{Data sources}

The data used for this analysis come from Statistics New Zealand's Household Economic Survey (HES). The HES is a household survey that has been run annually since the April 1974 year, except for a brief period where it was taken triennially between 1998 and 2006. The HES surveys 5,000 private households ${ }^{1}$, with 3,000-4,000 responses of sufficient quality each year. HES years are denoted using the year when the survey ended. For example HES95 refers to the household survey that took place between April 1994 until March 1995.

The survey collects data on income by source, hours of work, and a variety of household, family, and personal characteristics (eg ethnicity). A key advantage of the survey is that it links familial relationships. As a result, this survey allows the construction of economic family units. This allows the estimation of separate wage equations for individuals based on their familial role and to also include variables related to family status (eg partners income, child's age) into the estimation. An economic family unit refers to an adult, the partner, and their dependants. ${ }^{2}$

Using these familial linkages, five key groups are constructed: coupled men, coupled women, single men (without children), single women (without children), and sole parents.

Given these demographic groups there are four separate pooled data sets

\footnotetext{
${ }^{1}$ Private households exclude institutional households, such as rest homes and prisons.

${ }^{2}$ Partnership is defined as a situation where a defacto or married partner exists. Dependants are children aged below 15 , or below 18 and in full-time education.
} 
for which preference parameters are estimated: HES88-93, HES94-98, HES0108, and HES09-13. For each pooled data period net incomes were inflated to the final quarter of that period (eg March 1993 for the HES88-93 pooled data). As a result, the average wage rates reported for a given period are not nominal average wage rates of the period but the average real wage rate deflated by CPI for the final quarter of that period.

Survey weights are available for this data, along with Treasury estimates of calibrated weights for 1984-2013 available following the method used by Ball and Creedy (2015). However, weights are not used in the estimation of the the preference parameters in this chapter given that it is the labour supply response of the simulated sample data that is of interest. This justification is discussed in more detail in New Zealand Wage Equations: 1988-2013.

\subsubsection{Wage imputation and assumptions}

The wage data used to construct net incomes for all possible hours levels is the implied wage from wage and salary income in the HES data. This is equal to total current weekly wage and salary earnings from the individual's primary job divided by the number of hours worked per week in their primary job. ${ }^{3}$

As the wage rate is based upon an individual's primary job, the model assumes that the individual only varies labour supply for one job with a fixed gross wage. The labour supply decision that is modelled is the decision of how many hours to work in this job.

\footnotetext{
${ }^{3}$ The earnings from prior jobs, self-employed work, and secondary jobs are ignored when calculating the wage. The primary job is defined as the wage and salary job the individual is currently employed in that offers the largest average weekly income at current hours of work.
} 
On a few occasions inconsistent and unreliable wage data were removed. ${ }^{4}$ The key times this occurred were when the calculated wage rate was less than half the minimum wage and when the wage above $\$ 150$ was reported.

However, this wage measure leaves a gap in the data with individuals who are currently not working and therefore not reporting a wage rate. As a result, wage rates have been imputed for those who are not employed. This question of wage imputation for those who are out of work is covered in Chapter 4.

When it comes to implementing this wage imputation for the calculation of net incomes there is a strand of the literature that suggests there are advantages to replacing all wages with their imputed value (eg Loffler et al. (2013) and MacCurdy et al. (1990)).

However, in this chapter observed wages are used for those who are employed. The difference between the observed and estimated wage rates is due to unobserved differences between individuals. Using the estimated wage is equivalent to assuming that the unobserved heterogeneity is zero, when in fact we have observed that it is not. This difference is especially important when the a large proportion of the variability in wages is not explained by observed characteristics, as is the case for the estimates used here which come from Chapter 4 .

As a result, there is a significant amount of unobserved heterogeneity in the wage data that would be ignored if imputed values were used and so the observed wages rate is the rate applied to calculate the net incomes for those who are currently employed.

A related issue to wage imputation is how the wage available to an individual may vary as they change their hours of work. In the preference parameter estimation performed in this chapter, the gross wage is fixed

\footnotetext{
${ }^{4}$ Due to Statistics New Zealand confidentiality an exact number cannot be cited. XXX
} 
irrespective of the tax-transfer policies used, irrespective of the number of hours worked by the individual, and irrespective of the aggregate number of hours being supplied by all individuals.

However, estimating a labour supply model for such changes, and ignoring the inherent importance of demand (with associated changes in gross wage rates and general equilibrium effects) may lead to a bias in the results. The competing biases, as given by Muller (2014) are:

1. A preference bias: An individual who would be willing to work may not be able to find a job (or sufficient hours). However, the model treats them as if they are voluntarily unemployed. As a result, their preference for leisure is overstated. This downward biases labour supply responses. (eg the labour demand constraint holding in the data is taken as a preference for leisure).

2. A participation bias: An individual facing rationing of hours will be treated as voluntarily unemployed (or underemployed), leading to increases in predicted hours in the model that will not occur. This biases labour supply responses upwards. Here, the labour demand constraint is not allowed to bind in the counterfactual equilibrium.

3. A specification bias: If the labour supply model itself is incorrectly specified, there is an ambiguous bias in the labour supply elasticities that are estimated. For example the model itself being misspecified.

Varying preferences over leisure and consumption in a labour supply model do not solely imply that the relative value individuals place on leisure and consumption changes through time as these differing estimates may in part be due to a changing labour demand conditions, with the availability of jobs at a given wage varying through time. In this chapter, each pooled set of years represented different aggregate labour market conditions and as a result the functional job choice set that individuals faced due to labour demand will have also varied. As a result, labour demand considerations 
appear important for the analysis at hand.

As the bias in the estimated labour supply response is ambiguous, computationally costly, and difficult to apply in practice, it is commonly not accounted for in applied work that aims to solely consider the change in labour market outcomes that occurs. However, if welfare analysis was to be undertaken correcting for this bias would be important - as welfare costs could be considerable from a given policy change even without a large change in hours of work.

There are five ways that the model could be extended, directly or indirectly, to allow some form of labour demand and account for demand associated biases:

1. Iterating the model with labour demand elasticities for industries and/or occupations as in Creedy and Duncan (2005) to estimate how the gross wage will adjust given the estimated change in aggregate employment in a labour supply model. Iteration continues until the estimated change in gross wages is sufficiently small.

2. Computable General Equilibrium (CGE) and Behavioural Microsimulation (BMSM) model integration: Full integration between a CGE model and a BMSM offers the most comprehensive structural framework for considering the impact of policy, as not only is the labour market specified, but relative returns to factors are also forced to equalize introducing true GE effects. Examples of this are given in Ahmed and O'Donoghue (2008).

3. Interacting with explicit labour demand models by estimating a labour demand model directly from firm level data as in Bargain et al. (2010).

4. Incorporating a rationing probability (also termed risk of unemployment) directly into the labour supply model as in Bargain et al. (2006) and Muller (2014). In the NZ context this would involve using the HLFS Income supplement data to estimate the rationing probabili- 
ties.

5. Job types modelling as in Dagsvik and Strom (2006). Instead of assuming fixed hours or fixed gross wages for the individual, the individual is modelled to choose between a series of combinations of hours and gross wages that exist in the data.

Prior research that has included labour demand extensions have generally shown a reduction in labour supply responses as discussed in Spadaro (2007), Peichl (2008), and Peichl and Siegloch (2012).

However, each of these five methods involves a large extension to the estimation that is applied in this chapter and would require additional data and resources to integrate. Furthermore, relevant quality labour demand data such as from the longitudinal business database (LBD) are unavailable for the first two time periods of interest. As a result, in this chapter the gross wage has been left fixed. All five of these methods are potential extensions to this analysis which would be especially necessary if welfare analysis were to be undertaken.

\subsubsection{Selection criteria}

In addition to the selection criteria used for selecting HES respondents, this chapter restricts the sample that is used for preference parameter estimation further. For couples, the income unit (both individuals) is excluded from analysis if one of the individuals in the couple meets one of the following conditions. For single individuals the income unit is excluded from analysis if it meets one of these conditions.

- The individual is part of a same-sex couple.

- An individual is self employed.

- The individual is receiving National Superannuation or another re- 
tirement payment.

- The individual is deemed unable to work (temporarily or permanently) based on their receipt of a sickness or invalid's benefit.

- The individual's wage rate is above \$150 in June 2008 dollars.

- The non-wage income of the entire income unit is above $\$ 260,0000$ in June 2008 dollars.

Given those selection criterion, the remaining sample has the following summary statistics.

\subsubsection{Summary of samples}

Table 5.1: Summary Statistics HES88-HES93

\begin{tabular}{|c|c|c|c|c|c|}
\hline & Couple Men & Couple Women & Single Men & Single Women & Sole parents \\
\hline $\begin{array}{l}\text { Average wage rate (if } \\
\text { working) }\end{array}$ & $\$ 13.10$ & $\$ 10.47$ & $\$ 11.73$ & $\$ 11.14$ & $\$ 12.16$ \\
\hline Employment rate & $81.03 \%$ & $66.58 \%$ & $79.02 \%$ & $77.09 \%$ & $33.80 \%$ \\
\hline Average hours worked & 34.10 & 24.09 & 34.01 & 29.82 & 10.45 \\
\hline $\begin{array}{l}\text { Proportion that are fe- } \\
\text { male }\end{array}$ & & & & & 0.8609 \\
\hline Age/10 & 3.99 & 3.84 & 2.95 & 3.22 & 3.459 \\
\hline Number of Children & 1.291 & & & & 1.807 \\
\hline Size of selected sample & 9,620 & & 3,230 & 2,760 & 1,860 \\
\hline \multicolumn{6}{|c|}{ Highest Educational Achievement (proportion) } \\
\hline No qualification & 0.2925 & 0.3425 & 0.2950 & 0.2848 & 0.5337 \\
\hline School Certificate & 0.2591 & 0.3052 & 0.3677 & 0.3912 & 0.2652 \\
\hline Vocational & 0.2919 & 0.2390 & 0.2095 & 0.1857 & 0.1439 \\
\hline University Graduate & 0.1189 & 0.0815 & 0.0990 & 0.1129 & 0.0356 \\
\hline Other & 0.0376 & 0.0319 & 0.0288 & 0.0253 & 0.0216 \\
\hline \multicolumn{6}{|c|}{ Children Variables (proportion of families with dependants) } \\
\hline Youngest 0 & 0.141 & & & & 0.0857 \\
\hline Youngest 1-3 & 0.1209 & & & & 0.0884 \\
\hline Youngest 4-5 & 0.1035 & & & & 0.1197 \\
\hline Youngest 6-9 & 0.1630 & & & & 0.2070 \\
\hline Youngest 10+ & 0.4719 & & & & 0.4992 \\
\hline
\end{tabular}


Table 5.2: Summary Statistics HES94-98

\begin{tabular}{|c|c|c|c|c|c|}
\hline & Couple Men & Couple Women & Single Men & Single Women & Sole parents \\
\hline $\begin{array}{l}\text { Average wage rate (if } \\
\text { working) }\end{array}$ & $\$ 17.70$ & $\$ 12.97$ & $\$ 13.50$ & $\$ 12.90$ & $\$ 13.54$ \\
\hline Employment rate & $82.09 \%$ & $79.68 \%$ & $84.37 \%$ & $84.70 \%$ & $43.80 \%$ \\
\hline Average hours worked & 34.13 & 32.00 & 37.26 & 33.26 & 13.31 \\
\hline $\begin{array}{l}\text { Proportion that are fe- } \\
\text { male }\end{array}$ & & & & & 0.8779 \\
\hline Age/10 & 4.05 & 3.99 & 3.13 & 3.47 & 3.52 \\
\hline Number of Children & 1.1914 & & & & 1.806 \\
\hline Size of selected sample & 6680 & & 1,890 & 1,650 & 1,050 \\
\hline \multicolumn{6}{|c|}{ Highest Educational Achievement (proportion) } \\
\hline No qualification & 0.2416 & 0.2702 & 0.2618 & 0.2273 & 0.4475 \\
\hline School Certificate & 0.2829 & 0.2923 & 0.3476 & 0.3519 & 0.2910 \\
\hline Vocational & 0.2757 & 0.2721 & 0.2268 & 0.2062 & 0.1708 \\
\hline University Graduate & 0.1642 & 0.1366 & 0.1404 & 0.1753 & 0.0725 \\
\hline Other & 0.0355 & 0.0287 & 0.0233 & 0.0393 & 0.0181 \\
\hline \multicolumn{6}{|c|}{ Children Variables (proportion of families with dependants) } \\
\hline Youngest 0 & 0.1303 & & & & 0.0802 \\
\hline Youngest 1-3 & 0.1148 & & & & 0.0954 \\
\hline Youngest 4-5 & 0.1146 & & & & 0.1269 \\
\hline Youngest 6-9 & 0.1841 & & & & 0.1889 \\
\hline Youngest 10+ & 0.4562 & & & & 0.5086 \\
\hline
\end{tabular}

Table 5.3: Summary Statistics HES01-08

\begin{tabular}{|c|c|c|c|c|c|}
\hline & Couple Men & Couple Women & Single Men & Single Women & Sole parents \\
\hline $\begin{array}{l}\text { Average wage rate (if } \\
\text { working) }\end{array}$ & $\$ 20.88$ & $\$ 18.60$ & $\$ 18.18$ & $\$ 17.89$ & $\$ 17.73$ \\
\hline Employment rate & $89.67 \%$ & $76.99 \%$ & $83.96 \%$ & $84.22 \%$ & $57.25 \%$ \\
\hline Average hours worked & 38.23 & 28.75 & 34.98 & 32.05 & 18.46 \\
\hline $\begin{array}{l}\text { Proportion that are fe- } \\
\text { male }\end{array}$ & & & & & 0.8659 \\
\hline Age/10 & 4.31 & 4.23 & 3.35 & 3.78 & 3.70 \\
\hline Number of Children & 1.0273 & & & & 1.7210 \\
\hline Size of selected sample & 5,540 & & 1,650 & 1,450 & 840 \\
\hline \multicolumn{6}{|c|}{ Highest Educational Achievement (proportion) } \\
\hline No qualification & 0.1462 & 0.1637 & 0.1731 & 0.1462 & 0.2611 \\
\hline School Certificate & 0.3629 & 0.3770 & 0.4320 & 0.3988 & 0.4192 \\
\hline Vocational & 0.1893 & 0.1987 & 0.1671 & 0.1632 & 0.1449 \\
\hline University Graduate & 0.2456 & 0.2048 & 0.1908 & 0.2370 & 0.1198 \\
\hline Other & 0.0559 & 0.0558 & 0.0371 & 0.0548 & 0.0551 \\
\hline \multicolumn{6}{|c|}{ Children Variables (proportion of families with dependants) } \\
\hline Youngest 0 & 0.1315 & & & & 0.0635 \\
\hline Youngest 1-3 & 0.0971 & & & & 0.0683 \\
\hline Youngest 4-5 & 0.1171 & & & & 0.1222 \\
\hline Youngest 6-9 & 0.1973 & & & & 0.2036 \\
\hline Youngest $10+$ & 0.4570 & & & & 0.5425 \\
\hline
\end{tabular}


Table 5.4: Summary Statistics HES09-13

\begin{tabular}{|c|c|c|c|c|c|}
\hline & Couple Men & Couple Women & Single Men & Single Women & Sole parents \\
\hline $\begin{array}{l}\text { Average wage rate (if } \\
\text { working) }\end{array}$ & $\$ 29.81$ & $\$ 22.07$ & $\$ 21.53$ & $\$ 21.57$ & $\$ 22.55$ \\
\hline Employment rate & $94.14 \%$ & $68.52 \%$ & $78.08 \%$ & $78.12 \%$ & $55.86 \%$ \\
\hline Average hours worked & 41.10 & 23.34 & 31.18 & 28.18 & 18.26 \\
\hline $\begin{array}{l}\text { Proportion that are fe- } \\
\text { male }\end{array}$ & & & & & 0.8686 \\
\hline Age/10 & 4.27 & 4.16 & 3.35 & 3.70 & 3.79 \\
\hline Number of Children & 1.0058 & & & & 1.7025 \\
\hline Size of selected sample & 4,510 & & 2,130 & 2,130 & 1,130 \\
\hline \multicolumn{6}{|c|}{ Highest Educational Achievement (proportion) } \\
\hline No qualification & 0.1161 & 0.1303 & 0.1310 & 0.1072 & 0.2131 \\
\hline School Certificate & 0.4164 & 0.4477 & 0.5399 & 0.4534 & 0.4929 \\
\hline Vocational & 0.1421 & 0.1323 & 0.0948 & 0.1171 & 0.1057 \\
\hline University Graduate & 0.2717 & 0.2335 & 0.1986 & 0.2723 & 0.1394 \\
\hline Other & 0.0537 & 0.0562 & 0.0357 & 0.0499 & 0.0488 \\
\hline \multicolumn{6}{|c|}{ Children Variables (proportion of families with dependants) } \\
\hline Youngest 0 & 0.1410 & & & & 0.0675 \\
\hline Youngest 1-3 & 0.2791 & & & & 0.2149 \\
\hline Youngest 4-5 & 0.1050 & & & & 0.1083 \\
\hline Youngest 6-9 & 0.1669 & & & & 0.2123 \\
\hline Youngest $10+$ & 0.3079 & & & & 0.3970 \\
\hline
\end{tabular}

The summary data shows that there were clear differences between the sample periods.

One of the largest differences between the HES09-13 period and other periods is the higher employment rate of coupled men in this selected sample. While the Global Financial Crisis saw employment rates for all other groups decline, coupled men sample employment rates rose significantly. Although a higher employment rate is consistent with other data such as the Household Labour Force Survey, the magnitude of the difference is not and is a primary driver of the difference in the couples model for HES09-13 below.

Other key differences were a decline in the number of children, age of children, an increase in in highest educational achievement, and a higher average age.

The number of children declined for both couples and sole parents across 
the surveys. In both proportional and absolute terms the decline was largest for couples, with the average number of children among couples falling from 1.291 in HES88-93 to 1.006 in HES03-13. The average number of children in sole parent households declined from 1.807 to 1.703 over the same period.

The HES09-13 sample was also an outlier in terms of the age grouping of children. The HES09-13 period had a disproportionately large number of children aged 1-3 for couples and sole parents, and a correspondingly disproportionately small number of children aged 10+.

Educational attainment also increased over the time period, with the proportion of the sample who were university graduates rising by 15-16 percentage points for coupled men, coupled women, and single women and by 10 percentage points for single men and sole parents.

The average age of the sample rose over time for all demographic groups, increasing by between 3 years for coupled women and 5 years for single women.

There were also certain between demographic-subgroup differences that were maintained over time.

Single women and coupled men remained more qualified than other demographic subgroups, with higher proportions of university graduates and lower proportions of those without high school certificate.

Single men always tended to be younger than other demographic subgroups in the sample, with the average age reaching only 33 by HES09-13. The average age of both partners in a couple tends to be older than other demographic subgroups, with single women and sole parents inbetween couples and single men.

Employment rates tended to be lower for coupled women and sole parents than other groups over the entire time horizon. This is consistent with the 
fact that having a child increases the reservation wage for individuals. As, in the majority of cases, it is the female partner who takes a break from work to look after a child, this shows up more strongly in coupled women participation than coupled men participation.

Further differences in the distribution of participation and hours are discussed in Section 2.3.

\subsubsection{Distribution of hours}

The purpose of this chapter is to model the observed distribution of primary job wage and salary (W\&S) hours worked as a function of individuals preference over leisure and consumption. As a result, it is valuable to describe the distribution of observed hours for each demographic subgroup and how these distributions changed over time.

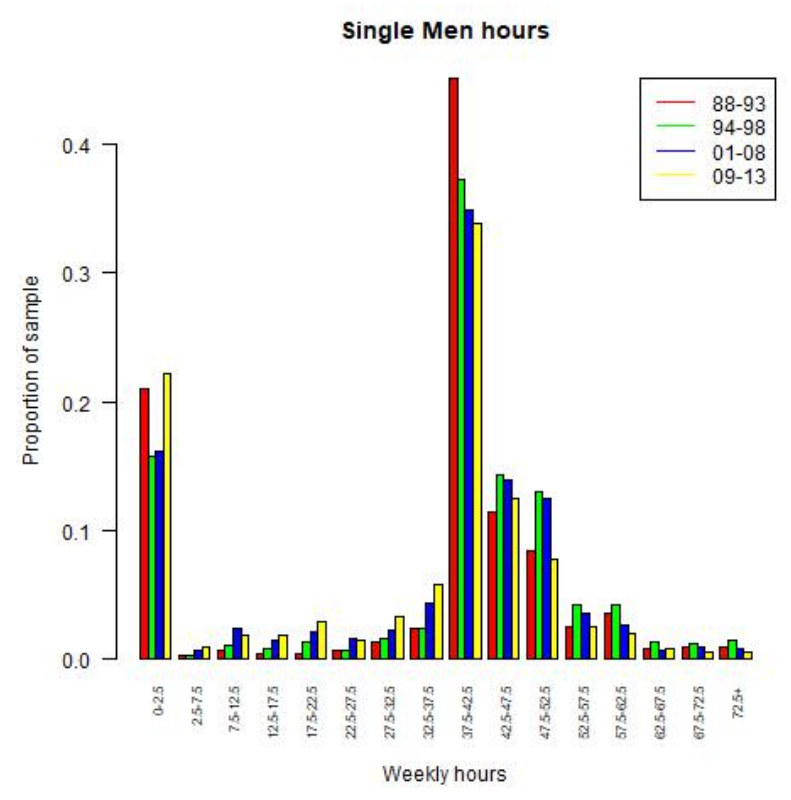

Figure 24: Single men W\&S hours distribution 


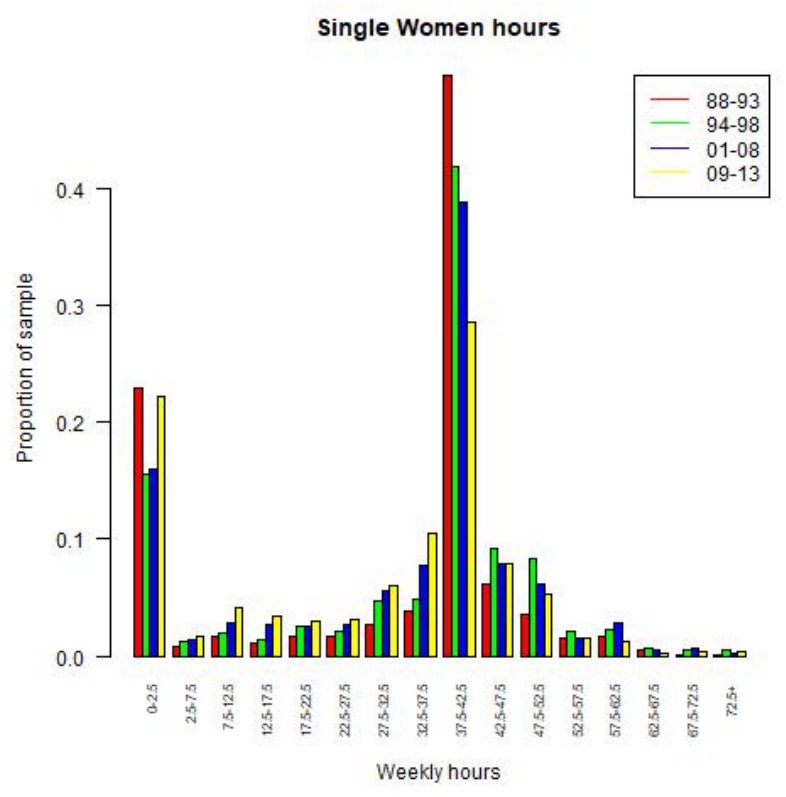

Figure 25: Single women W\&S hours distribution

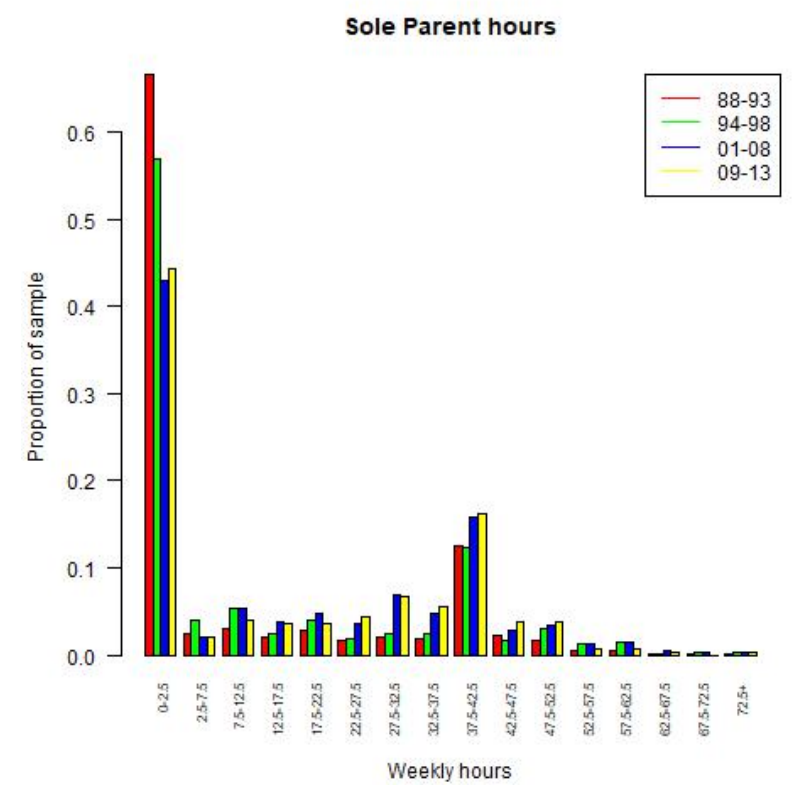

Figure 26: Sole parent W\&S hours distribution 


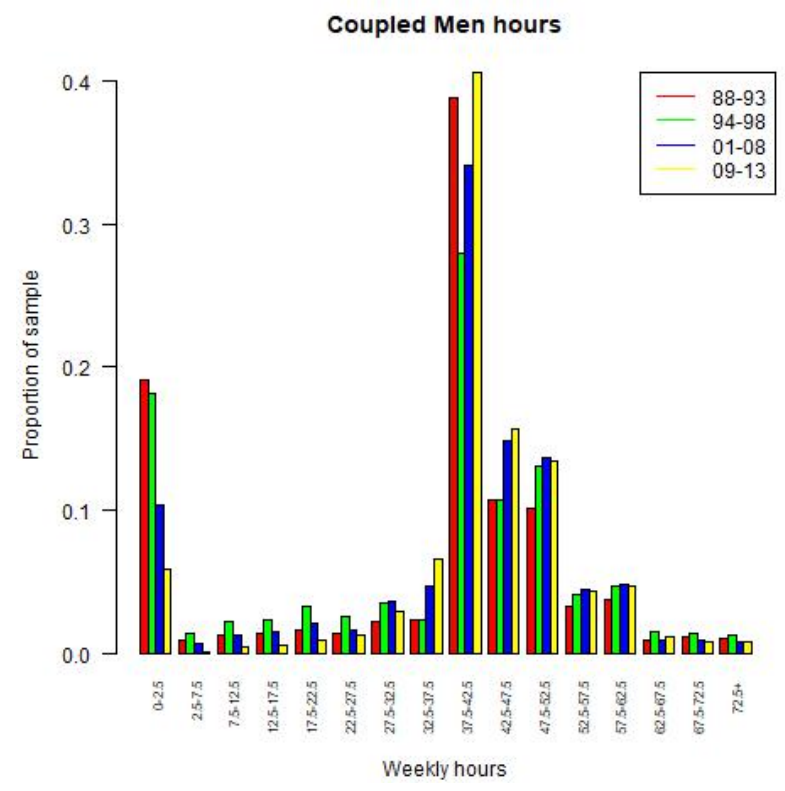

Figure 27: Coupled men W\&S hours distribution

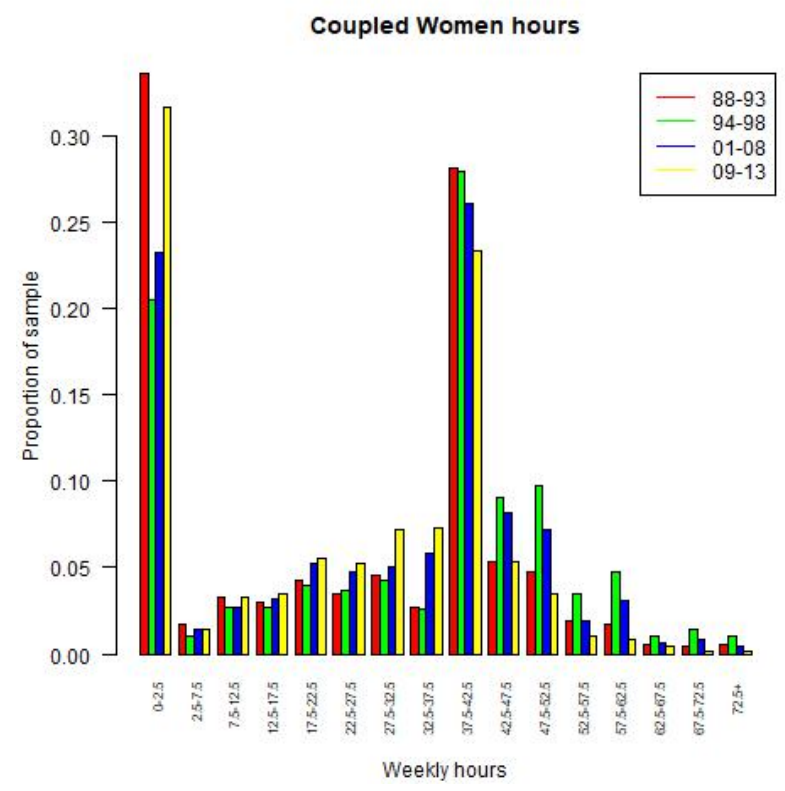

Figure 28: Coupled women W\&S hours distribution 
The above graphs show that, apart from sole parents and coupled men in HES09-HES13, there has been a movement away from approximately 40 hours of work per week in the HES sample.

As part of this movement all groups, except for coupled men, have experienced an increase in the share of the demographic group working less than 40 hours per week. The proportion of single men working between 2.5 and 37.5 hours per week rose from $5.7 \%$ to $17.8 \%$ between HES88-93 and HES909-13, for single women the increase was from $13.6 \%$ to $32 \%$, for sole parents it was $15.8 \%$ to $30 \%$, and for coupled women from $22.8 \%$ to $33.4 \%$. Unlike other groups, the increase in hours worked below 40 for sole parents was also associated with an increase in the proportion of individuals working $40+$ hours, as for sole parents there has been a general move away from non-participation to participation.

Coupled men have behaved differently to other groups in this regard. By HES09-13, 12.6\% of coupled men worked less than 40 hours per week up slightly from $11.2 \%$ in HES88-93. However, the rate of non-participation had declined during this period. As a result, the proportion of coupled men working more than 42.5 hours per week rose from $30.8 \%$ to $40.8 \%$.

The differences in non-participation between the late 1980s/early 1990s recession and the recession following the 2008 Global Financial Crisis (GFC) can also be seen in the data. Both samples had lower aggregate employment rates than the intervening years, but the distribution of these lower employment rates varied based on the individuals demographic subgroup.

Single men, single women, and coupled women all experienced a sharp increase in non-participation between HES01-08 and HES09-13 towards the levels reported in the HES88-93 survey. Although sole parent nonparticipation rates rose slightly between HES01-08 and HES09-13, nonparticipation for this group was well below its level in earlier years. Finally for coupled men non-participation in the sample continued to decline sharply in the GFC period - a shift that was at odds with all other 
groups.

All across the hours ranges in Figures 1-5 there is no instance when there was no-one in the sample at a given hours level. As a result, there is a broad range of hours that are relevant to consider when thinking about the labour supply choices of individuals: it is not the case that individual's only have the opportunity to work either zero or 40 hours, with a variety of hours points being observed in reality.

\subsubsection{Variables used}

The model of preferences for income and work is specified in terms of weekly income and weekly hours of work. However, these preferences are not homogeneous among individuals of the same group, and as a result other characteristics are included in the estimation to account for some of this observed heterogeneity.

Due to the smaller sample size used in each model than in Guyonne Kalb and Rosanna Scutella (2003), this chapter focuses on a reduced number of characteristics. When estimating heterogeneity in the linear parameters for the preference to work and preference for income, data on age, highest educational achievement, spouses highest educational achievement, number of children, and age of youngest child is used.

The key variable missing from prior estimates is a variable denoting region of residence. However, unemployment and year trends were also removed and interaction terms were not included. Interaction terms added very little to prior estimates and increased standard errors when they were introduced in many of the estimates below, as a result they were excluded from all equations. 


\subsection{Parametric model, specification, and estima- tion}

When considering the labour supply response of individuals to changes in their net incomes it is necessary to define and estimate the parameters of a decision rule that these agents follow. The preference parameters that are estimated in this chapter represent the preferences of agents who follow a defined rule when choosing their hours of work.

The decision rule assumes that agents maximise their family level utility with their choice of hours of work. A family is defined as an Economic Family Unit which is comprised of an adult, their partner (if applicable), and any dependent children.

This utility function is a positive function of consumption, $c$, and leisure, $l$. Families are endowed with characteristics $z$, a quantity of hours $T E$, and some non-labour income $y_{0}$. The families decision rule then allocates these hours between leisure and hours of work, where working generates income that can be spent on consumption. Here the choice variable in the decision rule is the hours of work for adults in the family, $h$.

The labour supply choice can then be modelled as a choice between hours of work and hours of leisure. An early version of this model which focuses on the choice of the hours of work in continuous time is Hausman (1980). For this model the notation of Spadaro (2007) is used. The vector of gross wages, including imputed wages, are termed $w$ and net taxes are denoted $N T$. The agent's maximisation problem then takes the form:

$$
\operatorname{Max} u(c, l ; z ; \beta, \epsilon) \text { st } c \leq y_{0}+w h-N T\left(w h, h, y_{0} ; z ; \gamma\right)
$$

Where $\gamma$ represents parameters of the tax-benefit system, and $\beta$ and $\epsilon$ are coefficients that parameterise preferences. The goal of this chapter is to 
estimate these preference parameters.

The maximisation yields a continuous labour supply function that can be estimated from household microdata as:

$$
h=F\left(w, y_{0} ; z ; \beta, \epsilon ; \gamma\right)
$$

Where $\beta$ and $\epsilon$ need to be estimated, as everything else is observed. For each agent, $i, \beta$ is defined as a shared preference term, and $\epsilon_{i}$ is an idiosyncratic individual preference (treated as a random error term). Given this, for each agent hours are estimated as:

$$
h_{i}=F\left(z_{i}, w_{i}, y_{0 i} ; \beta, \epsilon_{i} ; \gamma\right)
$$

However, MacCurdy et al. (1990) raised significant concerns about this type of model. Given non-linear taxes and transfers the data give a nonlinear budget constraint, and it is possible for parts of the budget constraint to be non-convex. Furthermore, there is an endogeniety problem with the tax rate and hours of work jointly determined.

As a result, in order to get model coherency it is essential to make a prori assumptions about the functional form of preferences in order to ensure that necessary conditions for the parameters of the model are met and/or to oversimplify the budget constraint relative to reality. This limits the flexibility of the model, makes maximum likelihood estimation of the parameters more difficult, and also may place inappropriate restrictions on model outcomes.

In order to deal with these criticisms, a discrete hours approach to estimating the labour supply can be utilised. 


\subsubsection{Discrete hours: van Soest's method}

A common way to reduce the computational burden of estimation and limit assumptions about the functional form of preferences, is to have agents choose from a discrete set of potential working hours as shown in van Soest (1995). In this case the agent $i$ picks from a discrete choice set of $j$ income and leisure alternatives, $\left\{\left(y_{j}, l_{j}\right)\right\}$. In the same way as in the continuous hours approach, $\beta$ and $\epsilon_{i}$ are estimated given the assumption that the agent is picking the level of hours $h$ that is optimal.

Creedy and Kalb (2005) discusses the process of estimation in more detail. The agent is assumed to maximise utility with error. This implies that they choose $h$ that maximises expected utility where: ${ }^{5}$

$$
u_{j}^{*}=u_{j}\left(h_{j} \mid z_{i}\right)+v_{j}
$$

This model is known as a Random Utility Model. When interpreting $v_{j}$ this error term could be due to mismeasurement of characteristics, unobserved characteristics, or optimization errors by agents. Given this characterisation of the agents choice, it is possible to generate a probability distribution for labour supply which can be used to calibrate labour supply choices in a microsimulation model.

Equation 5.4 describes a distribution of utility for each discrete hours level, depending on the distribution of $v_{j}$. Utility maximisation implies that for $K$ discrete hours levels, where $j, g \in K, u_{j}^{*}$ is chosen when $u_{j}^{*} \geq u_{g}^{*} \forall g$. Replacing these terms with the deterministic utility component and the stochastic error, then for $v_{j}$ the probability of $j$ being chosen is the joint probability of $v_{g} \leq v_{j}+u_{j}-u_{g}$ over all $g$.

Take $P\left(v_{g} \leq v_{j}+u_{j}-u_{g}\right)$ as the probability that $u_{j}^{*}>u_{i}^{*}$ and so $j$ is chosen

\footnotetext{
${ }^{5}$ A significantly more detailed discussion with reference to the Melbourne model MITTS can be found in the book Creedy et al. (2002).
} 
above $i$. Assuming the various distributions are independent gives the conditional probability for a given value of $v_{j}$ :

$$
\Pi_{g \neq j} P\left(v_{g} \leq v_{j}+u_{j}-u_{g}\right)
$$

As this provides the conditional probability for a single draw of $v_{j}$, the full probability of the $j$ th hours level being chosen can be found by summing this probability over all possible values of $v_{j}$.

If $v_{j}$ takes only a discrete values, $a_{k}$ for $k=1, \ldots, K$ then $p_{j}$ (the probability $h_{j}$ is chosen) can be represented as:

$$
p_{j}=\sum_{k=1}^{K}\left[\Pi_{g \neq j} F\left(a_{k}+u_{j}-u_{g}\right)\right] f\left(a_{k}\right)
$$

Where $f\left(a_{k}\right)$ is the proportion of values in the error distribution that equals $a_{k}$, and $F\left(a_{k}\right)$ is the proportion of values that are less than or equal to $a_{k}$. A numerical example of this is given in Creedy and Kalb (2005).

When $v$ is a continuous random variable (although the hours choice continues to be discrete) this sum becomes:

$$
p_{i}=\int_{-\infty}^{+\infty}\left[\Pi_{g \neq j} F\left(v_{j}+u_{j}-u_{g}\right)\right] f\left(v_{j}\right) d v_{j}
$$

Where $f(v)$ is the density function of $v$ and $F(v)$ is the distribution function of $v$.

The functional form of $v$ is often assumed to be of the extreme value distribution. ${ }^{6}$. This involves taking the density function:

\footnotetext{
${ }^{6}$ A detailed description of why this functional form is used can be found in Maddala (1983) This function holds the favourable property of independence from irrelevant alternatives McFadden (1974). Another way of viewing this assumption is discussed in Dagsvik and Jia (2008), with the condition termed the assumption of probabilistic rationality.
} 


$$
f(v)=e^{-v} e^{-e^{-v}}=\exp \left(-v-e^{-v}\right)
$$

Which gives the distribution function:

$$
F(v)=e^{-e^{-v}}
$$

Then $p_{j}$ can be derived as:

$$
p_{j}=\frac{e^{u_{j}}}{\sum_{g=1}^{n} e^{u_{g}}}
$$

Given $p_{i j}$ as the probability that hours level $j$ is selected by individual $i$, given $N$ individuals, and given a variable $d_{i j}$ that equals 1 when $j$ hours levels are selected and 0 otherwise, the log likelihood function is defined as:

$$
\ln L=\sum_{i}^{N} \sum_{j}^{J} d_{i j} \ln p_{i j}
$$

McFadden (1974) states that the maximum likelihood estimator is then the appropriate estimator for the parameters in this model.

Given this structure, microdata are then used to estimate the unobserved parameters of the model, the preference parameters that make up unobserved utility.

In the discrete hours approach, the relevant parameters can be defined over any legitimate utility function. Once a form for the utility function has been decided upon, the maximum likelihood estimator over the previously defined probability function can be used to estimate the parameters of interest. These parameters give a probability distribution of hours for each individual. 
A quadratic utility function is used in the same vein as Blundell et al. (2002), Guyonne Kalb and Rosanna Scutella (2003), and Mercante and Mok (2014a). This utility function is used due to its ease of implementation, and the fact that the type of utility function used appears to have little impact on the calculated labour supply elasticities, according to Loffler et al. (2013).

For a family unit, a quadratic utility function takes the form:

$$
\begin{aligned}
u_{i}= & \beta_{1} Y_{i}+\beta_{2} Y_{i}^{2}+\beta_{3} L m_{i}+\beta_{4} L f_{i}+\beta_{5} L m_{i}^{2}+\beta_{6} L f_{i}^{2} \\
& +\beta_{7} Y_{i} L m_{i}+\beta_{8} Y_{i} L f_{i}+\beta_{9} L m_{i} L f_{i}
\end{aligned}
$$

Where $Y_{i}$ is the family unit's income, $L m_{i}$ is male leisure and $L f_{i}$ is female leisure. Leisure is defined as the time endowment remaining after hours of work are subtracted. Conceptually, this framework can be further extended to consider changes in time use by splitting the leisure component into pure leisure and housework as it is in Kabátek et al. (2014). However, the purpose of such a decomposition is to add to the welfare analysis of hours worked rather than to improve estimates of the labour supply choice. As the choice of hours of work is the focus of this chapter this additional decomposition is not undertaken in this chapter.

Following Guyonne Kalb and Rosanna Scutella (2003) and Mercante and Mok (2014a) the utility function has been defined in terms of hours worked rather than leisure time. Defining male hours of work as $\mathrm{hm}$ and female hours of work as $h f$ the estimated utility function takes the form:

$$
\begin{aligned}
u_{i}= & \beta_{1} Y_{i}+\beta_{2} Y_{i}^{2}+\beta_{3} h m_{i}+\beta_{4} h f_{i}+\beta_{5} h m_{i}^{2}+\beta_{6} h f_{i}^{2} \\
& +\beta_{7} Y_{i} h m_{i}+\beta_{8} Y_{i} h f_{i}+\beta_{9} h m_{i} h f_{i}
\end{aligned}
$$

The utility function used incorporates a fixed cost of work. As an extension of labour supply models this stems from Cogan (1980). This was first 
implemented in this specific discrete hours framework in Euwals and van Soest (1999). The purpose of the fixed cost of work extension is two-fold. First there are fixed costs associated with taking up a job for an individual, and secondly as van Soest (1995) notes the incorporation of fixed costs helps to improve the fit of the model given that discrete labour hours models tend to overestimate the number of individuals taking on part time work.

As a result, the researcher can either adjust the utility function as in van Soest (1995) or remove an estimate of the fixed cost of employment from the net income for potential set of hours of work as in Mercante and Mok (2014a). The second option is used in this chapter to keep consistency with prior estimates of preference parameters for New Zealand. However, estimates for both forms were produced and the results reported were not very sensitive to the form of fixed costs used.

Fixed cost estimates in these models may be higher than an analyst intuitively expects when considering the material costs of taking up a job. In this model, the estimate of a fixed cost of working should not be seen as an estimate of the material costs of moving into work, but an estimate that includes the non-pecuniary costs of working as argued by Aaberge et al. (1995).

The role of the fixed costs parameter is to make part time work relatively unattractive, as a result estimates tend to be higher for groups that have a smaller observed group of individuals working part time. Given this, the fixed cost estimate can be seen as picking up unobserved characteristics that may be driving the choice about whether to participate in the labour market or not, or the choice about whether to work full time or part time. Furthermore, if the availability of hours is constrained on the demand side, which is likely, the fixed cost of work parameter will also represent this demand side constraint.

The final extension to the model involves making the preference param- 
eters vary based on the observed characteristics of the individuals surveyed. The linear preference parameters over both income and hours of work can be made dependent on a variety of socio-demographic characteristics. This allows for heterogeneity in the preference parameters to be estimated as a function of the observed characteristics of the individuals.

\subsubsection{Estimation}

The preference parameters are estimated using maximum likelihood where the log-likelihood function is defined using equation (5.11).

Numerical methods, specifically the BFGS quasi-Newtown method, are applied for optimisation in this chapter. The general-purpose optimization package in R, opm, is used to perform this as outlined in Nash (2016). In each case this involved minimising a negative log-likelihood and as a result the positive semi-definiteness of the Hessian was checked to ensure a local minimum was achieved.

A wide range of initial conditions were used with this method without the estimated parameters varying considerably. Given that the likelihood surface can become relatively flat, convergence was checked with initial conditions starting both above and below the estimated values. Furthermore, initial conditions from an estimated model without demographic characteristics were used to check for convergence.

Other methods were experimented with, especially for the single person estimates. Initial estimates using the non-gradient Nelder-Mead method appeared reasonable relative to prior New Zealand estimates and on average required a lower fixed cost to fit the data. However, both the magnitude and sign of these estimates were very sensitive to initial conditions, especially the estimates of fixed costs. 
For comparison purposes all the available models in the optimization package opm were estimated for singles, including a box-constraint model using economically intuitive constraints. The BFGS method gave the most consistent results, that satisfied quasi-concavity and local minimisation, among these methods.

It is possible to introduce unobserved heterogeniety into the preference parameters of the model using simulated maximum likelihood as discussed in Guyonne Kalb and Rosanna Scutella (2003). This can be applied using the mlogit package in $\mathrm{R}$ as described by Croissant (2018).

However, the unobserved heterogeneity terms tend to add little to the results as shown in Guyonne Kalb and Rosanna Scutella (2003) and Mercante and Mok (2014a) and TAXWELL-B is already designed to make use of results without these terms. Preliminary estimates for single people in HES01-08 using unobserved heterogeniety also indicated that these terms do not effect the parameter estimates. As a result, estimates excluding these terms, which are the same coefficients that can be applied to TAXWELL$B$, are reported in this chapter.

\subsection{Results of estimation}

The estimated quadratic utility function includes observed heterogeneity in the preference for work and income, typically dummy variables representing given characteristics of individuals. As a result, the estimated parameters for the individual characteristics are relative to a reference individual. In the case of all individuals, the reference individual is someone without Year 11 or above qualifications. Furthermore where the demographic grouping includes dependants, the youngest child is assumed to be over 9 years of age.

It is common for the preference for work to rise with age, peak, and then 
decline for all demographic groups. The approximate peak age and its change through time is described below.

Table 5.5: Single Men Estimates

\begin{tabular}{|c|c|c|c|c|c|c|c|c|}
\hline & \multicolumn{2}{|c|}{$1988-93$} & \multicolumn{2}{|c|}{$1994-98$} & \multicolumn{2}{|c|}{$2001-08$} & \multicolumn{2}{|c|}{$2009-13$} \\
\hline & Coefficient & P-value & Coefficient & P-value & Coefficient & P-value & Coefficient & P-value \\
\hline \multicolumn{9}{|c|}{ Hours worked } \\
\hline Constant & 2.1134 & 0.0000 & 1.6122 & 0.0000 & -0.6536 & 0.0041 & -0.7137 & 0.0001 \\
\hline Age $\div 10$ & 1.0703 & 0.0000 & -0.0277 & 0.7810 & 0.9868 & 0.0000 & 0.8153 & 0.0000 \\
\hline Age $^{2} \div 100$ & -0.1360 & 0.0000 & -0.0067 & 0.6211 & -0.1223 & 0.0000 & -0.0907 & 0.0000 \\
\hline High school diploma & 0.0944 & 0.1378 & 0.1334 & 0.0046 & -0.0330 & 0.5939 & -0.0592 & 0.2555 \\
\hline Vocational training & 0.2893 & 0.0000 & 0.2493 & 0.0000 & 0.1286 & 0.0779 & -0.1166 & 0.0860 \\
\hline Other education & -0.0330 & 0.8186 & 0.0263 & 0.8403 & -0.1065 & 0.3390 & -0.0538 & 0.5688 \\
\hline University graduate & 0.1296 & 0.1409 & 0.0432 & 0.5595 & 0.0457 & 0.5316 & 0.0020 & 0.9734 \\
\hline \multicolumn{9}{|c|}{ Weekly Income (hundreds) } \\
\hline Constant & 0.5582 & 0.0000 & 3.2719 & 0.0000 & -0.0196 & 0.8262 & 0.1466 & 0.0658 \\
\hline Age & 0.3587 & 0.000 & 0.1427 & 0.5075 & 0.2303 & 0.0008 & 0.1618 & 0.0009 \\
\hline Age $^{2} \div 100$ & -0.0441 & 0.0000 & 0.0118 & 0.6795 & -0.0241 & 0.0034 & -0.0160 & 0.0085 \\
\hline High school diploma & -0.0260 & 0.2775 & -0.4714 & 0.0000 & -0.0295 & 0.3020 & -0.0153 & 0.5772 \\
\hline Vocational training & 0.0357 & 0.2227 & -0.5099 & 0.0000 & 0.0028 & 0.9389 & -0.0276 & 0.4439 \\
\hline Other education & -0.0411 & 0.4656 & -0.6512 & 0.0061 & -0.0779 & 0.1436 & -0.0152 & 0.7627 \\
\hline University graduate & -0.0304 & 0.3984 & -0.1142 & 0.3753 & -0.0079 & 0.8267 & 0.0061 & 0.8506 \\
\hline Fixed Costs (hundreds) & 13.3261 & 0.0000 & 2.0388 & 0.0000 & 12.2844 & 0.0000 & 11.5981 & 0.0000 \\
\hline \multicolumn{9}{|c|}{ Quadratic Terms } \\
\hline Hours & -0.7111 & 0.0000 & -0.1971 & 0.0000 & -0.1322 & 0.0000 & -0.1237 & 0.0000 \\
\hline Income & 0.0003 & 0.947 & -0.0374 & 0.0000 & 0.0006 & 0.7377 & 0.0011 & 0.4349 \\
\hline \multicolumn{9}{|c|}{ Interaction Terms } \\
\hline Hours Income & -0.2135 & 0.0000 & -0.3549 & 0.0000 & -0.0510 & 0.0009 & -0.0844 & 0.0000 \\
\hline \multicolumn{9}{|c|}{ Model Fit } \\
\hline $\begin{array}{l}\text { Percent correctly pre- } \\
\text { dicted }\end{array}$ & $24.2 \%$ & & $34.4 \%$ & & $25.5 \%$ & & $24.6 \%$ & \\
\hline
\end{tabular}

Estimates for single men are reported in Table 5.5.

As expected, for single men the marginal utility of work declines as the hours of work increase for all time periods. However, the estimated rate of decline was very different between the HES88-93 period and other periods - with a much sharper decline in the preference for work in HES8893. ${ }^{7}$

The age relationship for the utility of work is relatively consistent for all

\footnotetext{
${ }^{7}$ These are shown by the quadratic hours term in Table 5.5
} 
periods except HES94-98. Each other period shows the utility of work peaking in the 40s for single men - at 40 for HES88-93, 41 in HES01-08, and 45 in HES09-13. In HES94-98, the estimated marginal utility of work falls monotonically by age with both the age and squared age terms not statistically different from zero.

Vocational training appeared to increase the utility of work in the HES8893 and HES94-98 estimates, but outside of this single men preference for work was invariant to highest qualification achieved.

For single men, the utility of income varies across periods. The largest discrepancy is between HES94-98 and the other time periods. For other time periods the coefficient on squared income, which represents the way the marginal utility of income changes with the level of income, is small and positive, but not significantly different from zero. In the HES94-HES98 estimate this term is negative and significant.

The effect of age on the utility of income is relatively constant across periods except HES94-98. The estimated age where the preference for income peaks was 41 in HES88-93, 48 in HES01-08, and 51 in HES09-13. For the HES94-98 estimate the preference for income rises continuously with age.

Other than the HES94-98 estimates, highest education level was largely unrelated to single men's utility of income. However, for HES94-98 the achievement of school certificate, vocational training, and other education were all strongly negatively related to the utility of income.

Estimated fixed costs for single mens are high for all periods except HES9498. These high fixed costs were above the Guyonne Kalb and Rosanna Scutella (2003) estimates but significantly below the large Mercante and Mok (2014a) estimates. Higher fixed costs for the single men group is consistent with the fact that this group has a low proportion of individuals in part-time employment. 
However, the fixed cost estimates for the HES94-98 year were substantially lower than the Guyonne Kalb and Rosanna Scutella (2003) estimates and this chapter's estimates for other years, even though the proportion of individuals in part time work was not out of line with other years. This in combination with the varying estimates for other variables in this model indicates that the underlying data-generating process for this sample differed strongly from the other periods.

Table 5.6: Single Women Estimates

\begin{tabular}{|c|c|c|c|c|c|c|c|c|}
\hline & \multicolumn{2}{|c|}{$1988-93$} & \multicolumn{2}{|c|}{ 1994-98 } & \multicolumn{2}{|c|}{ 2001-08 } & \multicolumn{2}{|c|}{$2009-13$} \\
\hline & Coefficient & $\mathrm{P}$-value & Coefficient & P-value & Coefficient & $\mathrm{P}$-value & Coefficient & $\mathrm{P}$-value \\
\hline \multicolumn{9}{|c|}{ Hours worked } \\
\hline Constant & 0.9121 & 0.0000 & 0.4808 & 0.0287 & -0.4749 & 0.0130 & 0.5817 & 0.0000 \\
\hline Age $\div 10$ & 0.6148 & 0.0000 & 0.4678 & 0.0000 & 0.7061 & 0.0000 & & \\
\hline Age $^{2} \div 100$ & -0.0915 & 0.0000 & -0.0689 & 0.0000 & -0.0892 & 0.000 & & \\
\hline High school diploma & 0.2304 & 0.0000 & 0.3535 & 0.0000 & 0.1372 & 0.0073 & -0.1071 & 0.3939 \\
\hline Vocational training & 0.2603 & 0.0000 & 0.3850 & 0.0000 & 0.2288 & 0.0002 & 0.1478 & 0.0266 \\
\hline Other education & 0.1393 & 0.0852 & 0.2847 & 0.0021 & 0.1204 & 0.1569 & 0.1331 & 0.0155 \\
\hline University graduate & 0.1682 & 0.0013 & 0.5601 & 0.0000 & 0.1880 & 0.0042 & 0.3101 & 0.0000 \\
\hline \multicolumn{9}{|c|}{ Weekly Income (hundreds) } \\
\hline Constant & 1.6754 & 0.0000 & 0.7986 & 0.0005 & 0.5248 & 0.0086 & 0.2969 & 0.0006 \\
\hline Age & 0.4154 & 0.0044 & 0.1175 & 0.3433 & 0.2706 & 0.0111 & & \\
\hline Age $^{2} \div 100$ & -0.0522 & 0.0073 & -0.0122 & 0.4361 & -0.0309 & 0.0195 & & \\
\hline High school diploma & 0.1075 & 0.1124 & 0.0912 & 0.1506 & -0.1124 & 0.0819 & -0.0432 & 0.3746 \\
\hline Vocational training & 0.0850 & 0.2728 & 0.0877 & 0.2145 & 0.0193 & 0.8048 & -0.0161 & 0.6859 \\
\hline Other education & 0.1072 & 0.5038 & 0.1774 & 0.1532 & -0.0347 & 0.7422 & 0.1237 & 0.6042 \\
\hline University graduate & 0.3737 & 0.5999 & 0.4641 & 0.000 & 0.0547 & 0.4772 & 0.0301 & 0.1072 \\
\hline Fixed Costs (hundreds) & 3.0819 & 0.0000 & 4.358 & 0.0000 & 4.1312 & 0.0000 & 13.5790 & 0.0002 \\
\hline \multicolumn{9}{|c|}{ Quadratic Terms } \\
\hline Hours & -0.2756 & 0.0000 & -0.2170 & 0.0000 & -0.1272 & 0.0000 & -0.1222 & 0.0000 \\
\hline Income & 0.0129 & 0.0439 & -0.0198 & 0.0120 & 0.0018 & 0.6276 & 0.0014 & 0.2576 \\
\hline \multicolumn{9}{|c|}{ Interaction Terms } \\
\hline Hours Income & -0.4406 & 0.0000 & -0.1443 & 0.0000 & -0.1444 & 0.0000 & -0.0502 & 0.0000 \\
\hline \multicolumn{9}{|c|}{ Model Fit } \\
\hline $\begin{array}{l}\text { Percent correctly pre- } \\
\text { dicted }\end{array}$ & $39.7 \%$ & & $23.5 \%$ & & $23.4 \%$ & & $24.0 \%$ & \\
\hline
\end{tabular}

Estimates for single women are reported in Table 5.6.

In a similar fashion to single men, single women marginal utility of work declines as the number of hours worked rises - but the size of this reduction fell over time. Outside of HES88-93, this falling marginal utility of 
work closely matched that of single men.

The general shape of the age relationship for the utility of work is consistent with prior estimates, with the marginal utility of work rising with age but at a declining rate. The marginal utility of work by age peaks at 34 in the HES88-93 and HES94-98 estimates, and at 40 in the HES01-08 estimates.

For HES09-13, the age relationship was removed. When age variables are included the model still converges, and the likelihood function is maximised. However, the constant and age terms for both the utility of income and hours are large (with opposite signs) and the estimated marginal utility of income at observed hours is negative for nearly a third of the sample data. As a result, this suggests that there is insufficient variation with age and that the model is poorly specified with age included.

Although educational attainment is positively associated with the utility of work for single women, it is only university level qualifications that offer a statistically significant increase over all time periods.

For single women, the estimate for the change in the marginal utility of income as income rises varied across the time periods from slightly positive in HES88-HES93 to slightly negative in HES94-98.

The utility of income is estimated to rise with age until the age of 40 in HES88-93, 49 in HES94-98, and 44 in HES01-08.

Through HES88-93 until HES01-08 the fixed-cost estimates are low relative to other groups but marginally higher than previous estimates for New Zealand. However, fixed cost estimates increase considerably in the HES09-13 estimate, rising above the estimate for single men.

Given that part time employment was at a higher level than at any prior period in HES09-13 the sudden increase in estimated fixed costs appears surprising. However, with the age relationship removed from this model 
the underlying estimate is fundamentally different from other years.

Table 5.7: Sole Parent Estimates

\begin{tabular}{|c|c|c|c|c|c|c|c|c|}
\hline & \multicolumn{2}{|c|}{$1988-93$} & \multicolumn{2}{|c|}{ 1994-98 } & \multicolumn{2}{|c|}{ 2001-08 } & \multicolumn{2}{|c|}{$2009-13$} \\
\hline & Coefficient & P-value & Coefficient & P-value & Coefficient & P-value & Coefficient & P-value \\
\hline \multicolumn{9}{|c|}{ Hours worked } \\
\hline Constant & -1.0906 & 0.0533 & -0.7633 & 0.0719 & 0.0921 & 0.8444 & -1.7977 & 0.0155 \\
\hline Age $\div 10$ & 0.700 & 0.0134 & 0.2482 & 0.2333 & 0.2130 & 0.3369 & 1.1785 & 0.0001 \\
\hline Age $^{2} \div 100$ & -0.0847 & 0.0168 & -0.0326 & 0.1631 & -0.0320 & 0.2564 & -0.1297 & 0.0011 \\
\hline High school diploma & 0.1352 & 0.0323 & 0.2168 & 0.0001 & 0.1954 & 0.0020 & & \\
\hline Vocational training & 0.2168 & 0.0011 & 0.3030 & 0.0000 & 0.3046 & 0.0002 & & \\
\hline Other education & 0.3172 & 0.0244 & 0.3773 & 0.0130 & 0.1103 & 0.3232 & & \\
\hline University graduate & 0.3794 & 0.0001 & 0.4020 & 0.0000 & 0.1466 & 0.1045 & & \\
\hline Youngest Child 0 & -0.1096 & 0.5321 & -0.5218 & 0.0022 & -0.7731 & 0.0000 & -0.0568 & 0.7734 \\
\hline Youngest Child 1-3 & -0.4107 & 0.0000 & -0.4509 & 0.0000 & -0.4576 & 0.0000 & -0.0564 & 0.5891 \\
\hline Youngest Child 4-5 & -0.1997 & 0.0342 & -0.4106 & 0.0000 & -0.3903 & 0.0000 & -0.2454 & 0.0229 \\
\hline Youngest Child 6-9 & -0.3396 & 0.0000 & -0.2468 & 0.0000 & -0.2477 & 0.0000 & -0.1179 & 0.1096 \\
\hline Number of Children & 0.0333 & 0.2893 & -0.0668 & 0.0284 & 0.0063 & 0.8302 & -0.0669 & 0.0523 \\
\hline \multicolumn{9}{|c|}{ Weekly Income (hundreds) } \\
\hline Constant & 0.7484 & 0.0212 & 0.7853 & 0.1707 & 1.9090 & 0.0048 & -0.0810 & 0.5786 \\
\hline Age & -0.1353 & 0.3570 & 0.1110 & 0.7005 & -0.3560 & 0.2724 & 0.0910 & 0.4474 \\
\hline Age $^{2} \div 100$ & 0.0172 & 0.3569 & -0.0079 & 0.8248 & 0.0402 & 0.3256 & -0.0105 & 0.4723 \\
\hline High school diploma & -0.0573 & 0.1147 & -0.1516 & 0.0931 & 0.0548 & 0.5385 & & \\
\hline Vocational training & -0.0767 & 0.0769 & -0.1600 & 0.1163 & -0.1271 & 0.2382 & & \\
\hline Other education & -0.0301 & 0.7416 & -0.3285 & 0.1325 & 0.07573 & 0.6189 & & \\
\hline University graduate & -0.0575 & 0.4139 & 0.1604 & 0.2523 & 0.06908 & 0.5371 & & \\
\hline Youngest Child 0 & 0.2677 & 0.0119 & 0.7272 & 0.0071 & 0.2549 & 0.1857 & 0.0616 & 0.2399 \\
\hline Youngest Child 1-3 & 0.0326 & 0.5442 & 0.3087 & 0.0188 & 0.1522 & 0.1765 & 0.0284 & 0.3243 \\
\hline Youngest Child 4-5 & 0.0624 & 0.2668 & 0.0396 & 0.7526 & -0.0492 & 0.6599 & -0.0093 & 0.6119 \\
\hline Youngest Child 6-9 & -0.0329 & 0.4164 & -0.0316 & 0.7477 & -0.0696 & 0.4095 & -0.0055 & 0.7150 \\
\hline Number of Children & 0.0370 & 0.0567 & 0.0641 & 0.1467 & -0.0172 & 0.6168 & 0.0032 & 0.6026 \\
\hline Fixed Costs (hundreds) & 6.7716 & 0.0000 & 2.6157 & 0.0000 & 3.271 & 0.0000 & 23.41 & 0.1084 \\
\hline \multicolumn{9}{|c|}{ Quadratic Terms } \\
\hline Hours & -0.0768 & 0.0020 & 0.0702 & 0.0074 & -0.1058 & 0.0004 & -0.1400 & 0.0000 \\
\hline Income & -0.0170 & 0.0179 & -0.0663 & 0.0000 & -0.0253 & 0.0003 & -0.0026 & 0.2965 \\
\hline \multicolumn{9}{|c|}{ Interaction Terms } \\
\hline Hours Income & -0.0359 & 0.0429 & -0.0646 & 0.0022 & -0.0565 & 0.0009 & -0.01297 & 0.3660 \\
\hline \multicolumn{9}{|c|}{ Model Fit } \\
\hline $\begin{array}{l}\text { Percent correctly pre- } \\
\text { dicted }\end{array}$ & $66.3 \%$ & & $57.9 \%$ & & $43.5 \%$ & & $43.4 \%$ & \\
\hline
\end{tabular}

Estimates for sole parents are reported in Table 5.7.

In terms of the marginal utility of work for sole parents, every period except HES94-HES98 had marginal utility falling as the hours of work rose. This decline increased through time in the data. The HES94-HES98 es- 
timate suggested that the marginal utility of work increased with hours worked. This time period had the highest proportion of sole parents working part time, while EMTR's were high and so the additional income associated with increasing hours for part time work was limited. As a result, increasing marginal utility of work was the only way to fit the sole parent data for this period.

The age relationship for sole parents takes a similar shape over the time periods under investigation. The utility of work peaks at the age of 42 in HES88-93, 39 in HES94-98, 34 in HES01-08, and 46 in HES09-13. However, the implied disutility of work increases more rapidly with age in HES0913 than other years implying that the relative preference for young sole parents to work is much higher during this time.

In the first three time periods the age of the child has a strong negative relationship on a sole parents utility from work at all ages. However, the HES09-13 sample shows a much weaker relationship.

Through HES88-93 until HES01-08, educational completion had a positive impact on the utility of work for sole parents. In the HES09-13 sample the effect was unstable and the variables were removed from the analysis.

In terms of the marginal utility of income, diminishing marginal utility of income holds for all the estimated time periods.

The age relationship is inconsistent across years. However, the estimated relationship is not statistically significant in any of the time periods. The same holds for educational attainment and the child variables.

The fixed-cost term required to fit the distribution behaved in a similar manner to single women between HES88-93 and HES01-08. The estimated fixed costs were well below the estimates in Guyonne Kalb and Rosanna Scutella (2003), and declined as employment including part time employment increased for sole parents. 
However, the fixed cost term increased significantly in the HES09-13 estimate, well above the low estimates in Mercante and Mok (2014a). The employment rate declined in this period (although it is still higher than it was in HES88-93) and furthermore the proportion of employed individuals in part time employment had more than doubled between HES88-93 and HES09-13. At face value these facts makes the increase in the fixed cost surprising.

As mentioned above the effect of age on the utility from work is substantially different in magnitude in HES09-13 suggesting that the behaviour of sole parents in different age groups varied more significantly in this period then it did in other periods. Given this heterogeneity by age, a higher fixed cost term will have been necessary to ensure that sufficient numbers of sole parents stayed out of employment. 
Table 5.8: Couple Estimates

\begin{tabular}{|c|c|c|c|c|c|c|c|c|}
\hline & \multicolumn{2}{|c|}{$1988-93$} & \multicolumn{2}{|c|}{ 1994-98 } & \multicolumn{2}{|c|}{ 2001-08 } & \multicolumn{2}{|c|}{$2009-13$} \\
\hline & Coefficient & P-value & Coefficient & P-value & Coefficient & P-value & Coefficient & $\mathrm{P}$-value \\
\hline \multicolumn{9}{|c|}{ Male partner Hours worked } \\
\hline Constant & 2.700 & 0.0000 & 0.6132 & 0.0002 & 2.0286 & 0.0000 & 3.7669 & 0.0000 \\
\hline Age $\div 10$ & 0.4659 & 0.0000 & 0.4461 & 0.0000 & 0.3612 & 0.0000 & 0.8555 & 0.0000 \\
\hline $\mathrm{Age}^{2} \div 100$ & -0.0667 & 0.0000 & -0.0632 & 0.0000 & -0.0503 & 0.0000 & -0.1035 & 0.2132 \\
\hline High school diploma & 0.0533 & 0.0072 & 0.0808 & 0.0028 & 0.0552 & 0.1626 & -0.0028 & 0.9573 \\
\hline Vocational training & 0.1461 & 0.0107 & 0.2295 & 0.0005 & 0.1005 & 0.1305 & -0.1036 & 0.1261 \\
\hline Other education & 0.1009 & 0.0043 & 0.1567 & 0.0000 & 0.0137 & 0.7501 & -0.5861 & 0.2350 \\
\hline University graduate & 0.3186 & 0.0000 & 0.2635 & 0.0000 & 0.1129 & 0.0007 & -0.1506 & 0.0001 \\
\hline Youngest Child 0 & -0.3473 & 0.0000 & -0.3924 & 0.0000 & -0.2525 & 0.0000 & & \\
\hline Youngest Child 1-3 & -0.2968 & 0.0000 & -0.3219 & 0.0000 & -0.2331 & 0.0000 & & \\
\hline Youngest Child 4-5 & -0.2742 & 0.0000 & -0.2619 & 0.0000 & -0.1811 & 0.0000 & & \\
\hline Youngest Child 6-9 & -0.1487 & 0.0000 & -0.1502 & 0.0000 & -0.0394 & 0.3730 & & \\
\hline Number of Children & -0.0425 & 0.0845 & -0.0351 & 0.2640 & -0.0312 & 0.3801 & & \\
\hline $\begin{array}{l}\text { Partner High school } \\
\text { diploma }\end{array}$ & 0.0941 & 0.0000 & 0.0822 & 0.0017 & 0.1332 & 0.0003 & 0.0473 & 0.3768 \\
\hline $\begin{array}{l}\text { Partner } \quad \text { Vocational } \\
\text { training }\end{array}$ & -0.0310 & 0.5932 & -0.0411 & 0.5909 & -0.0245 & 0.7176 & 0.1469 & 0.0261 \\
\hline Partner Other education & 0.0918 & 0.0087 & 0.0778 & 0.0423 & 0.1959 & 0.0000 & 0.0976 & 0.0422 \\
\hline $\begin{array}{l}\text { Partner University } \\
\text { graduate }\end{array}$ & -0.1118 & 0.0583 & -0.0442 & 0.5297 & 0.0647 & 0.3585 & 0.0956 & 0.7764 \\
\hline \multicolumn{9}{|c|}{ Female Hours worked } \\
\hline Constant & 0.5392 & 0.0000 & 0.0530 & 0.7327 & 0.8839 & 0.0000 & -0.0748 & 0.6001 \\
\hline Age $\div 10$ & 0.5327 & 0.0000 & 0.4495 & 0.0000 & 0.2550 & 0.0000 & 0.2138 & 0.0000 \\
\hline $\mathrm{Age}^{2} \div 100$ & -0.0785 & 0.0000 & -0.0640 & 0.0000 & -0.0420 & 0.0000 & -0.0231 & 0.7333 \\
\hline High school diploma & 0.0755 & 0.1480 & 0.0736 & 0.3562 & -0.0098 & 0.8470 & 0.0535 & 0.2233 \\
\hline Vocational training & 0.2199 & 0.0000 & 0.1983 & 0.0000 & 0.1085 & 0.0038 & 0.0248 & 0.4598 \\
\hline Other education & 0.1712 & 0.8332 & 0.3457 & 0.2832 & -0.1056 & 0.9130 & -0.0434 & 0.9887 \\
\hline University graduate & 0.3389 & 0.4849 & 0.2721 & 0.3851 & 0.0416 & 0.953 & -0.0230 & 0.9743 \\
\hline Youngest Child 0 & -0.6013 & 0.0000 & -0.3586 & 0.0000 & -0.5273 & 0.0000 & & \\
\hline Youngest Child 1-3 & -0.4640 & 0.0000 & -0.2793 & 0.0000 & -0.3505 & 0.0000 & & \\
\hline Youngest Child 4-5 & -0.3557 & 0.0000 & -0.2336 & 0.0000 & -0.2326 & 0.0000 & & \\
\hline Youngest Child 6-9 & -0.2123 & $0.0000 \mathrm{c}$ & -0.1143 & 0.0000 & -0.1531 & 0.0000 & & \\
\hline Number of Children & -0.0402 & 0.0000 & -0.03996 & 0.0000 & -0.04833 & 0.0000 & & \\
\hline $\begin{array}{l}\text { Partner High school } \\
\text { diploma }\end{array}$ & 0.0968 & 0.0653 & 0.1008 & 0.1233 & -0.0232 & 0.6774 & 0.0376 & 0.4095 \\
\hline $\begin{array}{l}\text { Partner } \\
\text { training }\end{array}$ & -0.0519 & 0.0087 & -0.0382 & 0.2626 & -0.0278 & 0.4440 & 0.0749 & 0.0245 \\
\hline Partner Other education & -0.0340 & 0.0063 & -0.0387 & 0.1092 & -0.0873 & 0.0025 & 0.0976 & 0.0004 \\
\hline $\begin{array}{l}\text { Partner } \\
\text { graduate }\end{array}$ & -0.1297 & 0.0000 & -0.1555 & 0.0000 & -0.0578 & 0.0863 & 0.0956 & 0.0060 \\
\hline
\end{tabular}


198CHAPTER 5. INCOME-LEISURE PREFERENCES IN NEW ZEALAND

\section{Couple Estimates (continued)}

\begin{tabular}{|c|c|c|c|c|c|c|c|c|}
\hline & \multicolumn{2}{|c|}{$1988-93$} & \multicolumn{2}{|c|}{ 1994-98 } & \multicolumn{2}{|c|}{ 2001-08 } & \multicolumn{2}{|c|}{$2009-13$} \\
\hline & Coefficient & P-value & Coefficient & P-value & Coefficient & P-value & Coefficient & $\mathrm{P}$-value \\
\hline \multicolumn{9}{|c|}{ Weekly Income (hundreds) } \\
\hline Constant & 0.5846 & 0.0000 & 0.8050 & 0.0000 & 0.5193 & 0.0000 & 0.3049 & 0.0000 \\
\hline Number of Children & -0.0132 & 0.1877 & -0.0228 & 0.0497 & -0.0196 & 0.1327 & 0.0061 & 0.9017 \\
\hline $\begin{array}{l}\text { Male Fixed Costs (hun- } \\
\text { dreds) }\end{array}$ & 14.791 & 0.0000 & 5.5014 & 0.0000 & 13.5514 & 0.0000 & 39.82 & 0.0000 \\
\hline $\begin{array}{l}\text { Female Fixed Costs } \\
\text { (hundreds) }\end{array}$ & 8.9528 & 0.0000 & 5.6627 & 0.0000 & 9.9019 & 0.0000 & 13.98 & 0.0000 \\
\hline \multicolumn{9}{|c|}{ Quadratic Terms } \\
\hline Male Hours & -0.4590 & 0.0000 & -0.1388 & 0.0000 & -0.3455 & 0.0000 & -0.7795 & 0.0000 \\
\hline Female Hours & -0.1332 & 0.0000 & -0.0342 & 0.0032 & -0.1117 & 0.0000 & -0.1229 & 0.0000 \\
\hline Income & -0.0033 & 0.0000 & -0.0092 & 0.0000 & -0.0009 & 0.0542 & -0.0006 & 0.0115 \\
\hline \multicolumn{9}{|c|}{ Interaction Terms } \\
\hline Male Hours Income & -0.0592 & 0.0000 & -0.0578 & 0.0000 & -0.0394 & 0.0000 & -0.0295 & 0.0000 \\
\hline Female Hours Income & -0.0371 & 0.0000 & -0.0472 & 0.0000 & -0.0234 & 0.0000 & -0.0151 & 0.0000 \\
\hline Male Hours Female & -0.2362 & 0.0000 & -0.1121 & 0.0000 & -0.1198 & 0.0000 & -0.0794 & 0.0000 \\
\hline Hours & & & & & & & & \\
\hline \multicolumn{9}{|c|}{ Model Fit } \\
\hline $\begin{array}{l}\text { Percent both correctly } \\
\text { predicted (deterministi- } \\
\text { cally) }\end{array}$ & $11.6 \%$ & & $11.8 \%$ & & $10.7 \%$ & & $17.2 \%$ & \\
\hline
\end{tabular}


Estimates for couples are reported in Table 5.8.

For both coupled men and women, the marginal utility of work declines with hours worked for all estimated periods.

For coupled men, the effect of age on the utility of work was relatively consistent between HES88-93 and HES01-08. However, by HES09-13 the estimated peak utility of work by age rose significantly along with the associated constant, a result that is consistent with the very high employment rate for couple men in the HES09-13 sample. The peak utility of work occurred at 35 in HES88-93, 36 in HES94-98 and HES01-08, and 42 in HES09-13.

The effect of age on coupled women's utility of work was relatively consistent between HES88-93 and HES94-98. However, in HES01-08 and HES0913 the estimated peak utility of work had fallen. In HES09-13 the constant also declined, helping to fit the drop in the employment rate during this period.

The peak utility of work for coupled women occurred at 34 in HES8893, 36 in HES94-98, 31 in HES01-08, and 47 in HES09-13. However, the difference in peak ages is partially a result of the varying specification of the HES09-HES13 model relative to other time periods. Specifically, information about the number and age of children in not used for the hours preference estimation in this time period.

Educational attainment increased the utility of work, especially for coupled men, in the HES88-93 and HES94-98 periods. However, this effect became insignificant over the 2000s and for coupled men it broadly turned negative by HES09-13.

Relative to other time periods, the HES09-13 estimates do not include children variables in the estimation of couples preferences for hours of work. The introduction of these terms led to the Hessian no longer being positive semi-definite. The only terms that were estimated to be significant were 
the age of the child for women, and the inclusion of these variables also increase the linear coefficient for hours of work. As a result, the exclusion of the child variables seems appropriate for this period.

For earlier time periods the estimated coefficient for coupled women took the expected sign given that, on average, the male-breadwinner view of family organisation remained dominant during this period. The younger the child, the lower a coupled women's preference for work, and the greater the number of children, the lower the estimated utility of work. These estimates were relatively in line with prior literature.

However, a lower marginal utility of work given a younger child and more children was also estimated for coupled men. Although the coefficients were smaller than for coupled women they were still large and significant. A result that differs from prior New Zealand estimates. These results were robust to multiple specifications and initial values. Intuitively, having a child increases the opportunity cost of an hour of work for both men and women so these estimates appear consistent.

The marginal utility of income declines with income for all periods, indicating that diminishing marginal utility holds for these estimates.

The number of child term was relatively insignificant across time periods, except for HES94-HES98 when the number of children had a statistically significant negative effect on the utility of income. This is surprising given that a greater number of children would be expected to increase the value of income to the family unit. However, this result is consistent with prior New Zealand estimates.

Men's fixed cost estimates were higher than women's estimates for all periods, excepting HES94-98 where the two terms were close. Coupled men's fixed costs were lower than prior estimates for New Zealand between HES88-93 and HES01-08. However, fixed cost estimates were much higher in the HES09-13 estimates, above the already high HES07-11 esti- 
mates in Mercante and Mok (2014a). The same relative trend, although at a lower level, holds for women's fixed costs.

In the HES09-13 period the coupled men data behaved very differently from other demographic subgroups, with part-time employment and nonparticipation both falling sharply. The sharp increase in the density of the hours distribution towards high hours of work irrespective of the individual's characteristics forces a large fixed cost term to ensure that some individuals do not participate.

\subsubsection{Estimated hours distribution}

Given the estimated parameter values the probability of an individual working at a discrete hours point is given by equation (5.10). The average value of these probabilities for a discrete hours point over the entire sample gives the probabilistically predicted employment at each of these points. These values can then be compared to the observed values in order to evaluate the fit of the models.

The reported part time employment percentage is the proportion of people who are employed and working one of the employment categories that are 25 hours or below. For coupled men the discrete hour categories are larger, and part time employment is for those in the 20 hour or below group. 
202CHAPTER 5. INCOME-LEISURE PREFERENCES IN NEW ZEALAND

Table 5.9: Single Women Hours Frequency Distributions

\begin{tabular}{|c|c|c|c|c|}
\hline & $1988-93$ & 1994-98 & 2001-08 & 2009-13 \\
\hline \multicolumn{5}{|c|}{ Observed } \\
\hline Employment rate & $77.09 \%$ & $84.70 \%$ & $84.22 \%$ & $78.13 \%$ \\
\hline Employed Part Time \% & $9.1 \%$ & $\%$ & $\%$ & $.8 \%$ \\
\hline Employed 0 hours & $22.98 \%$ & $15.60 \%$ & $15.98 \%$ & $22.25 \%$ \\
\hline Employed 5 hours & $0.83 \%$ & $1.27 \%$ & $1.35 \%$ & $1.65 \%$ \\
\hline hours & $1.74 \%$ & 1.9 & $2.84 \%$ & $4.19 \%$ \\
\hline Employed 15 hours & $1.09 \%$ & $1.39 \%$ & $2.71 \%$ & $3.48 \%$ \\
\hline Employed 20 hours & $1.63 \%$ & $2.54 \%$ & $\%$ & $2.96 \%$ \\
\hline Employed 25 hours & $1.70 \%$ & $2.18 \%$ & $2.71 \%$ & $3.15 \%$ \\
\hline Employed 30 hours & $2.71 \%$ & $4.78 \%$ & $5.62 \%$ & $6.07 \%$ \\
\hline Employed 35 hours & $3.87 \%$ & $4.90 \%$ & $7.72 \%$ & $10.49 \%$ \\
\hline Employed 40 hours & $49.76 \%$ & $41.34 \%$ & $38.86 \%$ & $28.65 \%$ \\
\hline 5 hours & $6.23 \%$ & $\%$ & & $7.95 \%$ \\
\hline Employed 50 hours & $\%$ & 14 & 11 & $\%$ \\
\hline Total & 2760 & 16 & & \\
\hline \multicolumn{5}{|c|}{ Probabilistically Predicted } \\
\hline Employment rate & $77.01 \%$ & $84.42 \%$ & $83.95 \%$ & $77.67 \%$ \\
\hline Employed Part Time \% & $10.0 \%$ & $13.0 \%$ & $16.9 \%$ & $23.4 \%$ \\
\hline Employed 0 hours & $22.99 \%$ & $15.58 \%$ & $16.05 \%$ & $22.33 \%$ \\
\hline Employed 5 hours & $0.09 \%$ & $0.38 \%$ & $0.77 \%$ & $1.23 \%$ \\
\hline Employed 10 hours & $0.32 \%$ & $0.88 \%$ & & $2.04 \%$ \\
\hline Employed 15 hours & $0.85 \%$ & $1.65 \%$ & $2.22 \%$ & $3.23 \%$ \\
\hline Employed 20 hours & $2.00 \%$ & $2.94 \%$ & $3.69 \%$ & $4.94 \%$ \\
\hline Employed 25 hours & $4.46 \%$ & $5.13 \%$ & $6.15 \%$ & $7.11 \%$ \\
\hline Employed 30 hours & $8.96 \%$ & $8.56 \%$ & $9.67 \%$ & $9.47 \%$ \\
\hline Employed 35 hours & $14.56 \%$ & $12.83 \%$ & $13.40 \%$ & $11.54 \%$ \\
\hline Employed 40 hours & $17.89 \%$ & $16.60 \%$ & $15.98 \%$ & $12.84 \%$ \\
\hline Employed 45 hours & $16.43 \%$ & $18.30 \%$ & $16.34 \%$ & $13.08 \%$ \\
\hline Employed 50 hours & $11.44 \%$ & $17.14 \%$ & $14.38 \%$ & $12.20 \%$ \\
\hline Total & 2760 & 1650 & 1480 & 2130 \\
\hline
\end{tabular}


Table 5.10: Single Men Hours Frequency Distributions

\begin{tabular}{|c|c|c|c|c|}
\hline & $1988-93$ & 1994-98 & 2001-08 & $2009-13$ \\
\hline \multicolumn{5}{|c|}{ Observed } \\
\hline Employment rate & $79.02 \%$ & $84.36 \%$ & $83.96 \%$ & $78.08 \%$ \\
\hline Employed Part Time \% & $2.6 \%$ & $4.5 \%$ & $9.3 \%$ & $11.3 \%$ \\
\hline Employed 0 hours & $20.98 \%$ & $15.69 \%$ & $16.10 \%$ & $22.21 \%$ \\
\hline Employed 5 hours & $0.25 \%$ & $0.16 \%$ & $0.61 \%$ & $0.89 \%$ \\
\hline Employed 10 hours & $0.56 \%$ & $0.95 \%$ & $2.31 \%$ & $1.83 \%$ \\
\hline Employed 15 hours & $0.31 \%$ & $0.74 \%$ & $1.34 \%$ & $1.83 \%$ \\
\hline Employed 20 hours & $0.37 \%$ & $1.32 \%$ & $2.00 \%$ & $2.82 \%$ \\
\hline Employed 25 hours & $0.56 \%$ & $0.58 \%$ & $1.58 \%$ & $1.46 \%$ \\
\hline Employed 30 hours & $1.30 \%$ & $1.48 \%$ & $2.25 \%$ & $3.24 \%$ \\
\hline Employed 35 hours & $2.35 \%$ & $2.28 \%$ & $4.25 \%$ & $5.77 \%$ \\
\hline Employed 40 hours & $45.25 \%$ & $37.36 \%$ & $34.93 \%$ & $33.90 \%$ \\
\hline Employed 45 hours & $11.36 \%$ & 14.2 & 13. & $12.44 \%$ \\
\hline Employed 50 hours & 16.7 & & & 13. \\
\hline Total & 3230 & 20 & 1650 & 2130 \\
\hline \multicolumn{5}{|c|}{ Probabilistically Predicted } \\
\hline Employment rate & $79.00 \%$ & $84.36 \%$ & $83.87 \%$ & $77.79 \%$ \\
\hline Employed Part Time \% & $1.9 \%$ & $4.7 \%$ & $10.3 \%$ & $13.0 \%$ \\
\hline Employed 0 hours & $21.00 \%$ & $15.64 \%$ & $16.13 \%$ & $22.21 \%$ \\
\hline Employed 5 hours & $0.00 \%$ & $0.06 \%$ & $0.37 \%$ & $0.40 \%$ \\
\hline Employed 10 hours & $0.00 \%$ & & $0.71 \%$ & $0.78 \%$ \\
\hline Employed 15 hours & $0.03 \%$ & $0.54 \%$ & $1.29 \%$ & $1.46 \%$ \\
\hline Employed 20 hours & $0.23 \%$ & $1.06 \%$ & $2.30 \%$ & $2.70 \%$ \\
\hline Employed 25 hours & $1.23 \%$ & $2.04 \%$ & $4.00 \%$ & $4.77 \%$ \\
\hline Employed 30 hours & $4.73 \%$ & $4.43 \%$ & $6.64 \%$ & $7.71 \%$ \\
\hline Employed 35 hours & $12.24 \%$ & $9.56 \%$ & $10.30 \%$ & $11.17 \%$ \\
\hline Employed 40 hours & $20.78 \%$ & $17.15 \%$ & $14.79 \%$ & $14.48 \%$ \\
\hline Employed 45 hours & $23.03 \%$ & $23.84 \%$ & $19.59 \%$ & $16.81 \%$ \\
\hline Employed 50 hours & $16.72 \%$ & $25.44 \%$ & $23.89 \%$ & $17.52 \%$ \\
\hline Total & 3230 & 2010 & 1650 & 2130 \\
\hline
\end{tabular}


204CHAPTER 5. INCOME-LEISURE PREFERENCES IN NEW ZEALAND

Table 5.11: Sole Parents Hours Frequency Distributions

\begin{tabular}{|c|c|c|c|c|}
\hline & $1988-93$ & $1994-98$ & $2001-08$ & $2009-13$ \\
\hline \multicolumn{5}{|c|}{ Observed } \\
\hline Employment rate & $33.80 \%$ & $43.80 \%$ & $57.25 \%$ & $55.86 \%$ \\
\hline Employed Part Time & $35.6 \%$ & $40.9 \%$ & $34.2 \%$ & $32.0 \%$ \\
\hline Employed 0 hours & $66.68 \%$ & $56.87 \%$ & $42.99 \%$ & $44.23 \%$ \\
\hline Employed 5 hours & $2.43 \%$ & $3.91 \%$ & $2.04 \%$ & $2.04 \%$ \\
\hline Employed 10 hours & $3.02 \%$ & $5.44 \%$ & $5.27 \%$ & $4.09 \%$ \\
\hline Employed 15 hours & $2.05 \%$ & $2.39 \%$ & $3.83 \%$ & $3.64 \%$ \\
\hline Employed 20 hours & $2.75 \%$ & $4.01 \%$ & $4.79 \%$ & $3.64 \%$ \\
\hline Employed 25 hours & $1.62 \%$ & $1.91 \%$ & $3.59 \%$ & $4.44 \%$ \\
\hline Employed 30 hours & $2.10 \%$ & $2.48 \%$ & 6.95 & $6.66 \%$ \\
\hline Employed 35 hours & $1.89 \%$ & $2.39 \%$ & $4.79 \%$ & $5.51 \%$ \\
\hline Employed 40 hours & $12.45 \%$ & $12.31 \%$ & $15.81 \%$ & $16.25 \%$ \\
\hline Employed 45 hours & $2.16 \%$ & $1.72 \%$ & $2.87 \%$ & $3.82 \%$ \\
\hline Employed 50 hours & $2.86 \%$ & $6.58 \%$ & $7.07 \%$ & $5.68 \%$ \\
\hline Total & 1860 & 1050 & 840 & 1130 \\
\hline \multicolumn{5}{|c|}{ Probabilistically Predicted } \\
\hline Employment rate & $33.27 \%$ & $43.41 \%$ & $57.26 \%$ & $56.00 \%$ \\
\hline Employed Part Time & 38.82 & $43.2 \%$ & $37.8 \%$ & $35.2 \%$ \\
\hline Employed 0 hours & $66.73 \%$ & $56.59 \%$ & $42.74 \%$ & $44.00 \%$ \\
\hline Employed 5 hours & $1.93 \%$ & $4.38 \%$ & $2.54 \%$ & $2.10 \%$ \\
\hline Employed 10 hours & $2.32 \%$ & $4.08 \%$ & $3.73 \%$ & $2.94 \%$ \\
\hline Employed 15 hours & $2.60 \%$ & $3.63 \%$ & & $3.81 \%$ \\
\hline Employed 20 hours & $2.88 \%$ & $3.34 \%$ & $5.14 \%$ & $4.88 \%$ \\
\hline Employed 25 hours & $3.18 \%$ & $3.32 \%$ & $5.63 \%$ & $5.96 \%$ \\
\hline Employed 30 hours & $3.50 \%$ & $3.54 \%$ & $6.31 \%$ & $6.93 \%$ \\
\hline Employed 35 hours & $3.84 \%$ & $3.99 \%$ & $7.07 \%$ & $7.60 \%$ \\
\hline Employed 40 hours & $4.16 \%$ & $4.68 \%$ & $7.65 \%$ & $7.79 \%$ \\
\hline Employed 45 hours & $4.39 \%$ & $5.60 \%$ & $7.64 \%$ & $7.43 \%$ \\
\hline Employed 50 hours & $4.47 \%$ & $6.84 \%$ & $6.96 \%$ & $6.56 \%$ \\
\hline Total & 1860 & 1050 & 840 & 1130 \\
\hline
\end{tabular}


Table 5.12: Coupled Women Hours Frequency Distributions

\begin{tabular}{|c|c|c|c|c|}
\hline & $1988-93$ & 1994-98 & $2001-08$ & $2009-13$ \\
\hline \multicolumn{5}{|c|}{ Observed } \\
\hline Employment rate & $66.58 \%$ & 79.68 & $76.99 \%$ & $68.52 \%$ \\
\hline Employed Part Time & $15.6 \%$ & $14.1 \%$ & $17.3 \%$ & $19.0 \%$ \\
\hline Employed 0 hours & $33.65 \%$ & $20.53 \%$ & $23.26 \%$ & $31.65 \%$ \\
\hline Employed 5 hours & $1.68 \%$ & $1.02 \%$ & $1.39 \%$ & $1.44 \%$ \\
\hline Employed 10 hours & $3.24 \%$ & $2.69 \%$ & $2.72 \%$ & $3.24 \%$ \\
\hline Employed 15 hours & $2.99 \%$ & $2.67 \%$ & $3.16 \%$ & $3.53 \%$ \\
\hline Employed 20 hours & $4.22 \%$ & $3.98 \%$ & $5.24 \%$ & $5.53 \%$ \\
\hline Employed 25 hours & $3.47 \%$ & $3.72 \%$ & $4.78 \%$ & $5.22 \%$ \\
\hline Employed 30 hours & $4.57 \%$ & $4.24 \%$ & $5.04 \%$ & $7.21 \%$ \\
\hline Employed 35 hours & $2.69 \%$ & $2.61 \%$ & $5.86 \%$ & $7.26 \%$ \\
\hline Employed 40 hours & $28.09 \%$ & $27.97 \%$ & $26.12 \%$ & $23.37 \%$ \\
\hline Employed 45 hours & $5.31 \%$ & $9.08 \%$ & $8.23 \%$ & $5.35 \%$ \\
\hline Employed 50 hours & $10.09 \%$ & 21 & 14 & $6.19 \%$ \\
\hline Total & 7060 & 4600 & 3890 & 4500 \\
\hline \multicolumn{5}{|c|}{ Probabilistically Predicted } \\
\hline Employment rate & $66.34 \%$ & $79.38 \%$ & $76.60 \%$ & $69.84 \%$ \\
\hline Employed Part Time & $16.6 \%$ & $13.6 \%$ & $17.0 \%$ & $22.8 \%$ \\
\hline Employed 0 hours & $33.66 \%$ & $20.62 \%$ & $23.40 \%$ & $30.16 \%$ \\
\hline Employed 5 hours & $1.36 \%$ & $1.22 \%$ & $1.25 \%$ & $1.93 \%$ \\
\hline Employed 10 hours & $2.12 \%$ & $1.74 \%$ & $2.01 \%$ & $3.00 \%$ \\
\hline Employed 15 hours & $3.10 \%$ & $2.45 \%$ & $3.07 \%$ & $4.37 \%$ \\
\hline Employed 20 hours & $4.32 \%$ & $3.43 \%$ & $4.46 \%$ & $5.95 \%$ \\
\hline Employed 25 hours & $5.72 \%$ & $4.77 \%$ & $6.19 \%$ & $7.55 \%$ \\
\hline Employed 30 hours & $7.24 \%$ & $6.59 \%$ & $8.20 \%$ & $8.94 \%$ \\
\hline Employed 35 hours & $8.77 \%$ & $9.02 \%$ & $10.29 \%$ & $9.85 \%$ \\
\hline Employed 40 hours & $10.19 \%$ & $12.22 \%$ & $12.27 \%$ & $10.09 \%$ \\
\hline Employed 45 hours & $11.36 \%$ & $16.34 \%$ & $13.90 \%$ & $9.62 \%$ \\
\hline Employed 50 hours & $12.16 \%$ & $21.58 \%$ & $14.96 \%$ & $8.55 \%$ \\
\hline Total & 7060 & 4600 & 3890 & 4500 \\
\hline
\end{tabular}


Table 5.13: Coupled Men Hours Frequency Distributions

\begin{tabular}{|c|c|c|c|c|}
\hline & $1988-93$ & $1994-98$ & $2001-08$ & 2009-13 \\
\hline \multicolumn{5}{|c|}{ Observed } \\
\hline Employment rate & $81.03 \%$ & $82.09 \%$ & $89.67 \%$ & $94.14 \%$ \\
\hline Employed Part Time & $5.7 \%$ & $10.6 \%$ & $6.3 \%$ & $2.8 \%$ \\
\hline Employed 0 hours & $19.69 \%$ & $18.90 \%$ & $10.75 \%$ & $5.93 \%$ \\
\hline Employed 10 hours & $2.35 \%$ & $4.19 \%$ & $2.52 \%$ & $0.78 \%$ \\
\hline Employed 20 hours & $3.38 \%$ & $6.37 \%$ & $3.80 \%$ & $2.06 \%$ \\
\hline Employed 30 hours & $4.32 \%$ & $5.19 \%$ & $5.55 \%$ & $4.88 \%$ \\
\hline Employed 40 hours & $48.97 \%$ & $38.35 \%$ & $50.26 \%$ & $59.62 \%$ \\
\hline Employed 50 hours & $21.29 \%$ & $26.99 \%$ & $27.12 \%$ & $26.73 \%$ \\
\hline Total & 7060 & 4600 & 3890 & 4500 \\
\hline \multicolumn{5}{|c|}{ Probabilistically Predicted } \\
\hline Employment rate & $80.37 \%$ & $81.06 \%$ & $89.31 \%$ & $93.97 \%$ \\
\hline Employed Part Time & $3.9 \%$ & $9.0 \%$ & $4.6 \%$ & $0.9 \%$ \\
\hline Employed 0 hours & $19.63 \%$ & $18.94 \%$ & $10.69 \%$ & $6.03 \%$ \\
\hline Employed 10 hours & $0.33 \%$ & $2.36 \%$ & $0.51 \%$ & $0.01 \%$ \\
\hline Employed 20 hours & $3.57 \%$ & $6.68 \%$ & $4.13 \%$ & $0.87 \%$ \\
\hline Employed 30 hours & $16.44 \%$ & $14.86 \%$ & $17.13 \%$ & $14.53 \%$ \\
\hline Employed 40 hours & $32.52 \%$ & $25.21 \%$ & $34.41 \%$ & $47.70 \%$ \\
\hline Employed 50 hours & $27.57 \%$ & $31.94 \%$ & $33.13 \%$ & $30.86 \%$ \\
\hline Total & 7060 & 4600 & 3890 & 4500 \\
\hline
\end{tabular}

The above tables show that the model tends to fit the employment rate fairly well, with the estimated number out of work very close to the observed number.

However there are two clear differences between the prediction and the 
observed data: part time employment of $15+$ hours tends to be slightly overestimated, while the clear peak in hours worked at 40 hours per week is spread across the 35-50 hours levels by the model. These issues are common for this form of estimation, as mentioned by Guyonne Kalb and Rosanna Scutella (2003).

\subsubsection{Quasi-concavity}

One of the advantages of a discrete hours framework for preference parameter estimation is that restrictions to parameter values do not need to be imposed ex-ante, and can instead be checked following the estimation. This involves checking the quasi-concavity of the utility function at the observed data points after estimation as in Guyonne Kalb and Rosanna Scutella (2003) and Mercante and Mok (2014a).

No more than $0.5 \%$ of the observed data failed a test of quasi-concavity for any of the observed models, implying that the utility function is quasiconcave in the relevant regions of the model for the majority of households.

\subsection{Marginal Effects}

The marginal effects are shown below. These effects take the sample as given for each time period, and then change a single characteristic to a counterfactual value for all individuals in the sample. The average expected hours of work per week, and estimated participation rates, given this change in characteristics are then calculated. 
Table 5.14: Sole Parents Marginal Effects

\begin{tabular}{|c|c|c|c|c|}
\hline & $1988-93$ & $1994-98$ & $2001-08$ & $2009-13$ \\
\hline \multicolumn{5}{|c|}{ Expected hours per week } \\
\hline From base & 10.36 & 12.94 & 17.97 & 17.92 \\
\hline $\begin{array}{l}\text { Disposable income in- } \\
\text { crease of } 10 \%\end{array}$ & 10.70 & 12.97 & 18.48 & 18.40 \\
\hline Youngest Child aged 0 & 12.16 & 7.13 & 7.49 & 16.51 \\
\hline Everyone Graduate & 5.96 & 17.71 & 17.65 & 17.92 \\
\hline Age incr & 10.36 & 12.51 & 17.53 & 18.84 \\
\hline \multicolumn{5}{|c|}{ Participation } \\
\hline From base & $33.80 \%$ & $43.80 \%$ & $57.26 \%$ & $56.00 \%$ \\
\hline $\begin{array}{l}\text { Disposable income in- } \\
\text { crease of } 10 \%\end{array}$ & $34.55 \%$ & $44.76 \%$ & $59.30 \%$ & $57.57 \%$ \\
\hline Youngest Child aged 0 & $38.89 \%$ & $32.98 \%$ & $31.19 \%$ & $51.05 \%$ \\
\hline Everyone Graduate & $15.06 \%$ & $46.56 \%$ & $53.82 \%$ & $56.00 \%$ \\
\hline Age increase $10 \%$ & $33.42 \%$ & $42.18 \%$ & $56.57 \%$ & $58.32 \%$ \\
\hline
\end{tabular}

For sole parents a $10 \%$ boost to disposable income at each hours point increases participation rates and average hours in all periods.

Setting the age of the youngest child of all sole parent to zero leads to lower participation rates in HES94-98, HES01-08, and HES09-13. Given that it is common for a parent to stay home to look after their child in the months after their birth this makes sense. HES88-93 shows the opposite relationship, with a higher participation rate for those with a youngest child at the age of 0 . Even though the coefficient on the preference to work is negative for this equation, the term is much more negative for children aged 1-9 while the preference for income is higher. Furthermore, even after increasing overall participation rates are low relative to other 
groups.

The effect of education varies through time for sole parents. In HES9498 there was a small increase in participation when considering university graduates, HES01-08 a small decline, and HES09-13 education was excluded. In HES88-93 graduate education led to a significant drop in participation. However, this was based on a very small sample (66 individuals or $3.5 \%$ of the time period sole parent sample).

A higher age for sole parents led to a slight decline in participation in HES88-93, HES94-98, and HES01-08. For HES09-13 participation rates increased following an exogenous $10 \%$ increase in the age of the sample.

Table 5.15: Single Men Marginal Effects

\begin{tabular}{|c|c|c|c|c|}
\hline & $1988-93$ & 1994-98 & 2001-08 & $2009-13$ \\
\hline \multicolumn{5}{|c|}{ Expected hours per week } \\
\hline From base & 33.10 & 35.81 & 34.01 & 30.39 \\
\hline $\begin{array}{l}\text { Disposable income in- } \\
\text { crease of } 10 \%\end{array}$ & 34.90 & 35.48 & 34.87 & 30.93 \\
\hline Age increase $10 \%$ & 33.04 & 35.53 & 33.34 & 30.79 \\
\hline Graduate & 35.55 & 35.25 & 34.70 & 31.22 \\
\hline \multicolumn{5}{|c|}{ Participation } \\
\hline From base & $78.90 \%$ & $84.36 \%$ & $83.87 \%$ & $77.79 \%$ \\
\hline $\begin{array}{l}\text { Disposable income in- } \\
\text { crease of } 10 \%\end{array}$ & $83.72 \%$ & $82.65 \%$ & $85.11 \%$ & $78.36 \%$ \\
\hline Age increase $10 \%$ & $78.52 \%$ & $83.31 \%$ & $81.58 \%$ & $78.06 \%$ \\
\hline Graduate & $84.83 \%$ & $81.99 \%$ & $84.73 \%$ & $78.70 \%$ \\
\hline
\end{tabular}

An exogenous $10 \%$ increase in disposable income is predicted to increase single men participation and hours worked for most of the time period, ex- 
cept for 1994-98. Similarly, educational attainment increases participation in all time periods except 1994-98. These two results illustrate the difference between the HES94-98 estimates and other years for single men.

The effect of a $10 \%$ increase in the average age in the sample was to reduce participation in HES88-93, HES94-98, and HES01-08. However, an increase in the sample's age increased participation and hours in the HES0913 estimates. Single men are the, on average, youngest demographic subgroup. With the age that represents the peak preference for work for single men also shift out to their 50s in this period, the increase in participation in the final time period is logically consistent.

Table 5.16: Single Women Marginal Effects

\begin{tabular}{|c|c|c|c|c|}
\hline & $1988-93$ & $1994-98$ & $2001-08$ & $2009-13$ \\
\hline \multicolumn{5}{|c|}{ Expected hours per week } \\
\hline From base & 29.73 & 32.73 & 31.31 & 27.52 \\
\hline $\begin{array}{l}\text { Disposable income in- } \\
\text { crease of } 10 \%\end{array}$ & 27.53 & 37.04 & 32.92 & 33.28 \\
\hline Age increase $10 \%$ & 28.90 & 31.67 & 30.21 & 27.52 \\
\hline Graduate & 28.50 & 37.40 & 32.80 & 33.37 \\
\hline \multicolumn{5}{|c|}{ Participation } \\
\hline From base & $77.00 \%$ & $84.42 \%$ & $83.95 \%$ & $77.67 \%$ \\
\hline $\begin{array}{l}\text { Disposable income in- } \\
\text { crease of } 10 \%\end{array}$ & $69.89 \%$ & $85.35 \%$ & $85.31 \%$ & $85.88 \%$ \\
\hline Age increase $10 \%$ & $74.77 \%$ & $81.86 \%$ & $81.60 \%$ & $77.67 \%$ \\
\hline Graduate & $71.68 \%$ & $87.51 \%$ & $84.91 \%$ & $85.92 \%$ \\
\hline
\end{tabular}

Higher disposable income led to an increase in average hours of work for single women in the HES94-98 and HES09-13 estimates. Although the HES09-13 figure was also associated with a large increase in participation, 
the HES94-98 estimate only saw a small increase in participation, indicating that single women were working longer hours. HES01-08 saw a small increase in participation and hours due to higher disposable income, while HES88-93 saw participation fall sharply.

An increase in age was associated with lower labour force participation across all time periods for single women, except for HES09-13 where age was excluded from estimation.

Table 5.17: Coupled Women Marginal Effects

\begin{tabular}{|c|c|c|c|c|}
\hline & $1988-93$ & 1994-98 & 2001-08 & 2009-13 \\
\hline \multicolumn{5}{|c|}{ Expected hours per week } \\
\hline From base & 23.55 & 30.65 & 27.87 & 22.90 \\
\hline $\begin{array}{l}\text { Disposable income in- } \\
\text { crease of } 10 \%\end{array}$ & 23.73 & 30.71 & 28.23 & 23.28 \\
\hline Youngest Child 0 & 17.81 & 27.50 & 22.72 & 22.90 \\
\hline Graduate & 31.19 & 35.20 & 28.53 & 21.39 \\
\hline Partner Graduate & 18.91 & 25.85 & 27.05 & 23.81 \\
\hline Age increase $10 \%$ & 22.03 & 29.30 & 26.17 & 22.86 \\
\hline $\begin{array}{l}\text { Partner age increase } \\
10 \%\end{array}$ & 23.80 & 30.82 & 27.93 & 22.64 \\
\hline \multicolumn{5}{|c|}{ Participation } \\
\hline From base & $66.34 \%$ & $79.38 \%$ & $76.60 \%$ & $69.84 \%$ \\
\hline $\begin{array}{l}\text { Disposable income in- } \\
\text { crease of } 10 \%\end{array}$ & $66.93 \%$ & $79.90 \%$ & $77.45 \%$ & $70.88 \%$ \\
\hline Youngest Child 0 & $52.52 \%$ & $72.63 \%$ & $65.06 \%$ & $69.84 \%$ \\
\hline Graduate & $80.85 \%$ & $87.29 \%$ & $77.94 \%$ & $66.40 \%$ \\
\hline Partner Graduate & $57.50 \%$ & $70.89 \%$ & $75.24 \%$ & $71.32 \%$ \\
\hline Age increase $10 \%$ & $63.10 \%$ & $76.81 \%$ & $73.19 \%$ & $69.78 \%$ \\
\hline $\begin{array}{l}\text { Partner age increase } \\
10 \%\end{array}$ & $66.58 \%$ & $79.45 \%$ & $76.47 \%$ & $68.98 \%$ \\
\hline
\end{tabular}


For coupled women, a 10\% increase in disposable income leads to a rise in both participation and expected hours of work in all time periods.

An increase in a coupled women age reduced average expected hours of work and participation in all time periods. Increasing the age of the individual's partner had a more mixed effect, increasing participation in HES88-93 and HES94-98 while decreasing participation in HES01-08 and HES09-13. However, the magnitude of the change in expected hours and participation from an increase in the age of a coupled women partner was very small.

From HES88-93 to HES01-08, graduate education increased participation for coupled women and having a partner with a graduate qualification reduced participation. This effect reversed in HES09-13, with graduate education reducing participation while having a partner with graduate education increased participation.

Although this effect wasn't mirrored for coupled men, the reversal from higher participation when the individual's are graduates to higher participation when partners are graduates in the HES09-13 estimates did occur. As a result, the intuitive relationship that the most qualified partner will be the partner that works - which held in the HES88-93 to HES01-08 estimates - appears to have been contradicted in the HES09-13 estimates.

Setting the age of the youngest child to 0 for all couples with children lead to a large decline in participation and average expected hours in HES88-93 and HES01-08. Participation and hours also declined in HES94-98, but by a smaller magnitude than in the neighbouring years. The decline in the HES94-98 estimates is similar to the reduction in participation by coupled men, while the decline in HES88-93 and HES01-08 was much larger for women than men. No effect is observed in HES09-13 as child variables were excluded from estimation. 
Table 5.18: Coupled Men Marginal Effects

\begin{tabular}{|c|c|c|c|c|}
\hline & $1988-93$ & $1994-98$ & $2001-08$ & $2009-13$ \\
\hline \multicolumn{5}{|c|}{ Expected hours per week } \\
\hline From base & 32.44 & 32.09 & 36.34 & 39.04 \\
\hline $\begin{array}{l}\text { Disposable income in- } \\
\text { crease of } 10 \%\end{array}$ & 32.35 & 31.97 & 36.36 & 39.15 \\
\hline Youngest Child 0 & 29.99 & 28.94 & 34.88 & 39.04 \\
\hline Graduate & 38.53 & 36.17 & 37.35 & 37.73 \\
\hline Partner Graduate & 27.48 & 30.21 & 36.36 & 38.10 \\
\hline Age increase $10 \%$ & 31.15 & 30.77 & 35.21 & 37.95 \\
\hline $\begin{array}{l}\text { Partner age increase } \\
10 \%\end{array}$ & 32.71 & 32.25 & 36.42 & 39.04 \\
\hline \multicolumn{5}{|c|}{ Participation } \\
\hline From base & $80.37 \%$ & $81.06 \%$ & $89.31 \%$ & $93.97 \%$ \\
\hline $\begin{array}{l}\text { Disposable income in- } \\
\text { crease of } 10 \%\end{array}$ & $80.43 \%$ & $81.26 \%$ & $89.55 \%$ & $94.36 \%$ \\
\hline Youngest Child 0 & $74.35 \%$ & $74.45 \%$ & $85.97 \%$ & $93.97 \%$ \\
\hline Graduate & $91.30 \%$ & $87.83 \%$ & $90.95 \%$ & $91.84 \%$ \\
\hline Partner Graduate & $71.18 \%$ & $78.24 \%$ & $89.52 \%$ & $92.23 \%$ \\
\hline Age increase $10 \%$ & $77.70 \%$ & $78.59 \%$ & $87.21 \%$ & $91.86 \%$ \\
\hline $\begin{array}{l}\text { Partner age increase } \\
10 \%\end{array}$ & $80.65 \%$ & $81.14 \%$ & $89.19 \%$ & $93.96 \%$ \\
\hline
\end{tabular}

Increasing family disposable income for coupled men slightly increased participation for all time periods. However, average hours of work were close to unchanged.

For coupled men an increase in age lead to a relatively consistent decline 
in participation across time periods, falling by between 2 to 3 percentage points. A rise in the age of the coupled men partner increased participation in the HES88-93 and HES94-98 estimates and reduced participation in the HES01-08 and HES09-13 estimates, but these changes were much smaller in scale than those associated with own-age changes.

The education relationship varied across the time periods analysed. In HES88-93 graduate qualification led to a sizeable increase in participation, while partner graduate qualifications led to a reduction. These effect narrowed in HES94-98 and HES01-08, but participation when coupled men were graduate qualified remained higher than participation when males partners were graduate qualified. In HES09-13, both own and partner graduate qualification led to a decline in participation, with own-qualification leading to a lower participation rate.

Having a new born child reduces the labour supply of both couple men and women, the effect appears to be strong for coupled women in most time periods. This reduction shrunk in HES01-08 relative to the estimated reduction in the 1990s.

\subsection{Conclusion}

In this chapter preference parameters were estimated for four demographic groups, single men, single women, sole parents, and couples. These estimates were performed for four separate time periods: HES88-93, HES9498, HES01-08, and HES09-13.

During the 1988-2013 period the aggregate and subgroup outcomes in the labour market changed considerably, and in ways that varied across the subgroups. While part time work became more popular among single people without children and coupled women, sole parents and coupled men moved more heavily into full time work. Although the evolution of 
labour market outcomes may partially be the result of changes in the characteristics of individuals, the institutional structure of the labour market, economic conditions in the period of analysis, and the preferences of individuals towards work and work income also changed over this time. This can be seen in the way preference parameter estimates varied across time horizons.

For all demographic groups the age where the utility of work peaks shifted, becoming older. Estimates of the fixed costs of work tended to fall in the HES94-98 estimates and rose sharply in the HES09-13 estimates across demographic groups. Across most demographic groups the disutility associated with work rose at a slower rate in later time periods than it did in HES88-93, with the coupled men HES09-13 the only outlier although this is likely due to the change in the model specification which sharply increased the fixed cost of work for this subgroup.

However, there is enough in common between the estimates, and associated economic logic, to make them credible. The utility associated with work peaks between an individuals mid-30s and mid-40s, having a child lowers the utility from supplying labour to women, and in most instances higher educational attainment leads to a greater labour force participation.

Similar relationships held in the previous New Zealand research in Guyonne Kalb and Rosanna Scutella (2003) and Mercante and Mok (2014a). However, there were some clear differences. Coupled men's labour supply falls when their are dependants in the household in this chapter, while no significant effect is found in the prior research. Furthermore, the HES09-13 education results differ from both other years and the prior New Zealand research - with the prior strong increase in labour force participation associated with graduate education becoming a small increase or even reduction in participation across the demographic subgroups.

The child result is found over the same time period, and using roughly the 
same data, as previous studies. However, the model specification was different than these prior models with region variables and interaction terms missing. This new specification also produced sizeably lower fixed costs of work for couple men during the HES88-93 to HES01-08 estimates than those found in prior estimates. When children are removed in HES09-13 the fixed cost of work increases substantially, implying that the child variable is relevant for explaining some of the non-participation during the entire time horizon.

The education result stems directly from the relatively poor participation of those with graduate qualifications in the HES09-13 period. Graduate couples males, who experienced the largest graduate work gap, made up over $27.1 \%$ of the coupled men sample but only $25.6 \%$ of the employed coupled men.

Overall, the reasonable fit to the underlying hours distribution and credible outcomes of the model suggest that these models provide a reasonable starting point for simulations of labour supply outcomes given income shocks to households.

In that vein, the models estimated in this chapter will be used to simulate the change in labour supply behaviour by individuals following adjustments in the structure of the tax-transfer system. Such a model takes these preference estimates and calibrates the model to start at the initial set of hours points for each individual. From their changes in net incomes associated with an adjustment in the tax-transfer system are introduced, and these estimated preference parameters indicate how labour supply choices would be expected to adjust. 


\section{Chapter 6}

\section{Decomposing New Zealand inequality changes from 1988-2013 into policy and non-policy related contributions}

\subsection{Introduction}

Numerous measures of disposable income inequality in New Zealand increased in the late 1980s and early 1990s, and have remained elevated since. The purpose of this chapter is to investigate the role changes in tax and transfer policies played in this increase.

Although Chapter 3 established that the redistributive effect of the taxtransfer system declined over this period, the impact of tax-transfer policy cannot be described by comparing the change in the redistributive effect alone. Changes in the structure of the population between two periods of time can change the redistributive properties of the tax-transfer system, 
even if the underlying policies remain unchanged.

As a result, in order to describe how changes in tax and transfer policies specifically influenced disposable income inequality outcomes, it is necessary to model how these payments are made. In this chapter, a behavioural tax-transfer microsimulation model is used to model this process. This model allows for the calculation of tax-transfer payments and labour supply responses for a given tax-transfer system. By using such a model, counterfactual scenarios can be created that apply the tax-transfer system of one year onto the population of another year. Given these scenarios and the associated disposable income inequality measures for these scenarios, any change in the income distribution can be decomposed into policy and non-policy related contributions. These scenarios are constructed and analysed for two pooled sets of years: 1988-91 and 2010-13.

This type of decomposition between population and tax-transfer determinants of changing income inequality gives differing results depending on the sequencing of the counterfactuals. As a result, since no ordering is more economically intuitive than another ordering for the analysis at hand, the Shapley value is used to estimate an average marginal effect of policy as motivated by Shorrocks (2013). This process mirrors the analysis undertaken by Bargain (2012) for the United Kingdom and Herault and Azpitarte (2016) for Australia.

The population effect on income inequality can be further decomposed, in order to describe the relative roles of changing observed population characteristics in the evolution of income inequality over this period. Each of these population factors influences the potential orderings available for the policy effect thereby changing the estimated impact of policy. The changes in population characteristics that will be evaluated in this chapter are the age, employment, and highest qualification level distributions.

In order to evaluate the role of these population factors the semi-parametric approach of DiNardo et al. (1996) is utilised. This approach reweights the 
weighted sample of a given year to represent the population characteristic of interest for a different year. The change in the disposable income inequality measure due to this reweighting then provides an estimate of the role the change in the population characteristic had on disposable income inequality.

By combining the role of changing population characteristics with a structural model of tax-transfer policy settings, this chapter intends to give a clearer understanding of how tax-transfer policy changes in New Zealand since 1988 have influenced disposable income inequality outcomes. Both by providing a quantitative estimate of the role of tax-transfer policies, and by offering a comparison to the role played by other factors during that time period.

The chapter is organised as follows: Section 2 motivates the investigation of the role tax and transfer changes played in changing inequality outcomes. Section 3 provides a literature review about decompositional methods. Section 4 covers the data sources used including imputation of missing data. Section 5 provides a methodological outline of microsimulation modelling and the use of weighting and labour supply estimation to improve the ability to use microsimulation to make inferences about tax-transfer questions.

Given this background section 6 introduces the decomposition method for the effects of tax-transfer policy on the income distribution. Section 7 then outlines the changes in some population characteristics and how this can be incorporated in a decompositional analysis. Section 8 provides the results of the decomposition while section 9 concludes. 


\subsection{New Zealand Decomposition motivation}

The increase in income inequality measures during the mid-1980s and early 1990s, followed by the persistence of those higher inequality measures through into the 2000s, has been widely documented (Perry 2017, Ball and Creedy 2015, Jeram and Wilkinson 2016).

In this chapter, the role tax and transfer payment changes played in the increase in disposable income inequality is investigated using a tax-transfer microsimulation model. By using such a model to create counterfactual scenarios that represent the role of tax-transfer policy, it is possible to decompose the change in inequality into policy and non-policy related contributions.

The purpose of such a decomposition is to investigate the first order effect that tax-transfer policy changes had on the income distribution during this time, with the direct change in payments and the indirect labour supply response to these changes both modelled.

The unit of analysis in this chapter is the individual. The inequality of individual incomes is represented using the Gini coefficient, as shown in Figures 29 and 30. Here market income refers to the gross income of individuals excluding transfer payments, while disposable income includes transfer payments and subtracts tax payments. The income measure used is income per adult equivalent person using a parametric scale which is parametrised to be close to the Jensen (1988) scale. The data come from Statistics New Zealand's Household Economic Survey, however tax and transfer payments have been imputed using a microsimulation model instead of taken directly from survey results. Furthermore, the calibrated weights applied in Ball and Creedy (2015) are used in these figures to reweight the HES to represent the New Zealand population in each HES year. 


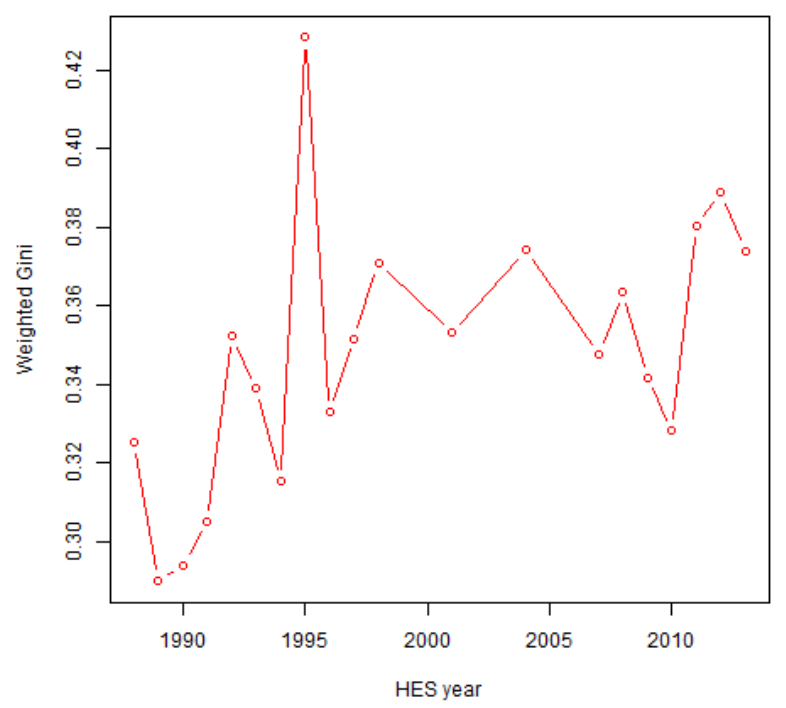

Figure 29: Gini coefficient for equivalised Disposable Income

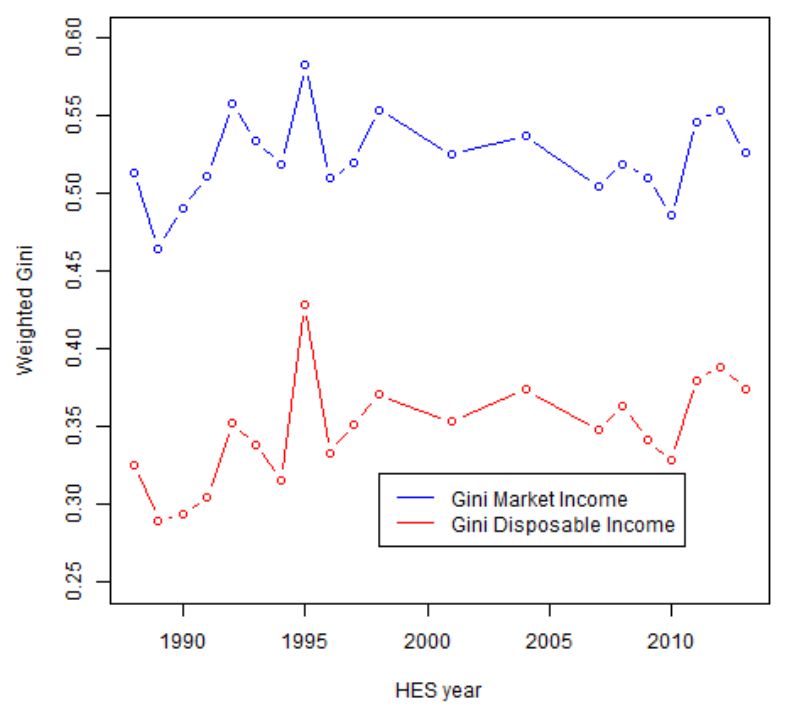

Figure 30: Market vs Disposable Income Gini coefficients 
Figure 29 shows the increase in disposable income inequality between 1988 and 2013 in terms of adult equivalent income per person. Although there is significant variation in the Gini coefficient over this time period, for the weighted sample investigated in this chapter the Gini coefficent climbs from just over 30 to nearly 38 between 1988 and 2013.

However, this fact alone does not indicate that policy was the reason for rising inequality outcomes. Figure 30 suggests that market income and disposable income moved together over most of the 1988-2013 period. As a result, it is unlikely that changes in the tax-transfer system alone can explain why inequality in disposable income increased. ${ }^{1}$

Over the same period, other characteristics of the population changed in ways that may have influenced the distribution of income. The age distribution, education distribution, and employment status distribution all shifted - with the population ageing, average highest educational achievement rising, and an increasing number of individuals moving into part time work.

Changing characteristics of the population, along with the complexity of the interaction between the population and the tax-transfer system, implies that the decline in the redistributive effect between 1988 and 2013 is not sufficient to estimate the role of policy.

When analysing the role policy played in the change in income inequality in New Zealand, Podder and Chatterjee (2002a) provided a description based on decompositional analysis of factor incomes to discuss how rising inequality was the result of policy changes. However, this analysis had two key issues for such an interpretation: it did not model the tax and

\footnotetext{
${ }^{1}$ Changes in the tax-transfer system may have led to a corresponding change in market incomes. Outside of changes in market incomes associated with adjustments in hours of work, the assumption of fixed incomes as in Kasten et al. (1994) is still maintained in this chapter. The shortcomings associated with such an assumption are discussed in detail when the decomposition method is outlined.
} 
transfer payments in a way that allows for clear counterfactual analysis regarding what factor incomes would have looked like in the absence of the reform (both due to changing characteristics and behaviour), and it relied on household survey data for tax and transfer payments which are unreliable for these income measures as noted in Ball and Ormsby (2017).

There have also been studies investigating the role that changing population characteristics played in the rise in income inequality outcomes in New Zealand, specifically by Ball and Creedy (2015) and Hyslop and Mare (2005). However, these analyses did not model what the income distribution would have been if another year's tax and transfer system had been applied to the population of a given year, and so were unable to provide estimates of the role of tax-transfer policies played in inequality outcomes.

The analysis in this chapter expands on both the factor share and characteristics based decompositions of the increase in New Zealand income inequality by offering a structural analysis of tax-transfer policy, including endogenous labour supply responses to these changes in policy.

\subsection{Literature review}

Decomposition of income inequality indices, as summary measures of an income distribution, are an important part of distributional analysis in economics. Shorrocks wrote two of the seminal papers on decomposition of general inequality indices, considering (additive) decomposition by population subgroup (Shorrocks 1984) and decomposition by factor income (Shorrocks 1982). The conclusion from Shorrocks (1988) was that such a decomposition was non-interpretable, a position that Cowell (2009) notes is still widely held. Here non-interpretability implies that rising inequality in one factor/subgroup does not logically contribute to rising inequality 
overall.

Podder and Chatterjee (2002b) and Podder and Chatterjee (2002a) suggested that it was possible to perform an interpretable decomposition of an inequality index (in this case the Gini coefficient) based on a single factor. The authors then used a decomposition by income source to discuss the role of policy changes on income inequality in the New Zealand context. However, Jurkatis and Strehl (2013) argue against the interpretability of the decomposition given in these papers, instead suggesting that researchers focus on marginal effects stemming from the estimated Gini elasticity with respect to income source (which is closely related to the semi-elasticity method used in the Podder and Chatterjee papers) when interpreting factor income decompositions of the Gini coefficient.

Without the ability to link the inequality of income for a subgroup directly to aggregate inequality, it is necessary to clearly model the income distribution in terms of factors of interest in order to allow for clear counterfactual analysis. As a result, in this chapter the focus is on constructing counterfactual distributions to perform multi-dimensional decompositions of the type suggested by Shorrocks (2013). Here a series of counterfactual models are defined that represent the change of a given factor that determines the income distribution and thereby income inequality.

When the change in an inequality index is decomposed on the basis of more than one factor, the estimated marginal effect of a factor can vary based upon its ordering in the sequencing of the decomposition. If there is no reason why a researcher would expect one effect to come before another in the sequencing of analysis Shorrocks (2013) suggested that you could calculate all the possible sequences and average the marginal effects to get an estimate of the true marginal effect. This logic was based on the Shapley value from cooperative game theory Shapley (1953).

Hyslop and Mare (2005) and Daly and Valletta (2000) offered this form of decomposition of income distributions, using the semi-parametric method 
of DiNardo et al. (1996) to estimate counterfactuals. This form of counterfactual construction made the differences between types of sequencing clear. If a factor is sequenced first, for example age, then the estimated marginal effect is that of age. If a factor is sequenced second - for example age after household structure - then the marginal effect is that of age conditional on the change in household structure. In this way, if there is a relationship between these factors this will be captured in their ordering.

Jenkins and Kerm (2005) applied a similar method. However, instead of decomposing the distribution on the basis of changes in the distribution of other factors, the authors considered the ways the shape of the distribution changed through time. These corresponded to a sliding, a stretching, and a squashing of the estimated probability distribution function.

All these methods are non-causal, but provide a clear description of the way the income distribution has changed and what other population factors have been correlated to this movement.

In the New Zealand context, Hyslop and Mare (2005) offered a description of how important characteristics of the population were related to the change in income inequality between households in terms of gross income between 1984 and 1998. Household structure was a major contributor to the rise in household income inequality, with employment status and socio-demographic attributes also contributing. As is the general case with this method, a large proportion of the change in income inequality (around half) remained unexplained.

A second way of constructing counterfactual distributions for decomposition of an aggregate index, such as an inequality measure, is through direct imputation using a microsimulation model. An example of this type of counterfactual stems from Bargain (2012). Unlike the semi-parametric approach, these papers tend to focus on disposable income rather than gross or market income as the tax-transfer structure has been modelled allowing 
for the construction of counterfactual disposable incomes. ${ }^{2}$

The full technique used in this chapter combines these two approaches and is based on Herault and Azpitarte (2016). In Herault and Azpitarte (2016) the microsimulation decomposition of Bargain (2012) is combined with a semi-parametric decomposition based on DiNardo et al. (1996). Both microsimulation and semi-parameteric methods are ways of creating counterfactual income distributions which allow the decomposition of catalysts for changing income inequality based on what if analysis.

In the New Zealand context, Creedy and Eedrah (2014) decomposed the change in income inequality between 2007 and 2011 into policy and nonpolicy effects using Treasury's microsimulation model (TAXWELL). Over this period income inequality was virtually unchanged. However, policy changes were estimated to have increased inequality while non-policy effects reduced these measures. In terms of reweighting, Ball and Creedy (2015) investigated the influence of various population factors in the change in disposable and market income inequality in the 1983-2013 period by using a set of calibrated weights that kept population characteristics constant across the period.

Combining the microsimulation and semi-parametric approaches, Nolan (2016) performed an analysis of the change in disposable income inequality in New Zealand (using the Gini coefficient) over the 1995-2013 period. These results showed that the combination of policy changes had no impact on income inequality once labour supply responses were taken into account, and that an ageing population had put upward pressure on inequality during this period. This age effect was similar to the results found for gross households income in Hyslop and Mare (2005) where socio-demographic characteristics increased income inequality. However,

\footnotetext{
${ }^{2}$ Using a microsimulation model only allows the distribution of gross income to vary in so far as labour supply changes. This assumption is discussed more when the method is outlined.
} 
Hyslop and Mare (2005) also indicated that employment status had played an important role in increasing income inequality, a relationship that is investigated here over a longer time horizon.

\subsection{Data and data treatment}

The data used for this analysis comes from Statistics New Zealand's Household Economic Survey (HES). Two sets of pooled years are compared: the period including the HES 88 until the HES91 and the period including the HES10 until the HES13. The first set of pooled years are termed HES91 and the second set HES13 for brevity.

These periods were selected as the goal is to explain the increase in disposable income inequality that occurred between these years. The two four year periods are the same length and as a result allow for the construction of counterfactual tax-transfer systems based on the equivalent period in the other set of pooled data.

Another reason for selecting these specific pooled years is because both periods involve a similar change in economic and labour market conditions. HES91 refers to the period following Black Monday/Tuesday 1987, with the associated fall in economic output and sharp increase in unemployment in New Zealand. HES13 refers to the period following the initial shock of the Global Financial Crisis which also led to a decline in economic activity and rising unemployment. As discussed in Chapter 4 the downturn experienced in the earlier period was more severe, both in terms of the decline in GDP and employment and the increase in unemployment. As a result, although both periods refer to economic downturns there is a relevant difference in the intensity of the change which must be considered when comparing the two periods.

Furthermore, the entire income distribution is not considered in this chap- 
ter. Gini coefficients cannot be calculated for those with negative incomes while some populations (eg students and dependants) are commonly excluded from analysis as they receive zero income even though they still have access to resources. As a result, all families with an disposable income below $\$ 5,000$ in June 2013 prices, or with negative market incomes, are excluded from analysis. ${ }^{3}$ This also makes the sample used consistent with that used in Chapter 3 and in prior research using TAXWELL-B (eg Creedy and Mok 2015).

\subsubsection{Imputation}

\section{Wages}

When counterfactual years are defined for analysis the real imputed wage for a given HES year is left fixed. Alternatives to this are discussed in Chapter 5, however each of these alternatives involves a large or currently impractical extension of the underlying microsimulation framework. As a result, fixed gross wages are used.

A fixed gross wage allows the construction of both the current budget constraint for individuals, and alternative budget constraints they would face when the tax-transfer system changes. This allows for counterfactual analysis both through the calculation of how direct tax-transfer changes are allocated to households (eg tax incidence falls entirely on the worker), and through any effect it has on the behavioural response of individuals to changes in the tax-transfer system.

Given that the technique assumes a fixed gross wage at all possible hours to construct these budget constraints it is necessary to calculate the available wage for every adult in the sample. For individuals, the wage mea-

\footnotetext{
${ }^{3}$ This was less than $7 \%$ of the same for HES91 and less than $4 \%$ of the sample for HES13
} 
sure used in this chapter is the implied wage from wage and salary income in the HES data. This is equal to total current weekly wage and salary earnings from the individuals primary job divided by the number of hours worked per week in their primary job. ${ }^{4}$

However, for individuals who are not working but are able to participate in wage and salary work it is not possible to calculate a wage rate in this way. As a result, it is necessary to impute wages for those who are not working. The wage imputation process and results for the periods of interest are reported in Chapter 4.

In Bourguignon et al. (2008) and Jessen (2016) further use is made of this imputed wage to perform further decompositional analysis. A counterfactual wage is estimated using these imputed wages, and counterfactual income distributions are created using the wage distribution generated from the wage equation for a different year. However, given the large amount of unobserved heterogeneity in wage rates, issues of comparability of certain relevant characteristics across the surveys (ethnicity, occupation, industry), and the already significant number of decomposition paths investigated in this chapter this is not a direction that will be taken further in this chapter.

\section{Tax-transfer imputation}

A tax-transfer microsimulation model allows an analyst or researcher to impute values for tax and transfer payments for a given tax-transfer system and an agent with a set of characteristics. The HES data provides individuals with characteristics, and as a result such a model can be used

\footnotetext{
${ }^{4}$ The earnings from prior jobs, self-employed work, and secondary jobs are ignored when calculating the wage. The primary job is defined as the wage and salary job the individual is currently employed in that offers the largest average weekly income at current hours of work.
} 
to impute tax and transfer payments for a variety of counterfactual taxtransfer systems.

However, in order to make comparisons to a given base year the modelled tax-transfer system that transforms market into disposable income has to be consistent with the data. At this point there is a modelling dilemma the model could be used to describe the change in tax-transfer payments from their observed level, or the reported tax-transfer payments could be fully replaced by imputed values.

In this instance, reported HES data on the modelled tax and transfer payments is removed from the data and replaced by imputed values. The reason for this is the lack of reliability regarding household survey based tax and transfer payments and the ability to replace these values with estimates from a microsimulation model as discussed in Figari et al. (2012). The specific lack of reliability of household survey data on benefits is discussed in the New Zealand context by Hyslop and Mare (2005) and Ball and Ormsby (2017).

Observed transfer payments are still used to determine who receives additional unmodelled payments and who is eligible for benefits that require specific characteristics (eg the Invalid's Benefit during this time period now referred to as the Supported Living payment).

The full set of policies modelled and the nominal values for the years of interest are given in Chapter 2, along with hyperlinks to the relevant legislative documentation. These values and policies were coded into Treasury's tax-transfer microsimulation model (TAXWELL) thereby increasing the period where tax-transfer payments could be imputed in this model from 2007-2013 to 1988-2013. This extension allows for the imputation of alternative tax-transfer systems which was not possible when Ball and Creedy (2015) investigated income inequality trends with the same underlying HES data. 


\subsection{Methodology and simulation}

Economic modelling involves the construction of counterfactual worlds, which allows the researcher to deduce conclusions about a specific fictional world - this is also known as the creation of what-if scenarios. A model can be seen as useful for policy analysis if it is credible: data and this counterfactual scenario can be used to inductively reach conclusions about the real world Sugden (2001).

When it comes to looking at the impact of policy change Spadaro (2007) discusses three outcomes of value in a model:

- Simplicity of use and interpretation.

- An ability to describe the complexity of the socioeconomic structure.

- The ability to capture the heterogeneity of agents.

However, there is no one model that is dominant over all three outcomes, and as a result modellers face a trade-off between these outcomes when picking a modelling technique. Typically representative agent models focus on the first outcome, while models that ignore the first element too much (thereby giving results that are hard to explain or causally link) tend to be termed black box approaches to analysis.

While a representative agent model limits the degree of heterogeneity in modelled agents, it is both clear to interpret and is able to incorporate substantial behavioural elements. In some sense, this allows modellers to answer the Lucas Critique (Lucas 1976) when observing the impact of policy.

However, by excluding heterogeneity this approach is unable to fully deal with the Lucas Critique - as the heterogeneity of agents in terms of their characteristics (and the behavioural responses this entails) is policy rele- 
vant information that influences the impact of policy. ${ }^{5}$

In this the Lucas Critique is stating that there needs to be appropriate behavioural structure in order to estimate the impact of policy through the lens of historic data. As a result, when trying to look at the impact of policy, a modelling approach (or approaches) that satisfies this requirement as much as possible is preferable. Furthermore, there should be clarity about the ways the model does not capture this structure.

For an investigation of the role of tax-transfer policy a tax transfer microsimulation model offers this clarity and allows for the introduction of important behaviour.

A microsimulation model requires three broad elements for its construction as noted in Spadaro (2007):

- A microdata set containing the economic and sociodemographic characteristics of individual agents.

- An institutional framework. This is the rules of the policies to be simulated and income generating process inherent in the economy (e.g. budget constraints).

- A theoretical model representing the behaviour of agents.

A microsimulation model takes microdata and rules/policy, then applies

\footnotetext{
${ }^{5}$ Looking at the macroeconomy, representative agent models rose in popularity out of criticism of large-scale econometric models on the basis of the mathematical/logical link between aggregate variables. In a similar way, the mathematical link between the primitives of individuals and macro-aggregates, is often not available or cannot be defined. This is discussed in Orcutt (1957), Goldman and Uzawa (1964), and Shafer and Sonnenschein (1982) with regards to individuals to macro theory, Mas-Colell (1989) for the capital controversy, and Hoover (2001) for the relation between macro and micro economics. A series of related essays can be found in Hahn and Petri (2004). The key point in what we are discussing is that the behaviour of groups can often not be sufficiently described as a mathematical function of the behaviour of a representative individual for many questions of interest.
} 
the behaviour of individuals in order to simulate the economy as a function of policy. Given this, it is possible to discuss the impact of a policy based on the different characteristics of individual agents - where the heterogeneity of individual agents is described through differences in the agents measured characteristics.

Any counterfactual analysis preformed with an Arithmetic Microsimulation model involves fully modelling the institutional structure but not behaviour - it implicitly assumes that labour supply and gross wages are unchangeable. In this way, the impact of policy measured in such an analysis is often termed a morning after effect.

More broadly such changes is termed the direct effect of tax-transfer policy changes in the analysis performed in this chapter.

When it comes to individual behaviour, labour supply choices are included in the analysis in this chapter. As a result, the full form of the microsimulation model used is a static Behavioural Microsimulation model. The policy effect from such a model includes the direct effect of policy and an associated change in labour supply behaviour - which is termed the indirect effect of policy in this chapter.

By using varying combinations of behaviour and policy a decomposition between the direct and behavioural effects of policy can be made. Following Herault and Azpitarte (2016) the labour supply behaviour of individuals in a given year is subject to their expectations regarding their tax liability and transfer payments. For example, someone in 2013 may expect the tax-transfer system of 1991 and behave in a way that is consistent with this. If this behaviour is modelled only the direct effect of the change in tax-transfer settings between 1991 and 2013 will occur. 


\subsubsection{Deflators, annual comparisons, and equivalent poli- cies}

Two different deflators are used in this chapter in order to make the data comparable for the question at hand.

The first deflator is the Consumer Price Index including interest payments (CPI). ${ }^{6}$ The CPI is used to set pooled years to the same base year, with all nominal sums set to the given quarters price level. This implies that the HES91 period has been shifted to March 1992 prices, while HES13 is shifted to June 2013 prices.

When it comes to setting up counterfactual policies it may also seem appealing to deflate the payments and thresholds in the tax-transfer system by CPI for creating the counterfactual years. The results reported by Nolan (2016) used this method.

However, as Bargain and Callan (2010) argue, in order to keep the policies distributionally neutral they would need to rise or fall with average growth in the income distribution. As a result, deflating tax-transfer rates and thresholds by a wage/income index is required to prevent making normative assumptions about counterfactual policies as stated in Bargain (2014). In this way a government's decision to not increase tax-transfer thresholds and transfer rates as quickly as average wage/income growth is seen as a direct policy choice to cut these payments. This assumption is also consistent with a view regarding the affordability of the tax-transfer system, where the ability to fund redistribution rises as average incomes increase. As a result, Average Weekly Earnings (including overtime) from the Quarterly Employment Survey is used to deflate tax-transfer policies

\footnotetext{
${ }^{6}$ This series started in March 1994 and is back indexed using the standard CPI.
} 
between the two periods. ${ }^{7}$

Compared to results that use CPI to deflate policies in a nation experiencing economic growth, a wage/income index will naturally suggest that a tax-transfer system that indexes against CPI inflation is inequality increasing.

\subsubsection{Weights and the treatment of tax and transfers in sim- ulation}

Although the Household Economic Survey (HES) data are used for analysis, making any inference about how this survey relates to the New Zealand population requires a series of initial assumptions.

Statistics New Zealand first applies judgement to the HES when they clean up data responses and offer sampling weights based on calibration to population parameters as stated in Statistics New Zealand (2001). The purpose of weights is to make the sample representative of the New Zealand population as a whole. Initially Statistics New Zealand did not offer sampling weights for the HES (pre-1988), but then introduced sampling weights based on the inverse probability of the unit (in this case the household) being sampled in that given year. In 2001 Statistics New Zealand changed to calibrated weights (Statistics New Zealand 2001) which uprate the sample to make it representative of a set of known aggregate characteristics of the population (population size, ethnic make-up, age composition).

As well as weighting assumptions, the timing of collection matters. Each reported income series is split into 24 spells, or two week periods. The household can be surveyed at any point in the HES period (running from

\footnotetext{
${ }^{7}$ The QEX series only began in 1989 , and directly replaced a similar quarterly employment survey. In order to link the two series, wage growth is assumed to equal consumer price growth between December 1988 and March 1989. Furthermore, wage growth is assumed to be generally comparable between the two indices.
} 
July to June). ${ }^{8}$ When surveyed HES asks households about their income during the entire prior year. In this way, income data for the HES as a whole refers to earnings for the two years prior to the survey end date.

TAXWELL takes this HES data and applies two clear adjustments/assumptions:

1. New calibrated weights to match the number of beneficiaries by benefit type. The standard HES data undersamples beneficiaries (largely due to their higher non-response rate). As a result, new calibrated weights are estimated given population information on beneficiary numbers from the Ministry of Social Development. This is discussed in Aziz, Ball, Creedy and Eedrah (2013) and Creedy and Tuckwell (2003).

2. The replacement of primary transfers and tax payments based on observed eligibility, rather than reported benefit and tax income alone.

The second assumption is a central part of what is required for simulating alternative income distributions in the face of changes in policy settings. By directly attributing transfers and taxation on the basis of eligibility, this deals with potential measurement errors due to recall bias and avoids the issue of approximate imputation in survey data. The reason for imputing data rather than using reported survey data in these instances is justified in Figari et al. (2012). Most secondary and tertiary payments remain unmodelled, and their values are taken directly from the HES (eg Emergency benefit payments).

However, such an assumption is not necessarily innocuous due to the fixed cost of benefit take-up and the potential for individuals and households to avoid taxation - and the fact that recall bias exists for the characteristics we determine eligibility from. However, it does give an idea of how the distribution of income is likely to change in the face of policy

\footnotetext{
${ }^{8}$ The July-June year began with the HES01 survey. Prior surveys had been based on a April-March year
} 
changes - subject to the still strong assumption that rates of take-up and tax avoidance do not shift too sharply.

The behavioural microsimulation model (TAXWELL-B) does not deal with the same detail in the data - taking the income and benefit eligibility of the family in the final spell and annualising it, rather than considering income and benefit status in each spell (two week period) reported for the period. As a result, TAXWELL-B implicitly assumes that the family has supplied labour and received transfer income in the same way all year that they have over the reported period (the final spell is annualised). ${ }^{9}$ This is the final data used for the analysis in this chapter.

The calibrated weights are used in the construction of the Gini coefficients in this chapter. Ginis were calculated using the R package IC2 Plat (2015). The details of constructing Gini coefficients using weights can be found in Creedy (2015) while a full discussion of measuring and measurement Gini coefficients is given in Yitzhaki and Schechtman (2013).

\subsubsection{Behavioural policy responses}

Changes in the tax-transfer system would be expected to have consequences in terms of the choices made by individuals. As a result, a behavioural component is added to Treasury's arithmetic microsimulation model (TAXWELL) to account for how these changes in available net incomes lead to a labour supply response. This model is termed TAXWELL-B.

Taking gross wages as fixed, a behavioural model takes changes in policies (which are defined through the use of procedures and the parameters they define) and allows them to influence net wages available at different discrete hours of work (the budget constraint). This in turn influences

\footnotetext{
${ }^{9}$ This also implies that TAXWELL-B only looks at reported income for the year of the survey.
} 
labour supply choices through individual preferences over income and leisure. $^{10}$

The leisure-consumption preferences of individuals for this analysis come from Chapter 5. Utilising the discrete hours random utility framework of van Soest (1995), a quadratic utility function for families with preference parameters that are a function of family characteristic are estimated.

When incorporated into TAXWELL-B, the labour supply choice of each family is calibrated to match the observed choice. In this case, random terms are drawn from the error term (which is assumed to follow an extreme value distribution) and added to the utility for each hours value. If the hours level selected matches what is observed then this error term is kept for future simulations - if not the error term is redrawn. This process continues 100 times and if no error term gives the observed choice by this point the individual is thrown out. Less than 10 income units were removed from each data set due to this. The calibration process is discussed with examples in Creedy and Kalb (2005).

Two different estimates of the preference parameters are used in this chapter - one referring to the 1988-1993 period and one referring to the 20092013 period. When the HES91 data is referred to labour supply behaviour is based on the preference parameter model of HES88-93. Similarly when the HES13 data is referred to, it is based on a preference parameter model of HES09-13.

As a result, the behavioural response depends not just on the tax-transfer policy period but on the population period that is being analysed - due to the fact that the HES88-93 and HES09-13 preference parameter estimates

\footnotetext{
${ }^{10}$ This is still a comparative static model. As a result, the labour supply change is not necessarily representative of the change in long-run labour supply. This framework is discussed in Jia and Vattø (2013), but the convergence to the static result found by the authors stems from myopia on the part of the modelled agents - in the face of rational expectations equilibrium employment would differ.
} 
were quantitatively very different.

\subsection{Decomposition method: The role of tax-transfer policies}

\subsubsection{The policy model}

The microsimulation model utilised allows the construction of scenarios that consider what economic outcomes would have looked like in a given year if the tax-transfer system had taken a different value. A decomposition process involves constructing counterfactuals that isolate the specific effect of a given tax-transfer policy change.

As a result, when asking what effect tax and transfer payments had on income inequality it is possible to use a microsimulation model to ask what income inequality would have been in a given year if the tax-transfer system of a different year had been applied - but the other given population characteristics remained fixed. It is these counterfactual scenarios that provide the what if questions that allow for the decomposition.

The procedure that outlines this process formally is given by Bargain and Callan (2010), based on a non-behavioural (arithmetic) microsimulation model. At a point in time $t$ the income distribution, or an aggregate measure of the distribution (such as an inequality index, $I_{t}$ ), can be thought of as some function of the characteristics of individuals in the sample ${ }^{11}$ $\left(\mathbf{X}_{\mathbf{t}}\right)$ and the policy parameters of the tax-benefit system $\gamma_{\mathbf{t}}$. As a result the measure of interest at time $t$ can be written as:

$$
I_{t}=I\left[d_{t}\left(\mathbf{X}_{\mathbf{t}}, \gamma_{\mathbf{t}}\right)\right]
$$

\footnotetext{
${ }^{11}$ Eg Age, labour supply. These are weighted up to represent the overall population.
} 
Where $d_{t}$ represents a tax-benefit function that transforms market incomes into disposable incomes, termed by Bargain (2012) as the tax-benefit structure. As a result, the change in inequality between two periods of time (say 0 and 1 ) can be written as:

$$
\Delta=I\left(d_{1}\left(\mathbf{X}_{\mathbf{1}}, \gamma_{\mathbf{1}}\right)\right)-I\left(d_{0}\left(\mathbf{X}_{\mathbf{0}}, \gamma_{\mathbf{0}}\right)\right)
$$

The goal is to calculate the relative impact that shifts in these characteristics and tax-benefit policies had in changing this index between the two points in time. In this framework, the two points in time represent two mutually exclusive groups and the question is how differences in the relative effect of the characteristics of these groups (the tax benefit system, the attributes of individuals/families, and the structure of the implied income generating function) contribute to explaining the difference in the index I.

The relative contribution of these different factors can be calculated by considering what if questions such as "what would the income inequality index be if the period 1 population characteristics were in place, but the (appropriately deflated) tax-benefit policy parameters and structure from period 0 held". This counterfactual is represented by $I\left(d_{0}\left(\mathbf{X}_{\mathbf{1}}, \alpha \gamma_{\mathbf{0}}\right)\right)$.

Following Bargain and Callan (2010) a non-behavioural microsimulation model can be used to define the counterfactuals necessary to estimate a policy effect. A key advantage of using a microsimulation model to construct these counterfactual scenarios is the fact that it captures the full detail of the tax-benefit system and the vastly different impact policy changes have on the net incomes of the variety of individuals in society. For example, one way of structuring the decomposition in this instance is the following: 


$$
\begin{aligned}
\Delta= & \left\{I\left[d_{1}\left(\gamma_{\mathbf{1}}, \mathbf{X}_{\mathbf{1}}\right)\right]-I\left[d_{0}\left(\alpha_{1} \gamma_{\mathbf{0}}, \mathbf{X}_{\mathbf{1}}\right)\right]\right\} \quad \text { Policy effect } \\
& +\left\{I\left[d_{0}\left(\alpha_{1} \gamma_{\mathbf{0}}, \mathbf{X}_{\mathbf{1}}\right)\right]-I\left[d_{0}\left(\alpha_{1} \gamma_{\mathbf{0}}, \alpha_{1} \mathbf{X}_{\mathbf{0}}\right)\right]\right\} \quad \text { Population effect } \\
& +\left\{I\left[d_{0}\left(\alpha_{1} \gamma_{\mathbf{0}}, \alpha_{1} \mathbf{X}_{\mathbf{0}}\right)\right]-I\left[d_{0}\left(\gamma_{\mathbf{0}}, \mathbf{X}_{\mathbf{0}}\right)\right]\right\} \quad \text { Income growth }
\end{aligned}
$$

When constructed this way $\gamma_{t}$ and $d_{t}$ change subscript together, as the policy effect captures the full change in policy parameters and the structure of the tax system.

The above equation states that, starting at $t=1$ the change in an aggregate index between two periods can be defined as a sequence of counterfactuals involving period 0 (deflated) policy applied to the period 1 population characteristics (eg the weighted period 1 sample), and the index observed in period $t=0$. There is an additional term in the above equation due to the deflating of the policy and population variables moving from $t=1$ to $t=0$. For a relative income inequality index this income growth effect should be zero, and so can safely be ignored. ${ }^{12}$

When decomposing the difference between an index value at $t=1$ and $t=0$ either the policy effect or the population effect can be estimated first, giving two potential orderings to consider. Because of its sequential nature (the policy effect or the population effect could be estimated first), and the fact that the sequence does influence the estimate of the marginal effect, there needs to be some way to choose between these two potential orderings - or to set a weighted average of the orderings.

Shorrocks (2013) considered this problem and used the Shapley value from cooperative game theory to justify using an average of the possible decompositions - as there is no reason to favour one ordering above another.

\footnotetext{
${ }^{12}$ This is termed the assumption of linear homogeneity. If this assumption fails then this characteristic makes up part of the residual term.
} 


\subsubsection{Income counterfactuals and take-up rates}

The construction of counterfactual tax-transfer settings relies on assumptions about the take up rate of transfers and the payment of taxes relative to the base data. As survey data is used, then any difference between modelled tax and transfer payments and the survey data would need to be taken into consideration when forming counterfactual income distributions.

In this chapter, modelled transfer payments and tax liabilities are applied to the base data and as a result the modelled tax system can be applied without change to counterfactual years. This involves assuming full takeup of primary transfer payments and full payment of income tax liabilities in both the base and counterfactual scenarios. As a result, the take-up behaviour of individuals is not modelled.

There are situations where these take-up assumptions are violated as discussed by Keane and Moffitt (1998) and Wiemers (2015), which would be relevant for the distribution of observed income. However, in the analysis of this chapter the primary benefits modelled already have high take-up rates in both periods. As a result, the take-up assumption appears reasonable and is unlikely to influence the change in the income distribution which is the focus of analysis here.

\subsubsection{The behavioural response to policy}

In order to allow for the labour supply changes that follow from adjustments to tax-transfer policies, Bargain (2012) changes the Bargain and Callan (2010) framework by allowing characteristics to change. Specifically, this involves taking the data matrix $X_{t}$, and considering how policy transforms it. Previously, a change in policies did not directly influence $X_{t}$ as varying $\gamma_{t}$ did not lead to a change in gross incomes. However, when labour sup- 
ply is allowed to change both hours of work and gross income will also change. As a result, the data matrix at period $t$ facing the policy settings of period $l$ can be written as $X_{t}^{l}$. With this counterfactual for the data matrix, and keeping $X_{t}^{l}=X_{t}$ when $t=l$ for simplicity, the example decomposition extends to: ${ }^{13}$

$$
\begin{aligned}
\Delta= & I\left[d_{1}\left(\gamma_{\mathbf{1}}, \mathbf{X}_{\mathbf{1}}\right)\right]-I\left[d_{0}\left(\alpha_{1} \gamma_{\mathbf{0}}, \mathbf{X}_{\mathbf{1}}\right)\right] \quad \text { Policy effect } \\
& +I\left[d_{0}\left(\alpha_{1} \gamma_{\mathbf{0}}, \mathbf{X}_{\mathbf{1}}\right)\right]-I\left[d_{0}\left(\alpha_{1} \gamma_{\mathbf{0}}, \alpha_{1} \mathbf{X}_{\mathbf{0}}^{\mathbf{1}}\right)\right] \quad \text { Population effect } \\
& +I\left[d_{0}\left(\alpha_{1} \gamma_{\mathbf{0}}, \alpha_{1} \mathbf{X}_{\mathbf{0}}^{\mathbf{1}}\right)\right]-I\left[d_{0}\left(\alpha_{1} \gamma_{\mathbf{0}}, \alpha_{1} \mathbf{X}_{\mathbf{0}}\right)\right] \quad \text { Behavioural effect }
\end{aligned}
$$

Here labour supply behaviour is estimated on $t=0$ period data, and the behavioural effect is simulated by comparing the index value with labour supply on the $t=0$ sample with the policies of $t=1$ to the index value with labour supply observed at $t=0$.

Although it initially appears that there are six possible decompositions between the direct policy, behavioural (indirect), and population effects there are in fact only four: as this represents a further decomposition of the population effect from Bargain and Callan (2010) where the direct policy effect had already been identified, it implies to the authors that the population and behavioural effects must be positioned consecutively.

This argument admits that the potential for ordering does matter, as Sastre and Trannoy (2002) point out when discussing the Owen value and Nested Shapley value. This becomes important when looking at any breakdown of the initial decomposition. Specifically Sastre and Trannoy (2002) state:

The contribution of any given factor to overall inequality can be interpreted as the expected marginal impact of the factor when the expectation is taken over all the possible elimination sequences. Thus, it is important that the elimination sequences

${ }^{13}$ Assuming the income effect is zero. 
or, equivalently, the subsets of components considered in the calculation, have an economic appeal.

Implying that any decomposition that is provided needs to be based on only selecting counterfactuals that make economic sense.

Bargain (2012) recognised that, although the direct effect of policy was identified in the initial Bargain and Callan (2010) framework, the indirect effect of policy changes on labour supply was not. Instead, any change in the summary index which was due to changes in labour supply was being included in the population effect category.

In this chapter this view about the economically appropriate counterfactuals is not applied, and all orderings of population, behavioural, and direct policy decompositions are used. Each time an individual characteristic (such as employment behaviour) is changed the marginal effect of direct tax policy is changed in a way that is economically meaningful. As a result, the exclusion of these counterfactuals based on Sastre and Trannoy (2002) is not applied here.

The final results of this chapter can be viewed as an extension of Bargain (2012) in order to analyse the population effect in more detail. The Bargain and Callan (2010) and Bargain 2012 decomposition method has been applied to a number of high income countries (Bargain et al. 2013, Matsaganis and Leventi 2014) implying that a more detailed decomposition would have value for analysing inequality trends around the world.

\subsubsection{Interpreting the results of this method}

The decomposition process described in this chapter takes a counterfactual where the tax transfer system of one year (eg HES91) is applied to the population of another year (eg HES13). Full take up of transfer payments, and full payment of tax liabilities, is assumed and changes in labour sup- 
ply choices given new net incomes in the counterfactual scenario are estimated.

As a result, the output for this form of analysis should be interpreted as a first-order approximation of the role tax-transfer played in changing income inequality - with adjustments in production and consumption patterns, as well as individual characteristics (apart from labour supply), not accounted for.

Although this method provides a clear description of a type of policy effect on income inequality, there are other channels that tax-transfer changes could influence the distribution of income which are not included in this estimate such as:

- Policy's impact on market incomes (Gross wages, employment opportunities, general equilibrium effects).

- Policy's impact on individual/population characteristics (Educational attainment, family and household structure, migration).

Given that these channels will be relevant for the large tax-transfer policy changes during this period, the policy effect estimated in this chapter likely differs from the full dynamic effect of varying tax-transfer policies. For example, changes in tax rates relative to other countries may change the incentive for skilled migrants to come and work in a country - changing both the population and the characteristics of the population. Furthermore, without labour demand or general equilibrium effects a microsimulation model does not provide a closed system. As a result, the non-closure inherent in this model can provide implausible results - especially if the underlying tax change is not fiscally neutral.

In the scenarios modelled here, the shift from the HES91 tax-transfer system is not a revenue neutral change, with the increase in spending on transfers and the decline in tax income from lower aggregate labour supply exceeding the tax revenue raised from higher average tax rates. Given 
this, if the periods being compared involve questions about the affordability of the tax-transfer system then it needs to be made clear that the unaffordable tax-transfer system is not a reasonable counterfactual for taxtransfer purposes.

It is possible to consider whether the change in taxes and transfers increased income inequality between HES88 and HES09 by applying the opposite tax-transfer system to each year. But if the HES88 system was viewed as unaffordable or unsustainable then this places a question mark over using the HES88 tax-transfer system as a benchmark for changing income inequality outcomes.

Prior to HES88 and over the HES88-91 period, the constant fiscal deficits, increasing benefit expenditure as a percentage of GDP (McClure 1996), and 1991 credit rating cut by S\&P were all factors that suggest the taxtransfer system in HES91 was seen as fundamentally unaffordable. As a result, even though the change in the tax-transfer structure may have changed outcomes in terms of the distribution of income reversing any perceived negative changes is more complex than reinstituting the old taxtransfer regime.

However, since HES91 there have been cuts to average tax rates as well as reductions in certain benefit categories - implying that the fundamental nature of the tax-transfer changes reduced the magnitude of any income redistribution through the tax-transfer system. This is shown directly in Chapter 3. 


\subsection{Decomposition method: The role of other fac- tors}

The effect of tax and transfer policies on inequality measures depend on the underlying population, and therefore depend upon the characteristics of the individuals being analysed. In the prior decompositional method, all characteristic/population changes and their influence on the income distribution are bundled into a single residual term.

In order to account for other factors the weighted sample data of a given year is reweighted to more closely represent the population of an alternative year. This method was applied to Australian survey data in Herault and Azpitarte (2016), and is related to estimates performed in the New Zealand context in Hyslop and Mare (2005). Hyslop and Mare (2005) estimated the influence of general changes in employment and socio-demographic characteristics, but focusing on a different income unit (household income).

In this chapter, three other factors beyond the static role of policy are considered when looking at the change in income inequality: Changes in the distribution of employment status, age, and highest educational attainment.

Why have these changes been selected? It has been suggested that the changing age structure of the population can influence the income distribution in a number of ways (Goldstein and Lee 2014): The changing age structure, capital intensity, and increasing longevity (and associated lifecycle effects). In this chapter, the question is whether the growing proportion of individuals in their prime working age has contributed to the observed increase in income inequality. As a result, it is not the full effect of age that is investigated but instead a narrower question regarding changing age structure alone.

Varying employment status is also likely to generate differences in income 
inequality measures. Although both periods of analysis refer to recessions (New Zealand's recession of the early 1990s and the Global Financial Crisis), the deterioration of the labour market in 1988-1991 was worse than that experienced in 2010-2013 - both in terms of the magnitude of the decline and the relative timing in the economic cycle. However, the nature of the labour market had also changed substantially between those two periods - with part time work becoming more common. As a result, the distribution of employment status differed in a way that will influence income inequality outcomes between HES91 and HES13.

Finally, changes in the distribution of highest educational attainment have been linked to a changing dispersion of income (eg Coady and Dizioli 2017). Not only does this provide an additional mechanism with which the income distribution may have changed, it is also not likely to be independent of the nature of tax-transfer policy changes. As a result, the role of educational attainment is important to include in this analysis.

Several other distributional factors may have been relevant for the change in the income distribution but are not considered here: Wages, returns on characteristics, ethnicity, industry of work, and occupation.

Changes in the wage distribution are likely to have been an important determinant of the lift in income inequality, as outlined in Hyslop and Yahanpath (2005). As mentioned in the imputation section, decompositions based on counterfactual wage distributions have been performed within this framework previously in the literature (eg Jessen 2016). Using the wage equations from the wage imputation procedure for non-workers counterfactual wage distributions can be formed to allow for this analysis.

This form of analysis appears problematic at first due to the large unobserved heterogeniety in the wage data. A solution to this is to keep unobserved error terms in the wage rate for simulation. However, the underlying characteristics in the wage equation rely on characteristics that 
were not necessarily comparable over time due to changes in definitions (ethnicity, industry, occupation) and in many cases had to be imputed using correspondence tables. As a result this form of decomposition was rejected.

A replacement for wage distribution analysis is the return to characteristics approach of Hyslop and Mare (2005). However, Hyslop and Mare (2005), Dixon (1998), and preliminary analysis of the distribution performed for this chapter suggested that the changes in return to characteristics have played a limited role in changing inequality outcomes. With important characteristics also unreliable for comparison between periods, this form of decomposition was also not undertaken.

Ethnicity, industry of work, and occupation are also characteristics of the population that changed and will be related to inequality outcomes. With the structure of the economy changing, industry and occupation were of special interest for this analysis. However, these three characteristics that were not necessarily comparable over time due to changes in definitions. Industry and occupation had to be imputed using correspondence tables, while ethnicity categories remained incomparable between the wage equation years estimated. As a result, decomposition based on these factors was inappropriate.

In the New Zealand context this chapter can also be seen as an extension of Hyslop and Mare (2005) - by incorporating the impact of tax-transfer policies into the counterfactual decomposition analysis, and shifting the analysis from household income to individuals and families. 


\subsubsection{The method for investigating changing characteris- tics}

To extend the Bargain (2012) method Herault and Azpitarte (2016) separates out the employment effect into policy related and non-policy related changes in employment. They use the methodology of Bover (2010), which is essentially the DiNardo et al. (1996) method as applied by Hyslop and Mare (2005) and Daly and Valletta (2000).

As discussed in Fortin et al. (2011), the DiNardo et al. (1996) reweighting method for estimating counterfactual distributions is essentially a propensity score reweighting method, with the reweighting factor based on the estimation of a logit/probit model.

In this context, time is treated as a state/treatment variable. The impact of a specific factor on a distribution (eg the wage distribution in the case of DiNardo et al. 1996 or income distribution in the case of Hyslop and Mare 2005) can then be given by assuming the distribution of the factor is fixed over time (the assumption of the invariance of conditional distributions).

However, as noted in Fortin et al. (2011) this requires the strong economic assumptions that there are no general equilibrium effects and no selection based on unobservables. Both these assumptions, and thereby the assumption of conditional independence, are likely to be violated when considering an income distribution. As a result, the process of reweighting the data to make the distribution of one factor similar in one time period to another period should be seen as an exploratory form of analysis - not causal. For example, if a change in the education distribution explained a large section of the change in the relative density of income this does not tell us why both distributions changed and does not imply that an exogenous increase in education levels would lead to the given change in the density of income. 
Under this methodology, the counterfactual scenarios are defined in the following way over the entire income distribution. Assume there are $N$ individuals/income units, where the $i \in\{1, \ldots, N\}$. Partition the data matrix, $\mathbf{X}_{\mathbf{t}}$ into $\mathbf{y}_{\mathbf{t}}$ (which represent the income of all income units) and $\mathbf{z}_{\mathbf{t}}$ (which represents the attributes of all income units). An individual observation in the data set can be thought of as a vector $\left(y_{i}, \mathbf{z}_{\mathbf{i}}, t\right)$, where $y_{i}$ is income of the income unit, $\mathbf{z}_{\mathbf{i}}$ is a vector of attributes, and $t$ is the time variable. Each of these observations belongs to a joint distribution of incomes, attributes, and dates $F(y, z, t)$ - therefore the joint distribution of incomes and attributes at a point in time is the conditional distribution $F(y, z \mid t)$.

Assume that the distribution is also dependent on some policy variable, $\gamma$. Then the joint density of income and attributes at one point in time is $f_{t}(y)=f\left(y, z \mid t ; \gamma_{t}\right)$. The density of wages at a point in time, $f_{t}(y)$, is the integral of the density of income conditional on a set of individual attributes at a date $t_{y}{ }^{14}\left(f\left(y \mid z, t_{y} ; \gamma_{t}\right)\right)$ over the distribution of individual attributes at time $t_{z}{ }^{15}\left(F\left(z \mid t_{z}\right)\right)$, with $\Omega_{z}$ the domain of individual attributes. This gives:

$$
\begin{aligned}
f_{t}(y) & =\int_{z \in \Omega_{z}} d F\left(y, z \mid t_{y, z}=t ; \gamma_{t}\right) \\
& =\int_{z \in \Omega_{z}} f\left(y \mid z, t_{y}=t ; \gamma_{t}\right) d F\left(z \mid t_{z}=t\right) \\
& =f\left(y ; t_{y}=t, t_{z}=t, \gamma_{t}\right)
\end{aligned}
$$

Under the strong (especially in the case of income) assumption that the structure of income $\left(f\left(y \mid z, t_{w}=t ; \gamma_{t}\right)\right)$ does not depend on the distribution of attributes, the situation where $t_{z} \neq t_{w}$ can be defined. Then the "density that would have prevailed in 2013 if attributes had remained at their 1991

\footnotetext{
14 The time period of the income vector.

15 The time period of the attributes matrix.
} 
level and income had been shared according to the income schedule in 2013" $\left(f\left(y ; t_{w}=13, t_{z}=91, \gamma_{13}\right)\right)$ is:

$$
\begin{aligned}
f\left(y ; t_{y}=13, t_{z}=91, \gamma_{13}\right) & =\int f\left(y \mid z, t_{y}=13 ; \gamma_{13}\right) d F\left(z \mid t_{z}=91\right) \\
& =\int f\left(y \mid z, t_{y}=13 ; \gamma_{13}\right) \psi_{z}(z) d F\left(z \mid t_{z}=13\right)
\end{aligned}
$$

Where $\psi_{z}(z)=\frac{d F\left(z \mid t_{z}=91\right)}{d F\left(z \mid t_{z}=13\right)}$ is a reweighting function.

As a result counterfactual scenarios can be created by estimating the reweighting function and applying it to the sample weights that are attached to the HES data. However, this begs the question of how to practically estimate $\psi_{z}(z)$. DiNardo et al.'s innovation was to apply Bayes' Rule to the problem, which implies that:

$$
\widehat{\psi_{z}}(z)=\frac{P\left(t_{z}=91 \mid z\right)}{P\left(t_{z}=13 \mid z\right)} \cdot \frac{P\left(t_{z}=13\right)}{P\left(t_{z}=91\right)}
$$

Then the data set can be reweighted with the relevant relative probabilities, estimated with standard logit models as described in Cameron and Trivedi (2005), in order to form the counterfactual density.

As mentioned above, each counterfactual must be introduced sequentially (while holding other factors constant), as a result the estimated contribution of the factor associated with that counterfactual depends on the ordering of estimation.

Ordering matters as the characteristics the result is conditional on changes as the ordering change - and as a result, the later the ordering is the more other changes/factors the result is conditional on. When the effect of a factor first is estimated first, it is the unconditional contribution of that factor. Second it is the contribution of that factor, conditional on the first 
factor. With no reason to prefer a given ordering of the factors the Shapley value us applied to find the marginal effect of that factor. ${ }^{16}$

As a result, the number of counterfactuals needed to average over to estimate the marginal effect of the policy is $C$ ! where $C$ is the number of contributing factors used.

As noted when discussing Herault and Azpitarte (2016), the counterfactual corresponding to employment outcomes can be neatly fit within the microsimulation decomposition framework of Bargain (2012). Furthermore, Herault and Azpitarte (2016) goes on to analyse changes in the distribution of specific factors (age, education, distribution of income unit type and size, wage income, capital income). This chapters extension is to compare all factors at once.

An example of the estimation procedure with regards to the employment status characteristic is as follows. Take the data for HES91 and HES13 and pool it, adding a dummy variable to each dataset that represents that year $(y d)$. For each family an employment status dummy is provided $E S$, these are: ${ }^{17}$

- $E S=0$ : For both not employed.

- $E S=1$ : For one adult in part time work.

- $E S=2$ : For one adult in full time work.

- $E S=3:$ For one adult in full time work and one adult in part time work, or for two adults in part time work.

- $E S=4$ : For both adults in full time work.

\footnotetext{
${ }^{16}$ This can be thought of as the average of the marginal effects from each ordering hence why it corresponds to the fair value associated with the Shapley value.

${ }^{17}$ Part time work is defined as working less than 30 hours per week - note that this is the same definition as household surveys, but differs from the in-work tax credit where eligibility starts at 20 hours.
} 
Given these dummies and the year status of each family, the reweighting factor for the $j t h$ family type (in this case either single adult or couple) is estimated using the probability that a given family belongs to $y d=1$. As a result, the reweighting factor for the $j t h$ family type will take the form:

$$
\psi_{E}(E)=\frac{P(t=1 \mid E)}{P(t=0 \mid E)} \cdot \frac{P(t=0)}{P(t=1)}
$$

Which for notational simplicity can be written as:

$$
\psi_{E}(E)=\frac{P_{1}(E)}{P_{0}(E)} \cdot \frac{P_{0}}{P_{1}}
$$

Where $P_{t}(E)$ is the probability of being in time period $t$ given employment status $E$, and $P_{t}$ is the unconditional probability of being in time period $t$.

In this case, for the $j$ th subgroup, take the discrete set of employment outcomes - where $m=0, \ldots, 4$ represents the employment status described above. Defining $e_{m}=1$ if the household has employment outcomes $m$ and $e_{m}=0$ otherwise, then: ${ }^{18}$

$$
\psi_{E}(E)=\sum_{m=0}^{M} e_{m} \frac{P_{1}\left(e_{m}=1\right)}{P_{0}\left(e_{m}=1\right)} \cdot \frac{P_{0}}{P_{1}}
$$

Here $\frac{P_{1}\left(e_{m}=1\right)}{P_{0}\left(e_{m}=1\right)}$ can be estimated for all $m$ by using the relevant ratios of a

\footnotetext{
${ }^{18} \mathrm{Or}$ if this is ordered such that it is conditional on some other sociodemographic characteristics first this reweighting factor takes the form:

$$
\psi_{E \mid z}(E, z)=\sum_{m=0}^{M} e_{m} \frac{P_{1}\left(e_{m}=1 \mid z\right)}{P_{0}\left(e_{m}=1 \mid z\right)}
$$


given subgroup that has that employment status. ${ }^{19}$

The employment decomposition is inherently different to the policy and behavioural decompositions from Bargain (2012) as the direct impact of policy is not considered separately when looking at employment status. While the Bargain (2012) method simulates a counterfactual labour supply based on an estimated response to changes in policy settings, the employment decomposition reweights the data to change employment patterns in the base data. In that way the change in the employment distribution embodies both a labour supply response to changes in tax-transfer policy settings, and an unexplained change in the employment distribution. As a result, the estimated labour supply change from a behavioural microsimulation model can be used to estimate the relative contribution of this change in the employment distribution that is due to policy effects - as well as adding a term that represents the direct effect of tax-transfer policy changes on the index value.

One issue that needs to be highlighted when interpreting the decomposition of the employment effect is the difference in the intensive margin between the behavioural model and the employment status reweighting. Employment status varies between part time and full time work, while the policy behavioural model varies on the basis of fixed numbers of a larger set of discrete hours. As a result, the employment status model may not reweight due to some set of characteristics remaining in part time work, even though the policy response will see the individual change their hours.

When incorporating changes in the age and educational attainment in the population the same reweighting method is applied.

The population groupings for age are based on a division between those in the earlier stages of their labour market involvement (15-34), prime work-

\footnotetext{
${ }^{19}$ In the case where the decomposition involving sociodemographic characteristics takes place first, the relevant probabilities are estimated by using an ordinal logit model.
} 
ing age (35-64), and retired individuals (65+). For highest educational attainment the groupings are split between those with a maximum of Level 3 NCEA attainment, Level 4-6 attainment, and Level 7 and higher attainment.

With education, globalisation, and technological change all seen as major contributors of changing inequality outcomes, the implied return to characteristics for individuals would be expected to change as suggested in Goldin and Katz (2010). In Hyslop and Mare (2005) the potential for changing returns to characteristics are also investigated, but their role in changing income inequality between 1984 and 1998 is limited.

Preliminary analysis for this chapter using the Hyslop and Mare (2005) methodology suggested that the role of changing returns to characteristics remained low during the 2000s and as a result this factor was not investigated further. However, given the potential importance of this issue - especially in relationship to the significant change in educational attainment and potential inter-relationship between these factors - this is a worthwhile direction for future research.

\subsubsection{Changes in age, employment status, and highest ed- ucational attainment}

Between HES91 and HES13 there were significant changes in the age, employment status, and highest educational attainment distributions of the respective samples as shown in Table 6.1. 
Table 6.1: Proportions change

\begin{tabular}{lcccc}
\hline & \multicolumn{2}{c}{$1988-91$} & $2010-13$ \\
& Single adult & Coupled adult & Single adult & Coupled adult \\
\hline \multicolumn{5}{c}{ Age proportion } \\
\hline $15-34$ & $54.57 \%$ & $31.22 \%$ & $41.50 \%$ & $21.00 \%$ \\
$35-64$ & $26.34 \%$ & $54.72 \%$ & $38.14 \%$ & $61.87 \%$ \\
$65+$ & $19.09 \%$ & $14.06 \%$ & $20.36 \%$ & $18.14 \%$ \\
\hline \multicolumn{5}{c}{ Highest educational attainment proportion } \\
\hline Level 0-3 $28.01 \%$ & $28.63 \%$ & $22.35 \%$ & $16.88 \%$ \\
Level 4-6 & $64.35 \%$ & $62.04 \%$ & $48.19 \%$ & $41.51 \%$ \\
Level 7+ & $7.64 \%$ & $9.34 \%$ & $29.46 \%$ & $41.61 \%$ \\
\hline \multicolumn{5}{c}{ Employment status proportion } \\
\hline Not working or SE & $46.75 \%$ & $42.04 \%$ & $49.11 \%$ \\
Part time waged & $6.56 \%$ & $10.49 \%$ & $13.21 \%$ & $46.93 \%$ \\
Full time waged & $46.69 \%$ & $47.47 \%$ & $37.68 \%$ \\
\hline
\end{tabular}

With the baby boomer generation nearing or entering retirement age while fertility rates declined in New Zealand, the age distribution has shifted right over the past three decades. However, for the purpose of adjusting the age distribution the key proportions of interest are those between 15 and 34, those aged between 35 and 64, and finally those aged 65 and over.

Between the HES91 and HES13 periods the proportion of individuals aged between 15 and 34 declined sharply, falling by over 13 percentage points for single people and 10 percentage points for coupled individuals. Although this corresponded to an uptick in individuals over retirement age (especially for coupled people) most of the increase in the density of the age distribution has been in the 35-64 age group.

Educational attainment increased markedly for both single and coupled people between HES91 and HES13, with the proportion of people with Level 7 and above qualifications quadrupling. 
Both 1988-91 and 2010-13 involved recessions and marked increases in unemployment in New Zealand. However, in terms of the depth and length of the 1988-91 economic slowdown eclipsed that of the 2009 Global Financial Crisis for New Zealand. This led to higher unemployment during the earlier period. However, as noted in Chapter 5 part time employment increased sizably during this period. The change in the nature of the labour market will also have influenced inequality outcomes between HES91 and HES13.

\subsubsection{Interpreting the results of the method}

As mentioned at the start of this section, with regards to the analysis of tax-transfer policies such a decomposition makes a number of unsatisfactory assumptions if we were trying to interpret these results causally. The initial tax decomposition assumes:

1. Gross wages are fixed and labour demand is perfectly elastic.

2. No general equilibrium (change in other factor prices and quantities) or dynamic (endogenous changes in other characteristics) effects.

When decomposing on the basis of other non-policy factors, counterfactual incomes are no longer being simulated the same way. Instead, the limitations of interpretation associated with interpretation of the DiNardo et al. (1996) method as mentioned in Fortin et al. (2011) become relevant:

1. The method assumes no spillover effects from the reweighting procedure onto the rest of the distribution.

2. Omitted variable bias is ignored when estimating parameters

3. The deep structural parameters of the income generating process are not identified, as a result the model is non-causal - in terms of not having "pre-treatment" variables which in turn define the choice of 
income.

4. This method of applying a counterfactual based on the income generating process of the other time period involves mixing differences in both unobservable variables and the change in the income generating process, implying that the estimates are non-causal and depend on assumptions about the conditional distribution of unobservables. Although ignorability assumptions are often used to rescue these models in the case of an income generating function this assumption is likely to be violated.

The strength of these assumptions makes it non-credible to claim that such a method explains the causal impact of a given factor on the income distribution. As a result, this type of analysis needs to be justified as a descriptive analysis of the change in the income distribution - and more specifically the change in scalar measures of income inequality.

Another key issue is that the HES data, and the decomposition procedures that are being applied are static by nature - when the interest in income inequality is often driven by issues related to lifecycle and intergenerational inequality and endogenous changes in individual characteristics. As discussed in Atkinson and Bourguignon (1987) income distributions can be modelled in a variety of different ways due to the complex nature of the income generating process, each of which provide a different view on the distribution and rely on differing assumptions to achieve these results. As an overarching single model of the income distribution would be intractable, it is preferable to build a specific model for a specific question with clearly specified shortcomings - which is the goal of this chapter.

This can be seen in the New Zealand context by the types of discussion that occur regarding the 1984-1993 reform program. Stillman et al. (2008) used Census data to try and understand the long-run consequences of these reforms on 140 local labour markets - coming to the conclusion that the 
reforms had a long-lasting impact.

The comparison of static snapshots does allow some insight into factors that are likely to be important for disparities in income opportunities over an individuals lifecycle. However, inequality at a point in time does not imply inequality or injustice over a lifecycle - and so these concepts should be taken with care when viewing estimates.

\subsubsection{Selection of counterfactual orderings}

With six different effects modelled there would be $6 !=720$ combinations of these varying effects. This can be reduced by taking into account that the behavioural response to tax-transfer policy changes and the residual change in employment status must be placed consecutively given that they correspond to a decomposition of the employment status term. As a result, there are only 5 unique terms to be decomposed, so there are $5 !=120$ combinations that must be computed and averaged to estimate an average effect of a given factor.

However, unlike Bargain (2012) and Herault and Azpitarte (2016) this chapter does not keep the ordering between the residual and employment effects fixed.

As discussed in the policy decomposition section, Bargain (2012) states that "the other effects and behavioural effects must be positioned consecutively since they correspond to a split of the former other effects in primary decompositions 1 and 2". However, it is not clear that justifies fixing the ordering of the effects - for example if age is separated out it is still part of the other effects or residual term but it can be placed anywhere in the ordering of effects.

If instead the method had estimated a total policy response and that was being decomposed into behavioural or non-behavioural elements then the 
ordering would be fixed. But the residual term cannot be interpreted in the same way.

Specifically, Herault and Azpitarte (2016) discusses the behavioural term as the response of agents given the expectation they face a given tax system. If expectations provide the justification for why the policy decomposition into behavioural and non-behaviour terms makes sense then there is no economically meaningful reason to expect the behavioural and direct tax terms have to be consecutive. With all counterfactuals remaining economically meaningful, an application of the Shapley value requires that all orderings are calculated and averaged over.

\subsection{Results of the decomposition}

Unlike previous literature, this chapter compares pooled sets of years due to the smaller data sets available. In this section the Gini coefficient during the HES88-HES91 period will be compared to the HES10-HES13 period.

Both these periods followed on from the start of a financial crisis. In October 1987, a slump in global stockmarkets sparked off a broader based slowdown in the New Zealand economy. In September 2008 the failure of Lehman Brothers in the United States sparked the Global Financial Crisis which set off a broader based slowdown in the New Zealand economy.

In order to create counterfactuals the annual policy applied over a four year period are applied to the other four year period of analysis. For example, the HES88-HES91 with HES10-HES13 tax and transfer policies involves applying the policies of HES10 to HES88, the policies of HES11 to HES89, the policies of HES12 to HES90, and finally the policies of HES13 to HES91. 


\subsubsection{Equivalence Scale}

This decomposition concentrates on the Gini coefficient as the key inequality measure. The value of an inequality measure depends on the unit of analysis and equivalence scale used. In this chapter the individual is taken as the unit of analysis where an equivalised family income per person is attributed equally across members of the family. Although such an assumption satisfies the principle of anonymity the artificial construction of a family income figure implies that it does not necessarily satisfy the principle of transfers as discussed in Creedy (2017).

The relevant family income depends on the equivalence scale used, as this scale captures the degree of economies of scale within the family. At one extreme a per-capita income measure takes family income as observed and shares it equally across family members thereby assuming that there are no scale economies for larger families. At the other extreme is the family level income measure where full scale economies are assumed (eg there are no additional costs associated with having an extra family member) and so the overall family income is given to each individual in the family. In this instance economies of scale in the family imply that, for a given observed family income, each family member receives that income irrespective of family size. Between these two extremes is the parametric scale used in this chapter, with parameters that are close to those implied by the Jensen (1988) scale. Figure 31 illustrates the Gini measures between 1988 to 2013 for these three scales.

In each case inequality measures vary for each HES year, and it is unclear whether an equivalence scale that reduces the incomes of large families more (eg per capita) reduces or increases inequality measures. These complications indicate how important clarifying the unit of analysis, economies of scale, and where appropriate income sharing in the household or family is. Similar results hold if household income sharing is used instead of 


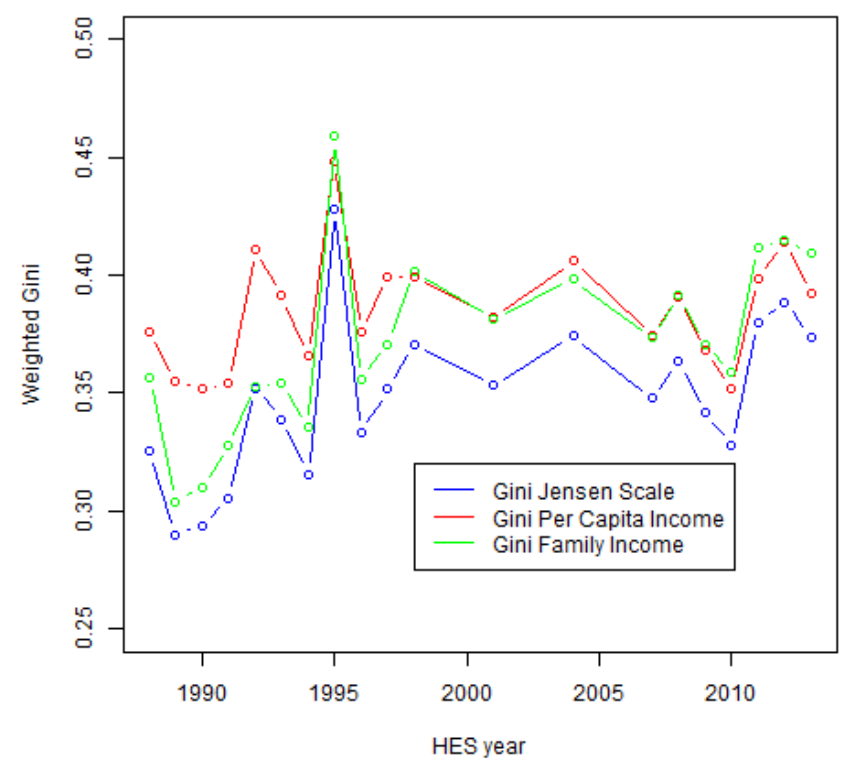

Figure 31: Disposable income Gini varying equivalence scales.

income sharing solely within the family.

The analysis performed in this chapter assumes that income sharing occurs between all members in the Economic Family unit (EFU). An economic family unit is made up of an adult, their partner (where a partner exists), and their children (termed dependants). Equivalised income is then given to each person in the family unit, and inequality statistics are calculated given that income distribution. Alternative Gini coefficients for per capita income per person are also provided for comparison in the results section.

The adult equivalence scale used was the parametric scale utilised in Creedy et al. (2010). This scale calculates the adult equivalent size of the family as: 


$$
m=\left(n_{a}+\theta n_{k}\right)^{\alpha}
$$

Where $n_{a}$ is the number of adults in the family, $n_{k}$ is the number of children, $0 \geq \theta \leq 1$ is the weight placed on the number of children, and $0 \geq \alpha \leq 1$ is a measure of scale economies among the family unit. Dividing family income by $m$ gives a measure of the equivalised income of each individual in the family unit. The results below use this adult equivalent scale to compare family income.

The base comparison for this parametric scale has values of $\alpha=0.6$ and $\theta=0.7$ and gives results comparable to Jensen scale (Jensen 1988).

\subsubsection{Results}

In Tables 6.2 the Gini coefficients for counterfactual scenarios are shown. Table 6.2 refers to the individual as the income unit. 
Table 6.2: Gini coefficients for each counterfactual

\begin{tabular}{|c|c|c|c|c|}
\hline & \multicolumn{2}{|c|}{$1988-91$} & \multicolumn{2}{|c|}{$2010-13$} \\
\hline & Per Capita & Equivalised & Per Capita & Equivalised \\
\hline \multicolumn{5}{|c|}{ Characteristics Fixed } \\
\hline Status Quo Policy & 36.83 & 30.30 & 40.01 & 36.69 \\
\hline Tax Change & 39.24 & 33.80 & 38.62 & 34.67 \\
\hline Behavioural Change & 36.61 & 29.72 & 39.89 & 36.12 \\
\hline Full Change & 38.59 & 32.74 & 38.46 & 34.59 \\
\hline \multicolumn{5}{|c|}{ Age distribution changed } \\
\hline Status Quo Policy & 34.54 & 29.89 & 38.35 & 36.76 \\
\hline Tax Change & 37.60 & 33.49 & 36.00 & 34.25 \\
\hline Behavioural Change & 34.02 & 29.02 & 38.18 & 36.71 \\
\hline Full Change & 36.51 & 32.04 & 35.83 & 34.19 \\
\hline \multicolumn{5}{|c|}{ Highest Qualification distribution changed } \\
\hline Status Quo Policy & 33.79 & 29.17 & 39.78 & 38.30 \\
\hline Tax Change & 36.98 & 32.90 & 37.76 & 36.21 \\
\hline Behavioural Change & 33.29 & 28.32 & 39.63 & 38.29 \\
\hline Full Change & 35.89 & 31.43 & 37.60 & 36.16 \\
\hline \multicolumn{5}{|c|}{ Age and Highest Qualification distribution changed } \\
\hline Status Quo Policy & 33.92 & 28.97 & 40.03 & 38.40 \\
\hline Tax Change & 37.27 & 32.97 & 38.10 & 36.41 \\
\hline Behavioural Change & 33.42 & 28.11 & 39.91 & 38.39 \\
\hline Full Change & 36.18 & 31.49 & 37.96 & 36.37 \\
\hline \multicolumn{5}{|c|}{ Employment Status distribution changed } \\
\hline Status Quo Policy & 33.81 & 29.70 & 37.78 & 37.00 \\
\hline Tax Change & 36.90 & 32.96 & 35.09 & 33.99 \\
\hline \multicolumn{5}{|c|}{ Age and Employment Status distribution changed } \\
\hline Status Quo Policy & 35.61 & 29.89 & 38.35 & 36.76 \\
\hline Tax Change & 38.57 & 33.49 & 36.00 & 34.25 \\
\hline \multicolumn{5}{|c|}{ Highest Qualification and Employment Status distribution changed } \\
\hline Status Quo Policy & 33.81 & 28.68 & 39.47 & 38.62 \\
\hline Tax Change & 36.90 & 32.27 & 37.19 & 36.20 \\
\hline \multicolumn{5}{|c|}{ Age, Highest Qualification and Employment Status distribution changed } \\
\hline Status Quo Policy & 33.96 & 28.43 & 39.71 & 38.61 \\
\hline Tax Change & 37.19 & 32.28 & 37.56 & 36.33 \\
\hline
\end{tabular}


The results in Table 6.3 use the Gini coefficients from Table 6.2 where an adult equivalence scale is applied.

The decomposition of the relevant factors come from one of two directional methods: taking the HES13 base population and applying a reweighting or imputation (in the case of taxation) factor to make the population more closely represent HES91, or taking the HES91 population that has been reweighted to more closely represent HES13 and comparing that to the actual population from that time. For each factor, its order in the decomposition determines what the change is conditional on - eg if age is positioned after highest education then the age effect is conditional on the change in the highest education distribution.

The residual term comes about from changing the base year of analysis from HES13 to HES91. A residual first decomposition switches from the observed HES13 base year to the HES91 base year with the HES13 age, education, taxation, and employment. A residual last decomposition takes HES13 with the age, education, taxation, and employment properties of HES91 and compares it to HES91. In this way the base year and residual term includes three changes: the change in the preference parameters (as the labour supply model is for a given population), a change in prices, and a change in other observed and unobserved characteristics of the sample. 
Table 6.3: Decomposition results

\begin{tabular}{|c|c|c|c|c|}
\hline & \multicolumn{4}{|c|}{ Gini contribution } \\
\hline & Gini points & Range & Proportion & Range \\
\hline \multicolumn{5}{|c|}{ Average of all orderings } \\
\hline Age & $(0.065)$ & $(0.416)-0.525$ & $(1.0 \%)$ & $(6.5 \%)-8.2 \%$ \\
\hline $\begin{array}{l}\text { Highest educational at- } \\
\text { tainment }\end{array}$ & (1.389) & $(2.203)-(0.518)$ & $(21.7 \%)$ & $(34.5 \%)-(8.1 \%)$ \\
\hline Direct taxation & 2.924 & $1.990-3.998$ & $45.7 \%$ & $31.1 \%-62.6 \%$ \\
\hline Behavioural response & $(0.426)$ & $(1.477)-0.078$ & $(6.7 \%)$ & $(23.1 \%)-1.2 \%$ \\
\hline Total policy effect & 2.497 & $2.019-3.261$ & $39.1 \%$ & $31.6 \%-51.0 \%$ \\
\hline $\begin{array}{l}\text { Residual employment } \\
\text { status }\end{array}$ & 0.112 & $(0.384)-1.442$ & $1.8 \%$ & $(-6.0 \%)-22.6 \%$ \\
\hline $\begin{array}{l}\text { Total employment sta- } \\
\text { tus }\end{array}$ & $(0.314)$ & $(0.834)-0.675$ & $(4.9 \%)$ & $(13.1 \%)-10.6 \%$ \\
\hline Residual & 5.268 & $4.417-6.311$ & $82.3 \%$ & $69.1 \%-98.8 \%$ \\
\hline Total change & 6.391 & - & - & - \\
\hline \multicolumn{5}{|c|}{ Residual last ordering } \\
\hline Age & $(0.041)$ & $(0.255)-0.420$ & $(0.6 \%)$ & $(4.0 \%)-6.6 \%$ \\
\hline $\begin{array}{l}\text { Highest educational at- } \\
\text { tainment }\end{array}$ & $(1.840)$ & $(2.203)-(1.542)$ & $(28.8 \%)$ & $(34.5 \%)-(24.1 \%)$ \\
\hline Direct taxation & 2.285 & $1.990-3.006$ & $35.8 \%$ & $31.1 \%-47.0 \%$ \\
\hline Behavioural response & 0.052 & $0.010-0.078$ & $0.8 \%$ & $0.2 \%-1.2 \%$ \\
\hline Total policy effect & 2.337 & $2.034-3.082$ & $36.6 \%$ & $31.8 \%-48.2 \%$ \\
\hline $\begin{array}{l}\text { Residual employment } \\
\text { status }\end{array}$ & $(0.097)$ & $(0.384)-0.597$ & $(1.5 \%)$ & $(6.0 \%)-9.3 \%$ \\
\hline $\begin{array}{l}\text { Total employment sta- } \\
\text { tus }\end{array}$ & $(0.044)$ & $(0.318)-0.675$ & $(0.7 \%)$ & $(5.0 \%)-10.6 \%$ \\
\hline Residual & 6.032 & - & $94.4 \%$ & - \\
\hline \multicolumn{5}{|c|}{ Residual first ordering } \\
\hline Age & $(0.100)$ & $(0.416)-0.525$ & $(1.6 \%)$ & $(6.5 \%)-8.2 \%$ \\
\hline $\begin{array}{l}\text { Highest educational at- } \\
\text { tainment }\end{array}$ & $(1.043)$ & $(1.457)-(0.518)$ & $(16.3 \%)$ & $(22.8 \%)-(8.1 \%)$ \\
\hline Direct taxation & 3.651 & $3.266-3.998$ & $57.1 \%$ & $51.1 \%-62.6 \%$ \\
\hline Behavioural response & $(1.061)$ & $(1.477)-(0.585)$ & $(16.6 \%)$ & $(23.1 \%)-(9.2 \%)$ \\
\hline Total policy effect & 2.590 & $2.019-3.261$ & $40.5 \%$ & $31.6 \%-51.0 \%$ \\
\hline $\begin{array}{l}\text { Residual employment } \\
\text { status }\end{array}$ & 0.527 & $(0.019)-1.442$ & $8.2 \%$ & $(0.3 \%)-22.6 \%$ \\
\hline $\begin{array}{l}\text { Total employment sta- } \\
\text { tus }\end{array}$ & $(0.534)$ & $(0.834)-0.000$ & $(8.4 \%)$ & $(13.1 \%)-0.0 \%$ \\
\hline Residual & 4.417 & - & $69.1 \%$ & - \\
\hline
\end{tabular}




\section{Average estimates}

The results in Table 6.3 indicate that tax-transfer policy changes played a large role in the rise in income inequality between HES91 and HES13, accounting for $39 \%$ of the increase in the Gini coefficient.

The direct effect of tax and transfer changes, including growth in most of the thresholds and payments that was linked to consumer prices rather than higher average wage growth, was behind this policy increase. The direct effect alone pushed up the Gini coefficient by nearly 2.9 points or $46 \%$ of the increase in inequality during this period.

As in prior research using this method (Bargain 2012 for the UK, Herault and Azpitarte 2016 for Australia, and Nolan 2016 for New Zealand), the change in labour supply behaviour by households partially mitigated the increase in inequality due to policy change, reducing the Gini coefficient by just over 0.4 points.

Unlike Nolan (2016) the behavioural response was insufficient to fully cancel out the increase in inequality due to the change in tax-transfer policies. Although Nolan (2016) dealt with a different time period (1995-2013) the main reason for this difference was the choice of deflator for counterfactual tax-transfer thresholds and transfer payments - with that result based on a CPI deflator while this chapter used average income growth.

Non-policy related changes in the employment status distribution partially cancelled out the behavioural policy response, with the change in employment status increasing income inequality. Overall, the change in employment status between these periods reduced disposable income inequality. This result was consistent with the labour force effect on disposable income estimated in Ball and Creedy (2015), but differed from the effect on gross income inequality due to employment status estimated in Hyslop and Mare (2005) for the 1984-1998 period. 
The age effect on the distribution of income was muted, reducing the Gini coefficient by 0.065 points. Over an individuals lifecycle the variability in individual income explains much of the variation in income in cross sectional data (Mierau and Rockey 2014, Creedy 1992). Furthermore even within age cohorts income inequality varies - following a parabolic relationship where inequality rises into individuals prime earning years before declining (Hirsch et al. 1980).

In this chapter the ageing population is captured solely by a rising proportion of individuals who are in their prime working age. A priori it is not clear what effect an ageing population has on inequality. Nolan (2016) found an increase in inequality due to the ageing population using the same method that was applied in this chapter.

However, both Aziz, Ball, Creedy and Eedrah (2013) and Ball and Creedy (2015) found that there was little relationship between the change in the age distribution and disposable income inequality. Furthermore, Herault and Azpitarte (2016) estimated that the ageing population in Australia lowered market income inequality but increased disposable income inequality. As a result, a limited age distribution effect is consistent with prior research using this method.

Educational attainment plays a complicated role in income inequality outcomes and the nature of the relationship has long been debated (Stack and Neubeck 1978). In order to achieve the result of higher educational attainment lowering income inequality, it usually necessary to view the change in educational outcomes as reducing inequality in educational outcomes. Given this, rising educational attainment in many countries has been associated with a reduction in income inequality (Coady and Dizioli (2017)). Similar results are found in this chapter, with the change in highest educational attainment reducing the Gini coefficient by nearly 1.4 points.

In terms of overall socio-demographic characteristics, Hyslop and Mare (2005) reweighted the data based on an aggregate of "age, sex, ethnicity, 
and education levels of adults in the household, together with the numbers of children in various age groups.". The authors found that changes in the shares of these characteristics accounted for around $10 \%$ of in the increase in income inequality between 1984 and 1998.

The Hyslop and Mare (2005) study referred to a different income unit, different income (gross as opposed to disposable) and time period. The difference between these results and the net effect of the characteristics analysed here (subtracting nearly a full point from the Gini coefficient) indicate that the role of socio-demographic characteristic changes depend strongly on the type of income unit and income type analysed.

Ball and Creedy (2015) found characteristics such as age and labour force status slightly increased inequality during this period, while the results of this chapter showed a very small decrease. Overall, the characteristics based results in this chapter are relatively close to those found in Ball and Creedy (2015) for the same period.

The residual effect remains substantial in this analysis, accounting for nearly three-quarters of the increase in the Gini-coefficient between HES91 and HES13. With every additional factor beyond the direct role of taxes and transfers (employment status, age, and highest educational attainment) suggesting a reduction in income inequality when an increase was observed this indicates that other major unexplained factors exist for explaining the change in income inequality.

\section{Estimate range}

Although these estimates seem plausible, it is of value to look at the range of estimates that made up the average. If there are systematic differences in the estimated marginal effect of a factor due to its ordering then this can provide more information about the underlying relationship between these factors and income inequality over the 1988-2013 period. 
The effect of behavioural responses on income inequality varied based on the HES population used. An economically significant change in the distribution of labour supply responses occurred based on the HES91 population, with virtually no distributional change when based on HES13 population. This is indicated in the above table by comparing the residual last ordering results (when the results are all based on the HES13 population) and the residual first results (where the population is shifted to the HES91 population before factors are decomposed).

Although this may in part be due to the different structures of the two populations, importantly the preference parameter models applied to the HES91 and the HES13 data were very different - as can be seen by the different structure of the HES88-93 and HES09-13 results in Chapter 5 which forms the basis of this analysis. Furthermore, this suggests some role for changes in the parameters of the labour supply model in explaining the change in observed behaviour.

The age effect estimated given different orderings varies between a $6.5 \%$ reduction in income inequality and a $8.2 \%$ increase. However, when the age effect is unconditional (the age effect occurs first or after the residual factors) the estimated effect is always within a percentage point to zero.

The range shown in overall employment status effects stems from the behaviour of the relative distributions to changes in employment status. Given differences in returns to employment status, reweighting a given population to have the same employment status as another population doesn't imply the same result will hold if the process occurs in reverse.

Starting with the HES91 population gives a decomposition that suggests that employment status decreased the Gini coefficient between then and 2010-13. The average estimated effect starting from the HES91 population is a 0.53 point drop in the Gini coefficent - or about $-8.4 \%$ of the increase. The range is between $-13 \%$ and $0 \%$. As a result the ordering of employ- 
ment relative to the residual leads to an economically different conclusion regarding the influence employment status had on the income distribution. Given a sharper decrease in income inequality due to the labour supply responses to tax-transfer policy changes (using behaviour estimated for HES88-93), this suggests that non-policy related employment status changes led to a large increase in disposable income inequality.

Conversely, while starting with the HES13 population the change in the employment status distribution has a more mixed effect. The average estimated effect starting from the HES10-13 population is a 0.044 point decrease in the Gini coefficent - or about $0.7 \%$. The range is between $-5.0 \%$ and $10.6 \%$. With the labour supply response to tax-transfer policy changes (using behaviour estimated for HES10-13) having very little impact on income inequality, this suggests that non-policy related employment status changes to an uncertain and likely small decrease in disposable income inequality.

The different behavioural models explain the varying behavioural effects - but not the full employment difference (which comes from the employment status reweighting exercise). As it is an inequality measure, differences in other elements (eg returns to characteristics) could drive such differences.

The educational attainment effect results are relatively robust to the ordering of variables. The shift in the educational attainment distribution led to an economically significant reduction in income inequality in almost all orderings.

All ordering for direct taxation also gave an economically significant increase in income inequality due to the policy changes. The estimated effect ranged between $31 \%$ and $63 \%$ of the increase in income inequality irrespective of the base year used. For all orderings the direct effect is significantly larger than the behavioural effect. Including the behavioural effect, the overall role of policy was also robust to the ordering used. 
One of the key reasons for expanding the number of factors analysed is to reduce the residual term - the change in income inequality not explained by factors in the model. However, the residual term remained large for all decomposition orderings and at its largest neared $100 \%$ of the total increase in the Gini coefficient.

\subsection{Conclusions}

In this chapter, potential reasons for the increase in income inequality between HES91 and HES13 were investigated. The change in inequality was decomposed into a variety of proximate causes based on the construction of counterfactual distributions. These distributions were created either from simulations provided from a tax-transfer microsimulation model or counterfactuals created by reweighting the data to more closely represent the age/education/employment distribution of the alternate years.

Gini coefficients were taken as the summary measure of income inequality in this analysis, with all the decomposition results based on changes in the Gini coefficient. When Gini coefficients were constructed the unit of analysis used was the individual, with each individual receiving income per adult equivalent person. The equivalence scale used was a parametric scale parametrised to be close to the Jensen (1988) scale.

Given this decomposition, tax and transfer policy changes accounted for nearly $40 \%$ of the increase in the Gini coefficient between HES91 and HES13. The range of estimates for this policy effect was wide (32\%-51\%) but the estimated role of tax and transfer policies was always positive and large.

This policy change can be further decomposed into a direct change, due to the change in payment rates and thresholds, and a behavioural change due to the labour supply responses of individuals. If no behavioural response occurred tax and transfer changes would have accounted for over $46 \%$ 
of the increase in income inequality - with the change in labour supply behaviour due to the change in tax and transfer settings reducing income inequality by nearly $7 \%$.

Between HES91 and HES13 the proportion of the population with Level 7 qualifications and above rose sizeably. This change in highest educational attainment is estimated to have reduced income inequality over the period by nearly 1.4 Gini points. The ageing of the New Zealand population also reduced income inequality during this period, although the estimated reduction was very small.

Over this same period there was a shift towards part time work. This change in the distribution of the employment status reduced income inequality by a small amount. However, the change in the employment status distribution includes the behavioural response to tax and transfer policy. As a result, the underlying non-policy change in employment status between HES91 and HES13 is estimated to have increased income inequality by over 0.1 Gini points cancelling out part of the decline due to the behavioural responses to tax and transfer changes.

One of the goals of this analysis had been to explain more of the residual or unexplained change in income inequality than had been possible in prior research by introducing more potential factors. However, rather than explaining more of the residual change in income inequality between HES91 and HES13 this decomposition process suggested that unexplained factors were even more important in determining the increase in income inequality than previous studies had suggested.

The shifts in the age and highest educational attainment distributions both reduced aggregate income inequality more than the change in the employment status distribution increased it. Given that overall income inequality rose, this implies that unexplained factors had a larger role in increasing income inequality. 
Given the static response to tax and transfer policies (both in terms of the way they transform market to disposable income and in terms of labour supply responses), the change in the age distribution, the change in educational attainment, and the change in employment status jointly account for only around a quarter of the change in the Gini coefficient is explained. This suggests that there is scope for future research to investigate the role of other characteristics, and the return on characteristics these characteristics.

However, the primary purpose of this chapter was to investigate the role tax and transfer policies played in the increase in income inequality between HES91 and HES13. By using a tax-transfer microsimulation model and taking into account labour supply responses, this method has provided a quantitative estimate of the role played by tax-transfer policies. Furthermore, given the robustness of the tax-transfer effect to varying orderings of the explanatory factors, the result that tax-transfer changes accounted nearly $40 \%$ of the increase in inequality is both economically significant and credible. 


\section{Chapter 7}

\section{Conclusions}

The key purpose of this dissertation was to investigate the role changes in income tax and transfer regimes played in rising disposable income inequality in New Zealand over the 1988 and 2013 period.

In order to do this the rates and structure of the tax-transfer system as given in the legislation, and how this changed through time, was outlined in Chapter 2. After modelling the structure of tax-transfer system for each HES year between 1988 and 2013 inclusive, disposable incomes were constructed that assume full take up of primary transfers and payment of income tax liabilities. Given these constructed disposable incomes, Chapter 3 investigated how the tax and transfer systems differed in terms of vertical and horizontal equity between 1988 and 2013.

The redistributive effect of the tax-transfer system is equal to the difference between the market income and disposable income Gini coefficients. According to estimates derived from HES data and the modelled tax-transfer system, between the 1988-1991 and 2011-2013 periods the redistributive effect declined from over 22 Gini points to 18 Gini points. However, given the potential for reranking of income units, a tax transfer system that has a smaller redistributive effect is not necessarily less vertically equitable. 
After allowing for income sharing and economies of scale in the household through an equivalence scale, reranking as a percentage of the redistributive effect was little different between HES88-91 and HES11-13. As a result, the decline in the redistributive effect between these periods also represented a decline in the vertical equity embedded in the tax-transfer system.

One motivation of the tax-transfer reforms during the late 1980s and early 1990s was to reduce horizontal inequities. As a result Chapter 3 also extends these results to consider changes in horizontal inequity in the tax system.

Reranking, by shifting families position in the income distribution, can be seen as fundamentally as horizontally unequal. Furthermore, by analysing groups of close equals classical horizontal inequity - the unequal treatment of equals - can be analysed. These combined sources of horizontal inequity did not decline after the change in the tax-transfer system, and classical horizontal equity (in absolute terms) increased.

However, the increase in classical horizontal inequity was predominantly the result of greater targeting in terms of transfer payments - with the new tax-transfer system more focused on targeting payments based upon need. As equals in this analysis are defined based upon income, rather than the equals that are considered when evaluating policy based on characteristics and need, the lift in horizontal inequity is not necessarily inconsistent with the policy intentions in the early 1990s.

Once it had been established that the tax-transfer system had become less redistributive, the role of tax-transfer policy relative to other potential drivers of income inequality was investigated.

In order to create the counterfactual scenarios required to investigate the association between tax and transfer policies and disposable income inequality over this period, it was necessary to estimate what families in- 
comes would have been under varying tax and transfer regimes. An arithmetic microsimulation model allows counterfactual family incomes to be constructed in the absence of any change in hours of work. However, given that policy changes will have led to a change in the labour supply behaviour of individuals this needed to be incorporated into the analysis. Such a counterfactual required an estimate of the gross wages available to individuals, including those who are not working, and an estimate of individuals preferences over leisure and consumption/income.

Chapter 4 provided an analysis of how New Zealand's estimated wage equation changed between 1988 and 2013 by estimating the wage equation for four distinct periods: 1988-1993, 1994-1998, 2001-2008, and 2009-2013. The analysis was undertaken for the HES sample, not the population overall, as the goal of the analysis was to imputed the wage of a individual in the sample.

Consistent with prior research, the age associated with the highest average wage rose from early 40 s to late 40 s over this period. Financial, professional, and public administration jobs all offered higher average wages relative to other jobs over the entire horizon. In terms of occupations, managerial and professional roles paid a higher average wage rate than other occupations while the wage premium on personal service work that existed in 1988/1993 had all but disappeared by 2009/13. The wage gap between coupled men and coupled women remained consistent over the period, while the gap between single men and women wages closed. The wage gap for women in managerial and professional roles shrunk more significantly than other groups over the period.

This process for estimating a wage equation allows for the imputation of wages for those who were out of work in the HES sample. A Heckman selection model was used to correct for sample selection bias, given that those who are employed and those who are not employed will differ in ways that are otherwise unobservable. The wage imputation procedure 
was also extended to deal with the presence of heteroskedasticity in the probit participation equation. Such a correction is essential in the case of a non-linear model such as a probit due to the fact that heteroskedasticity makes the parameter estimates inconsistent.

Imputed wages were higher for coupled men than all other groups throughout the period. Not employed single men in 1994/98 had low imputed wages relative to other groups and periods, while sole parents in 2001/08 also had low imputed wages. Both periods had strong employment growth and increases in labour market participation for the respective groups which will have influenced the result. Relative to prior New Zealand research imputed wages were higher for most family types, except for single men.

Chapter 5 used these imputed wage figures and budget constraints constructed using TAXWELL to estimate individual preferences over leisure and income. The analysis was undertaken for the HES sample, not the population overall, as the goal of the analysis was to describe the response of a individual in the sample.

Increasing participation and part time employment over the 1988-2013 period led to estimated preferences changing for all groups, although the changes for single men were more limited than for other groups. The importance of higher education for participation and hours of work declined over time for all groups, while the age effect remained relatively constant. The peak preference for work shifted towards an older age for all demographic groups, occurring in the mid to late 40s for all groups except for single women. For all groups except single men the estimated fixed cost of work rose considerably in the $2009 / 13$ period.

Given the HES microdata, the modelled structure of the tax-transfer system, and estimates of household labour-income preferences Chapter 6 investigates the role of tax-transfer changes, relative to other shifts in population characteristics, in the rise in income inequality between 1988 and 2013. 
A behavioural microsimulation model was used to create counterfactual income distributions that represent when the tax and transfer system of a different year was applied to a given years survey data. In this way the tax and transfer system during 1988-1992 was applied to the 2009-13 sample and vice-versa. Given these counterfactuals the decomposition process of Herault and Azpitarte (2016) was applied in order to calculate the role policy played in the change in income inequality between these periods.

Just over a third of the increase in income inequality between 1988 and 2013 was attributed to the static tax effect of policy - which includes the direct change in tax-transfer payments and thresholds and the labour supply responses of families to the changes in net incomes available at varying hours of work.

However, tax and transfer policy changes were not the only determinant of changes in the income distribution during this period. Characteristics of the population (age, educational attainment, and employment status) also changed. A reweighting process based on DiNardo et al. (1996) was used to create counterfactuals that took into account changes in the distribution of these characteristics. Consistent with prior research in New Zealand and overseas, increasing higher educational attainment was associated with lower income inequality, while the effect of population ageing was small relative to the range of results.

Although the change in the employment status distribution had little impact on disposable income inequality this hid significant variation between the causes. The response of individuals to changes in tax-transfer policy settings led to a reduction in income inequality which was nearly entirely cancelled out by a non-policy related change in the employment distribution. As a result, in the absence of tax-transfer policy changes underlying shifts in the labour market would have been expected to increase disposable income inequality.

Overall this research suggests that tax-transfer policy changes did have 
a sizable effect on income inequality outcomes in New Zealand, explaining around a third of the observed increase in the Gini coefficient between 1988/92 and 2009/13. When it comes to explaining the remaining twothirds the investigation of other factors indicated that there are important missing elements in terms of explaining the overall change in the income distribution over this period. With rising higher educational attainment having reduced the dispersion of income there is still a substantial unexplained element to rising income inequality in New Zealand over the past 30 years.

In terms of this research this matters in so far as changes in the structure of the tax and transfer system influenced the distribution of other drivers of income inequality (eg higher education). As a result, the full role of these policy changes may vary from the effect estimated in this research. However, as illustrated with the role of higher education in this research, if lower tax rates increased educational attainment then this would have reduced the policy impact on income inequality. As a result, it is ex-ante unclear whether further research would suggest that policy was more or less important in driving higher income inequality over this period.

The research in this dissertation provides a clear and structured quantitative interpretation of the effect tax-transfer policy played in the increase in disposable income inequality over the 1988 to 2013 periods. Future research could consider extending this analysis to include structural modelling of the dynamic responses to tax-transfer changes (eg household structure and formation, migration, higher educational attainment). Furthermore, once Statistics New Zealand's Integrated Data Infrastructure project is complete it will be possible to do the form of analysis that was performed in this dissertation with administrative data, thereby crosschecking the results of this thesis which were based on survey data against a more reliable dataset. 


\section{Bibliography}

[1] Aaberge, R., Dagsvik, J. and Strøm, S. [1995], 'Labor Supply Responses and Welfare Effects of Tax Reforms', The Scandinavian Journal of Economics .

[2] Ahmed, V. and O'Donoghue, C. [2008], 'CGE-Microsimulation Modelling: A survey', Munich Personal RePEc Archive (9307).

[3] Anderson, G. [1991], 'The Employment Contracts Act 1991: An Employers' Charter?', New Zealand Journal of Industrial Relations (16), 127142.

[4] Aronson, R. J., Johnson, P. and Lambert, P. J. [1994], 'Redistributive Effect and Unequal Income Tax Treatment', The Economic Journal 104(423), 262-270.

[5] Aronson, R. J. and Lambert, P. J. [1994], 'Decomposing the Gini Coefficient to Reveal the Vertical, Horizontal, and Reranking effects of Income Taxation', National Tax Journal 47(2), 273-94.

[6] Arrow, K. J. [1950], 'A Difficulty in the Concept of Social Welfare', The Journal of Political Economy 58(4), 328-346. Arrows Impossibility Theorem.

[7] Atkinson, A. B. [1980], The economics of taxation, Brookings Institution, Washington DC, chapter Horizontal equity and the distribution of the tax burden. 
[8] Atkinson, A. B. and Bourguignon, F. J. [1987], Arrow and the Foundations of the Theory of Economic Policy, London: Macmillan, chapter 12: Income distribution and differences in needs.

[9] Aziz, O. A., Ball, C., Creedy, J. and Eedrah, J. [2013], 'The Distributional Impact of Population Ageing', New Zealand Treasury Working Paper (13).

[10] Aziz, O. A., Gemmell, N. and Laws, A. [2013], 'The Distribution of Income and Fiscal Incidence by Age and Gender: Some Evidence from New Zealand', Victoria University Working Papers in Public Finance (10).

[11] Aziz, O. A., Gibbons, M., Ball, C. and Gorman, E. [2012], 'The Effect on Household Income of Government Taxation and Expenditure in 1988, 1998, 2007, and 2010', Policy Quarterly 8(1).

[12] Ball, C. and Creedy, J. [2015], 'Inequality in New Zealand 1983/84 to 2013/14', Treasury Working Papers (6), 1-33.

[13] Ball, C. and Huseynli, G. [2018], 'Adjusting New Zealand Wage Equation estimates for heteroskedasticity and sample weights', Forthcoming in VUW Chair in Public Finance Working Papers Series.

[14] Ball, C. and Ormsby, J. [2017], 'Comparing the Household Economic Survey to administrative records: An analysis of income and benefit receipt', Treasury Analytical Papers (1), 1-35.

[15] Bargain, O. [2010], 'Back to the Future: Decomposition Analysis of Distributive Policies using Behavioural Simulations', Institute for the Study of Labour: Discussion Paper Series (5226), 1-18.

[16] Bargain, O. [2012], 'Decomposition analysis of distributive policies using behavioural simulations', International Tax and Public Finance 19(5), 708-731.

[17] Bargain, O. [2014], Handbook of Microsimulation Modelling, Emerald 
Group Publishing Limited, chapter 5 Decomposing Changes in Income Distribution.

[18] Bargain, O., Caliendo, M., Haan, P. and Orsini, K. [2006], 'Making Work Pay in a Rationed Labour Market', IZA Discussion Paper Series (2033).

[19] Bargain, O. and Callan, T. [2010], 'Analysing the effects of tax-benefit reforms on income distribution: a decomposition approach', Journal of Economic Inequality 8(1), 1-21.

[20] Bargain, O., Callan, T., Doorley, K. and Keane, C. [2013], 'Changes in Income Distribution and the Role of Tax-Benefit Policy during the Great Recession: An International Perspective', IZA Discussion Paper Series (7737).

[21] Bargain, O., Immervoll, H., Peichl, A. and Siegloch, S. [2010], 'Distributional Consequences of Labor-Demand Adjustments to a Downturn', Gini Project Discussion Papers (1).

[22] Belgrave, M. [2012], Social Policy History: Forty Years on, Forty Years Back, in 'Affording our Future Conference'.

[23] Bhattacharya, N. and Mahalanobis, B. [1967], 'Regional disparities in household consumption in India', Journal of the American Statistical Asscociation 62, 143-61.

[24] Blundell, R., Duncan, A. and Meghir, C. [2002], Evaluating the Working Familes Tax Credit, Institute of Fiscal Studies.

[25] Borland, J. [2000], 'Economic Explanations of Earnings Distribution Trends in the International Literature and Application to New Zealand', Treasury Report .

[26] Bourguignon, F., Ferreira, F. and Leite, P. [2008], 'Beyond Oaxaca-Blinder: Accounting for differences in household income distributions', The Journal of Economic Inequality 6(2), 117-148. 
[27] Bover, O. [2010], 'Wealth Inequatily and Household Structure: US vs Spain', Reivew of Income and Wealth .

[28] Brash, D. [1998], 'New Zealand's remarkable reforms'.

URL:

http://www.rbnz.govt.nz/research-andpublications/speeches/1996/speech1996-06-04

[29] Buchanan, C. and Hartley, P. [2000], Equity as a social goal, New Zealand Business Roundtable.

[30] Cameron, A. C. and Trivedi, P. K. [2005], Microeconometrics: Methods and Applications, Cambridge University Press.

[31] Carr, S. A. and Chan, C. [2004], 'New Zealand's Fringe Benefit Tax 20 years on: An Empirical Investigation into Employers' Perception', New Zealand Journal of Taxation Law and Policy 10(3), 245-270.

[32] Castles, F. G. [1994], 'The Wage Earners' Welfare State Revisited: Refurbishing the Established Model of Australian Social Protection, 1983-1993', Australian Journal of Social Issues 29(2).

[33] Chatterjee, S., Dalziel, P., Daunfeldt, S.-O. and Podder, N. [2008], 'Income Inequality and Transformation of the Welfare State: A Comparative Study of the Reforms in New Zealand and Sweden', HUI Working Papers (20).

[34] Coady, D. and Dizioli, A. [2017], 'Income Inequality and Education Revisited: Persistence, Endogeneity, and Heterogeneity', IMF Working Paper 17(126), 129-158.

[35] Cogan, J. F. [1980], 'Fixed Costs and Labor Supply', NBER Working Paper Series (484).

[36] Conway, P., Meehan, L. and Parham, D. [2015], 'Who benefits from productivity growth? The labour income share in New Zealand', New Zealand Productivity Commission Working Paper 15(1). 
[37] Cowell, F. A. [2009], 'Measuring Inequality', Distributional Analysis Research Programme .

[38] Cowell, F. A. and Kuga, K. [1981], 'Inequality Measurement: An Axiomatic Approach', European Economic Review 15, 287-305.

[39] Crawford, R. [2009], 'Variations in Earnings Growth: Evidence from Earnings Transitions in the NZ Linked Income Survey', ISER Working Paper Series (18).

[40] Creedy, J. [1992], Income, Inequality and the Life Cycle, Edward Elgar Pub.

[41] Creedy, J. [2015], 'A Note on Computing the Gini Inequality Measure with Weighted Data ', Victoria University Working Papers in Public Finance (3).

[42] Creedy, J. [2017], 'Alternative Distributions for Inequality Comparisons', The Australian Economic Review 50(4).

[43] Creedy, J. and Duncan, A. [2005], 'Aggregating Labour Supply and Feedback Effects in Microsimulation', Australian Journal of Labour Economics 8(3), 277-290.

[44] Creedy, J., Duncan, A., Scutella, R. and Harris, M. [2000], 'Wage functions for demographic groups in Australia', Australian Journal of Labour Economics 4(4), 296-316.

[45] Creedy, J., Duncan, A., Scutella, R. and Harris, M. [2002], Microsimulation Modelling of Taxation and the Labour Market: The Melbourne Institute Tax and Transfer Simulator, Edward Elgar Publishing.

[46] Creedy, J. and Eedrah, J. [2014], 'The Role of Value Judgements in Measuring Inequality', Treasury Working Paper (13).

[47] Creedy, J. and Eedrah, J. [2016], 'Income redistribution and changes in inequality in New Zealand from 2007 to 2011: alternative distribu- 
tions and value judgements', New Zealand Economic Papers 50(2), 129_ 152.

[48] Creedy, J., Enright, J., Gemmell, N. and McNabb, N. [2008], 'Equity and Efficiency Measures of Tax-Transfer System: Some Evidence for New Zealand', Treasury Working Paper (4).

[49] Creedy, J., Enright, J., Gemmell, N. and McNabb, N. [2010], 'Income redistribution and direct taxes and transfers in New Zealand', Australian Economic Review 43(1), 39-51.

[50] Creedy, J. and Gemmell, N. [2018], 'The Elasticity of Taxable Income of Individuals in Couples', Victoria University Working Papers in Public Finance (4).

[51] Creedy, J., Gemmell, N. and Teng, J. [2017], 'Income effects and the elasticity of taxable income', New Zealand Economic Papers 52(2), 185203.

[52] Creedy, J. and Kalb, G. [2005], 'Discrete Hours Labour Supply Modelling: Specification, Estimation and Simulation', Journal of Economic Surveys 19(5), 697-734.

[53] Creedy, J. and Mok, P. [2015], 'Labour Supply in New Zealand and the 2010 Tax and Transfer Changes', New Zealand Treasury Working Paper (13).

[54] Creedy, J. and Tuckwell, I. [2003], 'Reweighting the New Zealand Household Economic Survey for Tax Microsimulation Modelling', New Zealand Treasury Working Paper (33).

[55] Creedy, J., van de Ven, J. and Lambert, P. J. [2001], 'Close equal and calculation of the vertical, horizontal and reranking effects of taxation', Oxford Bulletin of Economics and Statistics 63(3), 381-394.

[56] Croissant, Y. [2018], 'Estimation of multinomial logit models in R: The mlogit Packages'. 
[57] Dagsvik, J. K. and Jia, Z. [2008], 'An Alternative Approach to Labor Supply Modeling', Statistics Norway Research Department Discussion Papers (550).

[58] Dagsvik, J. K. and Strom, S. [2006], 'Sectoral Labor Supply, Choice Restrictions and Functional Form', Journal of Applied Econometrics .

[59] Daly, M. C. and Valletta, R. G. [2000], 'Inequality and Poverty in the United States: The Effects of Rising Male Wage Dispersion and Changing Family Behavior', FRBSF Working Paper (6).

[60] Dardanoni, V. and Lambert, P. J. [2001], 'Horizontal inequity comparisons', Social Choice and Welfare 18, 799-816.

[61] Davidson, A. [1989], Two Models of Welfare: The origins and development of the Welfare State in Sweden and New Zealand, 1888-1988, Acta Universitatis Upsaliensis.

[62] DiNardo, J., Fortin, N. M. and Lemieux, T. [1996], 'Labor Market Institutions and the Distribution of Wages, 1973-1992: A Semiparametric Approach', Econometrica 64(5), 1001-1044.

[63] Dixon, S. [1998], 'Growth in the dispersion of earnings: 1984-97', Labour Market Bulletin .

[64] Easton, B. [1983], Income Distribution in New Zealand: Research Paper 28, New Zealand Institute of Economic Research.

[65] Easton, B. [1994], 'Economic and other ideas behind the New Zealand reforms', Oxford Review of Economic Policy 10(3), 78-94.

[66] Easton, B. [2015a], 'Distribution of Pre-Tax Top Personal Incomes', Policy Quarterly 11(1), 47-51.

[67] Easton, B. [2015b], 'Top After-Tax Incomes', Policy Quarterly 11(1), 5255.

[68] Euwals, R. and van Soest, A. [1999], 'Desired and actual labour sup- 
ply of unmarried men and women in the Netherlands', Labour Economics 6(1), 95-118.

[69] Evans, L., Grimes, A., Wilkinson, B. and Teece, D. [1996], 'Economic Reform in New Zealand: In Pursuit of Efficiency', Journal of Economic Literature 34(1), 1856-1902.

[70] Figari, F., Sutherland, H. and Iacovou, M. [2012], 'Approximations to the truth: comparing survey and microsimulation approaches to measuring income for social indicators', Social Indicators Research 105(3), 387-407.

[71] Fortin, N. M., Lemieux, T. and Firpo, S. [2011], Handbook of Labor Economics, Vol. 4, chapter Chapter 1 - Decomposition Methods in Economics, pp. 1-102.

[72] Fraser, H. [2018], 'The Labour Income Share in New Zealand: An Update', New Zealand Productivity Commission Staff Research Note 18(1).

[73] Goldin, C. and Katz, L. F. [2010], The Race between Education and Technology, Belknap Press.

[74] Goldman, S. M. and Uzawa, H. [1964], 'A Note on Separability in Demand Analysis', Econometrica 32(3), 387-398.

[75] Goldstein, J. and Lee, R. [2014], 'How Large Are the Effects of Population Aging on Economic Inequality?', 12, 193-209.

[76] Gorter, C. and Poot, J. [1999], The Impact of Labour Market Deregulation: Lessons from the Kiwi and Polder Models, Tinbergen institute discussion papers, Tinbergen Institute.

[77] Gould, W. [1998], 'HETPROB: Stata module to estimate heteroskedastic probit model'.

[78] Greene, W. H. [2011], Econometric Analysis, Pearson. 
[79] Guyonne Kalb and Rosanna Scutella [2003], New Zealand Treasury Working Paper (23).

[80] Hahn, F. and Petri, F., eds [2004], General Equilibrium: Problems and Prospects, Routledge.

[81] Harvey, A. [1976], 'Estimating Regression Models with Multiplicative Heteroscedasticity', Econometrica 44(3), 461-65.

[82] Hausman, J. A. [1980], 'The effect of wages, taxes, and fixed costs on women's labour force participation', Journal of Public Economics .

[83] Heckman, J. [1979], 'Sample Selection Bias as a Specification Error', Econometrica 47(1), 153-161.

[84] Herault, N. and Azpitarte, F. [2014a], 'Recent Trends in Income Redistribution in Australia: Can Changes in the Tax-Transfer System Account for the Decline in Redistribution', Melbourne Institute Working Paper Series 14(2), 1-27.

[85] Herault, N. and Azpitarte, F. [2014b], Understanding Changes in the Distribution and Redistribution of Income: A Unifying Decomposition Framework, University of Bordeaux Seminar Series.

[86] Herault, N. and Azpitarte, F. [2015], 'Recent Trends in Income Redistribution in Australia: Can Changes in the Tax-Transfer System Account for the Decline in Redistribution', Economic Record 91(292), 3853.

[87] Herault, N. and Azpitarte, F. [2016], 'Understanding Changes in the Distribution and Redistribution of Income: A Unifying Decomposition Framework', Review of Income and Wealth 62(2), 266-282.

[88] Hirsch, B., Seaks, T. and Formby, J. [1980], 'Inter-Age and Intra-Age Income Inequality: A Cross-Sectional Analysis', Southern Economic Journal 46(4), 1187-1196. 
[89] Hoover, K. D. [2001], The Economic World View: Studies in the Ontology of Economics, Cambridge University Press, chapter 12: Is Macroeconomics for real?, pp. 225-245.

[90] Hyslop, D. R. and Mare, D. C. [1999], Understanding changes in the Distribution of household incomes 1983/86 to 1995/98.

[91] Hyslop, D. R. and Mare, D. C. [2005], ‘Understanding New Zealand's Changing Income Distribution, 1983-1998: A Semi-parametric Analysis', Econometrica 72, 469-496.

[92] Hyslop, D. R. and Yahanpath, S. [2005], 'Income Growth and Earnings Variations in New Zealand, 1998-2004', New Zealand Treasury Working Paper 05(11).

[93] IRD [1996], 'IRD Tax Information Bulletin', IRD Tax Information Bulletin 8(5).

[94] Jara, H. X. and Tumino, A. [2013], 'Tax-benefit system, income distribution and work incentives in the European Union', International Journal of Microsimulation 6(1), 27-62.

[95] Jenkins, S. P. and Kerm, P. V. [2005], 'Accounting for Income Distribution Trends: A Density Function Decomposition Approach', ISER Working Papers .

[96] Jensen, J. [1988], Income equivalences and the estimation of family expenditures on children. Department of Social Welfare (unpublished).

[97] Jeram, J. and Wilkinson, B. [2016], The Inequality Paradox: Why inequality matters even though it has barely changed, New Zealand Initiative.

[98] Jessen, R. [2016], 'Why Has Income Inequality in Germany Increased from 2002 to 2011? A Behavioral Microsimulation Decomposition', SOEPpapers on Multidisciplinary Panel Data Research .

[99] Jia, Z. and Vattø, T. E. [2013], Tax Response Inertia in Labor Sup- 
ply: Effects of State Dependence in Preferences and Opportunities, 4th General Conference of the International Microsimulation Association.

[100] Juhn, C., Murphy, K. M. and Pierce, B. [1993], ‘Wage inequality and the rise in returns to skill', Journal of Political Economy 101, 410-442.

[101] Jurkatis, S. and Strehl, W. [2013], 'Dos and Don'ts of Gini Decomposition', Berlin Doctoral Program in Economics and Management Science Working Paper Series (3).

[102] Kabátek, J., van Soest, A. and Stancanelli, E. [2014], 'Income taxation, labour supply and housework: A discrete choice model for French couples', Labour Economics 27(C), 30-43.

[103] Kakwani, N. C. [1977a], 'Applications of Lorenz Curves in Economic Analysis', Econometrica 45(3), 719-727.

[104] Kakwani, N. C. [1977b], 'Measurement of Tax Progressivitiy: An International Comparison', Economic Journal 87(345), 71-80.

[105] Kakwani, N. C. [1984], 'On the measurement of tax progressivity and redistributive effect of taxes with applications to horizontal and vertical equity', Advances in Econometrics (3), 149-168.

[106] Kalb, G. and Scutella, R. [2003], 'Wage and Employment Rates in New Zealand from 1991 to 2001', New Zealand Treasury Working Paper (13).

[107] Kaplow, L. [1989], 'Horizontal Equity: Measures in Search of a Principle', National Tax Journal (42), 139-54.

[108] Kasten, R., Sammartino, F. and Toder, E. [1994], Tax Progressivity and Income Inequality, Cambridge: Cambridge University Press, chapter Trends in federal tax progressivity, 1980-93, pp. 9-50.

[109] Keane, M. and Moffitt, R. [1998], 'A Structural Model of Multiple 
Welfare Program Participation and Labor Supply', International Economic Review 39(3), 553-89.

[110] King, M. [1983], 'An index of inequality with applications to horizontal inequity and social mobility', Econometrica (51), 99-115.

[111] Lambert, P. J. [1985], 'The redistributive effect of taxes and benefits', Scottish Journal of Political Economy 32, 39-54.

[112] Lambert, P. J. [2001], The Distribution and Redistribution of Income, third edn, Manchester University Press.

[113] Lambert, P. J. and Urban, I. [2008], 'Redistribution, Horizontal Inequity, and Reranking: How to Measure them Properly', Public Finance Review 36(5), 563-587.

[114] Littlewood, A. [2015], 'Re-designing New Zealand Superannuation', NBER Working Paper Series (1), 1-12.

[115] Loffler, M., Peichl, A. and Siegloch, S. [2013], Discrete Choice Labor Supply Models and Wage Exogeneity.

[116] Lucas, R. [1976], 'Econometric Policy Evaluation: A Critique', Carnegie-Rochester Conference Series on Public Policy 1(1), 19-46.

[117] MacCurdy, T., Green, D. and Paarsch, H. [1990], 'Assessing Empirical Approach for Analyzing Taxes and Labor Supply', The Journal of Human Resources .

[118] Maddala, G. S. [1983], Limited Dependent and Qualitative Variables in Econometrics, Cambridge University Press.

[119] Maloney, T. [1997], Benefit Reform and Labour Market Behaviour in New Zealand, Institute for Governance and Policy Studies.

[120] Martin, B. [1998], 'Men, Women, Employment and Earnings: Change in the distribution of income among individuals 1976-1996', Waikato Population Studies Centre Working Paper. 
[121] Martin, B. [2000], 'Change in the Distribution of Income in the Working Age Population, 1976-1996', Labour Market Bulletin 2000-2002: Special Issue pp. 132-156.

[122] Mas-Colell, A. [1989], Joan Robinson and modern economic theory, Macmillian, chapter 17: Capital theory paradoxes: anything goes.

[123] Massey, P. [1995], New Zealand: Market Liberalization in a Developed Economy, London: Palgrave Macmillan.

[124] Matsaganis, M. and Leventi, C. [2014], 'Distributive Effects of the Crisis and Austerity in Seven EU Countries', ImPRovE Working Paper (4).

[125] McClure, M. [1996], A Civilised Community: A History of Social Security in New Zealand 1898-1998, Auckland University Press, Auckland.

[126] McFadden, D. L. [1974], Frontiers in Econometrics, Academic Press, New York, chapter Chapter 4: Conditional logit analysis of qualitative choice behavior, pp. 105-142.

[127] Mercante, J. and Mok, P. [2014a], 'Estimation of Labour Supply in New Zealand', New Zealand Treasury Working Paper (8).

[128] Mercante, J. and Mok, P. [2014b], 'Estimation of Wage Equations for New Zealand', New Zealand Treasury Working Paper (9).

[129] Mercante, J. and Mok, P. [2014c], 'Working for Families changes: The effect on labour supply in New Zealand', New Zealand Treasury Working Paper (18).

[130] Mierau, J. O. and Rockey, J. [2014], 'Inequality in an Equal Society: Theory and Evidence', University of Leicester Working Paper (18).

[131] Morrison, P. S. [2004], 'Deregulation of the New Zealand labour market', GeoJournal 59(2), 127-136.

[132] Muller, K.-U. [2014], Analyzing economic policies that affect supply 
and demand: a structural model of productivity, labor supply and rationing, ECONSTOR.

[133] Musgrave, R. A. [1976], 'ET, OT and SBT', Journal of Public Economics 6(1), 3-16.

[134] Musgrave, R. A. [1990], 'Horizontal Equity, Once More', National Tax Journal 43(2), 113-122.

[135] Musgrave, R. A. [1993], 'Progressive Taxation, Equity and Tax Design', Ross School of Business Office of Tax Policy Research (9), 1-17.

[136] Musgrave, R. A. and Thin, T. [1948], 'Income Tax Progression 19291948', Journal of Political Economy (56), 498-514.

[137] Nash, J. C. [2016], 'R documentation: OPM'.

[138] Nelson, J. [1993], 'Household Equivalence Scales: Theory versus Policy?', Journal of Labor Economics 11(3), 471-93.

[139] Nelson, J. A. [1988], 'Household Economies of Scale in Consumption: Theory and Evidence', Econometrica 56(6), 1301-1314.

[140] Nolan, M. [2014], The Piketty Phenomenon, BWB Texts, chapter 11: What is the Piketty Model and Does it fit New Zealand?, pp. 50-57.

[141] Nolan, M. [2016], Decomposition of Income Inequality Changes in New Zealand: 1995-2013, in 'New Zealand Association of Economists Conference 2016', Auckland, New Zealand.

[142] Nolan, P. [2002], 'New Zealand's Family Assistance Tax Credits: Evolution and Operation', New Zealand Treasury Working Paper (16).

[143] Nolan, P. [2005], Targeting Families' Assistance: Evaluating Family and Employment Tax Credits in New Zealand's Tax-Benefit System, $\mathrm{PhD}$ thesis, Victoria University of Wellington.

[144] NZQA [2017], 'New Zealand Qualifications Framework'. 
[145] O'Dea, D. [2000], 'The Changes in New Zealand's Income Distribution', New Zealand Treasury Working Paper (13).

[146] Orcutt, G. H. [1957], 'A new type of socio-economic system', Review of Economics and Statistics 39(2), 116-123.

[147] Peichl, A. [2008], 'The benefits of linking CGE and Microsimulation Models - Evidence from a Flat Tax analysis', Institute for the Study of Labour: Discussion Paper Series .

[148] Peichl, A. and Siegloch, S. [2012], 'Accounting for labor demand effects in structural labor supply models', Labour Economics 19(1), 129138.

[149] Perry, B. [2017], 'Household Incomes in New Zealand: trends in indicators of inequality and hardship 1982 to 2016', Ministry of Social Development Monitoring Reports .

[150] Pickett, K. and Wilkinson, R. [2009], The Spirit Level, Allen Lane.

[151] Piketty, T. [2014], Capital in the Twenty-First Century, The Belknap Press of Harvard University Press.

[152] Plat, D. [2015], 'R Package IC2'.

[153] Plotnick, R. [1981], 'A measure of horizontal inequity', Review of Economics and Statistics (63), 283-88.

[154] Plotnick, R. [1985], Horizontal Equity, Uncertainty, and Economic WellBeing, University of Chicago Press, chapter 8: A comparison of measures of horizontal inequity, pp. 239-268.

[155] Podder, N. and Chatterjee, S. [1998], Sharing the national cake in post reform New Zealand: income inequality trends in terms of income sources, New Zealand Association of Economists. Published in 2002.

[156] Podder, N. and Chatterjee, S. [2002a], 'Economic Inequality in 
Colour: Some Ethnic Dimensions of Income Distribution in New Zealand 1984-1998', Massey University Discussion Papers 2(6).

[157] Podder, N. and Chatterjee, S. [2002b], 'Sharing the national cake in post reform New Zealand: income inequality trends in terms of income sources', Journal of Public Economics 86, 1-27.

[158] Rankin, K. and St John, S. [2009], 'Escaping the Welfare Mess', University of Auckland Working Paper (267).

[159] Rashbrooke, M. [2013], Inequality: A New Zealand Crisis, Bridget Williams Books.

[160] Report, C. [1988], 'Tax Compliance: Report to the Treasurer and Minister of Revenue by a Committee of Experts on Tax Compliance'.

[161] Reynolds, M. and Smolensky, E. [1977], Public Expenditure, Taxes, and the Distribution of Income: The United States, 1950, 1961, 1970, Academic Press, New York.

[162] Rosenberg, B. [2017], Transforming Workplace Relations in New Zealand 1976-2016, chapter A brief history of labour's share of income in New Zealand 1939-2016.

[163] Sastre, M. and Trannoy, A. [2002], 'Shapley Inequality Decomposition by Factor Components: Some Methodological Issues', Journal of Economics Supplement 9, 51-89.

[164] Sen, A. [2000], Handbook of Income Distribution, Vol. 1, Elsevier Science B. V., chapter 1: Social Justice and the distribution of income, pp. 60-85.

[165] Shafer, W. and Sonnenschein, H. [1982], Handbook of Mathematical Economics, Vol. II, Amsterdam: North-Holland, chapter 14: Market Demand and Excess Demand Functions. 
[166] Shapley, L. [1953], 'A Value for n-Person Games', Annals of Mathematics Studies (28), 307-317.

[167] Shorrocks, A. F. [1982], 'Inequality Decomposition by Factor Components', Econometrica 50(1), 193-211.

[168] Shorrocks, A. F. [1984], 'Inequality Decomposition by Population Subgroups', Econometrica 52(6), 1369-1385.

[169] Shorrocks, A. F. [1988], Measurement in Economics, Physica-Verlag Heidelberg, chapter Aggregation Issues in Inequality Measurement, pp. 429-51.

[170] Shorrocks, A. F. [2013], 'Decomposition Procedures for Distributional Analysis: A Unified Framework Based on the Shapley Value', The Journal of Economic Inequality 11(1).

[171] Spadaro, A. [2007], Microsimulation as a tool for the evaluation of public Policies: Methods and applications, Fundación BBVA.

[172] St John, S. [2013], 'Fiscal Sustainability In An Ageing Population: Adapting Universal Provision', Auckland University Retirement Policy and Research Centre Working Papers 1(2), 1-30.

[173] St John, S. [2015], 'Improving the Affordability of National Superannuation', Auckland University Retirement Policy and Research Centre Working Papers 1(1), 1-17.

[174] Stack, S. and Neubeck, K. [1978], 'Education and Income Inequality: A Cross-National Analysis', International Review of Modern Sociology 8(2), 159-166.

[175] Statistics New Zealand [1999], New Zealand Now - Incomes, Statistics New Zealand.

[176] Statistics New Zealand [2001], 'The Introduction of Integrated Weighting to the 2000/2001 Household Economic Survey'. 
[177] Statistics New Zealand [2006], 'Business Demographic Statistics Review'.

[178] Statistics New Zealand [2017a], 'ANZSIC06 Industry Classifications'.

[179] Statistics New Zealand [2017b], 'ANZSIC06 Occupation Classifications'.

[180] Stephens, R. [1987], 'Tax Reform in New Zealand', Australian Tax Forum 4(3), 327-346.

[181] Stephens, R. [1993], 'Radical Tax Reform', Review of Fiscal Studies 14(3), 45-63.

[182] Stephens, R. [2003], 'The Economic and Social Context for the Changes in Accident Compensation', Victoria University of Wellington Law Review 34(2), 351-366.

[183] Stillman, S., Velamuri, M. and Aitken, A. [2008], 'The Long-Run Impact of New Zealand's Structural Reform on Local Communities', Motu Working Paper (11).

[184] Sugden, R. [2001], 'Credible worlds: the status of theoretical models in economics', Journal of Economic Methodology 7(1), 1-31.

[185] Treasury [1996], 'Briefing to the Incoming Government 1996', Briefing to the Incoming Government 1996.

[186] Treasury [2001a], 'Tax Review 2001: Final Report', Treasury Tax Review 2001.

[187] Treasury [2001b], 'Tax Review 2001: Issues Report', Treasury Tax Review 2001.

[188] Urban, I. [2009], 'Kakwani decomposotion of redistributive effect: origins, critics and upgrades', ECINE Working Paper Series (148). 
[189] Urban, I. [2014], 'Contributions of Taxes and Benefits to Vertical and Horizontal Effects', Social Choice and Welfare 42(3), 619-645.

[190] van Soest, A. [1995], 'Structural Models of Family Labour Supply', The Journal of Human Resources .

[191] Victoria University of Wellington Tax Working Group [2010], 'A Tax System for New Zealand's Future: Report of the Victoria University of Wellington Tax Working Group'.

[192] Welfare Working Group [2011], 'Welfare Working Group Final Report'.

[193] Wiemers, J. [2015], 'Endogenizing take-up of social assistance in a microsimulation model: A case study for Germany', International Journal of Microsimulation 8(2), 4-27.

[194] Wooldridge, J. [2014], 'Test for heteroskedasticity in logit/probit models'.

[195] Wooldridge, J. M. [2010], Econometric Analysis of Cross Section and Panel Data, 2 edn, MIT Press.

[196] Yitzhaki, S. and Schechtman, E. [2013], The Gini Methodology, Springer.

[197] Young, H. P. [1990], 'Progressive Taxation and Equal Sacrifice', American Economic Review 80(1), 253-266. 